Universidade de Brasília

FACE - Faculdade de Economia, Administração,

Contabilidade e Ciência da Informação e Documentação

U⿴囗十 Departamento de Economia

\title{
Ensaios em Teoria de Contratos aplicada no Setor de Telecomunicações com foco nos Investimentos
}

Hélio Mauricio Miranda da Fonseca

Brasília - DF 
UNIVERSIDADE DE BRASÍLIA

FACE - DEPARTAMENTO DE ECONOMIA PÓS-GRADUAÇÃO EM ECONOMIA

Hélio Mauricio Miranda da Fonseca

\section{Ensaios em Teoria de Contratos aplicada no Setor de Telecomunicações com foco nos Investimentos}

Tese apresentada ao Departamento de Economia da Universidade de Brasília para obtenção do título de Doutor em Economia.

Orientador:

Dr. Ricardo Silva Azevedo Araújo

Brasília - DF

Março/2015 
Tese de Doutorado sob o título "Ensaios em Teoria de Contratos aplicada no Setor de Telecomunicações com foco nos Investimentos.", defendida por Hélio Mauricio Miranda da Fonseca e aprovada em 17 de março de 2015, em Brasília, Distrito Federal, pela banca examinadora constituída pelos doutores:

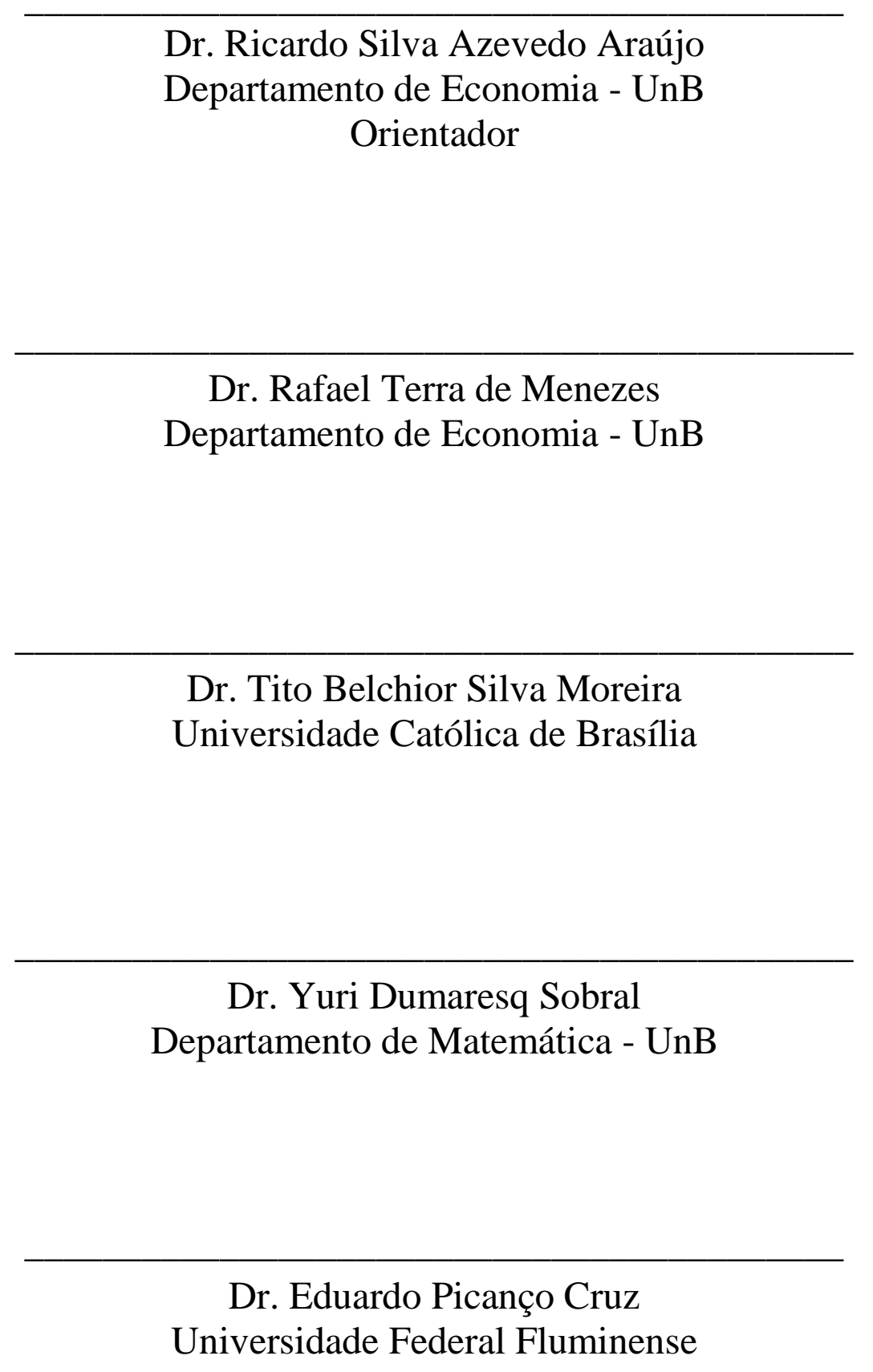

Dr. Ricardo Silva Azevedo Araújo

Orientador

Dr. Tito Belchior Silva Moreira

Universidade Católica de Brasília

Dr. Yuri Dumaresq Sobral

Departamento de Matemática - UnB

Dr. Eduardo Picanço Cruz

Universidade Federal Fluminense 
É concedida à Universidade de Brasília permissão para reproduzir cópias desta tese e para emprestar ou vender tais cópias somente para propósitos acadêmicos ou científicos. O autor reserva os direitos de publicação e nenhuma parte desta tese pode ser reproduzida sem autorização por escrito do autor.

Hélio Mauricio Miranda da Fonseca 
Aos meus pais, José e Hélia (in memoriam). 


\section{AGRADECIMENTOS}

Em primeiro lugar quero agradecer ao Deus Eterno pelo dom da vida e pela oportunidade que Ele me concedeu de cumprir mais essa etapa de minha vida. A Ele toda a Honra, Glória e Louvor!

Aos meus amados pais por todo amor, carinho, dedicação e apoio que me acompanharam desde a minha mais tenra infância. Aos meus tios Ronaldo e Maria Zilma pelo carinho e cuidado.

À minha amada esposa, Thais, mulher que Deus colocou em minha vida e com quem construí minha família, pela compreensão e estímulo durante toda a jornada do curso de Doutorado. Aos meus filhos Tiago e João, herança do Senhor, que me ensinam diariamente o que realmente importa nesta vida.

À sociedade brasileira por ter me proporcionado a oportunidade de estudar em uma universidade de excelência.

Agradeço ao meu orientador, Dr. Ricardo Silva Azevedo Araújo, pelo incentivo, compreensão e orientação ao longo de todo processo de formação no Programa de Pós-Graduação em Economia da UnB. Aos demais membros da banca de defesa, Rafael Terra de Menezes, Tito Belchior Silva Moreira, Yuri Dumaresq Sobral e Eduardo Picanço Cruz, agradeço pela disponibilidade e as valiosas contribuições.

Agradeço aos professores do departamento de matemática da UnB, em especial aos professores Rui Seimetz, Lineu Neto e Ary Medino, pelo grande incentivo no prosseguimento dos estudos em âmbito de doutorado no departamento de Economia.

Aos professores do departamento de economia da UnB, Bernardo Muller, Maria Eduarda TannuriPianto, Gil Riella, Roberto Ellery Jr., Milene Takasago, Moisés Resende e, em especial, aos professores Vander Lucas, José Guilherme Lara Resende, Daniel Cajueiro e Maurício Bugarin, minha gratidão pelo estímulo ao estudo da fascinante Ciência Econômica.

Aos meus colegas da Pós-Graduação em Economia da UnB pelo ambiente profícuo e estimulante de estudo. Em especial, agradeço aos meus amigos Roberto Batista e Maurício Machado pela constante troca de ideias e companheirismo ao longo do curso de doutorado.

À Agência Nacional de Telecomunicações, em especial, na figura do Conselheiro Rodrigo Zerbone Loureiro pelo apoio inestimável para a conclusão do programa de doutoramento.

Aos colegas da ANATEL Alexandre, Daniel, Rosa, Ronaldo, Cláudio, Egon, Nívia, Eliane, Paulo Vitor, Ana Carolina de Sá, Victor Epitácio, Fernanda Bussacos, pela amizade e apoio ao longo dessa jornada. 
"Aquele que tem os meus mandamentos e os guarda esse é o que me ama; e aquele que me ama será amado de meи Pai, e eи o amarei, e me manifestarei a ele.

$\underline{\text { João } 14: 21}$ 


\title{
Ensaios em Teoria de Contratos aplicada no Setor de Telecomunicações com foco nos Investimentos
}

\author{
Hélio Mauricio Miranda da Fonseca
}

\begin{abstract}
Resumo: O presente trabalho tem por objetivo contribuir com o aperfeiçoamento do processo de formulação e implementação de políticas públicas no Brasil, em particular no que se refere à celebração de contratos no setor de telecomunicações. Para tanto, foram desenvolvidos três capítulos que tratam de temas distintos, porém vinculados à ideia central de que o papel do órgão regulador é bastante relevante para o desenvolvimento saudável do setor de telecomunicações e para o próprio crescimento econômico do país. Inicialmente, busca-se estudar, com base em métodos econométricos, a relação entre investimentos em telecomunicações e o crescimento econômico, bem como a relação causal entre as variáveis do modelo teórico com fundamentação em uma equação de Cobb-Douglas ${ }^{1}$ adaptada para contemplar a variável de telecomunicações, nos moldes de Barro (1990). Os resultados indicam uma relação de causalidade unidirecional, tanto de longo como de curto prazos das variáveis para o produto para as últimas quatro décadas, o que contribui para um melhor entendimento das relações econômicas entre as variáveis no país. Em seguida busca-se mostrar como a atuação ex-ante ou preventiva do órgão regulador pode contribuir para a definição de contratos mais eficientes Para tanto, utiliza-se uma abordagem da teoria de informação. Os resultados indicam que a busca de melhores informações sobre o tipo das firmas que intentem atuar no setor, pode contribuir para uma formatação mais adequada e eficiente dos contratos, contribuindo para o processo de racionalização da atividade regulatória. Prosseguindo, o trabalho passa a tratar da definição de um mecanismo de licitação que visa maximizar a eficiência do processo de celebração de termos de ajustamento de conduta por parte da Anatel, bem como, por consequência, a maximizar a eficiência dos investimentos no setor. Utiliza-se uma abordagem baseada na teoria de leilões, sendo uma das duas modelagens relativa às licitações sequenciais com a definição do preço de reserva endógeno que busca verificar a hipótese de que o referido mecanismo é mais vantajoso para o Estado do que o modelo de licitação padrão, no sentido de promover a implementação de projetos relevantes para o desenvolvimento das telecomunicações, com o menor custo para o Estado. O resultado obtido aponta em sentido diverso, isto é, o modelo de licitação padrão mostrou-se mais vantajoso, contribuindo para descartar a ideia do modelo sequencial aventada. Sendo assim, pode-se afirmar que o presente trabalho buscou contribuir com o debate recente no setor de telecomunicações do Brasil. Considerando a importância do setor de telecomunicações sobre o crescimento econômico, e as recentes dificuldades enfrentadas pelo setor no que se refere ao volume de multas aplicadas, surge uma oportunidade de realizar investimentos economicamente menos atrativos de forma eficiente que de outra maneira não seriam feitos no curto prazo.
\end{abstract}

Palavras-Chave: Telecomunicações, causalidade, contrato, desenho de mecanismo, teoria de leilões, licitação.

\footnotetext{
${ }^{1}$ Inicialmente proposto por Knut Wicksell (1851 - 1926) e, posteriormente, testado contra a evidência estatística por Charles Cobb e Paul Douglas em 1928.
} 


\title{
Essays on Contract Theory applied to the Telecommunications Industry with a focus on investments
}

\author{
Hélio Mauricio Miranda da Fonseca
}

\begin{abstract}
This work aims to contribute towards the improvement of the formulation and implementation of public policies in Brazil, in particular with regard to the telecommunications sector. Thus, it encompasses three chapters dealing with different topics, but linked by the central idea that the role of regulator is fundamental for the healthy development of the telecommunications sector and, consequentely, for the country economic growth. Initially, we study, considering econometric methods, the relationship between investment in telecommunications and economic growth. Furthermore, we explore the causal relationship between variables from a Cobb-Douglas equation adapted to contemplate additional variables from the telecommunications sector, as it was in Barro (1990). The results indicate a one-way causal relationship in both long and short-term going from the variables to the product in the last four decades, which contributes to a better understanding of economic relations between the variables in the country. Then we seek to check the hypotheses that regulator ex-ante or preventive action in order to discover the firms types can contribute to the development of more efficient contracts for this, we use an approach based on information theory. The results indicates that the search for better information on the type of firms that intents to be an operator in the sector, can contribute to a more efficient contracts, contributing to improve the regulatory process. After the presentation of the problems that emerge in a setting of asymmetric information and the identification of a real case experienced by the regulator in relation to the volume of fines applied to providers of telecommunications industry, this work goes on to consider the definition of a mechanism in procurement auction which aims to maximize the efficiency of the process of agreement in terms of adjustment of Anatel's conduct, and therefore to maximize efficiency and investments in the sector. One of the two proposed models deals with the context of sequential auctions and the definition of endogenous reserve price that seeks to verify the hypothesis that this mechanism is more advantageous to the State than the standard procurement auction model in order to promote the implementation of relevant projects that may add to the development of telecommunications sector, by lowering the cost to the State and thus generating additional benefits to society. The results revealed the opposite, that is, the standard model is better than the sequential model. Thus, it can be said that this article aims to contribute to the recent debate in the telecommunications sector in Brazil. So considering the evidence of the importance of the telecommunications sector on economic growth and the recent difficulties faced by the sector in relation to the volume of fines, it become an opportunity to promote economically less attractive investments efficiently that otherwise would not be made in the short term.
\end{abstract}

Keywords: Telecommunications, causality, contract, mechanism design, auction theory, procurement auction. 


\section{Sumário}

CAPÍTULO 1 - Introdução

CAPÍTULO 2 - UM TESTE ECONOMÉTRICO DE CAUSALIDADE ENTRE INVESTIMENTO EM TELECOMUNICAÇÕES E CRESCIMENTO ECONÔMICO USANDO METODOLOGIA VAR. . .6

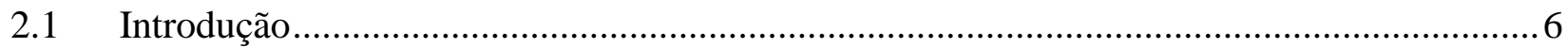

2.2 História econômico-institucional recente do setor de telecomunicações no Brasil ..............7

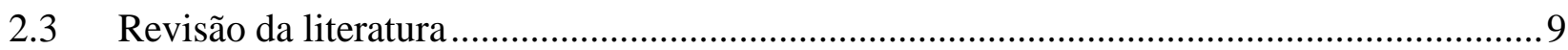

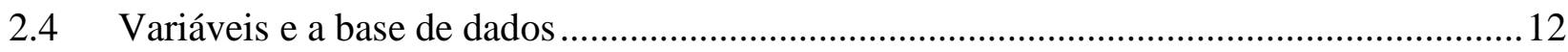

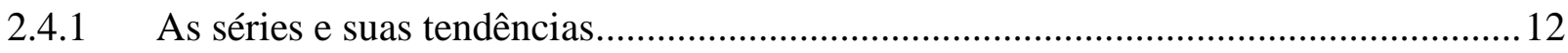

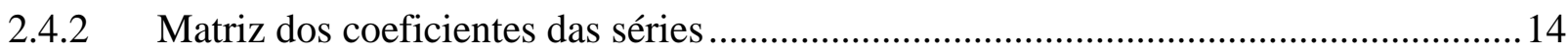

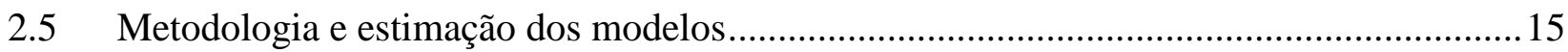

2.5.1 O modelo econométrico: efeito do investimento em telecomunicações sobre o produto

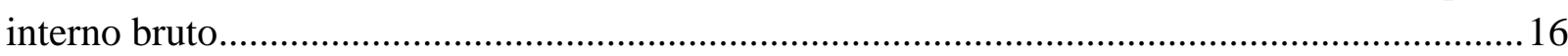

2.6 Testes, estimações e principais resultados .................................................................... 19

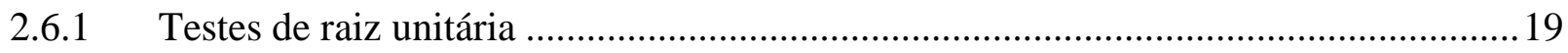

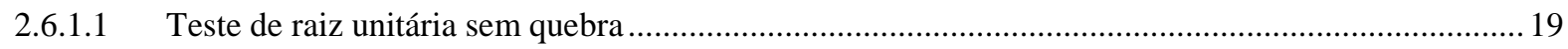

2.6.2 Mudanças estruturais e testes de identificação de quebras .........................................21

2.6.2.1 O teste de identificação de múltiplas quebras de Bai e Perron [Bai and Perron $(1998,2003)]$..........22

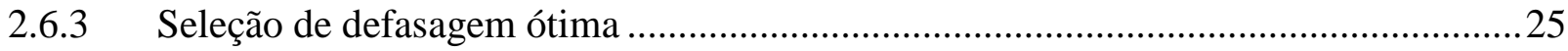

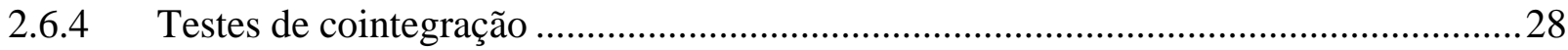

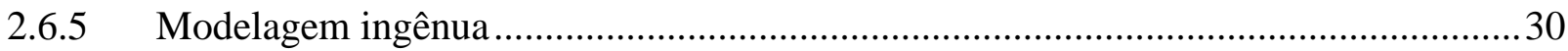

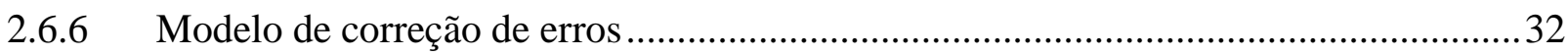

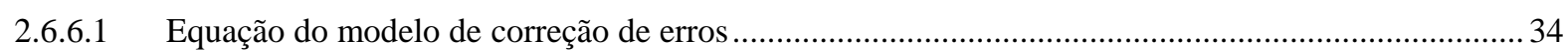

2.6.6.2 Teste para correlação serial ...................................................................................................... 35

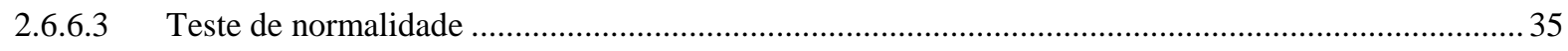

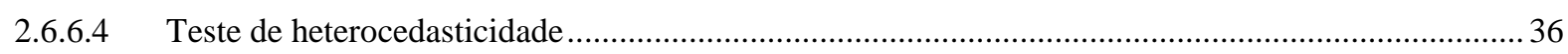

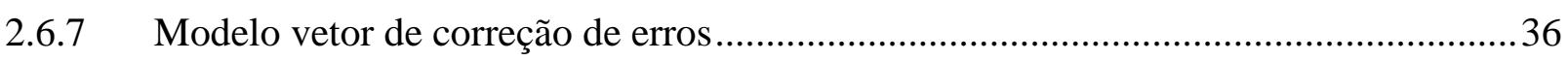

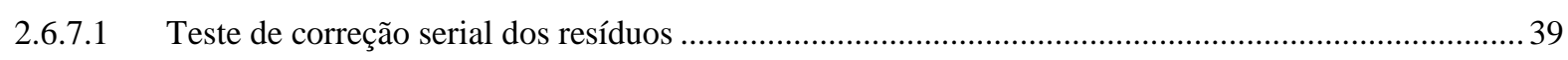

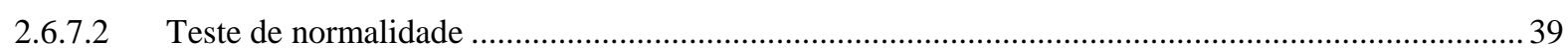

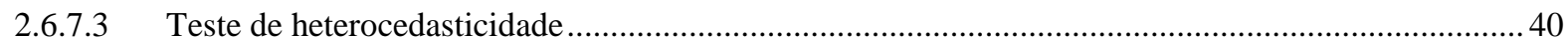

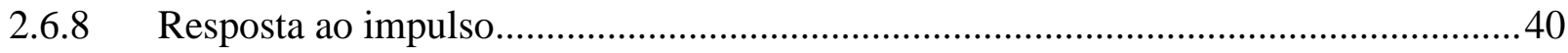

2.6.9 A análise de causalidade e o teste de causalidade de Granger ...................................43 
CAPÍTULO 3 - UMA ABORDAGEM DE TEORIA DE CONTRATOS aplicada AO SETOR DE TELECOMUNICAÇÕES................................................................................................................50

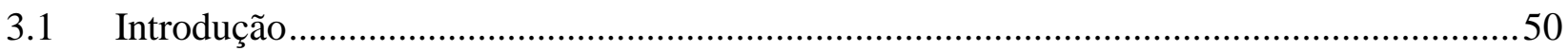

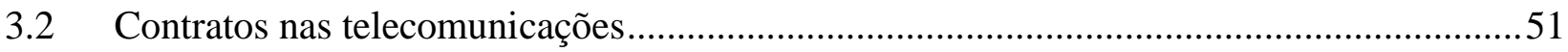

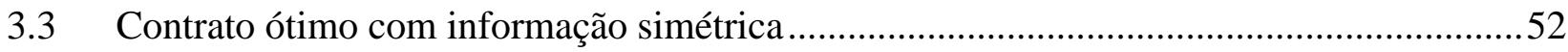

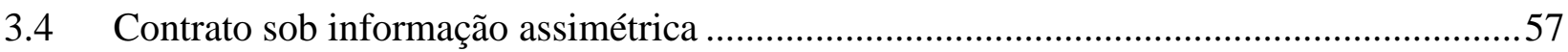

3.5 Considerações finais e sugestões de estudos futuros....................................................61

CAPÍTULO 4 - ANÁliSE DE LICITAÇÕES PARA CELEBRAÇÃO DE TERMOS DE

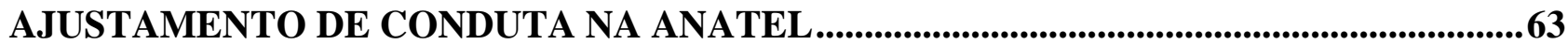

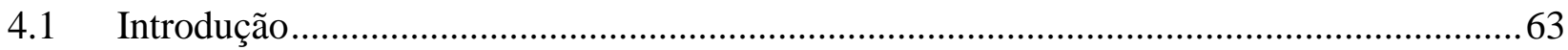

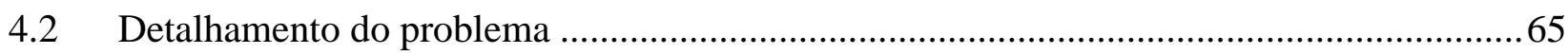

4.2.1 Histórico da regulamentação sobre sanções administrativas .................................... 71

4.2.2 Evidências quantitativas dos problemas das Multas ................................................. 72

4.2.3 A Consulta Pública do Regulamento de Sanções Administrativas: As discussões

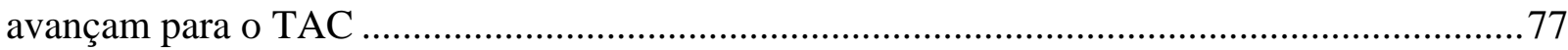

4.2.3.1 Inserção de item explicitando a possibilidade de celebração de termos de ajustamento de conduta (TAC): 77

4.3 A solução apresentada: uma descrição com análise crítica ............................................ 80

4.3.1 O regulamento de Termos de Ajustamento de Conduta: princípios gerais..................81

4.3.2 O regulamento de Termos de Ajustamento de Conduta: objeto central dos Termos de

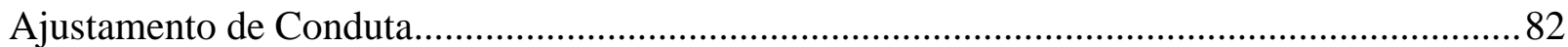

4.3.3 O regulamento de Termos de Ajustamento de Conduta: principais dispositivos, os

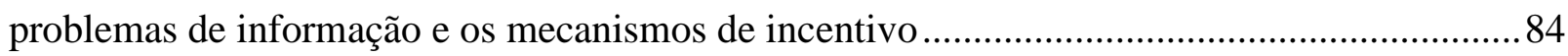

4.4 Uma breve revisão da literatura de leilões sequenciais de múltiplos objetos ....................88

4.5 Proposta de licitação e análise de licitações sequenciais para TAC na Anatel ..................97

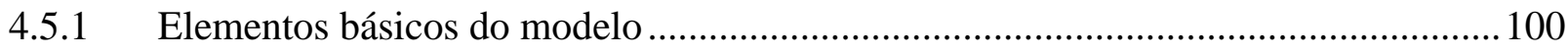

4.5.1.1 Valor atual esperado das operadoras antes da implementação do TAC ………………………….... 100

4.5.2 A possibilidade de TAC e o tipo de cada operadora ................................................. 102

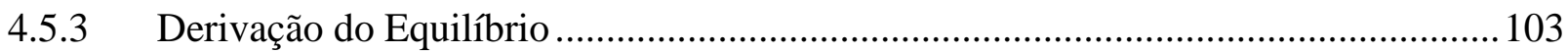

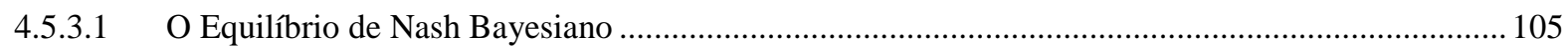

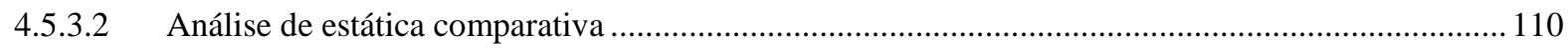

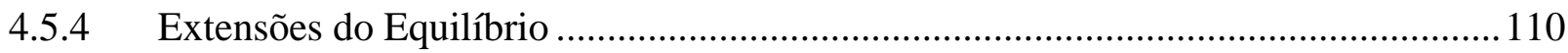

4.5.4.1 Caso 1: $\boldsymbol{G i}$ uniformemente distribuído no intervalo [0, $\mathbf{M}]$, onde $\mathrm{M}$ seria valor presente máximo do custo (líquido) do projeto. 
4.5.4.2 Caso 2: $\boldsymbol{G i}$ uniformemente distribuído no intervalo $[-\mathbf{1} / \mathbf{2}+\mathbf{m}, \mathbf{m}+\mathbf{1} / \mathbf{2}]: \boldsymbol{m}$ significa o valor esperado do custo do projeto que a Anatel estimará antes do processo licitatório. Caso $\boldsymbol{m}>\mathbf{0}$ (VPL negativo) caso $\boldsymbol{m}<\mathbf{0}$ (VPL positivo), caso excluído.

4.5.4.3 Caso 3: $\boldsymbol{G i}$ uniformemente distribuído no intervalo $[\boldsymbol{m}-\boldsymbol{M 2}, \boldsymbol{m}+\boldsymbol{M 2}]$ o caso mais geral. ........ 117

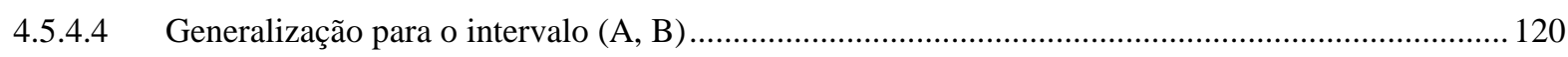

4.5.5 Generalização do modelo para mais de dois jogadores sem preço de reserva............122

4.5.5.1 Cálculo do abatimento esperado da dívida com dois jogadores para uma distribuição uniforme $[\mathbf{0 , 1}]$ 124

4.5.6 O preço ótimo de reserva/pagamento ótimo de reserva .........................................125

4.5.7 Equilíbrio da Licitação padrão $\boldsymbol{c} \sim \mathrm{U}[0,1]$ com teto de preço $\boldsymbol{r}$ :...............................127

4.5.7.1 Desconto de equilíbrio na licitação, considerando uma distribuição uniforme $[\mathbf{0}, \mathbf{1}]$ com desconto de reserva 129

4.5.7.2 Cálculo do retorno esperado do leiloeiro no modelo de licitação, considerando uma distribuição uniforme $[\mathbf{0 , 1}]$ e a ausência de valor de reserva. ................................................................................. 130

4.5.8 Duas Licitações com preço de reserva endógeno ………………………………......130

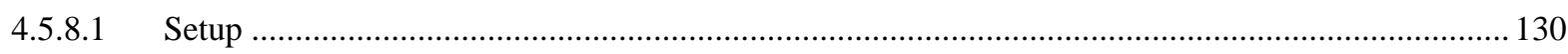

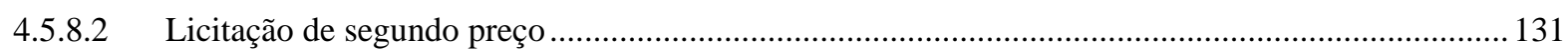

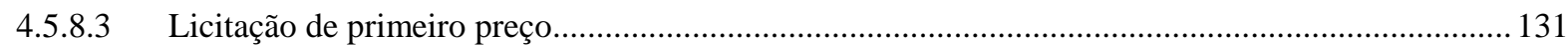

4.5.8.4 Recebimento esperado pelo fornecedor ......................................................................... 132

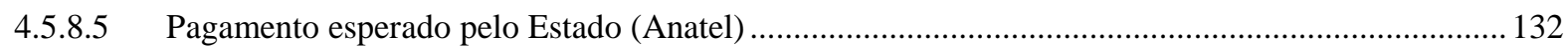

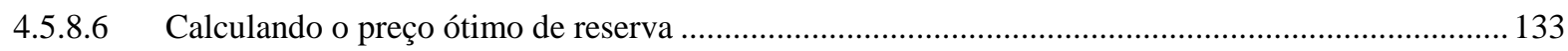

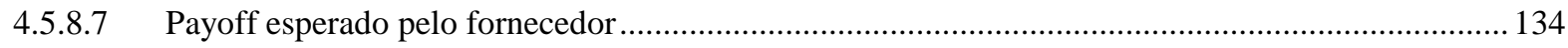

4.5.8.8 Primeiro período para Licitação de primeiro preço ................................................................... 135

4.5.8.9 Primeiro período para licitação de segundo preço ................................................................... 140

4.6 Considerações finais e sugestão de estudos futuros .................................................... 144

CAPÍTULO 5 - Conclusões ....................................................................................................146

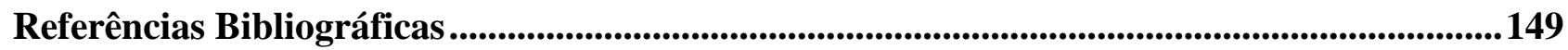




\section{Índice de Figuras}

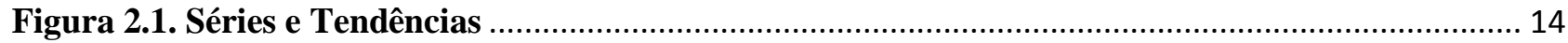

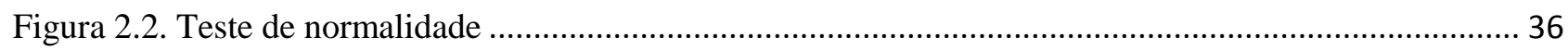

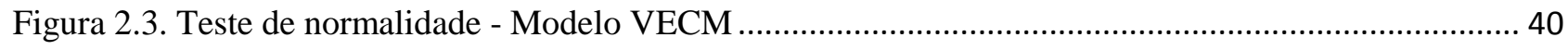

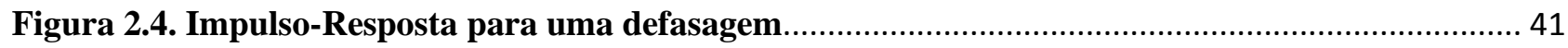

Figura 2.5. Impulso-Resposta para duas defasagens ............................................................................. 42

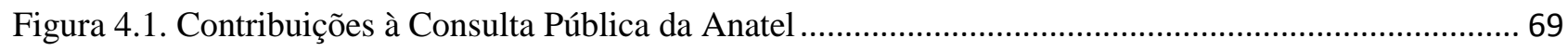

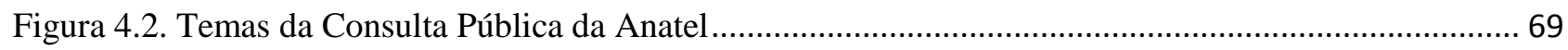

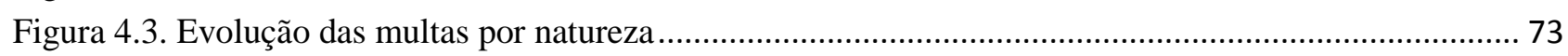

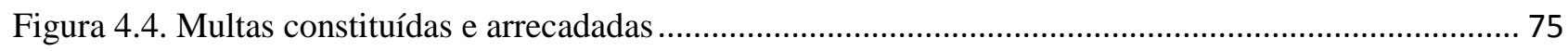

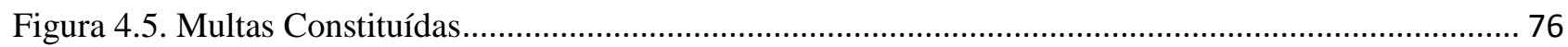

Figura 4.6. Licitação Sequencial - Primeiro Preço ..................................................................... 137

Figura 4.7. Licitação Sequencial - Primeiro Preço - Ajustamento …............................................... 138

Figura 4.8. Licitação padrão e sequencial - Primeiro Preço ............................................................... 139

Figura 4.9. Licitação Sequencial - Segundo Preço ….................................................................. 142

Figura 4.10. Licitação Sequencial - Segundo Preço - Ajustamento …................................................ 143

\section{Índice de Tabelas}

Tabela 2.1. Coeficientes de correlação, usando todas as observações 1976 - 2013 ..................................... 14

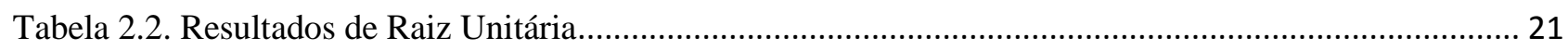

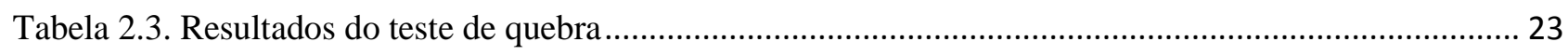

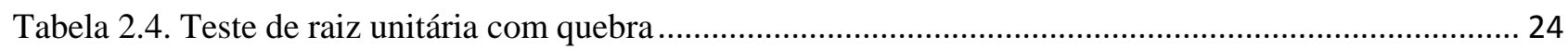

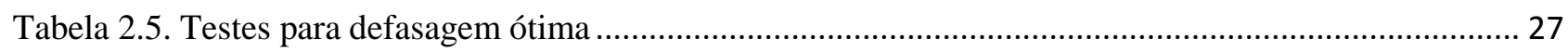

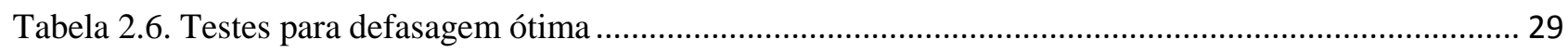

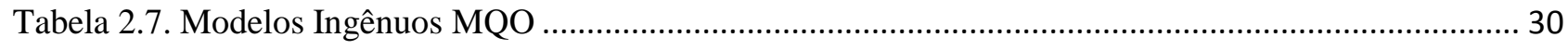

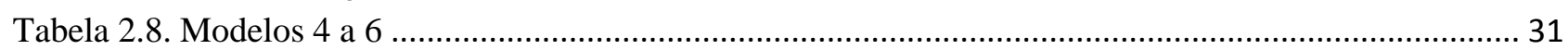

Tabela 2.9. Teste de estacionaridade dos resíduos .............................................................................. 33

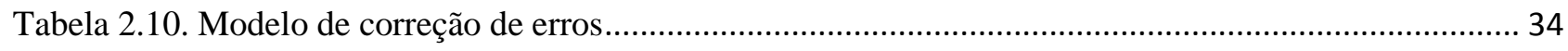

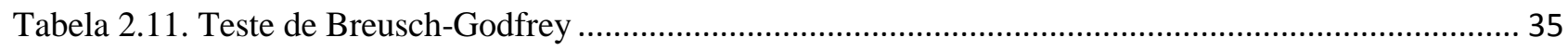

Tabela 2.12. Teste de Breusch-Pagan-Godfrey ..................................................................................... 36

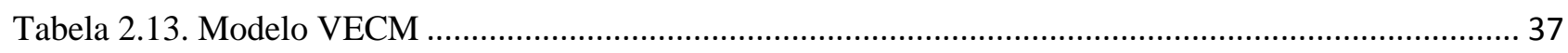

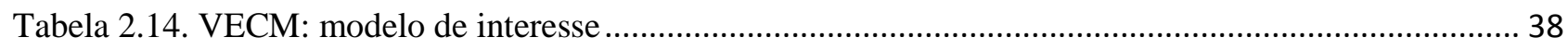

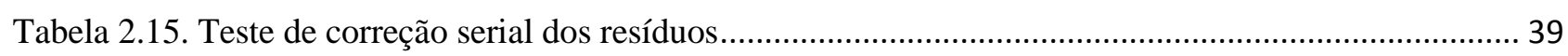


Tabela 2.16. Teste de heterocedasticidade: VECM......

Tabela 2.17. Síntese do teste de causalidade de Granger considerando uma e duas defasagens

Tabela 4.1. Evolução anual do Valor de mercado das principais empresas (R \$ Milhões) 


\section{CAPÍTULO 1 - INTRODUÇÃO}

Os setores de infraestrutura, conforme debatido na literatura econômica [Calderón e Sérven (2004), Calderón et. al. (2011), Cohen (2007)], tais como telecomunicações, energia elétrica, transporte aéreo, ferrovias e portos, têm importância central para o aumento da produtividade e para o desenvolvimento das economias ao longo do tempo. Sabe-se que o desenvolvimento e a expansão de setores de infraestrutura, que pressupõem grandes investimentos e longo prazo de maturação, demandam um ambiente regulatório transparente e estável.

No entanto, mesmo em cenários de estabilidade e transparência das regras, problemas podem surgir ao longo do processo de expansão e consolidação dos setores de infraestrutura, em decorrência da interveniência de fatos de natureza política-institucional, bem como de problemas de agência. Como exemplo desta afirmação, podem-se citar as dificuldades enfrentadas pelo regulador setorial das telecomunicações no que diz respeito ao alto índice de infrações, e a consequente elevação do número de sancionamentos e o atingimento de um cenário de risco de importante redução dos investimentos no setor, caso seja necessário o pagamento do estoque de multas no curto prazo, podendo vir a comprometer o processo de modernização do setor. Este problema enfrentado pelo regulador configurou-se como elemento motivador do presente trabalho.

Neste sentido, considerando a relevância do setor de telecomunicações para a dinamização das atividades econômicas, evidenciada em estudo empírico apresentado a seguir, e a importância da definição de mecanismos eficientes para favorecer a maior eficiência setorial, o presente trabalho tem por objetivo contribuir com o debate teórico acerca dos contratos celebrados no setor de telecomunicações, bem como na definição de mecanismo de licitação que contribui para o aperfeiçoamento da sistemática de celebração dos termos de ajustamento de conduta. Para tanto, foram desenvolvidos três capítulos que tratam de temas distintos, porém vinculados à mesma ideia central de que o papel do órgão regulador é bastante relevante para $\mathrm{o}$ desenvolvimento saudável do setor de telecomunicações, e como apresentado no trabalho, para o próprio crescimento econômico do país.

O capítulo 2 tem por objetivo estudar a relação entre investimentos em telecomunicações e o crescimento econômico, bem como a relação causal entre as variáveis do modelo teórico com 
fundamentação em uma equação de Cobb-Douglas adaptada para contemplar a variável de telecomunicações, nos moldes de Barro (1990). A hipótese a ser testada, portanto, é a de que telecomunicações Granger causam produto, isto é, os investimentos em telecomunicações contribuem para o crescimento econômico.

Para tanto são utilizadas séries das variáveis PIB real, população ocupada, estoque de capital e terminais por população ocupada para o período de 1976 a 2013. São utilizadas técnicas econométricas em séries de tempo, incluindo testes de estacionaridade com e sem quebra estrutural, testes para identificação de mudanças estruturais, os testes de cointegração, a estimação do modelo vetor autorregressivo restrito, análise da funções resposta ao impulso e, por fim, o teste de casualidade de Granger, além dos testes de diagnóstico que visam garantir a validade estatística das estimações.

Após garantir as condições necessárias para realização das estimações e a robustez do modelo estimado, pode-se destacar que os resultados obtidos, em síntese, apontaram para evidências de que:

- Existe relação de causalidade unidirecional de longo prazo indo das variáveis estoque de capital (K), população ocupada (L) e terminais por população ocupada (T) para PIB real, o que significa que o crescimento das três variáveis citadas causam o crescimento do produto;

- Existe também relação de causalidade de curto prazo indo de estoque de capital e telecomunicações para o produto, indicando que investimentos em formação bruta de capital e, em particular, em infraestrutura de telecomunicações implicam crescimento do produto no curto prazo.

Oportuno ressaltar que o impacto de telecomunicações sobre o produto pode se dar pela via direta, isto é, via aumento dos investimentos em capital fixo, e pela via indireta, isto é, contribuindo para o aumento de produtividade de múltiplos setores da economia.

Sendo assim, os resultados empíricos confirmam a hipótese levantada, no que tange à relação entre as variáveis de investimento em infraestrutura e crescimento, mas amplia um pouco a visão sobre o sentido da causalidade. Conforme evidenciado no presente estudo, o sentido da causalidade é de telecomunicações para produto, isto é, telecomunicações implica PIB e não o contrário. Neste sentido, ao se pensar em políticas públicas faz-se oportuno considerar essa relação, bem como o efeito multiplicador de telecomunicações nas demais indústrias. Referido 
efeito pode ser entendido como o efeito que telecomunicações têm de potencializar o desenvolvimento de outros setores da economia.

O capítulo 3 tem por objetivo mostrar como a atuação ex-ante ou preventiva do órgão regulador no que diz respeito à busca de maiores informações sobre o desejo e as condições reais das firmas que atuem ou venham a atuar como ofertantes dos serviços de telecomunicações poderiam contribuir para uma formatação mais adequada e eficiente dos contratos. A hipótese subjacente ao capítulo é a de que problemas de agência na regulação de serviços de telecomunicações podem ser mitigados com o aperfeiçoamento dos mecanismos de informação.

Cabe ressaltar que o capítulo 3 é escrito sob o pressuposto da existência de um ambiente contratual flexível, isto é, considerando a possibilidade de estabelecimento de regras contratuais em conformidade com o tipo de cada firma.

Para tanto, o capítulo discute a celebração de contratos em um ambiente de informação simétrica, sendo resolvido o problema da firma e a possibilidade de atuação do Estado no sentido de "forçar" o cumprimento dos dispositivos contratuais, via sanções pecuniárias, uma vez que tendo conhecimento do tipo da firma, pode usá-lo para ajustar o nível de compromisso e empenho da firma em cumprir a regulamentação.

Em seguida, o capítulo discute a realidade da celebração de contratos sobre informação assimétrica. O modelo apresentado mostra que o mecanismo desenhado para lidar com os descumprimentos afetos às questões consumeristas pode estimular as operadoras com menor habilidade/compromisso para cumprir as regras a escolher atuar ilegalmente, uma vez que desta forma obteria um lucro ótimo. Importante observar que multas não excluem a possibilidade de otimalidade do comportamento ilegal, uma vez que o regulador deverá escolher essa medida com atenção especial para não criar uma regulação extra para as operadoras que desejam atuar de forma correta e até mesmo inibir a entrada de novos 'players', o que prejudicaria o mercado no que tange aos resultados de um ambiente mais competitivo.

Por fim, o capítulo conclui apresentando os efeitos deletérios da assimetria de informações e destacando a importância de se reforçar a atuação ex-ante/preventiva do regulador no que tange ao rigoroso mapeamento das firmas de modo a identificar seus tipos e desenhar contratos mais eficientes, bem como na realização de estudos e na adoção de medidas que visem a reduzir o conjunto de obrigações e requerimentos potencialmente irrelevantes para a satisfação 
dos usuários de telecomunicações, de modo a superar as limitações da abordagem utilizada para lidar com os descumprimentos de obrigações.

O capítulo 4, por sua vez, tem por objetivo definir um mecanismo de licitação que visa maximizar a eficiência do processo de celebração de termos de ajustamento de conduta por parte da Anatel, bem como, por consequência, a maximizar a eficiência dos investimentos no setor. A hipótese a ser testada é a de que o mecanismo sequencial desenhado para a licitação é mais vantajoso para o regulador do que a licitação padrão.

Conforme destacado no capítulo 2, os investimentos no setor de telecomunicações apresentam relação de causalidade de curto e longo prazos com o crescimento econômico. Todavia, o capítulo 3 destaca eventuais dificuldades que podem ocorrer na atividade regulatória, em particular, devido aos problemas de informação.

Nesse contexto, o capítulo 4 foi desenvolvido com o intuito de apresentar o processo de discussão sobre a regulamentação dos termos de ajustamento de conduta (TAC), bem como propor um mecanismo que torne mais eficiente a implantação do instituto no que tange à realização dos investimentos setoriais.

Foi proposta uma modelagem para licitação de projetos de investimento com o pagamento a ser realizado pelo Estado oriundo do abatimento do montante de multas da prestadora. Em seguida foram realizadas algumas extensões do modelo básico, bem como análises sobre o comportamento dos jogadores e do leiloeiro.

Foi realizada uma segunda modelagem, mas agora para o contexto de leilões sequenciais com a definição do preço de reserva endógeno de modo a verificar se o referido mecanismo seria mais vantajoso para o Estado e, em última análise, para a sociedade, no sentido de promover a implementação de projetos relevantes para o desenvolvimento das telecomunicações, com o menor custo para o Estado e, em consequência gerando benefício para a sociedade.

Como resultado, foi possível verificar que a modelagem de licitação sequencial se apresentou menos vantajosa para o Estado do que a modelagem básica de licitação, uma vez que no mecanismo sequencial os lances são majorados, isto é, os jogadores tendem a cobrar um maior valor ou maior desconto do montante de multas para a realização dos projetos de investimento. 
Diante do exposto, pode-se afirmar que o presente trabalho buscou contribuir com o debate recente no setor de telecomunicações do Brasil. Ao evidenciar a importância do setor de telecomunicações para o crescimento econômico e a possibilidade de transformar os desafios enfrentados pelo setor no que se refere, em particular, ao volume de sanções aplicadas em oportunidade de favorecer a realização eficiente de investimentos economicamente menos atrativos, que de outra maneira não seriam feitos no curto prazo, o presente trabalho espera ter contribuído com o processo de tomada de decisão acerca das políticas públicas no Brasil, em particular no que tange ao setor de telecomunicações. 


\section{CAPÍTULO 2 - UM TESTE ECONOMÉTRICO DE CAUSALIDADE ENTRE INVESTIMENTO EM TELECOMUNICAÇÕES E CRESCIMENTO ECONÔMICO USANDO METODOLOGIA VAR}

\subsection{Introdução}

A economia mundial está, historicamente, relacionada com as grandes transformações tecnológicas. Como fruto de uma melhor adaptação e desempenho no que se refere ao paradigma tecnológico em surgimento, as nações, ao logo do tempo, foram apresentando diferentes níveis de crescimento econômico, o que as conduziu a diferentes níveis de poder na geopolítica mundial.

$\mathrm{Na}$ mesma direção, os setores de infraestrutura, tais como telecomunicações, energia elétrica, transporte aéreo, ferrovias e portos, são de importância fundamental para o aumento da produtividade e para o crescimento econômico de uma nação.

Ao longo das últimas décadas, a economia mundial e o setor de telecomunicações enfrentaram mudanças estruturais incluindo profundas transformações tecnológicas, alteração na dinâmica concorrencial em nível global e no processo produtivo.

Kaur e Malhotra (2014) destacam que as telecomunicações são um dos principais serviços necessários para a promoção do crescimento e da modernização de vários setores da economia e que possui uma grande conexão na cadeia produtiva a jusante e a montante.

No Brasil, a história das telecomunicações, apesar de apresentar relatos dos primeiros usos da telefonia ainda no período do império, com Dom Pedro II, presenciou grande difusão dos serviços ao longo da segunda metade do Século XX.

$\mathrm{Na}$ prática, ao longo dos últimos 60 anos, o setor de telecomunicações passou por períodos de grandes transformações com ciclos cada vez mais curtos. A definição e redefinição de serviços, bem como as mudanças tecnológicas foram intensas, sobretudo a partir de meados da década de 1990.

O Século XXI trouxe consigo indícios de maiores transformações no mercado de telecomunicações, em especial, com o processo de convergência tecnológica, onde diferentes plataformas e serviços tendem a se consolidar. 
Em decorrência dessas transformações e do surgimento de um ambiente crescentemente integrado, é possível observar mudanças nas relações econômicas, bem como o crescimento das oportunidades para celebração de negócios em nível mundial.

Assim, considerando esta inter-relação entre o ambiente favorável aos negócios propiciado pela evolução das telecomunicações e a consequente ampliação da dinâmica da atividade econômica, o presente capítulo busca estudar a relação entre investimentos em infraestrutura de telecomunicações e o crescimento do produto no Brasil nas últimas quatro décadas $^{2}$.

Para tanto, serão utilizados métodos econométricos em séries de tempo, de modo a possibilitar, inclusive, a identificação causal entre as variáveis de telecomunicações e de produto.

\title{
2.2 História econômico-institucional recente do setor de telecomunicações no Brasil
}

A partir de meados da década de 1990 foram tomadas inúmeras medidas que visavam reformar o aparelho do Estado. Neste contexto, aconteceu o processo de privatização das, até então, empresas estatais e a constituição de órgãos reguladores que teriam a incumbência de fiscalizar e regular os diferentes setores da economia.

No setor de telecomunicações, a reestruturação ocorrida a partir da Emenda Constitucional n. ${ }^{\circ} 8$, de 15 de agosto de 1995, teve seus principais objetivos detalhados pelo Poder Público ao introduzir o modelo vigente, na Exposição de Motivos n. ${ }^{o}$ 231/MC, de 10 de dezembro de 1996, que encaminhou o Projeto da Lei n. 9.472 de 16 de julho de 1997, Lei Geral de Telecomunicações (LGT), ao Congresso Nacional.

Ao analisar a situação naquele momento, de atendimento insuficiente da demanda pelos serviços telefônicos básicos, a E.M. n 231/MC destacou:

\begin{abstract}
"Essa situação é resultado da incapacidade de manutenção, pelas empresas sob controle acionário estatal, do nível necessário de investimentos ao longo do tempo, o que fez com que a taxa de crescimento da planta oscilasse aleatoriamente e fosse insuficiente para, pelo menos, igualar-se à do crescimento da demanda, e mais insuficiente ainda para proporcionar o atendimento à demanda reprimida."
\end{abstract}

\footnotetext{
${ }^{2}$ Kaur e Malhotra (2014) ressaltam que na economia global emergente o setor de telecomunicações tem apresentado um impacto significante no crescimento econômico.
} 
A incapacidade de investir derivou da artificial contenção das tarifas, utilizada como mecanismo para mascarar índices inflacionários. Basta lembrar que, em 1994, a assinatura residencial custava $\mathrm{R} \$ 0,44$ (líquida de tributos). Comparando-se este valor com o custo de impressão da fatura, com a despesa de postagem ou com a comissão de cobrança bancária observa-se o total descolamento entre tarifas e custo do serviço prestado.

Ressaltou ainda a E.M. no 231/MC:

"O setor das telecomunicações é hoje, sem dúvida, um dos mais atraentes e lucrativos para o investimento privado, em nível internacional. Trata-se de um dos setores líderes da nova onda de expansão econômica, que se formou a partir da chamada terceira revolução industrial. Pode-se contar que não faltarão investidores interessados em expandir essa atividade no mundo, em geral, e num país com as dimensões e o potencial do Brasil, em particular. O problema, que não é só do Brasil, é encontrar uma fórmula para a organização institucional do setor de telecomunicações que, ao mesmo tempo em que promova fortemente os investimentos privados, reforce o papel regulador do Estado e reserve ao setor público a atuação em segmentos estratégicos do ponto de vista social ou do interesse nacional."

Como objetivos da reforma do setor, previu a E.M. no 231/MC:

a) fortalecer o papel regulador do Estado $e$ eliminar seu papel de empresário;

b) aumentar e melhorar a oferta de serviços;

c) em um ambiente competitivo, criar oportunidades atraentes de investimento $e$ de desenvolvimento tecnológico e industrial;

d) criar condições para que o desenvolvimento do setor seja harmônico com as metas de desenvolvimento social do País; maximizar o valor de venda das empresas estatais de telecomunicações sem prejudicar os objetivos anteriores;

Para garantir o atendimento ao interesse público, no contexto apresentado, o legislador brasileiro explicitou dentre os deveres básicos do Poder Público, previstos no art. $2^{\circ}$ da LGT, o de fortalecer o papel regulador do Estado, bem como o de criar oportunidades de investimento e estimular o desenvolvimento tecnológico e industrial, em ambiente competitivo.

Os resultados gerais que advieram do processo de desestatização da prestação dos serviços de telecomunicações são de amplo conhecimento ${ }^{3}$, cabendo ressaltar a expansão do

\footnotetext{
${ }^{3}$ Vide página da Anatel na Internet www.anatel.gov.br.
} 
atendimento telefônico, decorrente do cumprimento das metas de universalização do acesso ao serviço telefônico fixo comutado (STFC), e posteriores avanços de notável magnitude, sobretudo relacionados aos serviços móveis (SMP), de banda larga (SCM) e de TV por assinatura. Tais resultados são decorrência, não só da qualidade do arcabouço regulamentar implantado, mas também da confiança e interesse dos agentes envolvidos e dos fatores socioeconômicos que interferem na atividade do setor.

Relativamente à atração de investimentos estrangeiros diretos, sabe-se que o setor de telecomunicações apresentou resultados expressivos após o processo de desestatização. Notadamente, a captação de recursos externos realizados pelas Concessionárias do STFC e prestadoras autorizadas do Serviço Móvel Pessoal (SMP), Serviço de Comunicação Multimídia (SCM) e de TV por assinatura constituiu fator preponderante para a obtenção destes resultados.

Uma série de fatores exógenos, entretanto, interfere no desempenho do setor de telecomunicações e na consecução do conjunto de objetivos. O crescimento da renda disponível, associada a sua melhor distribuição, e a consequente expansão da base de usuários são elementos fundamentais para o aumento da competitividade e eficiência dos agentes, bem como a apropriação de benefícios por parte do cidadão em geral que, mesmo diante de tarifas telefônicas com valores equivalentes aos dos países em condições econômicas similares, depende da melhoria do seu poder aquisitivo para o pleno acesso aos diferentes serviços de telecomunicações, ainda nos dias atuais.

\subsection{Revisão da literatura}

A literatura empírica sobre o impacto dos investimentos em infraestrutura no crescimento é bastante rica, mas, quando o tema é particularizado para o setor de telecomunicações, o número de trabalhos decresce de forma significativa. Esta seção ocupar-se-á em apresentar os trabalhos mais recentes e relevantes afetos ao tema do presente capítulo.

Taasim e Yusoff (2014) estudaram a contribuição da infraestrutura de telecomunicações para o crescimento econômico da Malásia. Um modelo econométrico de séries de tempo foi utilizado com dados do período de 1996 a 2014 para investigar o impacto do desenvolvimento das telecomunicações, considerando usuários de internet, banda-larga, telefones móveis e taxa de alfabetização, sobre o crescimento econômico. Foi utilizado como referência o modelo básico relacionado à hipótese de "Imposto-Gasto", como apresentado em Friedman (1978) e Buchanan 
e Wagner (1978). Os autores apontaram como resultado o fato de que a banda-larga e número de usuários de internet contribuíram para o desenvolvimento do país. Segundo os autores, os resultados mostraram que o crescimento do número de usuários, decorrente de investimentos iniciados nos primeiros anos da década de 2000 tiveram impacto sobre o crescimento econômico do país.

Kaur e Malhotra (2014) buscaram investigar a relação causal entre o desenvolvimento das telecomunicações e o produto doméstico bruto, bem como de componentes setoriais da Índia. Para tanto, os autores utilizaram dados referentes ao período de 1976 a 2012, obtidos no handbook de estatística sobre a economia da Índia. Segundo os autores, o estudo mostrou a existência de relação de longo prazo entre o crescimento das telecomunicações e o crescimento econômico em nível agregado, bem como em nível setorial. Os resultados também mostraram quebra estrutural, isto é, uma mudança estrutural na série de dados, nos anos de 1995 e 2005.

Masood (2012) buscou investigar a relação de causalidade entre a taxa de crescimento do PIB e os investimentos em tecnologias de comunicação e informação (ICT) na Suécia, utilizando modernas técnicas econométricas. Para tanto, foram utilizadas séries para um período de 30 anos (1980-2009). Foram realizados testes padrão de raiz unitária, de cointegração e de causalidade de Granger. Os resultados apresentaram uma indicação de que os investimentos em ICT são um fator que contribui para o desenvolvimento da infraestrutura de telecomunicações, mas não seriam suficientes o bastante para estimular o crescimento econômico (GDP). O estudo também encontrou relação de causalidade indo de investimento para crescimento econômico para um ano de defasagem, mas não no longo prazo. Segundo o trabalho, a razão da não existência de relação causal de longo prazo pode estar associada à incapacidade de refletir o efeito completo dos investimentos em ICT em segmentos complementares.

Calderón et. al. (2011) desenvolveram um trabalho empírico que buscou avaliar a contribuição da infraestrutura no produto. Os autores utilizaram um painel de estoque de infraestrutura com 88 países para o período compreendido entre os anos de 1960 e 2000 e usaram uma abordagem de séries de tempo em painel. O trabalho estimou uma função de produção agregada relacionando produto, capital humano, capital físico e uma medida de infraestrutura obtida a partir da dotação de infraestrutura de transporte, energia e telecomunicações. Como resultado mais relevante, os autores encontraram uma elasticidade de longo prazo da medida de infraestrutura em um intervalo entre 0.07 a 0.10 . 
Canning e Pedroni (2008) buscaram estudar o nível do estoque de infraestrutura, isto é, se este estava acima, abaixo ou no nível maximizador do crescimento econômico, tendo por base o modelo de crescimento de Barro (1990). Para tanto, estudaram as consequências da provisão de infraestrutura sobre o crescimento econômico para um painel de países no período de 1950 a 1992. Os autores mostraram que, apesar de haver uma tendência de causalidade indo de infraestrutura para crescimento de longo prazo, existe uma variação expressiva entre os países. Os autores também mostraram que cada tipo de infraestrutura é ofertado, em geral pela maioria dos países, em nível próximo ao nível maximizador do crescimento econômico, mas que existem países com sub-oferta ou sobre-oferta de infraestrutura.

Pereira (2006) destaca a importância do progresso técnico e da acumulação de capital para o desenvolvimento econômico. Ainda segundo o autor, os dois principais fatores responsáveis pelo desenvolvimento econômico são a acumulação de capital vis-à-vis ao produto nacional e à habilidade de incorporar o progresso técnico à produção.

Calderón e Servén (2004) avaliaram o impacto do desenvolvimento da infraestrutura sobre o crescimento econômico e sobre a distribuição de renda usando um painel de dados abrangendo mais de 100 países para os anos compreendidos entre 1960 e 2000. A estratégica empírica usada pelos autores envolveu a estimação de uma equação de crescimento do produto e medidas convencionais de desigualdade incrementada para incluir entre os regressores indicadores de quantidade e qualidade de infraestrutura, além de controles padrão. Os dois principais resultados obtidos pelos autores indicam que o estoque de ativos de infraestrutura afeta positivamente o crescimento, bem como a desigualdade de renda reduz com o aumento da quantidade e qualidade da infraestrutura. Os autores ainda destacam que os resultados obtidos sugerem que o desenvolvimento de infraestrutura pode ser bastante efetivo no combate à pobreza.

Roller e Waverman (2001) investigaram como a infraestrutura de telecomunicações afetou o crescimento econômico em um espectro de 21 países da OCDE durante 20 anos, entre 1970 e 1990. Simultaneamente, os autores estimaram um modelo micro para investimentos em telecom com uma função de produção macro e afirmaram ter encontrado evidência significativa de relação positiva, especialmente quando a infraestrutura de telecomunicações estava massificada, isto é, próximo a um nível de atendimento universal. 


\subsection{Variáveis e a base de dados}

Visando estudar a relação causal entre o crescimento do produto e o desenvolvimento do setor de telecomunicações foram utilizados dados anuais para o período de 1976 a 2013 das variáveis PIB real, estoque de capital, população ocupada e terminais por população ocupada. As séries foram usadas em seus logaritmos naturais de modo a que as estimações fossem obtidas em termos de elasticidade, contribuindo para a interpretação dos resultados.

Os dados para o estudo foram obtidos junto a fontes públicas como a base de dados do Instituto de Pesquisa Econômica Aplicada - IPEADATA, o banco de dados SIDRA do Instituto Brasileiro de Geografia e Estatística - IBGE - e sistemas e relatórios de gestão da Agência Nacional de Telecomunicações - ANATEL.

As séries de PIB real, estoque de capital $^{4}$ e de terminais de telecomunicações foram obtidas na íntegra das fontes citadas. A série de população ocupada foi em grande parte obtida junto ao IBGE e ao Ipeadata, mas para alguns anos (2000 e 2010) foi realizada interpolação via software OriginPro 8.0, devido à ausência das informações nas fontes consultadas.

A utilização do índice de terminais por população ocupada busca incorporar, no modelo, a ideia de estoque de investimentos em infraestrutura de telecomunicações, uma vez que quanto maior o índice maior é a infraestrutura disponível e, por consequência, evidencia a realização de investimentos.

Importante ressaltar que a ideia não foi utilizar variáveis per capita, o que traria a necessidade de se considerar as demais variáveis do modelo também em termos per capita, mas tão somente considerar uma proxy de investimento em infraestrutura de telecomunicações.

\subsubsection{As séries e suas tendências}

A partir da $\quad$ Figura 2.1 é possível verificar que as séries utilizadas no desenvolvimento do trabalho, quais sejam, PIB real (PIBreal), estoque de capital (estoquek), população ocupada (popocup) e terminal por população ocupada (termpopocup) apresentam tendência de crescimento positivo.

\footnotetext{
${ }^{4}$ As bases referem-se a valores de 2000, conforme disponível nas fontes IPEADATA e IBGE.
} 
A série do PIB real apresenta quedas importantes, caracterizando períodos de recessão entre os anos de 1979 e 1982, 1986 e 1994 (período mais longo) e entre 1997 e 2003. Os mínimos locais desses períodos fornecem indicação de presença de quebras estruturais, conforme discutido em pormenor mais à frente.

Outro aspecto a ser ressaltado é que a série de terminais por população ocupada parece apresentar um crescimento exponencial a partir de 1997, data que coincide com a privatização do setor de telecomunicações no Brasil. 
Figura 2.1. Séries e Tendências
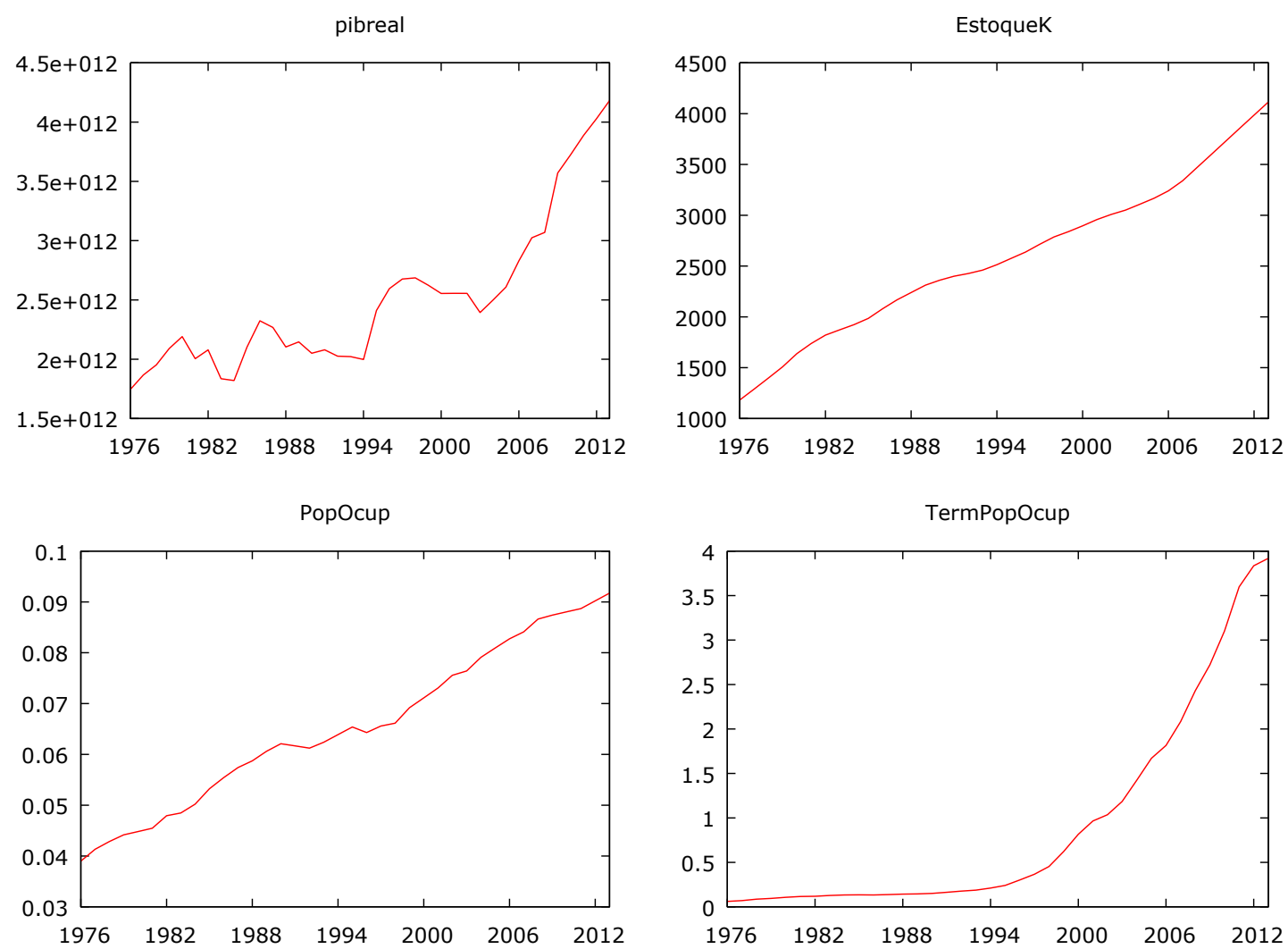

\subsubsection{Matriz dos coeficientes das séries}

Outra informação acerca do comportamento das séries refere-se aos níveis de correlação entre as variáveis, obtidos diretamente do software econométrico Gretl. Conforme evidenciado na Tabela 2.1 abaixo, os coeficientes de correlação apresentam-se positivamente elevados, podendo-se destacar os coeficientes entre popocup e estoquek (0.9904) e entre termpopocup e PIBreal (0.9496).

Tabela 2.1. Coeficientes de correlação, usando todas as observações 1976 - 2013 $5 \%$ valor crítico $($ bilateral $)=0.3202$ para $n=38$

\begin{tabular}{ccccl} 
PIBreal & EstoqueK & PopOcup & TermPopOcup & \\
\hline 10.000 & 0.8921 & 0.8608 & 0.9496 & PIBreal \\
& 10.000 & 0.9904 & 0.8764 & EstoqueK \\
& & 10.000 & 0.8662 & PopOcup \\
& & & 10.000 & TermPopOcup \\
\hline
\end{tabular}


Vale ressaltar que, apesar do esforço envidado no sentido de se obter as séries das variáveis para a realização do presente estudo, é possível registrar que, ainda assim, estas se mostraram relativamente pequenas, o que determina erros padrão dos estimadores maiores do que os que seriam obtidos caso fossem utilizadas séries mais longas, o que, em certa medida, traz um desafio a mais na realização de trabalhos empíricos como este.

Todavia, a indisponibilidade de séries mais longas no Brasil não pode ser um impeditivo à realização de trabalhos empíricos relevantes para a obtenção de novos conhecimentos acadêmicos sobre determinado tema e que possa servir de suporte para a tomada de decisão em políticas públicas. Por isso, o entendimento prevalecente é que, apesar de eventuais limitações do presente estudo no que tange ao tamanho da série de dados, espera-se que os resultados aqui apresentados sejam úteis ao debate sobre as políticas públicas de telecomunicações no país.

\subsection{Metodologia e estimação dos modelos}

Para realização do presente estudo optou-se por utilizar modelos vetores autorregressivos (VAR), isto é, modelos de séries temporais multivariados baseado somente na componente autorregressiva, que oferecem mais flexibilidade no que tange à imposição de restrições à estrutura da economia, para descrever a relação dinâmica entre as variáveis PIB real, estoque de capital, população ocupada (trabalho) e terminais por população ocupada, usada como proxy (referência) de investimentos em telecomunicações

Conforme destacam Lütkepohl e Krätzig (2004) para um conjunto de $K$ variáveis em série de tempo $y_{t}=\left(y_{1 t}, \ldots, y_{K t}\right)^{\prime}$, um modelo autorregressivo captura sua dinâmica de interação e apresenta como modelo básico de ordem $p$ :

$$
y_{t}=A_{1} y_{t-1}+\cdots+A_{p} y_{t-p}+u_{t}
$$

Onde $A_{i s}$ representam a matriz de coeficientes $(K x K)$ e $u_{t}=u_{1 t}, \ldots, u_{K t}$ é o termo de erro não observável. Assume-se que $u_{t}$ 's são vetores estocasticamente independentes, com $u_{t} \sim\left(0, \Sigma_{u}\right), \operatorname{com} \Sigma_{u}=E\left(u_{t} u_{t}^{\prime}\right)$, matriz de covariância definida positiva.

Apesar do modelo descrito pela equação 1, apresentada anteriormente, ser geral o suficiente para acomodar variáveis com tendência estocástica, não se mostra o tipo de modelo quando o interesse está em investigar as relações de cointegração, pois não aparece 
explicitamente. O modelo VECM se apresenta mais adequado para análise de cointegração (Lütkepohl e Krätzig, 2004):

$$
\Delta y_{t}=\Pi y_{t-1}+\Gamma_{1} \Delta y_{t-1}+\cdots+\Gamma_{p-1} \Delta y_{t-p+1}+u_{t}
$$

sendo, П o produto de uma matriz de pesos $\alpha$ pela matriz de cointegração $\beta$.

Lütkepohl e Krätzig, (2004) destacam ainda que os coeficientes $\Gamma_{j} s(j=1, \ldots, p-1)$ são usualmente tratados como parâmetros de curto prazo e $\Pi y_{t-1}$ é algumas vezes chamado de parâmetro de longo prazo.

Ressalte-se que foram realizados os testes necessários à correta identificação e estimação dos modelos, os quais são detalhados nas seções subsequentes. Ademais, estimou-se o modelo de correção de erros, uniequacional, para avaliar a robustez dos resultados do modelo multiequacional e, como é usual em estudos acerca da dinâmica dos sistemas econômicos, foram estimadas as funções de resposta ao impulso. Por fim, foi realizado o teste de causalidade de Granger de modo a identificar a existência e o sentido de relação causal entre as variáveis em análise.

Uma observação importante no que tange à realização do trabalho refere-se à necessidade de utilização de diferentes softwares e/ou pacotes econométricos devido à não existência de rotinas para todos os testes em um único software e à existência de eventual divergência de resultados entre os testes realizados. Ou seja, a utilização de mais de um software para realização dos testes e estimação dos modelos visou também a prover maior robustez e confiabilidade aos resultados e às conclusões obtidas.

\subsubsection{O modelo econométrico: efeito do investimento em telecomunicações sobre o produto interno bruto}

O modelo teórico proposto no presente trabalho é, em certa medida, uma derivação do modelo proposto por Barro (1990), bem como considera os trabalhos de Calderón e Servén (2004) e Calderón et. al.(2011). O modelo teórico apresentado aqui considera que o produto agregado $Y$ no tempo $t$ é produzido usando a infraestrutura de telecomunicações, outro estoque de capital $K$ e trabalho $L$, conforme equação (3): 


$$
Y_{t}=A_{t} K_{t}^{\alpha} L_{t}^{\beta} T_{t}^{1-\alpha-\beta}
$$

Onde $A$ é a produtividade total dos fatores no tempo $t$. Aplicando o logaritmo natural, obtemos a equação a ser estimada:

$$
\ln Y_{t}=\ln A_{t}+\alpha \ln K_{t}+\beta \ln L_{t}+(1-\alpha-\beta) \ln T_{t}
$$

A literatura econométrica de séries de tempo evoluiu nas últimas décadas, em especial desde a década de 1970, no sentido de inserir mais teoria econômica ao processo de análise das séries de tempo, dando origem aos modelos VAR - Vetores autorregressivos.

O surgimento dos modelos autorregressivos se deu na década de 1980, com o trabalho de Sims (1980), como forma de contornar as críticas às restrições existentes para a estimação de modelos estruturais. A ideia motriz era desenvolver modelos dinâmicos, onde todas as variáveis econômicas fossem tratadas como endógenas, com o mínimo de restrições.

A maior flexibilidade dos modelos VAR está relacionada à necessidade de impor como restrições à estrutura da economia apenas a escolha das variáveis relevantes e o número máximo de defasagens a ser aplicado às variáveis. Com essas especificações, os modelos VAR avaliam as relações lineares entre cada uma das variáveis e seus valores defasados, bem como os valores defasados das demais variáveis. [ Akaike (1974), Schwarz (1978), Engle e Granger (1987)]

Relativamente à definição das defasagens ótimas, como detalhado mais à frente, é comum a utilização dos critérios de Akaike (1974) ou Schwarz (1978).

Na prática, a utilização dos modelos VAR pressupõe a existência no vetor $X_{t}$ de pelo menos duas séries de tempo, isto é, $X_{t}=\left[\begin{array}{ll}y_{t} & z_{t}\end{array}\right]$, por exemplo, de modo que o modelo possa ser definido como:

$$
\begin{aligned}
& y_{t}=b_{10}-a_{12} z_{t}+b_{11} y_{t-1}+b_{12} z_{t-1}+\sigma_{y} \varepsilon_{y t}, \\
& z_{t}=b_{20}-a_{21} y_{t}+b_{21} y_{t-1}+b_{22} z_{t-1}+\sigma_{z} \varepsilon_{z t},
\end{aligned}
$$

Conforme destaca Bueno (2011), como as variáveis contemporâneas $y_{t}$ e $z_{t}$ dependem contemporaneamente uma da outra, isto é, estão correlacionadas aos erros $\varepsilon_{y t} \mathrm{e}$ $\varepsilon_{z t}$ respectivamente, o modelo não pode ser estimado diretamente. Neste sentido os modelos VAR buscam definir técnicas que contornem esse problema de modo a conseguir identificar o 
comportamento da variável de interesse diante de choques nos termos de erro (choques estruturais).

Para o referido modelo são assumidas as hipóteses de que as séries de tempo são estacionárias, os erros são ruídos brancos e mutuamente ortogonais. Bueno (2011). Uma maneira de se estimar o modelo apresentado anteriormente na forma estrutural que se apresenta endógeno é trabalhar com sua forma reduzida, isto é, colocando as equações somente em função das variáveis defasadas (exógenas).

Apesar dos benefícios trazidos pelo desenvolvimento dos modelos VAR, estes apresentam algumas limitações, dentre as quais se podem destacar duas mais comumente lembradas:

- A sobreparametrização, isto é, a estimação de um grande número de parâmetros que interfere na definição do tamanho da amostra para que se tenha uma estimação confiável;

- A estimação de um modelo em sua forma reduzida por serem compatíveis simultaneamente com diferentes modelos estruturais (que tratam também das relações contemporâneas das variáveis).

Visando superar essas limitações, a literatura, ao longo dos anos, foi sendo aperfeiçoada. Para tratar o caso de sobreparametrização foram desenvolvidos os modelos de vetores autorregressivos bayesianos, que eliminam o problema da ordem de integração das séries, deixando de lado a abordagem tradicionalmente considerada no que tange à discussão sobre raiz unitária. (Sims, 1988; Dejong; Whiteman, 1991; Sims; Uhlig, 1991; Koop, 1992). Todavia, Ahking (2009) estuda o poder do que Koop (1992) chamou de abordagem bayesiana objetiva para o teste de raiz unitária e concluiu pela sua não superioridade vis-à-vis à abordagem ADF tradicional pelo fato daquela conter viés para a tendência estacionária.

Relativamente à estimação dos modelos na forma reduzida foram desenvolvidos procedimentos para recuperar os parâmetros estruturais quando se fizesse necessário, uma vez que se o intuito fosse unicamente a realização de previsões, a estimação da forma reduzida atenderia perfeitamente a necessidade.

A seguir são apresentados os testes necessários à correta identificação do modelo, tais como, testes de raiz unitária, que mudança estrutural, para definição da defasagem ótima, os 
testes de cointegração, bem como são estimados os modelos VAR restrito (VECM), as funções resposta ao impulso e os testes de causalidade de Granger. Diante dos resultados das estimações procedem-se às análises e obtêm-se conclusões sobre a relação de causalidade entre as variáveis.

\subsection{Testes, estimações e principais resultados}

A presente seção trata de apresentar os testes necessários à correta identificação e estimação do modelo VAR restrito (VECM) e do modelo de correção de erros, bem como à realização do teste de resposta ao impulso e à análise de causalidade. Ademais, são realizados testes de diagnóstico para garantir a validade dos resultados das estimações conduzidas.

\subsubsection{Testes de raiz unitária}

O uso de regressões em séries de tempo entre variáveis não estacionárias tende a conduzir a um resultado espúrio e sem utilidade para qualquer tipo de análise. Neste sentido, o conhecimento da ordem de integração das séries econômicas torna-se relevante para a estimação dos modelos econométricos. Visando identificar a estacionaridade das séries temporais foram desenvolvidos testes que buscam identificar a existência de raiz unitária, ou seja, a ausência de estacionaridade das séries.

\subsubsection{Teste de raiz unitária sem quebra}

A Tabela 2.2 abaixo evidencia uma síntese dos resultados dos testes de raiz unitária bem como a conclusão extraída dos testes quanto à estacionaridade das séries, segundo três distintos métodos, a saber:

1) Teste ADF - Augmented Dickey-Fuller Test: trata-se de uma versão ampliada do teste de Dickey e Fuller (1979) que buscou corrigir o problema de que o teste inicialmente proposto considerava o erro um ruído branco, o que enfraquecia o seu poder. $\mathrm{Na}$ prática, o teste ampliado passou a considerar variáveis autorregressivas, em dimensão necessária, para tornar o resíduo um ruído branco. A hipótese nula do teste é a existência de raiz unitária. A implementação do teste está relacionada à estimação de 
um modelo autorregressivo de ordem 1, AR(1) e o teste das hipóteses conforme apresentado a seguir:;

$$
y_{t}=\phi y_{t-1}+\varepsilon_{t}
$$

$H 0: \phi=1, y_{t}$ não é estacionário

$$
H 1:|\phi|<1, y_{t} \text { é estacionário }
$$

Na prática, trata-se da realização de um teste t sobre o $\hat{\phi}$. Ressalte-se que modelo AR(1) está sujeito a $\varepsilon_{t} \sim \operatorname{iid} N\left(0, \sigma^{2}\right), \forall t$ e $E\left[\varepsilon_{t} \varepsilon_{s}\right]=0, \forall t \neq s$.

2) Teste de Phillips-Perron (1988): trata-se de um teste cuja hipótese nula é de que as séries são integradas de ordem 1. Da mesma maneira que o teste de Dickey-Fuller aumentado o teste de Phillips-Perron também busca tratar a questão de que o processo gerador de dados pode ter uma autocorrelação de maior ordem que admitido na equação de teste (DF), gerando endogeneidade e invalidando o teste original de Dickey-Fuller. Todavia, o teste de Phillips-Perron surgiu em um contexto em que se buscava definir de forma independente das ordens $p$ e $q$ do modelo autorregressivo. $\mathrm{O}$ teste inova ao fazer uma correção não paramétrica ao teste de Dickey-Fuller, sendo consistente, mesmo na presença autocorrelação. Segundo Bueno (2011) as equações e testes designados são idênticos aos de Dickey e Fuller;

3) Teste KPSS - Kwiatkowski-Phillips-Schmidt-Shin(1992): tendo em vista o baixo poder do teste de Dickey e Fuller na presença de um componente de médias móveis, o que leva à não rejeição da hipótese nula de raiz unitária, desenvolvidos outros testes de raiz unitária, incluindo o KPSS. Conforme aponta Bueno (2011) a forma de desenvolver o teste KPSS segue a literatura de modelos estruturais cujo ponto central é fornecer uma interpretação econômica aos componentes das séries. Neste teste a hipótese nula é de estacionaridade, $H 0: y_{t} \sim I(0)$, e sua importante contribuição é permitir a distinção entre a existência de raiz unitária da possibilidade de inconclusão a partir dos dados disponíveis.

A Tabela 2.2 abaixo sintetiza os resultados: 


\section{Tabela 2.2. Resultados de Raiz Unitária}

\begin{tabular}{lcccccc}
\multicolumn{7}{c}{ Resultados de Raíz Unitária do Stata } \\
\hline \multirow{2}{*}{ VARIÁVEIS } & \multicolumn{2}{c}{ ADF } & \multicolumn{3}{c}{ KPSS } & \multicolumn{3}{c}{ PPERRON } \\
\cline { 2 - 7 } & NÍVEL & PD & NÍVEL & PD & NÍVEL & PD \\
\hline PIBREAL & $\mathrm{I}(1)$ & $\mathrm{I}(1)$ & $\mathrm{I}(1)$ & $\mathrm{I}(1)$ & $\mathrm{I}(1)$ & $\mathrm{I}(1)$ \\
ESTOQUEK & $\mathrm{I}(1)$ & $\mathrm{I}(1)$ & $\mathrm{I}(1)$ & $\mathrm{I}(1)$ & $\mathrm{I}(1)$ & $\mathrm{I}(1)$ \\
POPOCUP & $\mathrm{I}(1)$ & $\mathrm{I}(1)$ & $\mathrm{I}(1)$ & $\mathrm{I}(1)$ & $\mathrm{I}(1)$ & $\mathrm{I}(1)$ \\
TERMPOPOCUP & $\mathrm{I}(1)$ & $\mathrm{I}(1)$ & $\mathrm{I}(1)$ & $\mathrm{I}(1)$ & $\mathrm{I}(1)$ & $\mathrm{I}(1)$ \\
\hline
\end{tabular}

Conforme apresentado na tabela 2.2, todas as variáveis mostraram-se não estacionárias em nível para os três testes realizados.

Vale ressaltar que alguns testes, quando variando o número de defasagens, apresentaram a variável termpopocup como integrada de ordem 2, I(2), mas o resultado majoritário indicou integração primeira ordem. Todavia, considerando o período de 1976 a 2013 para as séries em análise e as transformações econômicas enfrentadas pelo Brasil neste período, torna-se oportuno investigar a existência de quebras estruturais, conforme sugere a teoria econômica.

Ademais, a existência de quebras afeta os testes tradicionais no sentido de favorecer à não rejeição da hipótese nula, isto é, de existência de raiz unitária para os testes ADF e PhillipsPerron o que poderia comprometer as condições necessárias para a realização de cointegração e a aplicação do modelo autorregressivo.

Por isso, entendeu-se relevante a realização de testes para identificar empiricamente a existência de quebras estruturais nas séries econômicas, isto é, se há a confirmação do depreendido da teoria econômica.

\subsubsection{Mudanças estruturais e testes de identificação de quebras}

Como é de conhecimento comum, ao longo dos séculos, décadas e anos, as economias ao redor do planeta passaram por um processo de mudança em suas estruturas. Nesse ínterim, vale destacar que Galvão Júnior et al. (2005) encontraram evidências de mudança estrutural na indústria brasileira em data que varia de 1987 e 1994. Diante desta realidade, e conhecendo as possíveis distorções que podem ser trazidas para trabalhos empíricos, foram desenvolvidos testes de raiz unitária considerando a existência de quebras na economia. 
Chow (1960) desenvolve de forma sistemática um teste que visa investigar se, ao agregar mais $\mathbf{y}$ observações a uma regressão linear com $\mathbf{x}$ coeficientes, estes permanecem estáveis. Ou, de outra forma, se as relações entre variáveis econômicas se mantêm estáveis em dois períodos de tempo. Na prática, a ideia do teste de quebra de Chow é estimar uma regressão separadamente para cada subamostra e verificar se há diferença significativa entre as equações estimadas. Diferenças significativas indicam mudança estrutural.

Uma limitação do teste de Chow é que ele pressupõe um conhecimento prévio das datas das quebras. Visando relaxar o suposto de conhecimento prévio da data de quebra, Quandt (1960) realiza estudo considerando diferentes abordagens para testar a hipótese de que nenhuma mudança ocorre no verdadeiro valor de um sistema de regressão linear e modifica a abordagem de Chow para considerar a estatística F com maior valor sobre todas as possíveis datas de quebra, porém considerando ainda quebra simples.

Bai e Perron $(1998,2003)$ apresentam resultados teóricos e computacionais que estendem a abordagem de Quandt e Andrews para permitir a verificação de múltiplas datas de quebra desconhecidas.

A seguir é apresentado um maior detalhamento do teste proposto por Bai e Perron (1998), bem como o resultado para as séries em análise.

\subsubsection{O teste de identificação de múltiplas quebras de Bai e Perron [Bai and Perron (1998, 2003)]}

O desenvolvimento do trabalho de Bai e Perron (1998) trouxe importante contribuição para a literatura econométrica de séries de tempo, na medida em que possibilitou a identificação de múltiplas quebras, sem a necessidade de prévio conhecimento acerca do momento em que aconteciam.

Os testes de múltiplas quebras podem ser divididos, de forma geral, em três categorias: testes que consideram maximizadores globais, testes que consideram pontos de quebra determinados e testes híbridos.

Os diferentes métodos estão disponíveis para aplicação. Para o presente trabalho foi utilizado o método de maximizadores globais, o qual aplica um procedimento de otimização global para identificar as múltiplas quebras de modo a minimizar a soma dos quadrados dos 
resíduos do modelo de regressão e testa a hipótese alternativa de l quebra contra a hipótese nula de não existência de quebra estrutural.

O método sequencial se diferencia do anterior na medida em que aplica o teste de uma quebra até o número máximo enquanto a hipótese nula não possa ser rejeitada. Posto isto, a seguir apresenta-se o resultado obtido para as séries em estudo.

\section{Tabela 2.3. Resultados do teste de quebra}

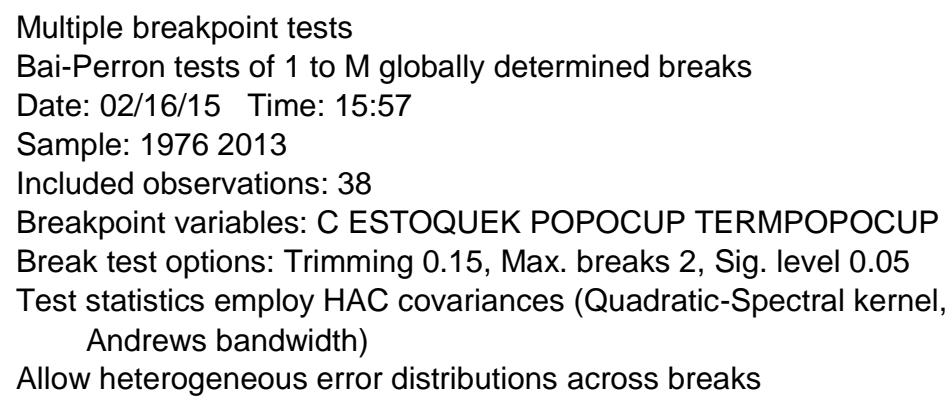

Considerando o tamanho amostral da base de dados, foram permitidas duas quebras, de modo a não permitir subamostras com tamanho inferior a 15 observações, e o resultado apresentado pelo software Eviews apontou para a existência de duas quebras, uma em 1983 que pode estar relacionada com o processo de redemocratização e, em especial, com a frágil situação de endividamento do Brasil que levou à assinatura de acordo com o FMI de rolagem da dívida em 1983 e outra em 1995 que provavelmente está relacionada com o processo de estabilização econômica do país, com a recente introdução do plano real.

Uma vez confirmada empiricamente a hipótese de quebra, torna-se necessária a investigação da existência de raiz unitária nas séries em estudo, considerando a existência de quebras estruturais. Para tanto, procedeu-se à realização de testes desenvolvidos por Lee e Strazicich (2003) ${ }^{5}$ e de Zivot e Andrews (1992).

Testes de raiz unitária com quebraTabela 2.4, apresentada a seguir, evidencia uma síntese dos resultados dos testes de raiz unitária considerando a existência de quebras estruturais, bem

\footnotetext{
${ }^{5}$ Rotina desenvolvida para o software R por Raphael Gouvêa e Thais Teixeira, do IPEA.
} 
como a conclusão extraída dos testes quanto à estacionaridade das séries. Os testes foram rodados considerando as rotinas desenvolvidas para o software $\mathrm{R}$ relativamente aos trabalhos de Lee e Strazicich (2003) e de Zivot e Andrews (1992).

Tabela 2.4. Teste de raiz unitária com quebra

\begin{tabular}{|c|c|c|c|c|c|}
\hline \multicolumn{6}{|c|}{ Resultados dos Testes de Raíz Unitária com Quebra - Software R } \\
\hline \multirow{4}{*}{ VARIÁVEIS } & \multicolumn{5}{|c|}{ LEE e STRAZICICH (2003) - H0: Existe Raiz Unitária } \\
\hline & \multicolumn{5}{|c|}{ Duas defasagens } \\
\hline & \multicolumn{2}{|c|}{ Uma quebra (estatística) } & \multicolumn{2}{|c|}{ Duas quebras (estatística) } & \multirow[b]{2}{*}{ Conclusão } \\
\hline & $\begin{array}{c}\text { mudança } \\
\text { somente no } \\
\text { nível } \\
\end{array}$ & $\begin{array}{c}\text { mudança no nível e } \\
\text { na tendência } \\
\text { simultaneamente }\end{array}$ & $\begin{array}{c}\text { mudança somente } \\
\text { no nível }\end{array}$ & $\begin{array}{c}\text { mudança no nível } \\
\text { e na tendência } \\
\text { simultaneamente } \\
\end{array}$ & \\
\hline PIBREAL & -2.918464 & -3.459359 & -3.298755 & -5.305248 & Nunca rejeita $\mathrm{I}(1)$ \\
\hline ESTOQUEK & -3.055775 & -4.101904 & -3.472697 & -6.207064 & $\begin{array}{l}\text { I(1). Somente rejeitaria } \\
\text { RU a } 10 \% \text { para o caso } \\
\text { com duas quebras e } \\
\text { mudança no nível e na } \\
\text { inclinação }\end{array}$ \\
\hline POPOCUP & -2.418536 & -2.590596 & -2.775008 & -4.270158 & Nunca rejeita $\mathrm{I}(1)$ \\
\hline TERMPOPOCUP & -2.344545 & -4.077643 & -2.801893 & -5.788066 & $\begin{array}{l}\text { I(1). Somente rejeitaria } \\
\text { RU a } 10 \% \text { para o caso } \\
\text { com duas quebras e } \\
\text { mudança no nível e na } \\
\text { inclinação }\end{array}$ \\
\hline \multirow[b]{2}{*}{ VARIÁVEIS } & \multicolumn{5}{|c|}{ ZIVOT e ANDREWS (1992) - H0: Existe Raiz Unitária } \\
\hline & $\begin{array}{c}\text { mudança } \\
\text { somente no } \\
\text { nível }\end{array}$ & $\begin{array}{l}\text { mudança somente } \\
\text { na tendência }\end{array}$ & $\begin{array}{l}\text { Duas defasagens (es } \\
\text { mudança no nível e } \\
\text { na tendência } \\
\text { simultaneamente }\end{array}$ & atística) & nclusão \\
\hline PIBREAL & -3.5276 & -3.7172 & -3.8138 & Nunca rejeita $\mathrm{I}(1)$ & \\
\hline ESTOQUEK & -2.3104 & -4.8093 & -4.291 & $\begin{array}{l}\text { I(1). Somente rejeit } \\
\text { com mudança na in }\end{array}$ & $\begin{array}{l}\text { ria RU a } 5 \% \text { para o caso } \\
\text { linação }\end{array}$ \\
\hline POPOCUP & -3.6135 & -2.5812 & -3.8607 & Nunca rejeita I(1) & \\
\hline TERMPOPOCUP & -0.3963 & -1.7424 & -0.7554 & Nunca rejeita $\mathrm{I}(1)$ & \\
\hline
\end{tabular}


De forma semelhante aos resultados obtidos nos testes que desconsideravam qualquer quebra os testes de Lee e Strazicich (2003) e de Zivot e Andrews (1992) não rejeitaram a hipótese nula de existência de raiz unitária, isto é, confirmaram o fato de as séries serem integradas de ordem um, I(1), considerando duas defasagens, bem como cenários distintos no que tange ao número de quebras e ao componente do processo a sofrer a mudança.

Com a confirmação obtida quanto à ordem de integração das séries, passamos à investigação quanto à existência de relação de longo prazo das séries, cointegração, o que possibilitará a utilização do modelo de vetor autorregressivo restrito, VECM, para analisar as relações de curto e longo prazos das variáveis e, em seguida à realização de teste de causalidade de modo a identificar a relação causal entre as variáveis econômicas para o período em análise.

Antes, porém, considerando a importância das defasagens para os resultados a serem obtidos no presente trabalho, convém definir o número ótimo de defasagens a ser utilizado nos testes subsequentes e na modelagem do VAR restrito.

\subsubsection{Seleção de defasagem ótima}

A definição do número de defasagens é um ponto relevante para a análise da relação de causalidade. Autores como Mandala (1992), Davidson e MacKinnon (1993), Mills (1993) apresentaram argumentações distintas acerca da melhor forma de definição das defasagem e da importância de sua definição para evitar vieses de estimação.

A despeito das teorias e dos testes disponíveis para definição do número ótimo de defasagens este tema deve ser entendido como a busca de equilíbrio entre a sobreparametrização, isto é, a estimação de grande número de parâmetros, e a possibilidade de autocorrelação dos resíduos, em especial para casos de amostras não muito grandes.

No caso em análise, como a frequência dos dados é baixa, espera-se que o resíduo da regressão se torne um ruído branco com poucas defasagens (1 ou 2), pois não há tanta persistência para os dados anuais. Ademais, o fato de as séries serem relativamente curtas traz à tona a preocupação com os graus de liberdade, isto é, a inclusão demasiada de defasagens pode gerar uma sobreparametrização da regressão, resultando em grande imprecisão, gerando dificuldades para implementação dos testes de hipótese.

Desta forma, se, por um lado, pode existir uma perda ao se reduzir o número de defasagens no que tange à possibilidade de deixar os resíduos autocorrelacionados, por outro, ao 
incluir um número maior de defasagens, pode-se incorrer na estimação de grande número de parâmetros com poucas observações.

A praxe em trabalhos aplicados é a utilização, nos testes, do número máximo de defasagens (para definição do número ótimo de defasagens) seguindo uma correlação com a frequência dos dados utilizados. Portanto, para dados mensais são utilizadas até 12 (doze) defasagens, para dados trimestrais são utilizadas até 4 (quatro) defasagens e para o caso de dados anuais é utilizada 1 (uma) ou, no máximo, 2 (duas) defasagens.

Relativamente aos testes para a definição da defasagem ótima podem-se destacar os principais critérios usados pelos softwares econométricos Gretl (BIC) e Eviews (todos os cinco testes).

a) Critério de Akaike (AIC);

b) Critério Bayesiano de Schwarz (BIC);

c) Critério de Hannan-Quinn (HQC);

d) LR modificado sequencial (LR); e

e) Erro de predição final (FPE).

Oportuno destacar que não foi encontrada uniformidade entre os critérios, no que tange à defasagem ótima.

Apesar do ponto já esclarecido anteriormente acerca do número máximo de defasagens a ser utilizado para os testes em séries anuais (o que implicaria, na prática, a desnecessidade de testes para definição de defasagem ótima), optou-se por realizar um conjunto de testes com faixa de variação de defasagens máximas de 2 a 6 nos softwares econométricos Gretl e Eviews, de modo a realizar uma melhor avaliação da defasagem ótima a ser utilizada no decorrer do trabalho ou, como destaca Bueno (2011), buscou-se, além dos procedimentos objetivos listados a seguir, o bom senso e a parcimônia no processo de definição da defasagem ótima. Os resultados são apresentados a seguir: 
Tabela 2.5. Testes para defasagem ótima

\begin{tabular}{ccccccc}
\hline \multicolumn{7}{c}{ TESTES PARA DEFASAGEM ÓTIMA } \\
\hline & \multicolumn{5}{c}{ EVIEWS } \\
\cline { 2 - 7 } $\begin{array}{l}\text { Num Max } \\
\text { Defasagens }\end{array}$ & LR & FPE & AIC & SC & HQ & BIC \\
\hline 2 & 2 & 2 & 2 & 2 & 2 & 1 \\
3 & 2 & 2 & 2 & 2 & 2 & 1 \\
4 & 2 & 2 & 4 & 2 & 2 & 1 \\
5 & 2 & 2 & 4 & 2 & 2 & 1 \\
6 & 2 & 2 & 6 & 2 & 6 & 1 \\
\hline
\end{tabular}

Fatos importantes a destacar acerca dos resultados dos testes de defasagem ótima são:

- Inicialmente cabe ressaltar, conforme asseverado por Bueno (2011), que o critério AIC superestima assintoticamente a ordem do VAR com probabilidade positiva, enquanto os critérios BIC e HQC estimam a ordem consistentemente sob hipóteses bem gerais;

- No software Gretl, o critério Bayesiano de Schwarz (BIC) estabeleceu uma única defasagem como ótima, independentemente do número máximo de defasagens estipulado, enquanto que para o software Eviews duas defasagens foram consideradas o número ótimo;

- O Critério de Akaike (AIC) mostrou-se bastante influenciado pelo número máximo de defasagens permitido, isto é, quanto maior o número de defasagens permitido maior o número de defasagens ótimo; e

- Por fim, os critérios LR modificado sequencial (LR) e de Erro de predição final (FPE) mostraram-se constantes ao definir o número ótimo de defasagens, a despeito do número máximo de defasagens permitido no teste.

Diante de todo o exposto na presente subseção, optou-se por realizar os testes subsequentes, bem como estimar o modelo VAR restrito e a regressão linear para o modelo de correção de erros tanto para uma como para duas defasagens, reportando e analisando os resultados.

A seguir são realizados os testes de cointegração considerando os cenários de uma e duas defasagens. 


\subsubsection{Testes de cointegração}

Os testes de cointegração permitem investigar as relações estruturais entre as séries econômicas envolvidas em determinado estudo, isto é, permitem verificar a tendência estocástica comum das séries. De forma mais específica, os testes de cointegração possibilitam determinar a existência de relação de longo prazo entre séries temporais, isto é, equilíbrio entre as variáveis econômicas.

A literatura apresenta diversos testes para identificar cointegração de séries temporais, indo desde modelos mais simples que consistem em regressões que investigam a existência de combinação linear entre as séries até modelos mais complexos baseados na representação por meio de vetor autorregressivo.

Um dos testes mais utilizados refere-se ao trabalho dos autores Engle e Granger (1987) que é de fácil aplicação, porém indicado para casos em que exista uma única equação no modelo. O teste apresentado por Phillips e Ouliaris (1990) foi resultado de um trabalho cujo objetivo foi contribuir com uma análise assintótica do teste baseado nos resíduos para a presença de cointegração em múltiplas séries de tempo. Todavia, o teste manteve-se restrito à verificação da existência ou não de cointegração e não caminhou no sentido de apontar o número de vetores.

Por outro lado, o teste desenvolvido por Johansen e Juselis (1990), apesar da maior complexidade, inovou em permitir a identificação da quantidade de vetores de cointegração entre as séries ao invés de identificar apenas a existência de cointegração como permitido pelos testes de Engle-Granger (1987) e de Phillips e Ouliaris (1990), motivo pelo qual passou a ser amplamente utilizado.

O teste de Johansen e Juselis (1990) caminha na direção de identificar o posto da matriz $\Phi=A^{-1} B_{i}$, utilizada para transformar o modelo de sua forma estrutural na forma reduzida, e, com isso, estimar os vetores de cointegração ${ }^{6}$.

Considerando as possibilidades das séries de apresentarem constante e tendência no nível do vetor de variáveis endógenas e no vetor de cointegração, Bueno (2011) definiu cinco possíveis casos para o modelo de cointegração. O presente trabalho se utilizou do caso 3:

\footnotetext{
${ }^{6} \Phi=A^{-1} B_{i}$ refere-se à transformação do modelo estrutural em sua forma reduzida, visando contornar o problema de endogeneidade.
} 


$$
\Delta X_{t}=\alpha\left(\beta^{\prime} X_{t-1}+\mu_{0}\right)+\delta_{0}+\sum_{i=1}^{p-1} \Lambda_{i} \Delta X_{t-i}+e_{t}
$$

A síntese dos resultados dos testes de cointegração considerando o intercepto apresentados na Tabela 2.6, apresentada a seguir, indicam, tanto para o caso de uma como para o caso de duas defasagens, conforme resultado dos testes para definição de defasagem ótima, a existência de um vetor de cointegração, isto é, existe relação de longo prazo entre as quatro variáveis do modelo no longo prazo. Quando considerada uma defasagem, rejeita-se a 10\% a não existência de cointegração, ao passo que ao considerar duas defasagens rejeita-se a $1 \%$ que não existe cointegração.

Tabela 2.6. Testes para defasagem ótima

\begin{tabular}{|c|c|c|c|}
\hline \multicolumn{4}{|c|}{ Teste do Traço } \\
\hline \multicolumn{2}{|c|}{ Duas defasagens } & \multicolumn{2}{|c|}{ Uma defasagem } \\
\hline Hipótese & & Hipótese & \\
\hline Nula & Prob.** & Nula & Prob.** \\
\hline Nenhum * & 0.0092 & Nenhum * & 0.0950 \\
\hline No Max 1 & 0.2188 & No Max 1 & 0.4630 \\
\hline No Max 2 & 0.4248 & No $\operatorname{Max} 2$ & 0.2800 \\
\hline No Max 3 & 0.4294 & No Max 3 & 0.1913 \\
\hline \multicolumn{4}{|c|}{ Teste do máximo autovalor } \\
\hline \multicolumn{2}{|c|}{ Duas defasagens } & \multicolumn{2}{|c|}{ Uma defasagem } \\
\hline Hipótese & & Hipótese & \\
\hline Nula & Prob.** & Nula & Prob. ** \\
\hline Nenhum * & 0.0151 & Nenhum * & 0.0945 \\
\hline No Max 1 & 0.2757 & No Max 1 & 0.7979 \\
\hline No Max 2 & 0.4032 & No Max 2 & 0.3488 \\
\hline No Max 3 & 0.4294 & No Max 3 & 0.1913 \\
\hline
\end{tabular}

Pelo exposto, diante das análises realizadas nos quatro cenários apresentados, não se rejeita a existência de no máximo um vetor de cointegração.

Desta forma, verifica-se o preenchimento das condições para a estimação do modelo VAR restrito, o que é realizado em subseção mais adiante. 
Antes, porém, nas duas subseções que se seguem serão apresentadas estimações desde modelos considerados 'ingênuos' até o modelo que se entende ser o mais indicado para o objetivo do trabalho, qual seja o modelo de vetor autorregressivo restrito considerando as variáveis PIB real, estoque de capital, população ocupada e terminal por população ocupada endógenas.

\subsubsection{Modelagem ingênua}

A ideia inicial foi estimar evolutivamente os modelos do mais simples até o mais sofisticado, visando identificar o comportamento dos resultados. Ressalte-se que para esta seção serão considerados como cenário padrão os modelos apenas com constante e para o caso do VECM duas defasagens. A Tabela 2.7 e a Tabela 2.8 abaixo apresentam uma síntese dos resultados, cujo detalhamento dos modelos é apresentado em seguida..

Tabela 2.7. Modelos Ingênuos MQO

\begin{tabular}{cccc}
\hline \multicolumn{4}{c}{ Modelos Ingênuos - MQO } \\
\hline Modelo 1 & Modelo 2 & Modelo 3 \\
\hline C & 27.83068 & 23.27115 & 24.78592 \\
& $0.0000 * * *$ & $0.0000 * * *$ & $0.0000 * * *$ \\
\hline Estoquek & 0.225207 & 0.473338 & 0.344518 \\
& 0.4891 & $0.0744 *$ & 0.1911 \\
\hline PopOcup & 0.395140 & 0.600654 & 0.185036 \\
& 0.3496 & 0.1289 & 0.6738 \\
\hline Termpopocup & & 0.133106 & 0.752814 \\
& & $0.0000 * * *$ & $0.0322 * *$ \\
\hline Penetração & & & 0.654589 \\
& & & $0.0738 *$ \\
\hline significante a 10\%; ** significante a 5\% e *** significante a 1\%
\end{tabular}

Os resultados das regressões lineares são evidenciados pelos modelos de 1-3:

- O modelo 1 considerou como variáveis explicativas o estoque de capital e a população ocupada. O resultado mostrou-se não significativo para ambas as variáveis, o que não parece coerente com o modelo teórico;

- O modelo 2 inclui a variável telecomunicações ao primeiro modelo e obteve resultados melhores no que tange ao poder explicativo das variáveis. Do resultado, é possível perceber que as variáveis estoquek e termpopocup são significativas. Em 
particular uma variação de $1 \%$ em termpopocup resulta numa variação de $0,13 \%$ no produto, uma vez que estamos trabalhando com as séries em logaritmo natural;

- O modelo 3 inclui o controle penetração dos serviços de telecomunicações à regressão do modelo 2. Para este caso a variável estoquek deixa de ser significativa, o que pelo modelo teórico não parece fazer sentido, enquanto a variável termpopocup continua significativa e com efeito majorado sobre o produto. A variável penetração também se revela significativa; e

- Um ponto a destacar para os três modelos se refere ao fato de que a variável população ocupada mostrou-se não significativa nas três estimações apresentadas.

A seguir são apresentados os resultados dos modelos de vetores autorregressivos restritos e realizada análise dos resultados obtidos.

Tabela 2.8. Modelos 4 a 6

\begin{tabular}{|c|c|c|c|c|c|}
\hline \multicolumn{2}{|c|}{ Modelo 4} & \multicolumn{2}{|l|}{ Modelo 5} & \multicolumn{2}{|l|}{ Modelo 6} \\
\hline PIBREAL(-1) & 1.000000 & PIBREAL(-1) & 1.000000 & PIBREAL(-1) & 1.000000 \\
\hline \multirow[t]{3}{*}{ ESTOQUEK(-1) } & -0.61577 & ESTOQUEK(-1) & -0.73938 & ESTOQUEK(-1) & -0.93258 \\
\hline & $(0.28767)$ & & $(0.26338)$ & & $(0.15357)$ \\
\hline & {$[-2.14057]$} & & {$[-2.80727]$} & & {$[-6.07259]$} \\
\hline \multirow[t]{3}{*}{ POPOCUP(-1) } & -0.19416 & POPOCUP(-1) & 0.074128 & POPOCUP(-1) & 0.101650 \\
\hline & $(0.33849)$ & & $(0.32208)$ & & $(0.19447)$ \\
\hline & {$[-0.57362]$} & & {$[0.23015]$} & & [ 0.52270] \\
\hline \multirow[t]{4}{*}{$\mathbf{C}$} & -2.421219 & $\mathbf{C}$ & -2.250838 & TERMPOPOCUP(-1) & 0.020635 \\
\hline & & & & & $(0.01726)$ \\
\hline & & & & & [ 1.19563$]$ \\
\hline & & & & $\mathrm{C}$ & -2.090044 \\
\hline
\end{tabular}

(.) erro padrão; [.] estatística t

- Para o modelo 4 foram consideras as variáveis produto, estoque de capital e população ocupada como endógenas. Para o modelo 5 foi adicionada a variável terminal por população ocupada como exógena e no modelo 6 esta foi incluída como endógena.

- Da tabela 2.8 é possível verificar que para os modelos de 4 a 6 apenas o coeficiente de estoque de capital é significativo. 
- Outro aspecto importante a mencionar é que entre os modelos 5 e 6 , apesar de serem consideradas as mesmas variáveis, isto é, PIB real, estoque de capital, população ocupada e terminais por população ocupada, o vetor de cointegração apresenta-se diferente entre os dois modelos e isso explica o fato dos parâmetros serem diferentes. Ou seja, ao mudar uma variável em cada equação do VECM para incorporar terminais por população ocupada endógena, ocorre alteração do vetor de cointegração, que ajusta os desequilíbrios, gerando uma tendência comum de longo prazo. Já quando tratamos uma das variáveis como exógena, ela deixa de entrar no vetor de cointegração, o que altera os coeficientes.

\subsubsection{Modelo de correção de erros}

A regressão de séries de tempo não estacionária em outra série de tempo não estacionária pode causar uma regressão espúria ou uma regressão sem sentido, ou seja, uma regressão indesejável.

Como é de conhecimento comum [Bueno (2011), Lütkepohl e Krätzig (2004)], temos séries não estacionárias em nível, mas que se tornam estacionárias em primeira diferença. Assim, a estimação do modelo com os dados em nível geraria uma regressão espúria que poderia ser evidenciada por um valor do R-quadrado maior que o valor da estatística de Durbin Watson [(1950); (1951)].

Entretanto, se os resíduos de um modelo aparentemente espúrio forem estacionários, então o modelo deixa de ser espúrio e pode ser aceito. Ademais, se os resíduos forem estacionários isso também significa que as variáveis do modelo são cointegradas, isto é, possuem relação de longo prazo ou relação de equilíbrio de longo prazo entre elas. Desta forma, o coeficiente estimado será um coeficiente de longo prazo.

Para avaliar a estacionaridade faz-se necessário usar os valores críticos de Engle-Granger para o teste de raiz unitária. Para $5 \%$ e $10 \%$ os valores críticos são respectivamente $-3,34$ e-3,04, porém, em geral, avaliados em módulo. Assim, depois de garantida a estacionaridade dos resíduos da regressão, ou seja, a cointegração das variáveis, poder-se-á rodar o modelo de correção de erros. 
Para a estimação do modelo de correção de erros faz-se necessário, inicialmente, estimar uma regressão de mínimos quadrados ordinários das variáveis em nível. Em seguida, realiza-se o teste para raiz unitária considerando os valores críticos de Granger. Havendo cointegração podese estimar o modelo de correção de erros. A seguir são apresentados os passos para a estimação do modelo de correção de erros.

- Estimação da regressão com as variáveis em nível

Após a estimação do modelo básico via mínimos quadrados ordinários, foram salvos os resíduos para a realização do teste de estacionaridade.

- Teste da estacionaridade dos resíduos, considerando os valores críticos de Granger

Tabela 2.9. Teste de estacionaridade dos resíduos

Null Hypothesis: $U$ has a unit root

Exogenous: Constant

Lag Length: 1 (Automatic - based on SIC, maxlag=9)

\begin{tabular}{lrcc}
\hline & t-Statistic & Prob. $^{*}$ \\
\hline \multicolumn{2}{l}{ Augmented Dickey-Fuller test statistic } & -3.591014 & 0.0109 \\
\hline Test critical values: & $1 \%$ level & -3.626784 & \\
& $5 \%$ level & -2.945842 & \\
$10 \%$ level & -2.611531 & \\
\hline
\end{tabular}

O resultado obtido apresenta a estatística t cujo valor em módulo, 3.591014, é maior do que os valores críticos de Engle-Granger tanto a 5\% quanto a 10\%, respectivamente, -3.34 3 3.04. Logo, podemos rejeitar a hipótese nula de raiz unitária, existindo, portanto, estacionaridade do resíduo, indicando que o modelo estimado não é espúrio.

Ademais, como o resíduo do modelo tornou-se estacionário pode-se afirmar que as variáveis do modelo são cointegradas, isto é, elas têm uma relação de longo prazo e o modelo pode ser dito de longo prazo. Os coeficiente de EstoqueK (0.473338), de TermPopOcup (0.133106) são coeficientes de longo prazo e são significantes. Atendido o requisito de cointegração pode-se rodar o modelo de correção de erros. 


\subsubsection{Equação do modelo de correção de erros}

A equação a ser estimada para o modelo de correção de erros pode ser assim definida:

$$
\begin{aligned}
\triangle P I B R E A L= & c+\alpha_{1} \Delta P I B R E A L(-1)+\alpha_{2} \Delta P I B R E A L(-2)+\alpha_{3} \Delta E S T O Q U E K(-1) \\
& +\alpha_{4} \Delta E S T O Q U E K(-2)+\alpha_{5} \Delta P O P O C U P(-1)+\alpha_{6} \Delta P O P O C U P(-2) \\
& +\alpha_{7} \Delta \mathrm{TERMPOPOCUP}(-1)+\alpha_{8} \Delta \mathrm{TERMPOPOCUP}(-2)+U(-1)
\end{aligned}
$$

A tabela 2.10 apresenta o resultado da estimação do modelo de correção de erros.

\section{Tabela 2.10. Modelo de correção de erros}

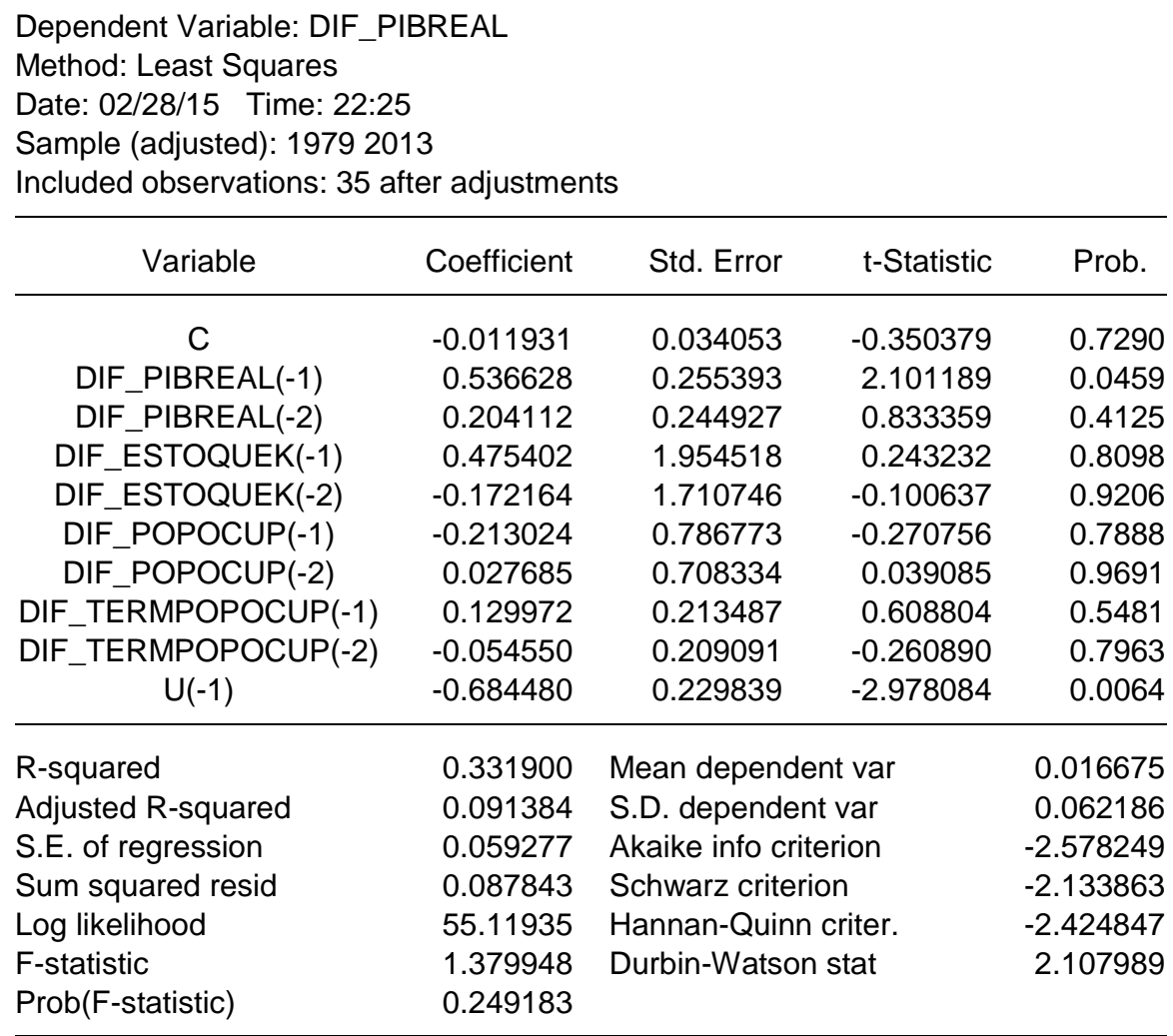

Os coeficientes estimados das variáveis são não significativos com exceção de dif_PIBreal(-2) a 5\%, o que nos permite inferir a existência de relação de curto prazo somente com esta variável. Todavia, o coeficiente do termo de correção de erro é -0.409991 e significativo, o que nos permite concluir que as variáveis do modelo possuem relação de longo prazo. Na prática, isto significa que o referido termo corrige o desequilíbrio do sistema a uma 
taxa (velocidade de ajustamento ou correção do desequilíbrio do período anterior) de $40.99 \%$ ao ano, uma vez que os dados usados para desenvolvimento do modelo são anuais.

Este modelo de correção de erro também não é espúrio ou sem sentido, uma vez que o valor do R-quadrado é menor do que a estatística de Durbin-Watson.

De modo semelhante ao realizado quando da estimação do modelo VAR restrito, faz-se necessário aqui realizar testes de diagnóstico do modelo de correção de erros, o que é feito em seguida.

\subsubsection{Teste para correlação serial}

O teste de correlação serial dos resíduos é de fundamental importância para a validade do modelo. Conforme os resultados do teste de Breusch-Godfrey para correlação serial apresentado a seguir, não rejeitamos a hipótese nula de resíduos não correlacionados. Logo, não existe correlação serial. O modelo de correção de erros é não serialmente correlacionado, o que é desejável.

Tabela 2.11. Teste de Breusch-Godfrey

\begin{tabular}{llll} 
Breusch-Godfrey Serial Correlation LM Test: & \\
\hline F-statistic & 1.695752 & Prob. F(2,23) & 0.2056 \\
ObsR-squared & 4.497759 & Prob. Chi-Square(2) & 0.1055 \\
\hline
\end{tabular}

\subsubsection{Teste de normalidade}

Ressalta-se que o teste de normalidade de resíduos é de grande importância para diagnóstico do modelo e, conforme caracterizado pela figura 2.2, a seguir, não rejeitamos a hipótese nula de normalidade dos resíduos, ou seja, os resíduos são normalmente distribuídos. 


\section{Figura 2.2. Teste de normalidade}

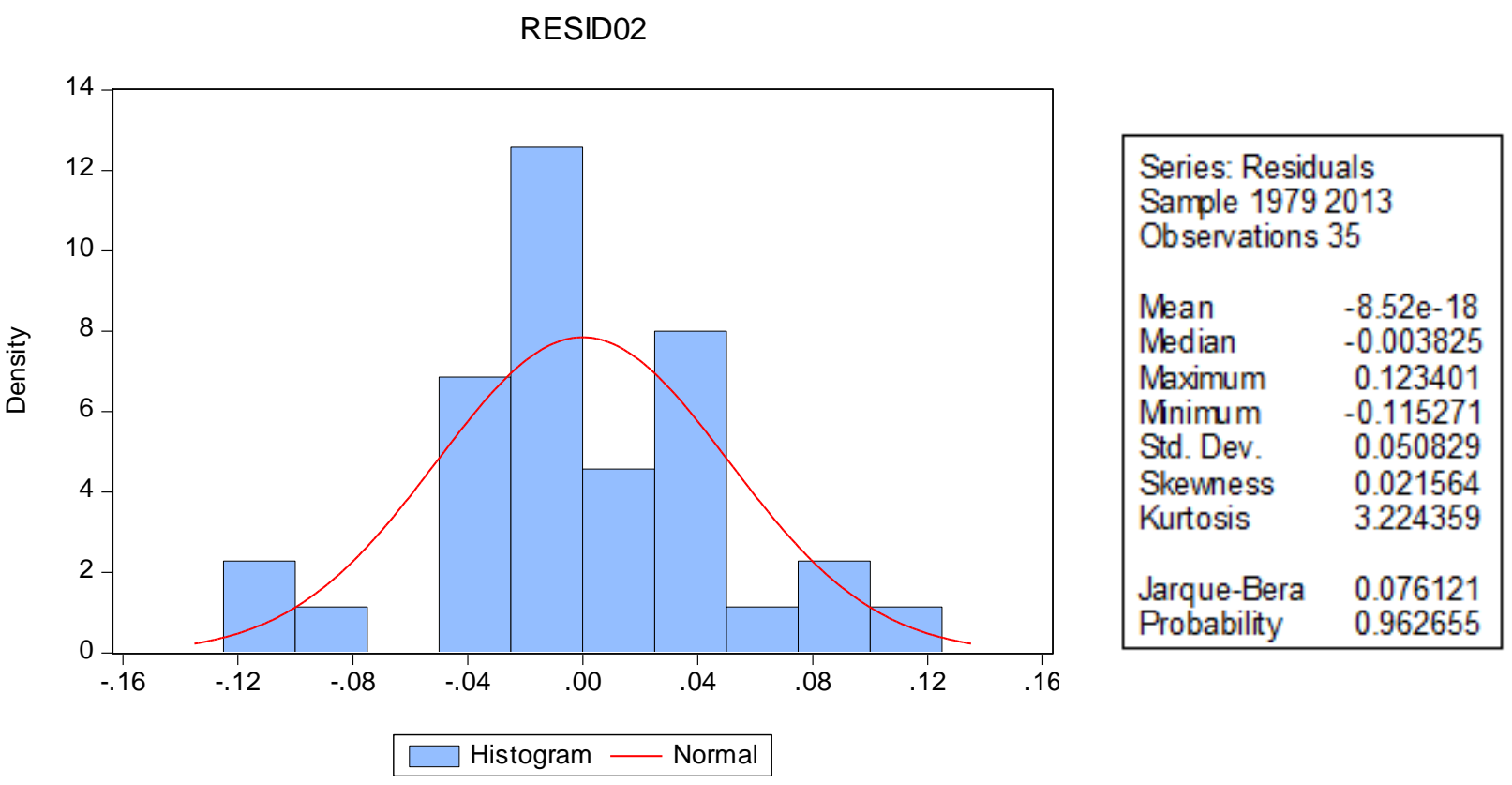

\subsubsection{Teste de heterocedasticidade}

Para o teste de heterocesdasticidade, evidenciado na tabela a seguir, não rejeitamos a hipótese nula de homocedasticidade pelo critério de Obs*R-squared, isto é, o teste nos informa que o termo de erro é homocedático, o que é desejável para a análise e garante a eficiência do estimador.

Tabela 2.12. Teste de Breusch-Pagan-Godfrey

Heteroskedasticity Test: Breusch-Pagan-Godfrey

\begin{tabular}{llll}
\hline F-statistic & 1.087470 & Prob. F(9,25) & 0.4059 \\
Obs ${ }^{\star}$ R-squared & 9.847095 & Prob. Chi-Square(9) & 0.3630 \\
Scaled explained SS & 5.587621 & Prob. Chi-Square(9) & 0.7804 \\
\hline
\end{tabular}

\subsubsection{Modelo vetor de correção de erros}

Após a definição do modelo de cointegração

A partir do output do modelo VECM é possível obter informação sobre as relações de curto e longo prazos entre as variáveis. A seguir, é apresentada a significância dos coeficientes dos modelos estimados, considerando cada uma das quatro variáveis como dependente e o nível de significância de cada coeficiente. 
Tabela 2.13. Modelo VECM

Significância dos coeficientes estimados no modelo VECM

\begin{tabular}{|c|c|c|c|c|}
\hline \multicolumn{5}{|c|}{ Com intercepto } \\
\hline \multirow{2}{*}{ Coeficiente } & \multicolumn{2}{|c|}{ Duas defasagens } & \multicolumn{2}{|c|}{ Uma defasagem } \\
\hline & Coeficiente & Prob. & Coeficiente & Prob. \\
\hline$C(1)$ & -1.065479 & 0.0066 & -0.748328 & 0.0082 \\
\hline$C(2)$ & 0.664634 & 0.0228 & 0.451905 & 0.0206 \\
\hline$C(3)$ & 0.200609 & 0.4289 & 3.356788 & 0.0265 \\
\hline$C(4)$ & 2.408553 & 0.2652 & 0.339716 & 0.5989 \\
\hline$C(5)$ & 2.246050 & 0.2656 & 0.250388 & 0.0943 \\
\hline$c(6)$ & 0.487243 & 0.5744 & -0.141992 & 0.0334 \\
\hline$C(7)$ & 0.669212 & 0.3441 & 0.022032 & 0.5359 \\
\hline$C(8)$ & 0.201145 & 0.3594 & 0.024858 & 0.3136 \\
\hline$C(9)$ & 0.159571 & 0.487 & 0.686899 & 0.0005 \\
\hline$C(10)$ & -0.221589 & 0.0201 & 0.002621 & 0.9746 \\
\hline$C(11)$ & -0.010432 & 0.8354 & -0.001177 & 0.9506 \\
\hline$C(12)$ & 0.040666 & 0.2811 & 0.008905 & 0.2923 \\
\hline$C(13)$ & 0.016593 & 0.6159 & 0.029410 & 0.6812 \\
\hline$C(14)$ & 0.700498 & 0.0142 & -0.116495 & 0.02 \\
\hline$C(15)$ & 0.086983 & 0.7405 & -0.046897 & 0.9029 \\
\hline$C(16)$ & -0.002816 & 0.9801 & 0.289363 & 0.0827 \\
\hline$C(17)$ & 0.067164 & 0.4665 & 0.006840 & 0.8579 \\
\hline$C(18)$ & -0.010052 & 0.7252 & 0.018388 & 0.2799 \\
\hline$C(19)$ & 0.019606 & 0.5129 & 0.206465 & 0.4138 \\
\hline$C(20)$ & 0.001863 & 0.8794 & 0.193045 & 0.2703 \\
\hline$C(21)$ & 0.130326 & 0.192 & -1.548812 & 0.2546 \\
\hline$C(22)$ & -0.192413 & 0.0111 & -0.033041 & 0.9549 \\
\hline$C(23)$ & -0.033019 & 0.6142 & 0.689760 & 0.0000 \\
\hline$C(24)$ & 0.106308 & 0.8487 & 0.082519 & 0.1697 \\
\hline$C(25)$ & -0.652786 & 0.2112 & & \\
\hline$C(26)$ & 0.183518 & 0.4137 & & \\
\hline$C(27)$ & 0.037458 & 0.8374 & & \\
\hline$C(28)$ & -0.002816 & 0.9603 & & \\
\hline$C(29)$ & -0.024255 & 0.6825 & & \\
\hline$C(30)$ & 0.042603 & 0.0821 & & \\
\hline$C(31)$ & 0.485758 & 0.1354 & & \\
\hline$C(32)$ & 0.081772 & 0.7359 & & \\
\hline$C(33)$ & -0.151932 & 0.4761 & & \\
\hline$C(34)$ & -2.317226 & 0.2029 & & \\
\hline$C(35)$ & -0.868459 & 0.6079 & & \\
\hline$C(36)$ & -0.525660 & 0.4714 & & \\
\hline$C(37)$ & -0.495709 & 0.4044 & & \\
\hline$C(38)$ & 0.745204 & 0.0001 & & \\
\hline$C(39)$ & -0.200112 & 0.3006 & & \\
\hline$C(40)$ & 0.176947 & 0.0271 & & \\
\hline
\end{tabular}


Para o caso do modelo de maior interesse para o presente trabalho, isto é, considerando o modelo em que PIBreal é a variável dependente, obtemos:

Tabela 2.14. VECM: modelo de interesse

\begin{tabular}{lcccc}
\multicolumn{5}{c}{ Significância dos coeficientes estimados no modelo VECM } \\
\hline \multirow{5}{c}{ Com intercepto } \\
\hline \multirow{2}{*}{ Coeficiente } & Duas defasagens & Uma defasagem \\
\cline { 2 - 5 } & Coeficiente & Prob. & Coeficiente & Prob. \\
\hline$C(1)$ & -1.065479 & 0.0103 & -0.748328 & 0.0115 \\
$C(2)$ & 0.664634 & 0.0293 & 0.451905 & 0.0257 \\
$C(3)$ & 0.200609 & 0.4345 & 3.356788 & 0.0322 \\
$C(4)$ & 2.408553 & 0.2732 & 0.339716 & 0.6018 \\
$C(5)$ & 2.246050 & 0.2736 & 0.250388 & 0.1021 \\
$C(6)$ & 0.487243 & 0.5781 & -0.141992 & 0.0396 \\
$C(7)$ & 0.669212 & 0.3509 & & \\
$C(8)$ & 0.201145 & 0.366 & & \\
$C(9)$ & 0.159571 & 0.4918 & & \\
$C(10)$ & -0.221589 & 0.0263 & & \\
\hline
\end{tabular}

Os coeficientes das variáveis dos modelos, apresentados na tabela 2.14, informam sobre a causalidade de longo e curto prazos entre as variáveis em análise.

Os coeficientes $\mathrm{C}(1), \mathrm{C}(11), \mathrm{C}(21)$ e $\mathrm{C}(31)$ referem-se à equação de cointegração quando PIBreal, EstoqueK, Popocup e Termpopocup são as variáveis dependentes, respectivamente. Estes coeficientes indicam a relação de longo prazo. Por outro lado, os demais coeficientes indicam a relação de curto prazo.

De modo particular, estamos interessados no primeiro modelo, onde PIBreal é a variável dependente. Neste caso, o coeficiente C(1) informa a velocidade do ajuste em direção ao equilíbrio de longo prazo, e por ter sinal negativo ${ }^{7}$, e ser significativo, garante a existência da referida relação de longo prazo, isto é, o resultado indica que existe causalidade de longo prazo vindo das três variáveis independentes (EstoqueK, PopOcup, TermPopOcup). Isso significa que EstoqueK, PopOcup, TermPopOcup têm influência na variável dependente PIBreal no longo

\footnotetext{
${ }^{7} \mathrm{O}$ sinal se deve à forma como o software informa o resultado.
} 
prazo. Em outras palavras, existe causalidade de longo prazo vindo de EstoqueK, PopOcup, TermPopOcup para PIBreal.

Para analisar a relação de causalidade de curto prazo usa-se o teste de significância conjunta (Wald test) ou o teste de causalidade de Granger no âmbito da modelagem VAR.

Todavia, optou-se por apresentar a análise de causalidade de curto prazo em seção específica apresentada a seguir, uma vez que se entende que desta forma o encadeamento do texto ficará mais claro.

Antes, porém, visando verificar se o modelo para a variável dependente PIBreal apresenta algum problema do ponto de vista estatístico, foram realizados testes de diagnóstico para o modelo VAR restrito, isto é, testes correlação serial e normalidade dos resíduos, bem como de heterocedasticidade, conforme reportado a seguir.

\subsubsection{Teste de correção serial dos resíduos}

Conforme já destacado anteriormente, o teste de correlação serial dos resíduos é de fundamental importância para a validade do modelo. Conforme os resultados do teste de Breusch-Godfrey para correlação serial, apresentados a seguir, não rejeitamos a hipótese nula de resíduos não correlacionados, o que garante a validade do modelo.

Tabela 2.15. Teste de correção serial dos resíduos

Breusch-Godfrey Serial Correlation LM Test:

\begin{tabular}{llll}
\hline F-statistic & 0.100475 & Prob. F(2,23) & 0.9048 \\
Obs*R-squared & 0.303144 & Prob. Chi-Square(2) & 0.8594 \\
\hline
\end{tabular}

\subsubsection{Teste de normalidade}

Novamente, ressalta-se que outro importante teste de diagnóstico do modelo é o teste de normalidade de resíduos e, conforme caracterizado pela figura 2.3, apresentada a seguir, também não rejeitamos a hipótese nula de normalidade dos resíduos, ou seja, os resíduos são normalmente distribuídos. 


\section{Figura 2.3. Teste de normalidade - Modelo VECM}

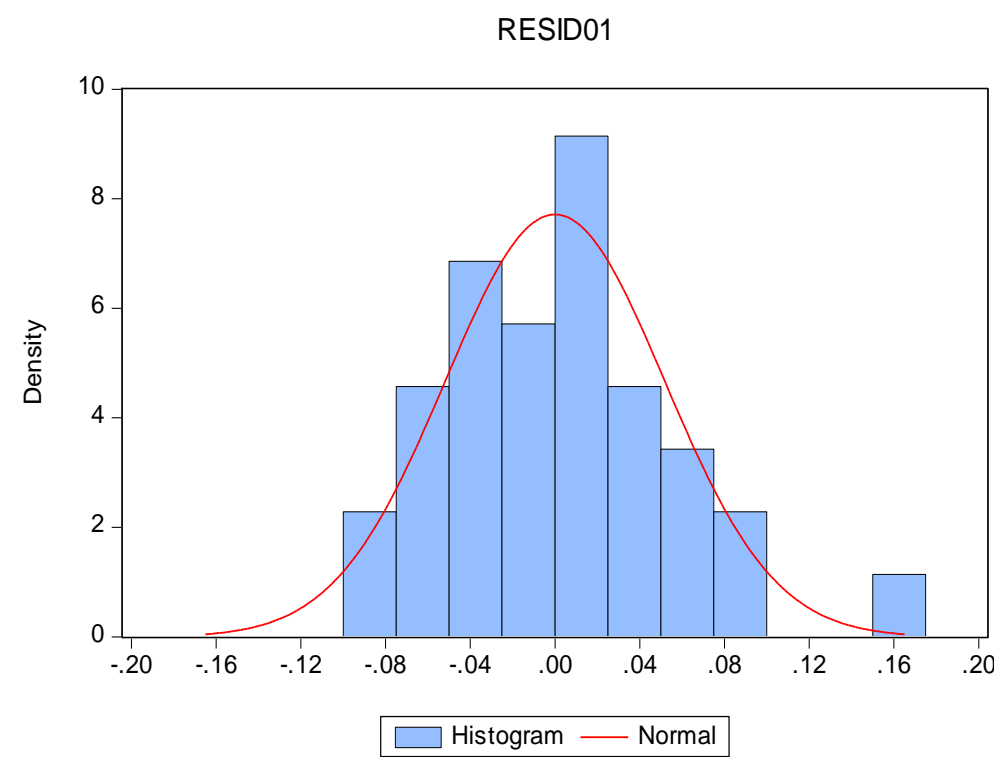

Ser ies : NORMALDADE_-

Sample 19762013

Obs ervations 35

Mean

$-5.71 \mathrm{e}-16$

Median 0.000778

Maximum

Minimum

0.150757

Std. Dev.

$-0.090489$

Sicewness

0.051722

0.583423

Kurtos is

3.500578

Jarque-Berg $\quad 2.217195$

Probability $\quad 0.330021$

\subsubsection{Teste de heterocedasticidade}

Para o teste de heterocesdasticidade, evidenciado na tabela 2.16, não rejeitamos a hipótese nula de homocedasticidade a $5 \%$ pelo critério de Obs*R-squared.

Tabela 2.16. Teste de heterocedasticidade: VECM

Heteroskedasticity Test: Breusch-Pagan-Godfrey

\begin{tabular}{llll}
\hline F-statistic & 2.238188 & Prob. F(12,22) & 0.0489 \\
Obs*R-squared & $\mathbf{1 9 . 2 4 0 1 2}$ & Prob. Chi-Square(12) & $\mathbf{0 . 0 8 2 9}$ \\
Scaled explained SS & 12.27333 & Prob. Chi-Square(12) & 0.4240 \\
\hline
\end{tabular}

\subsubsection{Resposta ao impulso}

A função de resposta ao impulso representa um choque de um desvio padrão no sistema VAR. A resposta ao impulso identifica a resposta da variável dependente (variável endógena) no

VAR à ocorrência de um choque no termo de erro da equação de outra variável. 
Um único choque é aplicado a cada variável (via perturbação no seu termo de erro) e se verifica seu efeito no sistema VAR.

Busca-se identificar em que medida ou de que maneira uma variável afeta a outra e viceversa (via choque no termo de erro da equação de cada variável).

Desta forma, para calcular a resposta ao impulso, a ordenação das variáveis é importante. Muitos métodos são oferecidos para a ordenação. Para o presente trabalho será utilizado o método "Cholesky dof Adjusted", disponível no software Eviews. Vale ressaltar que o impulso à resposta pode ser aplicado tanto no VAR irrestrito como no VAR restrito (VECM).

\section{Figura 2.4. Impulso-Resposta para uma defasagem}
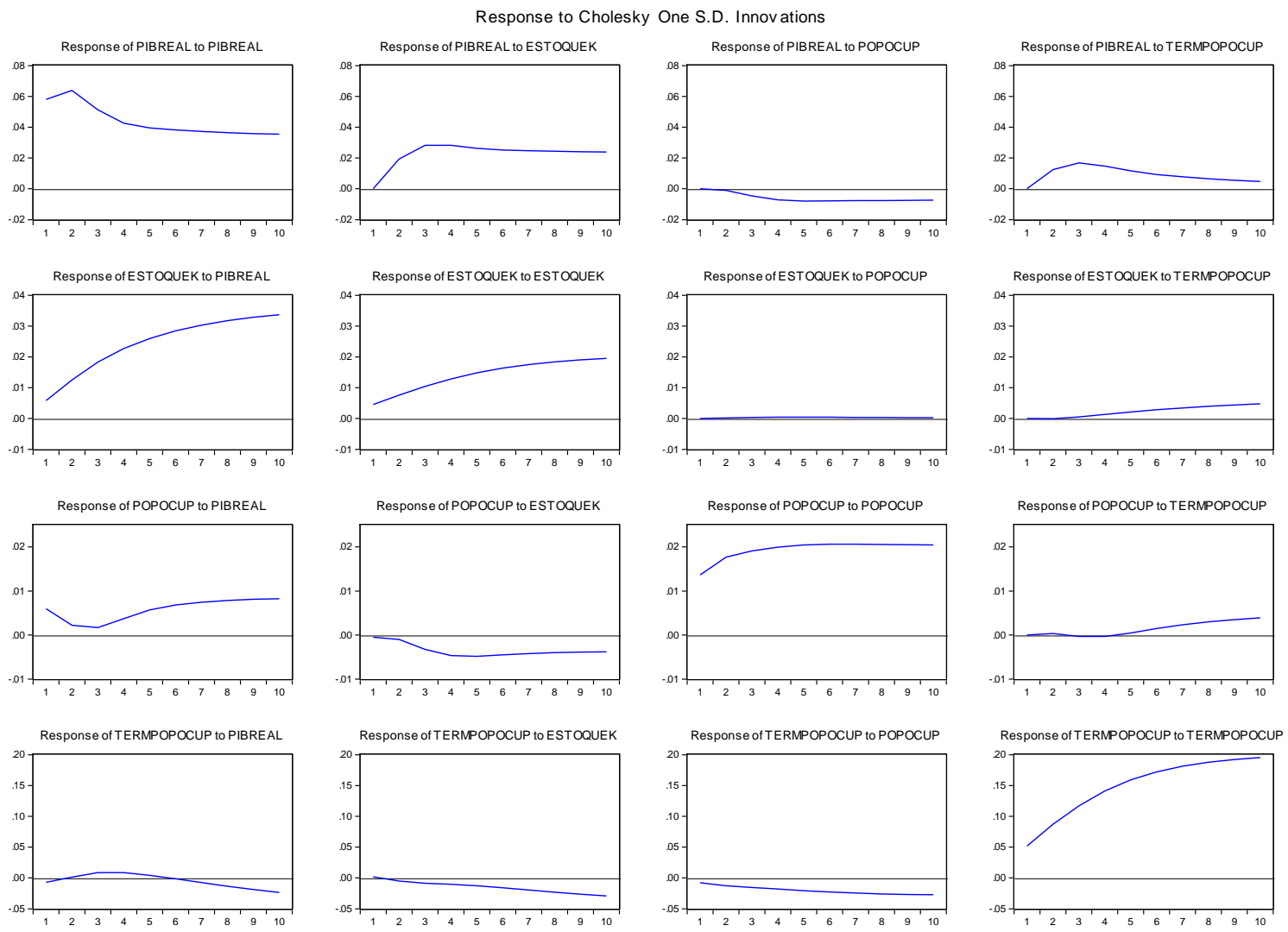
Figura 2.5. Impulso-Resposta para duas defasagens
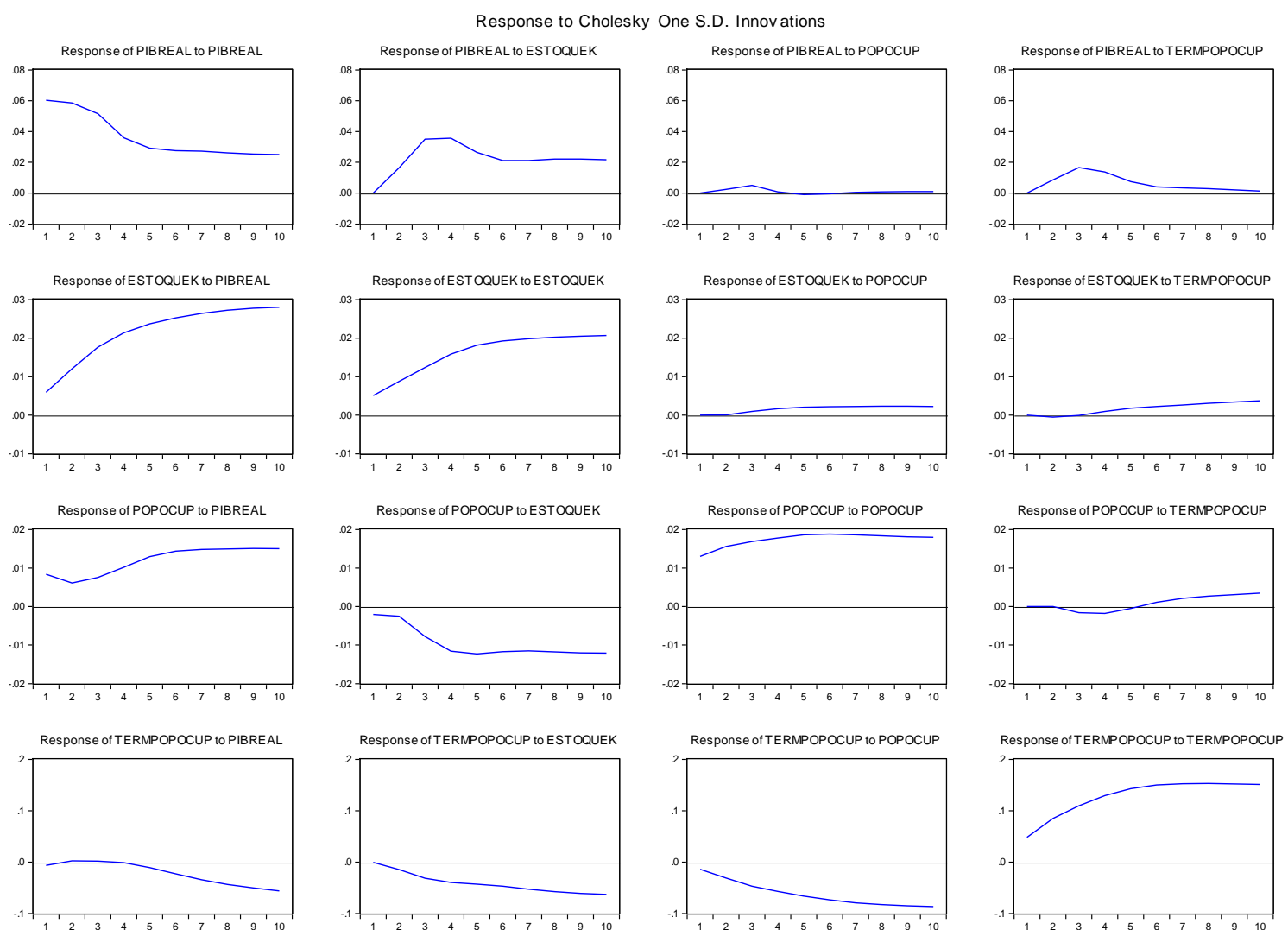

Só é possível rodar a resposta ao impulso quando o modelo atende as propriedades estatísticas requeridas, tais como: não existência de correlação serial, normalidade dos resíduos e homocedasticidade dos resíduos.

Considerando a Figura 2.4 e a

Figura 2.5, onde são apresentados os gráficos de resposta ao impulso para o modelo considerando cenários de uma ou duas defasagens, é possível destacar as seguintes relações:

- Para o cenário de uma defasagem é possível perceber que a resposta do PIBreal a um choque de um desvio padrão no erro em estoquek (na equação do estoquek) é positiva e crescente até o terceiro ano, vindo a sofrer uma queda até convergir para um nível superior ao período anterior ao choque. A resposta do PIBreal a um choque de um 
desvio padrão no erro em termpopocup (na equação de termpopocup) é positiva e crescente até o terceiro ano e começa a decrescer nos próximos sete anos de forma assintótica com o eixo horizontal, isto é, convergindo a um nível superior àquele existente antes do choque.

- Para o cenário de duas defasagens é possível observar que a resposta do PIBreal a um choque de um desvio padrão no erro em estoquek (na equação do estoquek) é positiva e crescente até o terceiro ano, vindo a sofrer uma queda a partir do quarto ano até convergir para um nível superior ao período anterior ao choque a partir do sétimo ano. A resposta do PIBreal a um choque de um desvio padrão no erro em termpopocup (na equação de termpopocup) é positiva e crescente até o terceiro ano e começa a decrescer nos próximos sete anos de forma assintótica com o eixo horizontal, isto é, convergindo a um nível ligeiramente superior àquele existente antes do choque.

- Relativamente à variável população ocupada é possível destacar que tanto no cenário com uma como de duas defasagens o efeito do produto sobre a variável popocup é positivo, ao passo que o efeito de popocup sobre produto é próximo a zero ou negativo.

Na seção subsequente é realizada a análise de causalidade de Granger, onde são detalhadas as relações entre as variáveis.

\subsubsection{A análise de causalidade e o teste de causalidade de Granger}

Lutkepohl e Kratzig (2004) apresentam o conceito de não-causalidade de Granger (e, por consequência, o conceito de causalidade) que está relacionado ao fato de não haver alteração da previsão ótima da variável $y_{1 t}$ para nenhum horizonte de tempo ao se excluírem observações passadas de $y_{2 t}$ do conjunto de informação, ou seja:

$$
y_{1, t+h \mid \Omega_{t}}=y_{1, t+h \mid \Omega_{t}\left\{y_{2, s} \mid s \leq t\right\}}, \quad h=1,2, \ldots \ldots
$$

De outra forma, pode-se dizer que $y_{2 t}$ Granger-Causa $y_{1 t}$ se $y_{1 t}$ pode ser melhor predito usando ambas as séries de tempo $y_{2 t}$ e $y_{1 t}$ do que se fosse usada apenas a série de $y_{1 t}$.

O estudo sobre a relação entre telecomunicações e variáveis econômicas pode ser realizado investigando a relação causal aos pares. A relação de causalidade entre as variáveis, após a estimação, pode ser didaticamente definida de quatro diferentes formas: 
1. Causalidade Unidirecional: Ocorre quando uma variável $x$ é causada por defasagens de outra variável $y$.

2. Causalidade Bidirecional: Quando as defasagens das variáveis $x$ e $y$ causam uma a outra.

3. Causalidade Instantânea: Quando as duas variáveis $x$ e $y$ são simultaneamente a causa uma da outra sem defasagem.

4. Sem Causalidade: Quando as variáveis $x$ e $y$ não se afetam, isto é, não apresentam relação de causalidade.

Assim, pode-se destacar que a causalidade ou a causação indica a direção da relação entre duas ou mais variáveis, restando claro que a simples presença de correlação não é suficiente para indicar a direção da causalidade. Ademais, Kendall e Stuart (1961) destacam que, por mais forte que seja a relação estatística via regressão entre duas ou mais variáveis, não se pode alegar causalidade. Na prática, a relação de causalidade está implícita em trabalhos econométricos tradicionais que, em geral, advêm da teoria econômica, conforme se depreende do fragmento transcrito a seguir:

Kendall and Stuart (1961, p. 279) asseveram que: “[a] statistical relationship, however strong and however suggestive, can never establish causal connection: our ideas of causation must come from outside statistics, ultimately from some theory or other. Nevertheless, correlation is often confused with causation."

Assim, os testes de causalidade contribuem para a identificação da direção da causalidade quando existe precedência temporal entre variáveis. Para a identificação da relação entre o crescimento do setor de telecomunicações, via uma proxy de investimento $\frac{\text { Terminais }}{\text { População Ocupada }}$, e o crescimento do produto serão usados o teste de causalidade de Granger (1969), bem como as variáveis de PIB real e população ocupada para o período de 1976-2013.

O teste de causalidade mais conhecido na literatura foi desenvolvido por Granger e parte da premissa de que o futuro não tem efeito sobre o passado e o presente. Cabe ressaltar, conforme observado por Mandala (1992), que o teste de Granger não visa identificar endogeneidade.

Granger (1969) buscou avançar na avaliação das relações entre variáveis, evoluindo de uma avaliação de correlações entre variáveis para uma definição de causa e efeito (causalidade). 
Assim, o teste de causalidade de Granger visa definir o sentido de uma relação causal entre duas variáveis, incluindo a relação de feedback, no sentido de que valores passados de uma variável ajudem a prever valores para outra variável.

O teste de causalidade de Sims também assume que valores futuros não causam o presente. Sims (1972) destacou a importância de que estudos econométricos envolvendo defasagens incluam, de forma preliminar, um teste para direção da causalidade que consiste em verificar se os coeficientes da variável $X$ futuros sejam conjuntamente iguais a zero, em termos estatísticos. Em seu trabalho, o autor explicitou que se a causalidade é de $X$ para $Y$ apenas então os coeficientes das variáveis $X$ futuros da equação apresentada a seguir devem ser $\gamma_{1}=\gamma_{2}=$ $\cdots=\gamma_{n}=0$, na equação $(\mathbf{1 0})$ :

$\mathrm{y}_{\mathrm{t}}=\mathrm{c}+\beta_{\mathrm{j}} x_{\mathrm{t}-\mathrm{j}}+\beta_{\mathrm{k}-1} \mathrm{x}_{\mathrm{t}-\mathrm{j}+1}+\cdots+\beta_{1} x_{\mathrm{t}-1}+\beta_{0} x_{\mathrm{t}}+\gamma_{1} x_{\mathrm{t}+1}+\gamma_{2} x_{\mathrm{t}+2}+\cdots+\gamma_{\mathrm{n}} \mathrm{x}_{\mathrm{t}+\mathrm{n}}+\mathrm{u}_{\mathrm{t}},(10)$

onde $j$ refere-se às defasagens e $n$ refere-se ao número de valores futuros.

Ao longo do tempo, os testes de causalidade tradicionais, descritos anteriormente, sofreram críticas pelo fato de não contemplarem informações do horizonte de longo prazo das séries de tempo das variáveis, uma vez que para atender a premissa de estacionaridade utilizavase de transformações não lineares, como, por exemplo, log-diferença, que conduzia à perda de informação das séries originais.

Desta forma, Engle e Granger (1987) propuseram um método de correção de erros que viabilizou a identificação de relação de causalidade entre duas variáveis originais com tendência de longo prazo comum. O referido método aperfeiçoa o teste padrão anterior de Granger ao possibilitar a análise de curto prazo considerando os efeitos de longo prazo, ou seja, ponto central da análise de cointegração.

Em seu trabalho, Granger (1969) apresenta um modelo causal de duas variáveis para ilustrar as definições por ele introduzidas. O modelo foi assim especificado, considerando $X_{t}$ e $Y_{t}$ duas variáveis estacionárias:

$$
\begin{aligned}
& X_{t}=\sum_{j=1}^{m} a_{j} X_{t-j}+\sum_{j=1}^{m} b_{j} Y_{t-j}+\varepsilon_{t}, \\
& Y_{t}=\sum_{j=1}^{m} c_{j} X_{t-j}+\sum_{j=1}^{m} d_{j} Y_{t-j}+\eta_{t},
\end{aligned}
$$


onde, segundo Granger (1969), $\varepsilon_{t}$ e $\eta_{t}$ são considerados não correlacionados e ruído branco, isto é, $E\left[\varepsilon_{t}, \varepsilon_{s}\right]=0=E\left[\eta_{t}, \eta_{s}\right], s \neq t$ e $E\left[\varepsilon_{t}, \varepsilon_{s}\right]=0, \forall t, s$.

Pela definição de causalidade apresentada pelo autor, $X_{t}$ causa $Y_{t}$ se algum $c_{j}$ não for zero e, de forma análoga, $Y_{t}$ causa $X_{t}$ se algum $b_{j}$ não for zero. Na hipótese de os dois eventos ocorrerem ao mesmo tempo temos uma relação de feedback entre as duas séries.

Em termos práticos, o teste de causalidade de Granger possui alguns elementos importantes e necessários para sua adequada realização. A correta definição da defasagem a ser utilizada no teste é fundamental para a obtenção de resultados confiáveis. Em geral utilizam-se os critérios de Akaike (1974) e Schwartz (1978) para definir o número ótimo de defasagens, conforme já discutido anteriormente no presente capítulo.

Outro aspecto importante para o teste de Granger é a estacionaridade das séries. Para o trabalho em tela estamos considerando as variáveis estacionárias em primeira diferença, conforme explanação detalhada das seções 2.6.1 e 2.6.2.

Vale ressaltar, ainda, que a existência de cointegração, isto é, relação de longo prazo entre séries de tempo, é fundamental para que seja possível a relação causal entre as referidas séries.

O teste, ademais, também requer que os resíduos sejam não correlacionados, requisito este atendido pelo modelo em análise, conforme demonstrado pelos testes realizados anteriormente no presente trabalho.

Por fim, é oportuno ressaltar que a hipótese nula do teste é de que "X não Granger-causa Y” e vice-versa e utiliza-se a estatística F para avaliar tal hipótese.

Tabela 2.17. Síntese do teste de causalidade de Granger considerando uma e duas defasagens

VEC Granger Causality/Block Exogeneity Wald Tests

Date: 02/20/15 Time: 18:28

Sample: 19762013

Included observations: 35

Uma defasagem

Duas defasagens

Dependent variable: D(PIBREAL) 


\begin{tabular}{ccccccc}
\hline Excluded & Chi-sq & df & Prob. & Chi-sq & df & Prob. \\
\hline D(ESTOQUEK) & $\mathbf{5 . 0 4 4 1 5 5}$ & $\mathbf{1}$ & $\mathbf{0 . 0 2 4 7}$ & $\mathbf{5 . 7 4 0 3 3 4}$ & $\mathbf{2}$ & $\mathbf{0 . 0 5 6 7}$ \\
D(POPOCUP) & 0.278086 & $\mathbf{1}$ & 0.5980 & 1.629236 & 2 & 0.4428 \\
D(TERMPOPOCUP) & $\mathbf{2 . 8 4 3 3 7 6}$ & $\mathbf{1}$ & $\mathbf{0 . 0 9 1 8}$ & 3.861947 & 2 & 0.1450 \\
\hline All & 5.717301 & 3 & 0.1262 & 7.079047 & 6 & 0.3136 \\
\hline Dependent variable: D(ESTOQUEK) & & & & & \\
\hline Excluded & Chi-sq & df & Prob. & Chi-sq & df & Prob. \\
\hline D(PIBREAL) & 1.023869 & 1 & 0.3116 & 1.230736 & 2 & 0.5404 \\
D(POPOCUP) & 0.001017 & 1 & 0.9746 & 0.566289 & 2 & 0.7534 \\
D(TERMPOPOCUP) & 0.003862 & 1 & 0.9504 & 0.442807 & 2 & 0.8014 \\
\hline All & 1.122127 & 3 & 0.7717 & 1.952315 & 6 & 0.9240 \\
\hline
\end{tabular}

Dependent variable: D(POPOCUP)

\begin{tabular}{ccccccc}
\hline Excluded & Chi-sq & df & Prob. & Chi-sq & df & Prob. \\
\hline D(PIBREAL) & $\mathbf{5 . 5 5 5 0 2 0}$ & $\mathbf{1}$ & $\mathbf{0 . 0 1 8 4}$ & $\mathbf{6 . 7 2 7 3 3 1}$ & $\mathbf{2}$ & $\mathbf{0 . 0 3 4 6}$ \\
D(ESTOQUEK) & 0.014941 & 1 & 0.9027 & 1.975353 & 2 & 0.3724 \\
D(TERMPOPOCUP) & 0.032201 & 1 & 0.8576 & 0.349958 & 2 & 0.8395 \\
\hline All & 6.637107 & 3 & 0.0844 & 7.879724 & 6 & 0.2470 \\
\hline
\end{tabular}

Dependent variable: D(TERMPOPOCUP)

\begin{tabular}{ccccccc}
\hline Excluded & Chi-sq & df & Prob. & Chi-sq & df & Prob. \\
\hline D(PIBREAL) & 1.226770 & 1 & 0.2680 & 0.799644 & 2 & 0.6704 \\
D(ESTOQUEK) & 1.310515 & 1 & 0.2523 & 3.880904 & 2 & 0.1436 \\
D(POPOCUP) & 0.003210 & 1 & 0.9548 & 1.672463 & 2 & 0.4333 \\
\hline All & 4.545819 & 3 & 0.2082 & 8.401816 & 6 & 0.2101 \\
\hline
\end{tabular}

A partir dos resultados dos testes de causalidade de Granger, apresentados na Tabela 2.17, é possível tecer os seguintes comentários:

- Para o teste de causalidade de Granger considerando uma defasagem foi possível identificar causalidade de EstoqueK sobre PIBreal a 5\%, causalidade de TermPopOcup sobre PIBreal a 10\% e causalidade de PIBreal sobre PopOcup a 5\%;

- Para o teste de causalidade de Granger considerando duas defasagens foi possível identificar causalidade de EstoqueK sobre PIBreal a $10 \%$ e causalidade de PIBreal sobre PopOcup a 5\%; 
Para ambos os casos analisados pode-se destacar apenas a existência de causalidade unidirecional.

Diante do exposto é possível sumarizar a análise afirmando que existe causalidade de longo prazo e causalidade de curto prazo entre estoque de capital e PIB real, bem como entre terminais por população ocupada e PIB real quando considerada uma defasagem.

\subsection{Considerações finais e sugestão de estudos futuros}

O presente capítulo buscou estudar a relação entre investimentos em infraestrutura de telecomunicações e o crescimento econômico no Brasil, considerando dados das últimas quatro décadas.

Nesse sentido, o trabalho contribui para o esclarecimento de uma questão relevante no que tange à formulação e implementação de políticas públicas, qual seja, a de compreender a relação causal entre as duas variáveis. Na prática, a pergunta que se buscou responder foi: o crescimento do PIB provoca o crescimento das telecomunicações ou ocorre o contrário?

Após a realização dos testes necessários à identificação e estimação dos modelos foi possível chegar ao resultado em que, em particular para o caso das duas variáveis retromencionadas, a relação causal vai na direção de que o crescimento das telecomunicações causa o crescimento do produto. Importante registrar que a causalidade foi verificada tanto no curto quanto no longo prazo.

Em um momento em que o país se defronta com uma situação desfavorável no que tange ao crescimento econômico, com fortes indícios de um processo de recessão em curso, o resultado obtido contribui para reforçar a importância da decisão recente da Anatel na direção de regulamentar a possibilidade de troca de valores de multas por investimentos no setor de telecomunicações, via assinatura de termos de ajustamento de conduta, assunto a ser explorado, em detalhes, no capítulo 4.

Outra informação relevante refere-se à relação causal entre PIBreal e popocup que vai na direção de que o crescimento do produto causa o crescimento da população ocupada, indicando a necessidade de crescimento econômico para que haja o aumento do emprego e, consequentemente, do bem estar. 
Por fim, é importante registrar que o estudo realizado no presente capítulo pode ser ampliado em estudos futuros a partir da possibilidade de utilização de análise de dados em painel para estudar o efeito das telecomunicações nos estados ou municípios, o que se apresenta como uma alternativa para lidar com a limitação do tamanho das séries. Ademais poder-se-á estudar o efeito conjunto das telecomunicações com outros setores de infraestrutura. 


\section{CAPÍTULO 3 - UMA ABORDAGEM DE TEORIA DE CONTRATOS APLICADA AO SETOR DE TELECOMUNICAÇÕES}

\subsection{Introdução}

As literaturas de informação e de contratos têm sido amplamente utilizadas para o estudo e desenvolvimento de trabalhos aplicados, em especial, relacionados com a atividade regulatória.

Nesse sentido, o presente capítulo objetiva estudar o problema de informação existente e inerente à atividade regulatória, em particular no que tange à celebração de contratos, e explorar o importante impacto da assimetria de informação sobre as propriedades de eficiência da atividade de regulação, bem como indicar um caminho de como superar as limitações de uma abordagem utilizada no combate ao descumprimento de obrigações consumeristas, e de forma análoga para outras áreas, por parte dos prestadores.

Para tanto, foi desenhado um mecanismo no qual a autoridade regulatória é o principal e as prestadoras de serviços de telecomunicações são os agentes. É adotada uma abordagem baseada em incentivos para analisar a relação entre regulador e os prestadores. O objetivo é analisar a eficiência da regulamentação de direitos dos usuários existente, excluindo a possibilidade de conluio entre o regulador e os operadores. Ademais, são consideradas modelagens em dois cenários definidos pela presença ou não de simetria de informação entre os agentes.

A partir da definição dos problemas enfrentados pelos agentes no contexto da relação contratual e a subsequente resolução dos mesmos são obtidas e apresentadas proposições e suas provas formais. Diante dos resultados teóricos obtidos são contextualizadas possíveis aplicações práticas de modo a contornar eventuais problemas identificados.

A seção que trata dos contratos celebrados em um ambiente de informação assimétrica, em particular, se aproxima de forma mais apropriada da realidade vivenciada pelos agentes econômicos. Neste sentido, a referida seção possibilita a obtenção de conclusões teóricas que contribuem para uma indicação mais apropriada das medidas a serem adotadas pelo principal no sentido de mitigar os problemas identificados. 
A título de exemplo, é possível destacar que um caminho a ser seguido pelo regulador relaciona-se a um processo de eliminação de regulamentação não essencial para o adequado atendimento da sociedade, não explorado em detalhes no presente trabalho, o que poderia redundar numa redução do custo operacional das firmas e o consequente aumento de empreendedores dispostos a atuar no setor, beneficiando o consumidor com uma maior oferta de serviços de telecomunicações e a possível redução de preços.

O capítulo está assim dividido, além desta introdução: na segunda seção é apresentada a dinâmica de celebração de contratos nas telecomunicações no Brasil. A terceira seção aborda a ideia de contrato ótimo sob o contexto de informação simétrica, onde é apresentada a possibilidade de o regulador atuar de forma conveniente na definição de sanção, de modo a tornar a operação legal mais atrativa à prestadora do que a ilegal, bem como a característica de eficiência do contrato celebrado neste ambiente de informação simétrica. Em seguida, a quarta seção apresenta o desenho de contratos em ambiente de informação assimétrica e suas consequências. Por fim, a última seção apresenta os principais resultados e considerações finais.

\subsection{Contratos nas telecomunicações}

A celebração dos contratos, tanto de concessão, como os termos de autorização nas telecomunicações não resultou, em certo sentido, em uma conduta esperada pelas prestadoras de serviços de telecomunicações. Isto se deve, em parte, ao problema de informação existente e inerente à atividade reguladora.

Nem mesmo a fixação e/ou a previsão, e posterior aplicação de severas multas, resultaram em um comportamento adequado das firmas. Como resultado, o setor de telecomunicações vivenciou ao longo dos anos um aumento bastante expressivo do volume de multas aplicadas, em grande parte, intempestivamente, o que conduziu a um longo processo de discussão regulatória que culminou na edição do regulamento dos termos de ajustamento de conduta - TAC, cujo detalhamento e tratamento serão abordados no capítulo 4.

Oportuno ressaltar que periodicamente são realizadas revisões dos contratos de concessão e renovações das autorizações de frequências e, consequentemente, dos serviços ofertados por meio do recurso de espectro radioelétrico, além do fato de que, a qualquer tempo, uma firma tem a possibilidade de requerer outorga para a prestação de qualquer serviço. 
Em particular, até o final de 2015, será assinada a renovação dos contratos para o penúltimo quinquênio (2016-2020) de vigência do período de concessão do serviço telefônico fixo comutado - STFC. Ademais, no período de 2015-2020 vencerão as licenças de radiofrequências (Banda A e Banda B), o que implicará a necessidade de se realizarem novos procedimentos licitatórios e, posterior assinatura de novos termos de autorização, ou seja, contratos no sentido apresentado pela literatura econômica.

Estes fatos tornam oportuna e conveniente a exposição do presente capítulo que buscará estudar, com base em uma abordagem baseada em incentivos, um mecanismo que contribua para a redução das infrações pelos operadores de serviços de telecomunicações no que tange, em particular, aos direitos dos usuários e à consequente melhoria dos serviços prestados aos consumidores. Araújo (2005) desenvolveu trabalho nesta mesma linha para o setor bancário, em particular, no que tange ao combate à lavagem de dinheiro.

Um dos resultados do presente trabalho indica que, sob informação perfeita, o contrato é eficiente, gerando assim uma adequada aplicação da regulamentação das telecomunicações. Todavia, quando o tipo da operadora, isto é, seu compromisso e empenho de cumprir a regulamentação não são conhecidos, a questão de informação oculta ou assimétrica surge e pode comprometer a eficiência da regulamentação baseada em incentivos.

Esta abordagem também mostra, conforme evidenciado a seguir, que uma melhoria da eficiência da regulação das telecomunicações pode ser atingida com o aumento da capacidade de identificar a disposição das operadoras de cooperar.

$\mathrm{Na}$ medida em que a Anatel ampliar sua capacidade de compreender os sinais das prestadoras, poderá adequar as propostas de contratos para os diferentes operadores e superar as limitações da regulamentação no combate aos descumprimentos regulamentares.

\subsection{Contrato ótimo com informação simétrica}

O problema central da regulação dos direitos dos usuários é desenhar um sistema de procedimentos e incentivos que induza o agente, no caso as operadoras dos serviços de telecomunicações, a agirem de modo a atender os direitos dos consumidores. Como é de conhecimento comum, muitos países implementaram reformas de modernização do seu arcabouço institucional, em particular no que tange à atuação do Estado na atividade econômica, 
entre as décadas de 1980 e 1990 [ZAGHA; NANKANI (2005)]. Com isso, a responsabilidade de cuidar dos diferentes setores de infraestrutura passou a cargo de órgãos reguladores, no Brasil, chamadas de agências reguladoras, a quem cabe o papel de definir um arcabouço jurídico regulatório que maximize os incentivos das operadoras de atenderem, a contento, as demandas legítimas dos usuários.

Nesse sentido, assumiremos que os operadores têm duas possíveis ações a escolher: atender ou não atender os direitos dos usuários. Isto significa que alguns operadores podem optar por não atender plenamente os direitos dos usuários, operando parcialmente na legalidade. Assim, considerando Jehle e Reny (2011), Mas Colell e Whinston (1995) e Tirole (1988), vamos assumir que o lucro de uma operadora, $\pi^{l}$ é dado por:

$$
\Pi^{1}=p\left(t^{1}\right) t^{1}-c\left(t^{1}, \delta\right)
$$

onde $p$ é o preço do serviço de telecomunicações que é função da quantidade produzida em uma operação legal ${ }^{8}, t^{l}$, que pode ser considerada o número de linhas em serviço. Vamos assumir, por simplicidade, uma função custo linear: $c\left(t^{l}, \delta\right)=(\beta+\delta) t^{l}$, onde $\beta$ é o custo unitário de manutenção da linha em serviço e o $\delta$ refere-se ao custo de conformidade de atender todos os direitos dos usuários, o que resulta na seguinte função lucro para a operadora dentro da legalidade:

$$
\Pi^{1}=p\left(t^{1}\right) t^{1}-\beta t^{1}-\delta t^{1}
$$

$\mathrm{O}$ valor de $\delta$ está relacionado à capacidade e/ou habilidade de cumprir a regulamentação relativa aos direitos dos usuários, isto é, quanto maior o valor de $\delta$, maior o custo envolvido no atendimento à regulamentação (custo de conformidade) afeta aos direitos dos usuários e, portanto, menor a capacidade e/ou habilidade para cumprimento das regras.

Dentre os fatores que influenciam o valor de $\delta$, e que podem não estar sob o controle pleno dos operadores, podem-se destacar a capacidade dos funcionários de atender adequadamente os consumidores e suas demandas e o perfil ou comportamento dos clientes.

\footnotetext{
${ }^{8}$ Legal aqui refere-se à ideia de conformidade com todos os direitos dos usuários previstos nos dispositivos jurídicoregulatórios.
} 
Ademais, o operador pode decidir não atender plenamente os direitos dos usuários, o que conduz a um lucro esperado sob uma operação ilegal, $\Pi^{i}$ :

$$
\Pi^{i}=\pi\left[p\left(t^{i}\right) t^{i}-\beta t^{l}-M\right]+(1-\pi)\left[p\left(t^{i}\right) t^{i}-\beta t^{i}\right]
$$

onde $t^{i}$ é a quantidade produzida sob uma operação ilegal e $\pi$ é a probabilidade de ser punido. O que a expressão (6) apresenta é que ao decidir não atender aos direitos dos usuários o operador deixa de incorrer no custo de conformidade, mas passa a poder incorrer em uma multa $M$ com probabilidade $\pi$. Assim simplificando a expressão (6), temos:

$$
\Pi^{i}=p\left(t^{i}\right) t^{i}-\beta t^{i}-\pi M
$$

Considerando uma função demanda linear, pode-se mostrar que a produção do prestador com uma operação ilegal é maior que aquela dentro da legalidade, donde obtemos a proposição 1 :

Proposição 1: Se o operador possui uma função demanda linear, então a produção de uma operação ilegal é maior do que de uma operação legal.

Prova: Resolvendo o problema de maximização do lucro da firma para os casos de operação legal e ilegal, obtemos as seguintes condições de primeira ordem:

$$
\begin{gathered}
C P O(L): p^{\prime}\left(t^{l}\right) t^{l}+p\left(t^{l}\right)-\beta-\delta=0 \\
C P O(I): p^{\prime}\left(t^{i}\right) t^{i}+p\left(t^{i}\right)-\beta=0
\end{gathered}
$$

Considerando uma função demanda linear: $p(t)=a-b t$, temos:

$$
\begin{gathered}
C P O(L):-b t^{l}+a-b t^{l}-\beta-\delta=0 \Rightarrow-2 b t^{l}=\beta+\delta-a \Rightarrow t^{l}=\frac{a-\beta-\delta}{2 b} \\
C P O(L):-b t^{i}+a-b t^{i}-\beta=0 \Rightarrow-2 b t^{i}=\beta-a \Rightarrow t^{i}=\frac{a-\beta}{2 b}
\end{gathered}
$$

Logo, temos que $t^{i}-t^{l}=\frac{\delta}{2 b}>0$ 
O resultado anterior evidencia um trade-off entre o cumprimento das regras e o custo de conformidade, indicando que o número de linhas em serviço tende a ser menor que no cenário de operação ilegal.

Este resultado contribui também com a discussão sobre o efeito do excesso de regras. $\mathrm{Na}$ prática, a introdução de regras desnecessárias tende a elevar o custo de prestação para os operadores, redundando em uma redução do número de linhas em serviço, ou seja, na redução da oferta, com o correspondente aumento dos preços ou no aumento da prestação ilegal do serviço de telecomunicações, efeito contrário ao desejado pelo órgão regulador.

Embora a produção seja maior em um cenário de produção ilegal, o lucro esperado pode ser menor do que em um contexto de produção legal, uma vez que o órgão regulador poderá estabelecer multa, isto é, $\Pi^{l}>\Pi^{i}$. Substituindo $t^{l}=\frac{a-\beta-\delta}{2 b}$ e $t^{i}=\frac{a-\beta}{2 b}$ nas expressões (5) e (7), respectivamente, e considerando uma função de demanda linear obtemos os seguintes lucros para as operações legais e ilegais, respectivamente:

$$
\begin{gathered}
\Pi^{l}=\frac{(a-\beta-\delta)^{2}}{4 b} \\
\Pi^{i}=\frac{(a-\beta)^{2}}{4 b}-\pi M .
\end{gathered}
$$

Assim, sob informação simétrica, isto é, com o conhecimento de $\delta$ pelo regulador, este pode definir convenientemente o valor de $M$ de modo que o lucro da operação legal seja maior que sob uma operação ilegal. Desta forma, é oferecido o contrato $\left(M, t^{l}\right)$ para a operadora de modo a induzir a escolha de uma operação legal. Assim, o contrato sob informação perfeita é:

$$
\begin{gathered}
\operatorname{Max} R=\pi M \\
\text { s.a } p\left(t^{l}\right) t^{l}-\beta t^{l}-\delta t^{l} \geq p\left(t^{i}\right) t^{i}-\beta t^{i}-\pi M
\end{gathered}
$$

Ou seja, o principal escolhe $t^{l}$ e $M$ de modo a maximizar seu ganho esperado sujeito à restrição de que a operadora escolha a operação legal, isto é, que o lucro da operação legal seja superior àquele da operação ilegal, $\Pi^{l}>\Pi^{i}$. A proposição 2, apresentada a seguir, destaca que este contrato é eficiente. 
Proposição 2: Sob informação simétrica o contrato é eficiente.

Prova: Para que a operadora escolha a operação legal deve valer $\Pi^{l}>\Pi^{i} \Rightarrow M^{*} \geq$ $\frac{p\left(t^{i}\right) t^{i}-p\left(t^{l}\right) t^{l}+\beta\left(t^{l}-t^{i}\right)+\delta t^{l}}{\pi}$.

Todavia, para evitar a inclusão de custos regulatórios extras deve valer a igualdade:

$$
M^{*}=\frac{p\left(t^{i}\right) t^{i}-p\left(t^{l}\right) t^{l}+\beta\left(t^{l}-t^{i}\right)+\delta t^{l}}{\pi}
$$

Substituindo esta expressão na função objetivo e derivando em $t^{l}$ obtemos exatamente a mesma condição de primeira ordem da firma sob operação legal da proposição 1: $C P O(L): p^{\prime}\left(t^{l}\right) t^{l}+p\left(t^{l}\right)-\beta-\delta=0$.

c.q.d.

O resultado evidencia que definir um contrato sob informação simétrica para que a operadora se comprometa a atender/cumprir os direitos dos usuários é fácil e eficiente, na medida em que leva o operador a escolher o nível de produção que maximiza seu lucro.

Agora, substituindo: $p(t)=a-b t, t^{l}=\frac{a-\beta-\delta}{2 b}$ e $t^{i}=\frac{a-\beta}{2 b}$ na expressão (23), temos:

$$
M^{*}=\frac{\delta[2(a-\beta)-\delta]}{4 b \pi}
$$

Como $M \geq 0 \Rightarrow(a-\beta) \geq \frac{\delta}{2}$. Derivando (11) com relação a $\delta$ e $\pi$, obtemos $\frac{\partial M^{*}}{\partial \delta}=$ $\frac{(a-\beta-\delta)}{2 b \pi}$ e $\frac{\partial M^{*}}{\partial \pi}=-\frac{\delta[2(a-\beta)-\delta]}{16 b^{2} \pi^{2}}<0$. O sinal de $\frac{\partial M^{*}}{\partial \delta}$ depende dos parâmetros $a, \beta e \delta$. Caso $(a-\beta) \geq \delta$ o sinal será positivo, isto é, a derivada será positiva, o que implica que a prestadora com um maior compromisso e empenho de cumprir/atender os direitos dos usuários tende a receber uma multa menor.

A segunda derivada indica que quanto maior a probabilidade de o regulador punir, o que indica uma maior eficiência no processo de fiscalização e monitoramento dos operadores, menor 
tende a ser o valor das multas, o que sinaliza para a importância desta atividade do órgão regulador no processo de sancionamento ótimo.

A seguir, na seção subsequente, é estudado o caso de informação assimétrica que faz surgir o problema de perigo moral, ou também conhecido como problema de ações escondidas, onde a assimetria de informação surge depois do contrato assinado (Bolton e Dewatripont, 2005).

\subsection{Contrato sob informação assimétrica}

Laffont e Martimort (2002) e Laffon et. al. (2003) destacam que as ações ou a performance do contratado é um problema que apresenta como ponto relevante as variáveis de esforço que ao mesmo tempo em que interfere no nível de produção também cria desutilidade para o agente, como nos casos de firmas reguladas na produção de bens socialmente valiosos.

Os autores ainda ressaltam que a ação dos agentes pode ser definida por uma complexa matriz de decisões, o que cria dificuldade para o principal (regulador) no processo de delegação.

Para o caso de atendimento pleno aos direitos dos usuários continuaremos a considerar a principal característica do operador com a qual o regulador está preocupado como sendo a capacidade e/ou habilidade de atender os referidos direitos.

A variável que mensura esta capacidade e/ou habilidade é definida como $\delta$. Quanto menor o $\delta$ maior é a capacidade e/ou habilidade do operador em cumprir a regulamentação consumerista ${ }^{9}$, implicando menores custos.

Suponhamos, por simplicidade, que existem dois tipos de operadores $\delta_{1}$ e $\delta_{2}$, com $\delta_{1}>\delta_{2}$, isto é, o operador 2 tem maior capacidade/compromisso/empenho, menor custo de conformidade, de atender plenamente os direitos dos usuários do que o operador 1.

Neste sentido, o principal tem que propor dois contratos para os operadores. Na proposição seguinte, destaca-se que, sob uma operação legal, a produção do operador 2, de maior compromisso, é maior.

\footnotetext{
${ }^{9}$ Como regulação consumerista devem ser entendidos o código de defesa do consumidor e demais regulamentações da Anatel afetas aos serviços prestados pelos operadores de serviços de telecomunicações.
} 
Proposição 3: Assuma que os dois operadores observem a mesma função demanda linear. Sob operação legal, a quantidade que maximiza o lucro do operador 1 é menor do que a quantidade que maximiza o lucro do operador 2 quando $\delta_{1}>\delta_{2}$.

Prova: $\mathrm{Da} \mathrm{CPO}(\mathrm{L})$ temos que $t_{1}^{l}=\frac{a-\beta-\delta_{1}}{2 b}$ e $t_{2}^{l}=\frac{a-\beta-\delta_{2}}{2 b}$. Como $\delta_{1}>\delta_{2}$. Logo, $t_{2}^{l}>t_{1}^{l}$.

O operador pode ofertar uma maior quantidade de linhas de serviços de telecomunicações devido a sua maior capacidade de lidar com o arcabouço de direitos dos usuários.

Conforme apresentado na seção precedente, $M^{*}=\frac{\delta[2(a-\beta)-\delta]}{4 b \pi}$. Para o caso em tela devese ter $M_{1}^{*}>M_{2}^{*}$, uma vez que $\delta_{1}>\delta_{2}$. Todavia, como não é possível observar $\delta$ então o prestador 1 poderá tentar agir como se seu tipo fosse dado por $\delta_{2}$ de modo a receber um contrato melhor do que aquele que receberia em condições normais.

De modo a contornar esse problema, o principal buscará resolver o seguinte problema:

$$
\operatorname{Max}\left[\rho \pi M_{1}+(1-\rho) \pi M_{2}\right]
$$

s.a.

$$
\begin{aligned}
& p\left(t_{1}^{l}\right) t_{1}^{l}-\beta t_{1}^{l}-\delta_{1} t_{1}^{l} \geq p\left(t_{2}^{l}\right) t_{2}^{l}-\beta t_{2}^{l}-\delta_{1} t_{2}^{l}, \\
& p\left(t_{2}^{l}\right) t_{2}^{l}-\beta t_{2}^{l}-\delta_{2} t_{2}^{l} \geq p\left(t_{1}^{l}\right) t_{1}^{l}-\beta t_{1}^{l}-\delta_{2} t_{1}^{l}, \\
& p\left(t_{1}^{l}\right) t_{1}^{l}-\beta t_{1}^{l}-\delta_{1} t_{1}^{l} \geq p\left(t_{1}^{i}\right) t_{1}^{i}-\beta t_{1}^{i}-\pi M_{1}, \\
& p\left(t_{2}^{l}\right) t_{2}^{l}-\beta t_{2}^{l}-\delta_{2} t_{2}^{l} \geq p\left(t_{2}^{i}\right) t_{2}^{i}-\beta t_{2}^{i}-\pi M_{2},
\end{aligned}
$$

em que $\rho$ é a parcela dos operadores de tipo 1 e o restante $(1-\rho)$ é a parcela de operadores do tipo 2. De forma análoga, $\rho$ pode ser interpretado como a probabilidade do principal oferecer um contrato a uma operadora do tipo 1 e $(1-\rho)$ a probabilidade de oferecer um contrato à operadora do tipo 2 .

As restrições de compatibilidade de incentivos (RCI1) e (RCI2) garantem que cada tipo escolherá o contrato desenhado para si. Já as restrições de participação (RP1) e (RP2) apresentam o requerimento contratual de que o operador atue dentro da legalidade. 
A proposição 4, a seguir apresentada, evidencia que o lucro da operação legal da operadora 2 é superior ao lucro da operação legal da operadora 1.

Proposição 4: Sob uma operação legal a operadora 2 tem lucro maior que operadora 1.

Prova: Pela RCI2 temos que $p\left(t_{2}^{l}\right) t_{2}^{l}-\beta t_{2}^{l}-\delta_{2} t_{2}^{l} \geq p\left(t_{1}^{l}\right) t_{1}^{l}-\beta t_{1}^{l}-\delta_{2} t_{1}^{l}$, mas como $\delta_{1}>\delta_{2}, \quad p\left(t_{1}^{l}\right) t_{1}^{l}-\beta t_{1}^{l}-\delta_{2} t_{1}^{l} \geq p\left(t_{1}^{l}\right) t_{1}^{l}-\beta t_{1}^{l}-\delta_{1} t_{1}^{l} . \quad$ Logo, $\quad p\left(t_{2}^{l}\right) t_{2}^{l}-\beta t_{2}^{l}-\delta_{2} t_{2}^{l} \geq$ $p\left(t_{1}^{l}\right) t_{1}^{l}-\beta t_{1}^{l}-\delta_{1} t_{1}^{l}$, ou seja, $\Pi_{2}^{l}>\Pi_{1}^{l}$.

c.q.d.

A proposição 4 explicita o fato de que a operadora que tem maior compromisso/empenho de cumprir/atender os direitos dos usuários aufere lucro maior. O corolário desta preposição destaca que o contrato é eficiente para a operadora 2.

Corolário: O contrato é eficiente para a operadora 2.

Prova: Para a operadora 2 a quantidade estabelecida em contrato é a mesma que maximiza seu lucro e a multa é a mesma que faz a operadora optar por uma operação legal. Não existe nenhum incentivo para a operadora 2 esconder seu tipo.

c.q.d.

Proposição 5: A operadora 1 produz uma quantidade menor ou igual à operadora 2.

Prova: Somando RCI1 com a RCI2 obtemos: $\left[\delta_{1}-\delta_{2}\right]\left[t_{1}-t_{2}\right] \leq 0$, como $\delta_{1}>\delta_{2}$, por hipótese, temos que $t_{1}<t_{2}$.

A proposição 5 mostra que o contrato sob informação imperfeita (assimétrica) não é eficiente, pois não evita que o operador 1 escolha a produção do operador 2, escondendo, assim, seu tipo para obter um contrato melhor $\left(M_{2}, t_{2}\right)$, o que é ressaltado no seguinte corolário.

Corolário: A operadora 1 é indiferente entre seu contrato e o contrato $\left(M_{2}, t_{2}\right)$ da operadora 2.

Prova: A RCI1 vale com igualdade. 
Além do disposto na proposição 5, da proposição 3 sabemos que a produção da operadora 2 é maior que a produção da operadora 1, o que leva ao entendimento de que a operadora 1 não escolhe uma produção que maximiza o lucro pelo fato de desejar obter um melhor contrato do que aquele desenhado para ela.

Todavia, pela proposição 1, sabemos que uma operação ilegal gera uma produção maior do que aquela obtida de uma operação legal. Além disso, sabemos que a RP1 vale com igualdade (evitar custos regulatórios excessivos), o que significa que a operadora 1 se utiliza de uma operação ilegal para aumentar sua produção e maximizar seu lucro, conforme destacado na próxima proposição.

Proposição 6: O operador 1 possui incentivo para escolher uma operação ilegal.

Prova: O operador 1, conforme descrito na proposição 5, pode escolher um nível de produção de modo a se parecer com o tipo $\delta_{2}$ e não $\delta_{1}$, recebendo, assim, um contrato melhor $\left(M_{2}, t_{2}\right)$. Ao receber este contrato, seu lucro é dado por $\Pi_{1}^{l}=p\left(t_{2}^{l}\right) t_{2}^{l}-\beta t_{2}^{l}-\delta_{1} t_{2}^{l}$. Caso a operadora escolha operar ilegalmente seu lucro seria $\Pi_{1}^{l}=p\left(t_{1}^{i}\right) t_{1}^{i}-\beta t_{1}^{l}-\pi M_{1}$. A RP1 vale com igualdade conforme já destacado $p\left(t_{1}^{l}\right) t_{1}^{l}-\beta t_{1}^{l}-\delta_{1} t_{1}^{l}=p\left(t_{1}^{i}\right) t_{1}^{i}-\beta t_{1}^{l}-\pi M_{1}$. Pela RCI1 sabemos que $p\left(t_{1}^{l}\right) t_{1}^{l}-\beta t_{1}^{l}-\delta_{1} t_{1}^{l} \geq p\left(t_{2}^{l}\right) t_{2}^{l}-\beta t_{2}^{l}-\delta_{1} t_{2}^{l}$. Logo, pode-se concluir que $p\left(t_{1}^{i}\right) t_{1}^{i}-\beta t_{1}^{l}-\pi M_{1} \geq p\left(t_{2}^{l}\right) t_{2}^{l}-\beta t_{2}^{l}-\delta_{1} t_{2}^{l}=\Pi_{1}^{l}$, com contrato $\left(M_{2}, t_{2}\right)$, o que significa que o operador 1 escolhe uma operação ilegal pelo fato de gerar um lucro maior ou igual ao da operação legal. c.q.d.

Esses resultados mostram que o mecanismo desenhado para promover o cumprimento da regulamentação pode estimular as operadoras de menor capacidade ou compromisso de cumprir com a regulamentação a escolher atuar dentro da ilegalidade ou a deixar o mercado, aspecto não considerado na modelagem, mas que poderá ser objeto de extensão do presente trabalho.

Uma explicação para este comportamento pode estar relacionado ao fato de que o mecanismo criado pode induzir a operadora com menor capacidade e/ou compromisso em cumprir a regulamentação a se passar como sendo de outro tipo, de modo a receber um contrato melhor. Entretanto, ao agir desta forma a prestadora obterá um lucro inferior, uma vez que a quantidade produzida para obter um contrato melhor não é aquela que realmente maximiza seu lucro. Diante deste cenário, a operadora entende que o comportamento ilegal proporciona um lucro ótimo. 
A aplicação de multas não elimina a possibilidade de que o comportamento ilegal continue a ser ótimo, uma vez que o regulador deverá defini-la tendo atenção especial para não criar regulação adicional para as operadoras cumpridoras da regulamentação.

Oportuno destacar que o presente trabalho pode ser estendido para um número maior de firmas ou para um contínuo de firmas, mas acredita-se que o resultado caminhará no mesmo sentido do resultado aqui apresentado.

Importante destacar que a inclusão do efeito do mecanismo sobre a competição no mercado de telecomunicações, via opção do agente por deixar o mercado pode trazer resultados mais interessantes, porém de modelagem mais complexa, o que poderá ser desenvolvido em trabalhos futuros.

\subsection{Considerações finais e sugestões de estudos futuros}

O presente capítulo buscou estudar um mecanismo baseado em incentivo para promover o cumprimento da regulamentação afeta aos direitos dos consumidores. A análise considerou a importância de um ambiente saudável de prestação dos serviços de telecomunicações para o desenvolvimento do setor, bem como das atividades econômicas baseadas nas tecnologias e serviços de telecomunicações.

Ao estudar a efetividade da regulamentação baseada em incentivos foi possível identificar que a adequada aplicação dos contratos possui uma dificuldade com o problema de informações ocultas, uma vez que o compromisso e a capacidade de as operadoras atuarem no sentido de cumprirem a regulamentação são informação privada.

Este cenário caracteriza o problema de perigo moral, isto é, as operadoras de telecomunicações tendem a desviar-se do comportamento desejado de modo a obter um contrato melhor ou operar de forma ilegal de modo a maximizar seu lucro.

Neste sentido, a baixa capacidade de identificar o tipo das prestadoras de telecomunicações de cumprir com a regulamentação, associada ao histórico de que as punições não são pagas, haja vista o estoque de multas não pagas há vários anos tramitando, seja na esfera administrativa seja na esfera judicial, gera um incentivo perverso para que as operadoras continuem a não se esforçar em cumprir a regulamentação. 
Esse resultado teórico evidencia a necessidade de o regulador investir em mapear bem o comportamento dos operadores, e eventuais interessados em atuar no setor, em especial no que tange ao compromisso e capacidade de atuar dentro dos dispositivos jurídico-regulamentares vigentes. Outra indicação que pode ser extraída do presente estudo se refere à possibilidade de se estudar a alternativa de desregulamentação, isto é, a redução do número de regras e obrigações potencialmente irrelevantes para a satisfação dos usuários que, ao elevar o custo operacional das firmas, acabam por incentivá-las a operar na ilegalidade. 


\section{CAPÍTULO 4 - ANÁLISE DE LICITAÇÕES PARA CELEBRAÇÃO DE TERMOS DE AJUSTAMENTO DE CONDUTA NA ANATEL}

\subsection{Introdução}

A prestação de serviços de telecomunicações evoluiu de forma bastante intensa, sobretudo após o processo de privatização das empresas do sistema Telebrás em meados da década de $1990^{10}$. Em período anterior à privatização, o país apresentava um cenário de demanda reprimida e o acesso aos serviços telefônicos estava concentrado nas classes mais ricas do país.

Tendo em vista as metas ${ }^{11}$ de implantação de redes e de atendimento telefônico em todo país, estabelecidas durante o processo de privatização, o que se pôde presenciar em todo o Brasil foi uma rápida expansão da oferta de serviços de telecomunicações em um curto espaço de tempo.

Ocorre que essa expansão não se deu sem nenhum custo nos aspectos de qualidade da prestação $^{12}$, o que, até certo ponto, é absolutamente compreensível dado o esforço para o cumprimento das metas de abrangência e atendimento fixadas.

Todavia, passados os primeiros anos de intenso esforço dos prestadores de serviços de telecomunicações em atender as metas, os níveis de qualidade da prestação dos serviços e de conformidade com as normas não melhoraram como esperado, levando a um crescimento exponencial do volume de sanções, resultando, em seguida, no aumento expressivo do estoque de multas.

Esse cenário foi agravado em anos mais recentes, o que culminou com a necessidade do setor avaliar alternativas ao mero pagamento dos valores de multas pelas operadoras, uma vez que, em muitos casos, o que deu causa ao sancionamento não seria resolvido com a simples punição, o que redundou na edição do regulamento dos termos de ajustamento de conduta (TAC) a ser detalhado mais à frente.

\footnotetext{
${ }^{10}$ Vide sítio www.anatel.gov.br ou www.teleco.com.br para estatísticas setoriais.

${ }^{11}$ Plano Geral de Metas de Universalização

${ }^{12}$ Relatório de Gestão da Anatel 2013 - abertura de procedimentos de apuração de descumprimento de obrigações e sancionamento.
} 
Nesse contexto, o presente capítulo busca contribuir com o processo de regulamentação do TAC proposto pela Anatel, podendo servir de referência para os demais órgãos da Administração Pública que venham a ter interesse na utilização de mecanismos de solução negociada, através da proposição de um mecanismo que seja apto a lidar com potenciais problemas de informação e gere incentivos compatíveis com os objetivos do poder público que, em última análise, é responsável por incorporar as demandas da sociedade.

Para tanto, é desenvolvido, primeiramente, um modelo básico para licitação e obtém-se seu equilíbrio. Em seguida, é apresentado um modelo de licitação sequencial com definição do preço de reserva endogenamente, ambos visando maximizar a eficiência no processo de definição do quantum de investimentos no setor de telecomunicações. Estes deverão ser realizados em troca de abatimento de parcela do estoque de multas quando da celebração de Termos de Ajustamento de Conduta entre poder público e os prestadores regulados.

Segundo as propriedades derivadas do modelo sequencial, é possível garantir que o referido modelo se mostra menos vantajoso para o Estado (Anatel) e em última análise para a sociedade brasileira, uma vez que ele tende a deprimir os lances na licitação.

Assim, o estudo do tema proposto estará dividido da seguinte maneira: na seção 2 será realizado um maior detalhamento do problema regulatório enfrentado pela Anatel, em especial no que tange à função regulamentadora acerca do processo sancionatório, à evolução quantitativa dos procedimentos para apuração de descumprimentos (Pados) instaurados e encerrados, dos montantes de multas constituídas e arrecadadas, bem como da situação administrativa das multas constituídas, além de apresentar a fundamentação jurídica dos TACs. Na seção 3, abordar-se-á, de forma crítica, a solução apresentada pela Anatel via regulamentação, incluindo o desenvolvimento da regulamentação dos Termos de Ajustamento de Conduta aplicável ao setor de Telecomunicações. Na seção 4, será realizada uma breve revisão da literatura de leilões, em especial acerca dos leilões sequenciais de múltiplos objetos. Já na seção 5 será proposto um formato de leilão de projetos de investimento no setor de telecomunicações, com potencial efeito para abatimento dos valores sancionados, isto é, das multas constituídas no âmbito dos processos de apuração de descumprimento de obrigações, derivando-se o equilíbrio bem como extensão do modelo básico, incluindo os casos de inclusão de preço de reserva com definição endógena, e apresentando os resultados mais relevantes para o leiloeiro, qual seja, no caso em tela, a Agência Nacional de Telecomunicações. Por fim, a seção 6 traz as considerações finais do trabalho. 


\subsection{Detalhamento do problema}

A Agência Nacional de Telecomunicações, desde sua criação, vem trabalhando para propiciar o desenvolvimento do setor de Telecomunicações no Brasil, conforme atribuição legal do órgão. Após o processo de privatização ocorrido em julho de 1998, seguiu-se um período importante de regulamentação que visava estabelecer os principais marcos setoriais.

Dentre as suas principais atribuições, podem-se citar as atividades de fiscalização e controle de obrigações. Essas atividades são de grande relevância para a adequada prestação de serviços à sociedade pelos detentores de outorga.

Naquele momento, os principais objetivos do órgão regulador era estimular a maximização do investimento privado no setor e garantir o cumprimento do Plano Geral de Metas de Universalização - PGMU/1998 que continha metas ousadas de abrangência e prazos de atendimento do Serviço Telefônico Fixo Comutado, em especial quando comparado ao modelo estatal vigente até então, conforme transcrição do texto do Decreto apresentado a seguir:

\section{Capítulo II}

Das Metas de Acessos Individuais

Art. $4^{\circ}$ As Concessionárias do Serviço Telefônico Fixo Comutado deverão:

I - ofertar, até o final dos anos de 1999, 2000 e 2001, por Unidade da Federação, as quantidades de Acessos Instalados constantes do Anexo I;

II - implantar o Serviço Telefônico Fixo Comutado, com acessos individuais, conforme a seguir:

a) até 31 de dezembro de 2001, em todas as localidades com mais de mil habitantes;

b) até 31 de dezembro de 2003, em todas as localidades com mais de seiscentos habitantes;

c) até 31 de dezembro de 2005, em todas as localidades com mais de trezentos habitantes.

III - atender às solicitações de acesso individual, nas localidades com Serviço Telefônico Fixo Comutado, nos seguintes prazos máximos:

a) a partir de 31 de dezembro de 2001, em quatro semanas;

b) a partir de 31 de dezembro de 2002, em três semanas;

c) a partir de 31 de dezembro de 2003, em duas semanas;

d) a partir de 31 de dezembro de 2004, em uma semana. 
De fato, conforme explicitamente apresentado na Exposição de Motivos n. ${ }^{\circ}$ 231/MC, um dos principais objetivos do processo de reestruturação do setor de telecomunicações era a ampliação da oferta dos serviços de telecomunicações o que, sem dúvida, requeria um massivo investimento e esforço de gestão das novas prestadoras.

Em decorrência das prioridades estabelecidas pela agenda pós-privatização, a dinâmica fiscalização-sancionamento, até mesmo pela escassez de recursos humanos disponíveis no órgão regulador das telecomunicações - Anatel, uma vez que ainda não tinha sido realizado concurso público para o órgão, contou com uma atuação menos estruturada.

Todavia, passado o primeiro ciclo de grandes investimentos e grande expansão das redes de telecomunicações e da oferta de serviços, a atividade regulatória entrou, a partir de 2005 , em uma nova fase: a de garantia dos direitos dos usuários relativamente aos serviços ofertados.

Oportuno ressaltar que, no momento anterior à reestruturação do setor, a insuficiência na oferta dos serviços de telecomunicações gerou uma demanda reprimida que somente foi atendida graças à ampliação na oferta decorrente do novo ambiente regulatório.

Entretanto, o rápido crescimento na oferta e prestação dos serviços de telecomunicações favoreceu a ocorrência de falhas nos serviços, problemas de qualidade e de atendimento aos usuários. De forma a contornar a situação apresentada e a dar um adequado tratamento às demandas dos usuários dos serviços de telecomunicações, a Anatel redefiniu suas prioridade e redirecionou seu foco de atuação para o tratamento e solução das demandas e reclamações dos consumidores.

Nesse momento, observou-se o aumento no volume de instauração, julgamento e sancionamento dos processos administrativos de apuração de descumprimento de obrigação (Pados), conforme evidenciado nas figuras 4.3-4.5 na seção 4.2.2.

Como consequência deste cenário, as prestadoras se viram obrigadas a rever seus procedimentos internos visando se adequarem à regulamentação. Não obstante, iniciou-se um processo intenso de recursos que acarretou, e acarreta, ônus tanto para o regulado como para o regulador, sem, contudo, a garantia de benefício aos usuários dos serviços de telecomunicações.

Diante deste cenário, com base em dispositivos constitucionais e legais, a Anatel iniciou um trabalho de discussão do marco regulatório sobre as metodologias de sanção e posteriormente para a celebração de Termo de Ajustamento de Conduta. 
Cabe ressaltar que a Lei $\mathrm{n}^{\circ}$ 9.472, de 16 de julho de 1997 - Lei Geral de Telecomunicações (LGT) remete à regulamentação da Anatel o estabelecimento de condicionamentos e métricas para a aplicação das sanções, e adicionalmente as consequências do descumprimento das obrigações.

Relativamente às metodologias de definição das multas, nos primeiros anos da atividade regulatória, era possível observar uma quantidade significativa de métodos para definição de sanção de multa. A ausência de uma padronização das metodologias de sanção associada à ausência de um adequado tratamento das demandas no sentido de gerar ações resolutivas das condutas infratoras levou a um aumento expressivo do volume das multas aplicadas, conforme divulgado em diversos veículos de comunicação ${ }^{13}$. Em alguns casos o volume de multas aplicadas chegou a corresponder a uma fração importante do valor de mercado de algumas prestadoras.

Ao longo do tempo, após rodadas de discussões internas sobre o arcabouço regulamentar e os anseios da sociedade, ficou evidente a necessidade de se revisitar, de forma sistêmica, o conteúdo dos regulamentos e as diferentes metodologias existentes para os diferentes tipos de infrações, ou seja, constatou-se que a regulamentação dos serviços de telecomunicações, de qualidade e de controle de obrigações associadas à dinâmica de sancionamento, estava, há algum tempo, dando sinais de que a prestação dos serviços de telecomunicações dentro dos parâmetros regulamentares vigentes não vinha produzindo um ambiente de satisfação plena ao consumidor, sobretudo pelo fato de que a regulamentação não estava em plena sintonia com os anseios ou os requisitos de qualidade percebidos pela sociedade.

Diante desses fatos e de demandas dos órgãos de defesa do consumidor, iniciou-se uma série de debates para o aperfeiçoamento da regulamentação de modo que estivesse mais alinhada aos anseios dos consumidores. Esse trabalho desenvolvido pela Anatel visou a aperfeiçoar a regulamentação relativa à dinâmica de fiscalização-sancionamento, de modo a racionalizar o processo de fiscalização e sancionamento dos prestadores de serviços de telecomunicações.

Como resultado de discussões internas e com a sociedade, por meio de Consulta e Audiências Públicas, foi publicada nova resolução sobre o tema, o Regulamento de Aplicação de Sanções (RASA), aprovado pela Resolução n. ${ }^{\circ}$ 589, de 7 de maio de 2012.

13 Mídias setoristas como Teletime, Telesíntese. Jornais e revistas de grande circulação, como a Veja de 28/08/2013 com a matéria de capa "Deputado do PT oferece "honorários" a conselheiro da Anatel para atuar a favor da Oi" 
Referido regulamento previa em seu artigo $5^{\circ}$ a possibilidade de celebração, com os infratores, de compromissos de ajustamento de conduta (TAC) às exigências legais a ser regulamentado em instrumento próprio:

Art. $5^{\circ}$ - A Anatel poderá, a seu critério e na órbita de suas competências legais, com vistas ao melhor atendimento do interesse público, celebrar, com os infratores, compromisso de ajustamento de conduta às exigências legais.

A Lei n. ${ }^{\circ}$ 7.347, de 24 de julho de 1985 (Lei da Ação Civil Pública), estabeleceu a legitimidade das autarquias para tomar dos interessados compromisso de ajustamento de sua conduta às exigências legais, mediante cominações, que terá eficácia de título executivo extrajudicial (art. $5^{\circ}$, inciso IV c/c art. $5^{\circ}, \S 6^{\circ}$ ).

Quando combinada com as competências da Anatel dirigidas à proteção ao consumidor, direitos coletivos e com a defesa da ordem econômica e da economia popular (art. $1^{\text {o }}$, II e V, da Lei $\mathrm{n}^{\circ} 7.347 / 85$ c/c art. $5^{\circ}$, LGT), bem como repressão das infrações a direitos dos usuários (art. $19^{\circ}$, XVIII, LGT), entendeu a Anatel que a competência para a celebração de termos de ajustamento de conduta, ou seja, a adoção de medidas substitutivas à sanção de multa pode atender com mais eficiência o interesse público.

Nesse sentido, após a análise de aspectos de legalidade atinentes ao tema e do entendimento por parte da Anatel da oportunidade e conveniência de celebração de acordos substitutivos à sanção de multa, foram iniciados os trabalhos para a regulamentação da matéria, isto é, para o estabelecimento de procedimentos e padrões mínimos para a celebração dos compromissos de ajustamento de conduta.

Ao longo do processo regulamentar de Consulta e Audiência Públicas foi apresentado um grande número de contribuições. Ao todo foram 259 (duzentas e cinquenta e nove) contribuições $^{14}$. O percentual dos contribuintes por categoria é apresentado na

Figura $4.1^{15}$, abaixo:

14 Segundo apresentado pelo Informe $n^{\circ}$ 12/2013-COQL/PRRE/SCO/SPR de 08/08/2013. 15 Segundo apresentado pelo Informe no 12/2013-COQL/PRRE/SCO/SPR de 08/08/2013. 
Figura 4.1. Contribuições à Consulta Pública da Anatel

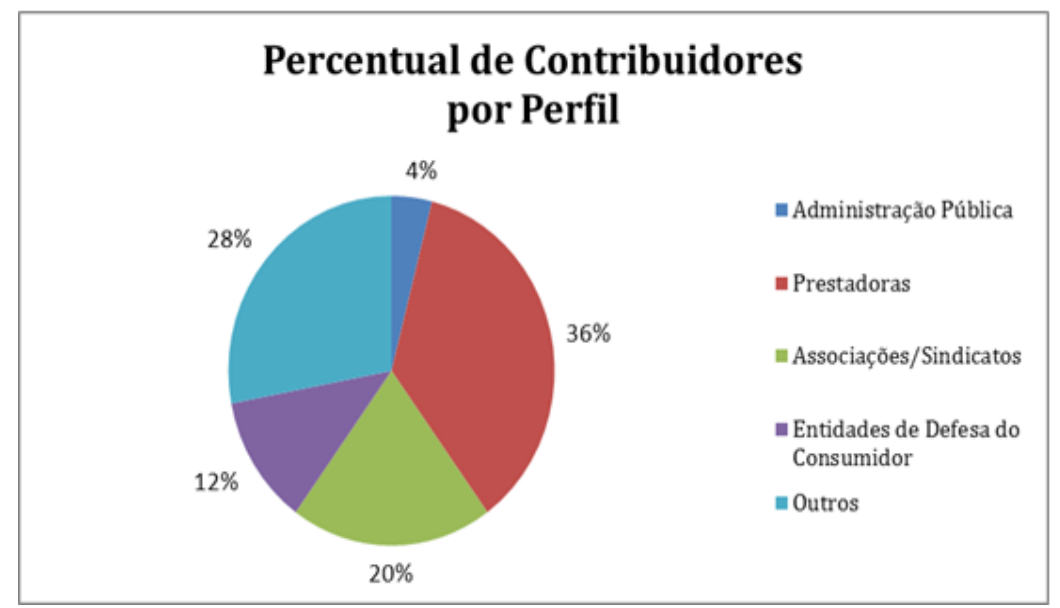

Fonte: Anatel

O gráfico revela que as prestadoras foram os principais participantes na Consulta Pública. Todavia a participação de Associações/Sindicatos juntamente com Entidades de Defesa do Consumidor perfaz um percentual igualmente relevante (32\%), o que demonstra pelo menos dois pontos que merecem destaque: a importância do tema para os mais variados segmentos da sociedade e a legitimidade do processo de regulamentação levado a cabo pela Anatel.

Relativamente aos temas das Contribuições, a Figura 4.2 abaixo ${ }^{16}$ apresenta a distribuição percentual:

Figura 4.2. Temas da Consulta Pública da Anatel

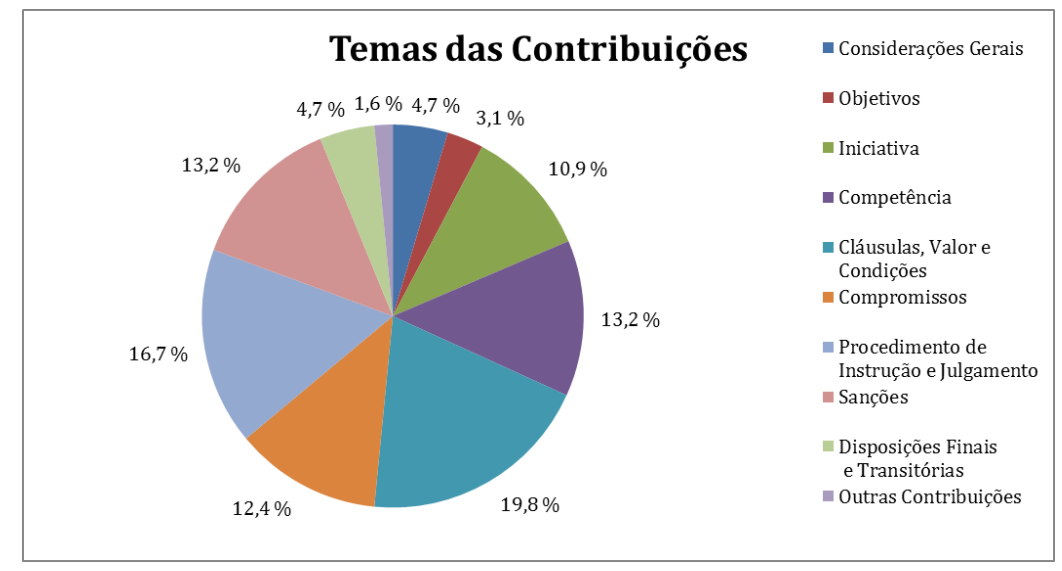

Fonte: Anatel 
Os temas "Cláusulas, Valor e Condições" e "Procedimento de Instrução e Julgamento" foram os que receberam o maior número de contribuições, perfazendo os dois itens conjuntamente mais de um terço das contribuições, o que era esperado tendo em vista a relevância desses temas para a celebração e implementação dos TACs.

A proposta inicial trazia como elemento central a ideia de que a celebração do TAC estava legalmente amparada e se constituía em uma solução mais adequada do que simplesmente litigar com os infratores até que estes pagassem as multas ou a justiça deliberasse. Todavia, a mecânica ou os procedimentos para celebração trazia para a Agência a responsabilidade de arbitrar elementos bastante complexos dos planos de negócios, fato que trazia embutido um risco elevado de ineficiência e risco moral.

Como é apresentada na literatura econômica ${ }^{17}$ a atividade regulatória é permeada de problemas de informação. No caso em tela percebia-se que a proposta em consulta não buscava mitigar os problemas de assimetria de informação e seleção adversa, o que aumentava as chances de alocações ineficientes dos recursos, exatamente um dos problemas que se visava corrigir.

No que tange ao problema de perigo moral, a proposta de regulamentação procurou endereçar na Seção III do Capítulo IV - Do Descumprimento do TAC - medidas que visavam reduzir os potenciais desvios de conduta pós-assinatura do Termo de Ajustamento de Conduto (contrato).

Todavia, como é sabido da literatura econômica sobre Informação, ao se tratar o problema de Perigo Moral o principal deve desenhar um contrato ${ }^{18}$ que induza o agente a escolher o nível de esforço que o Estado deseja implementar.

Assim, o problema do principal, neste caso representado pela Anatel, considerando um cenário de informação assimétrica, deve considerar duas restrições: a restrição de participação e a restrição de incentivos. Na referida proposta de regulamentação não fica clara a existência de regras que enderecem as duas restrições.

Após todo o processo de discussão, tanto internamente como com a sociedade, acerca dos principais dispositivos constantes da versão final da norma foi formulada proposta que buscava atacar os principais problemas de informação, mas não houve um avanço pleno na direção de um mecanismo que, por assim dizer, endereçasse o tratamento dos problemas de informação e 
favorecesse a otimização na alocação dos recursos no setor, o que será detalhadamente apresentado neste Capítulo 4.

Nas seções seguintes apresentar-se-á, de forma pormenorizada, a evolução do debate acerca do controle de obrigações e do processo de sancionamento, ao longo dos anos de atuação da Anatel, incluindo as evidências quantitativas do problema identificado, o que resultou em discussões no âmbito do regulamento de sanções que introduziram de forma definitiva, no arcabouço regulamentar, a possibilidade de celebração de TACs pela Anatel com os infratores, a seu critério e no âmbito de suas competências visando ao melhor atendimento ao interesse público.

A seção 4.2.3 se encarregará de detalhar as principais discussões no âmbito da Consulta Pública relacionadas à inclusão de dispositivo que permitisse a celebração de TAC pela Anatel.

\subsubsection{Histórico da regulamentação sobre sanções administrativas}

Em julho de 2003, por meio da Resolução n 344/03, foi aprovado o Regulamento de Aplicação de Sanções Administrativas da Agência Nacional de Telecomunicações, com o objetivo de estabelecer parâmetros e critérios para a aplicação de sanções administrativas em decorrência de infrações referentes às Leis, regulamentos e demais normas aplicáveis ao setor de telecomunicações, bem como em consequência da inobservância dos deveres decorrentes dos contratos de concessão ou dos atos e termos de permissão e de autorização de serviço ou dos atos de autorização de uso de radiofrequência.

Em seguida foi criado um grupo de trabalho no âmbito da Anatel, cujo objetivo era o de propor normas complementares ao Regulamento de Sanções, em cumprimento às disposições de seu artigo $25^{19}$.

Referido grupo de trabalho realizou estudos ao longo dos anos 2003 e 2004, tendo como foco o desenvolvimento de fórmulas e algoritmos para o cálculo de multas. Em decorrência da

19 Art. 25. Devem ser objeto de normas específicas, elaboradas de acordo com os parâmetros e critérios previstos neste Regulamento, as gradações e sanções das infrações relativas:

I - à prestação de serviços de telecomunicações, incluindo, no que tange aos aspectos técnicos, os serviços de radiodifusão;

II - ao direito de exploração de satélite;

III - ao uso de radiofreqüência; e

IV - aos demais regulamentos e normas, no que couber. 
apreciação pelo órgão de consultoria jurídica surgiram questionamentos acerca da legalidade da proposta, o que levou à constituição de novo grupo de trabalho.

No segundo semestre de 2004, foi constituído outro grupo de trabalho formado por procuradores federais em exercício na Anatel. O resultado dos trabalhos foi a manifestação pela necessidade de alteração do Regulamento de Sanções e de seus anexos. Foi também apresentada a sugestão de elaboração de instrumento contendo a metodologia para aplicação de sanções, em especial do cálculo do valor da multa, de modo a permitir a orientação e uniformização da aplicação das sanções no âmbito da Agência.

Nos anos de 2006 e 2007 foram redigidos novos estudos visando aperfeiçoar o regulamento, o que resultou no encaminhamento de nova minuta de proposta de alteração do Regulamento de Sanções para as instâncias deliberativas da Agência.

No início de 2008, a Anatel colocou em consulta pública a nova minuta de proposta de Regulamento de Aplicação de Sanções Administrativas.

Por fim, após o processo interno de avaliação dos documentos afetos à proposta de regulamentação, foi aprovado o novo regulamento de sanções por meio da Resolução n. ${ }^{\circ} 589$, de 7 de maio de 2012.

\subsubsection{Evidências quantitativas dos problemas das Multas}

O cenário de evolução das multas, destacado anteriormente, ao logo dos anos tem gerado preocupação por parte dos principais atores do mercado de Telecomunicações (Governo, prestadores, órgãos da sociedade civil etc.), conforme manifestações apresentadas por veículos de comunicações já citados.

Uma das principais discussões está atrelada à relação entre os objetivos traçados pela regulamentação e a percepção de valor pelos consumidores. Para o adequado desenvolvimento do setor, essa questão torna-se importante, pois poderá interferir na alocação eficiente dos recursos.

As 
Figura 4.3 a Figura 4.5, apresentadas a seguir, ilustram, em valores, a evolução temporal da dinâmica de fiscalização-sancionamento no setor de telecomunicações.

Figura 4.3. Evolução das multas por natureza

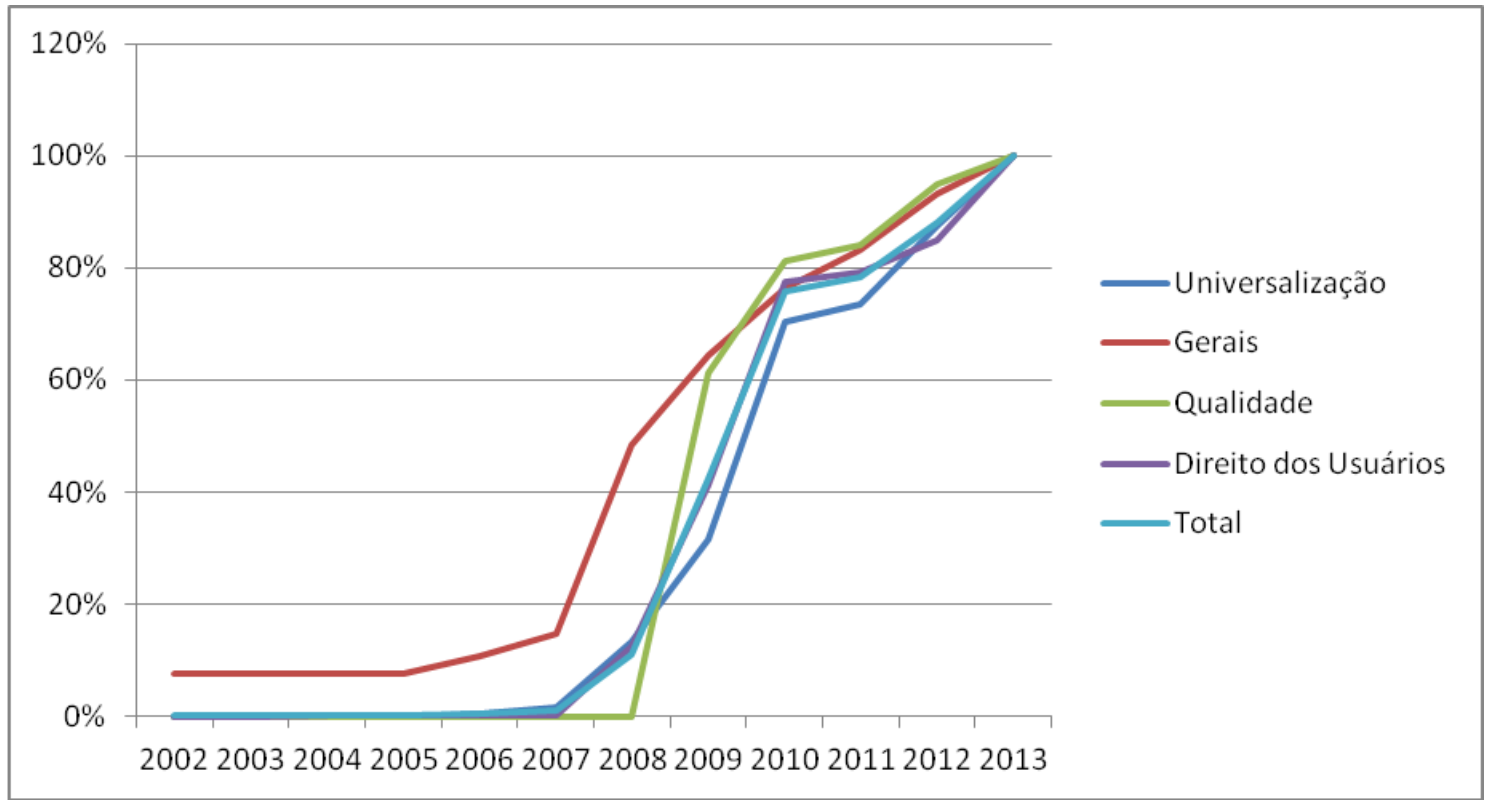

Fonte: Anatel

A partir do gráfico acima, pode-se destacar que o volume de sanções aplicadas experimentou um expressivo crescimento a partir do ano de 2007. Esse fato está ligado a, pelo menos, dois eventos: (i) o ingresso do corpo de concursados na Agência e (ii) a vinculação da remuneração variável dos servidores a metas de instrução processual, o que promoveu maior dinamismo no trâmite processual. Ou seja, inúmeros processos instaurados em anos anteriores (2000 a 2006) que estavam pendentes de encaminhamento tiveram seu curso processual normalizado.

Esse fato trouxe para o setor de telecomunicações um cenário indesejado, uma vez que um dos objetivos centrais do mecanismo de fiscalização-sancionamento, o efeito educativo, para que eventos irregulares não voltem a acontecer, ficou comprometido, dada a concentração temporal das decisões. 
Assim, as condutas irregulares que caso tivessem sido sancionadas tempestivamente poderiam ter sua reincidência evitadas e a concentração temporal dos valores sancionados tornaram-se motivo de questionamento pelo setor, uma vez que não tiveram a possibilidade de ajustar sua conduta em face de uma notificação tempestiva.

A Figura 4.4 abaixo evidencia o crescente descolamento entre a constituição das multas e sua arrecadação, sinalizando um aumento, possivelmente sem limite, do montante de multas constituídas caso não haja alteração nas condições de funcionamento do sistema.

O acúmulo das sanções, em alguns casos, tem feito surgir problemas relacionados à continuidade da prestação dos serviços, uma vez que o valor das sanções tem representado uma fração importante do passivo das companhias, chegando, no caso de uma prestadora, a patamar expressivo vis-à-vis ao seu valor de mercado. 


\section{Figura 4.4. Multas constituídas e $\operatorname{arrecadadas}^{20}$}

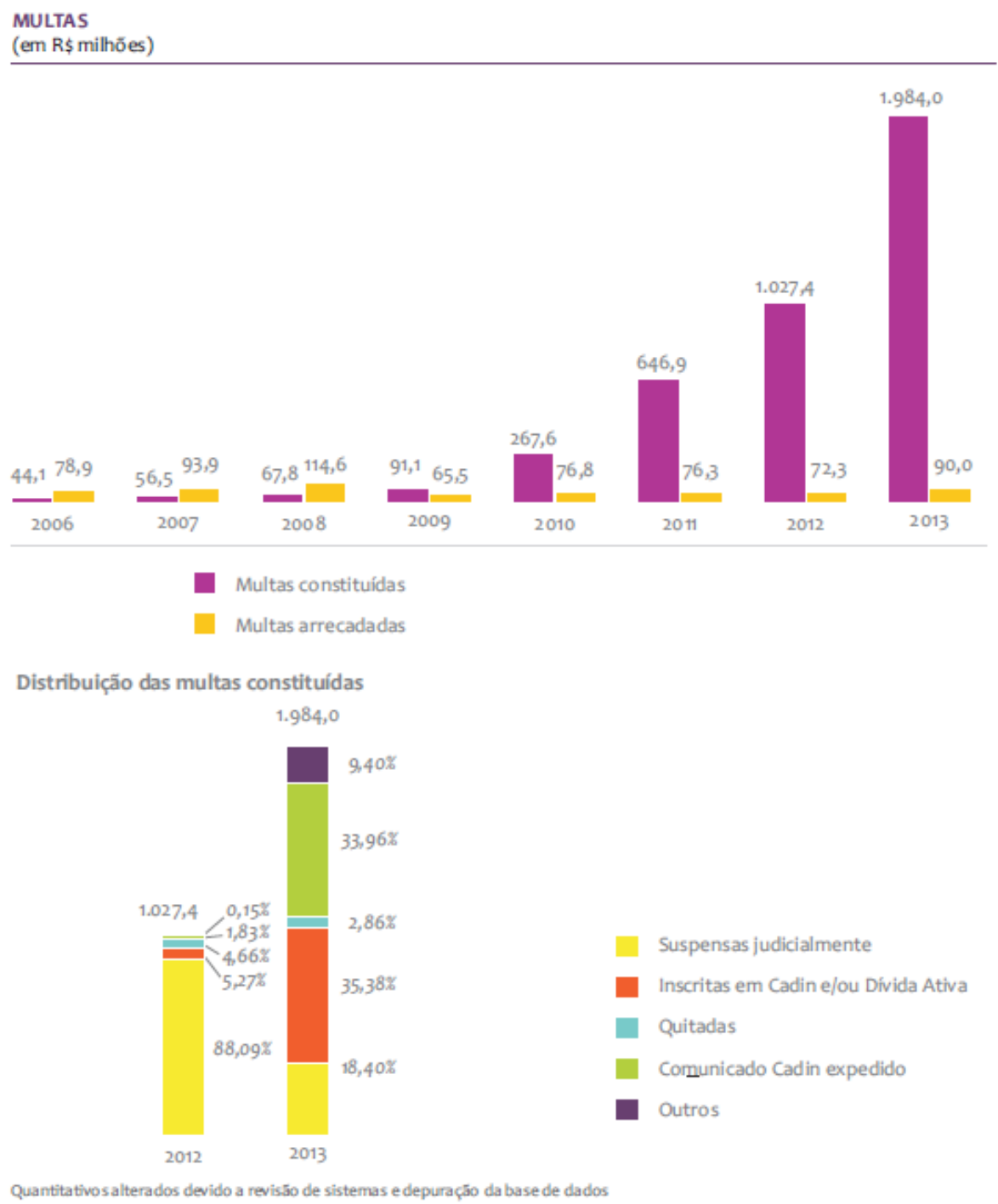

Fonte: Anatel

A tabela contida na Figura 4.5, por sua vez, apresenta para o período de 2000 a 2012 as multas constituídas divididas em arrecadadas, arrecadadas parcialmente e não arrecadadas distribuídas pelas diferentes situações: suspensas judicialmente, parceladas, Cadin e/ou Dívida Ativa, Comunicado Cadin expedido, Comunicado Cadin pendente de expedição.

A partir da tabela pode-se inferir acerca das inúmeras fases que o processo passa na esfera administrativa. Todo esse processo, por sua vez, implica custos, além de não agregar valor algum para o processo produtivo, nem para os consumidores. Pelo contrário, representa um custo elevado e sem qualquer expectativa de retorno para o negócio finalístico das prestadoras, a prestação dos serviços de telecomunicações.

20 Fonte: Relatório Anual Anatel, 2013. 
Figura 4.5. Multas Constituídas ${ }^{21}$

\begin{tabular}{|c|c|c|c|c|}
\hline \multicolumn{5}{|c|}{$\begin{array}{l}\text { Multas CONSTITUÍDAS ANATEL } \\
\qquad(2000-2013)\end{array}$} \\
\hline \multicolumn{5}{|c|}{ Montante Arrecadado Integralmente } \\
\hline \multirow{2}{*}{ Situação } & \multicolumn{2}{|c|}{ Financeiro } & \multicolumn{2}{|l|}{ Físico } \\
\hline & Em R\$s & Participação & Quantidade de multas & Participação \\
\hline Multas Arrecadadas & $550.479 .808,98$ & $12,69 \%$ & 24.060 & $57,74 \%$ \\
\hline \multicolumn{5}{|c|}{ Montante Arrecadado Parcialmente } \\
\hline \multirow{2}{*}{ Situação } & \multicolumn{2}{|c|}{ Financeiro } & \multicolumn{2}{|l|}{ Físico } \\
\hline & Em R\$ & Participação & Quantidade de multas & Participação \\
\hline Suspensas judicialmente & $2.643 .654,60$ & $0,06 \%$ & 7 & $0,02 \%$ \\
\hline Parceladas & $112.878,42$ & $0,00 \%$ & 152 & $0,36 \%$ \\
\hline CADIN e/ou Divida Ativa & $418.873,50$ & $0,01 \%$ & 575 & $1,38 \%$ \\
\hline Comunicado (CADIN) expedido & $129.038,88$ & $0,00 \%$ & 93 & $0,22 \%$ \\
\hline $\begin{array}{l}\text { Comunicado (CADIN) em fase de } \\
\text { notificação }\end{array}$ & $16.881,61$ & $0,00 \%$ & 18 & $0,04 \%$ \\
\hline Subtotal & $3.321 .327,01$ & $0,07 \%$ & 845 & $2,03 \%$ \\
\hline \multicolumn{5}{|c|}{ Montante Não Arrecadado } \\
\hline \multirow{2}{*}{ Situação } & \multicolumn{2}{|c|}{ Financeiro } & \multicolumn{2}{|l|}{ Físico } \\
\hline & Em R\$ & Participação & Quantidade de multas & Participação \\
\hline Suspensas judicialmente & $2.102 .77^{8.319,65}$ & $48,49 \%$ & 664 & $1,59 \%$ \\
\hline Parceladas & $4 \cdot 139 \cdot 509,34$ & $0,10 \%$ & 705 & $1,69 \%$ \\
\hline CADIN e/ou Dívida Ativa & $791 \cdot 349 \cdot 223,95$ & $18,25 \%$ & $13 \cdot 415$ & $32,19 \%$ \\
\hline Comunicado (CADIN) expedido & $697.883 .688,42$ & $16,09 \%$ & 1.378 & $3,31 \%$ \\
\hline $\begin{array}{l}\text { Comunicado (CADIN) em fase de } \\
\text { notificação }\end{array}$ & $187 \cdot 134,702,09$ & $4,31 \%$ & 602 & $1,44 \%$ \\
\hline Subtotal & $3.7^{8} 3 \cdot 285 \cdot 443,45$ & $87,24 \%$ & 16.764 & $40,23 \%$ \\
\hline TOTAL & $4 \cdot 337.086 .579,44$ & $100,00 \%$ & 41.669 & $100,00 \%$ \\
\hline
\end{tabular}

Os montantes integralmente e parcialmente arrecadados correspondem ao valor principal recolhido, sem o acréscimo de juros e correção monetária.

o montante ainda não arrecadado corresponde ao saldo devedor principal, desconsiderando os acréscimos moratórios.

Fonte: Sigec

Fonte: Anatel

Diante dessa realidade, a iniciativa da Agência em discutir um mecanismo, o Termo de Ajustamento de Conduta, para favorecer a adequação das prestadoras à regulamentação e de promover investimentos no setor torna-se interessante e oportuna, restando necessário atentar ao adequado desenho do mecanismo para sua implementação.

Por sua vez, o presente trabalho, ao buscar propor um mecanismo mais eficiente para a celebração dos Termos de Ajustamento de Conduta traz uma contribuição importante para a sistemática de alocação mais eficiente dos recursos no setor.

21 Fonte: Relatório Anual Anatel, 2013. 


\subsubsection{A Consulta Pública do Regulamento de Sanções Administrativas: As discussões avançam para o TAC}

A Consulta Pública do Regulamento de Sanções de 2007, n 847/2007, recebeu 197 (cento e noventa e sete) contribuições, em sua grande maioria advindas das prestadoras de serviços de telecomunicações, associações ou entidades representativas de prestadoras. Entretanto, a consulta pública contou ainda com a participação de outros atores da sociedade, como escritórios de advocacia, servidores da Anatel, entidade de defesa do consumidor, associações de outra natureza e de usuário de serviços de telecomunicações.

A avaliação das contribuições recebidas contou com o amparo de doutrinas variadas e um exame sistemático das normas legais e infralegais aplicáveis à Anatel.

A partir do referencial citado, foi possível formar consensos sobre grande parte dos pontos em análise. Todavia, os pontos não passíveis de consenso foram encaminhados para a deliberação das autoridades com a devida fundamentação das opções existentes.

Dentre as contribuições recebidas, pode-se destacar àquela relacionada à inserção de item explicitando a possibilidade de celebração de Termos de Ajustamento de Conduta (TAC), conforme descrito a seguir.

\subsubsection{Inserção de item explicitando a possibilidade de celebração de termos de ajustamento de conduta (TAC):}

Houve um elevado número de contribuições que propôs explicitar, no Regulamento de Sanções, a possibilidade de celebração de termos de ajustamento de conduta (TAC) com os administrados, salientando que esse instrumento permitiria estabelecer meios para compensar a reparação de eventual dano ou evitar a sua persistência, ajustando a conduta do administrado à lei e evitando, assim, a aplicação de sanções.

Conforme argumentado anteriormente, a possibilidade legal de celebração, pela Anatel, de Termos de Ajustamento de Conduta, decorre da interpretação sistemática dos dispositivos:

- $\mathrm{O}$ artigo $5^{\circ}, \S 6^{\circ}$ da Lei n. ${ }^{\circ} 7.347 / 85$ (Lei da Ação Civil Pública), que, na redação dada pela Lei n. ${ }^{\circ} 8.078 / 90$, dispõe: 


\section{Art. 5으. (...)}

§ 60 Os órgãos públicos legitimados poderão tomar dos interessados compromisso de ajustamento de sua conduta às exigências legais, mediante cominações, que terá eficácia de título executivo extrajudicial.

- O artigo $19^{\circ 22}$, inciso XVIII da LGT, conjugado com os termos do artigo $19^{\circ}$ e parágrafo único do Decreto $\mathrm{n}^{\circ}$ 2.338/97 (Regulamento da Anatel) ${ }^{23}$, de onde é possível depreender a legitimidade da Anatel, no âmbito de matérias relativas ao Direito do Consumidor, para celebrar Termos de Compromisso de Ajustamento de Conduta, conforme disciplinado pelo Decreto $n^{\circ} 2.181 / 97^{24}$.

Considerando, portanto, a legislação vigente foi possível concluir que a Agência é plenamente legítima para promover a celebração de compromissos de ajustamento de conduta em matérias relativas à defesa do consumidor e fornecer os principais parâmetros para sua efetiva celebração.

Com base nas contribuições recebidas e no arcabouço jurídico-regulatório positivado, no Brasil, a Anatel avaliou oportuno tornar explícita nas normas setoriais, a possibilidade genérica de celebração de TACs nos termos previstos pela legislação, sem prejuízo de futura regulamentação do tema ${ }^{25}$.

Assim, foi incluído no Regulamento de Sanções o artigo $5^{\circ}$ que reproduz parcialmente o disposto no caput do art. $5^{\circ}$ da lei $7347 / 85$ e no art. $6^{\circ}$ do decreto $\mathrm{n}^{\mathrm{a}} 2181 / 97$, conforme transcrito a seguir:

22 Art. 19. À Agência compete adotar as medidas necessárias para o atendimento do interesse público e para o desenvolvimento das telecomunicações brasileiras, atuando com independência, imparcialidade, legalidade, impessoalidade e publicidade, e especialmente: (...)

XVIII - reprimir infrações dos direitos dos usuários; (...)".

23 Art. 19. A Agência articulará sua atuação com a do Sistema Nacional de Defesa do Consumidor, organizado pelo Decreto $\mathrm{n}^{\circ}$. 2.181, de 20 de março de 1997, visando à eficácia da proteção e defesa do consumidor dos serviços de telecomunicações, observado o disposto nas Leis $\mathrm{n}^{\circ} .8 .078$, de 11 de setembro de 1990, e $\mathrm{n}^{\circ} .9 .472$, de 1997. Parágrafo único. A competência da Agência prevalecerá sobre a de outras entidades ou órgãos destinados à defesa dos interesses e direitos do consumidor, que atuarão de modo supletivo, cabendo-lhe com exclusividade a aplicação das sanções do art. 56, incisos VI, VII, IX, X e XI da Lei n ${ }^{\circ} .8 .078$, de 11 de setembro de 1990.

24 Art. $6^{\circ}$. As entidades e órgãos da Administração Pública destinadas à defesa dos interesses e direitos protegidos pelo Código de Defesa do Consumidor poderão celebrar compromissos de ajustamento de conduta às exigências legais, nos termos do parágrafo $6^{\circ}$ do art. $5^{\circ}$ da Lei 7.347, de 1985, na órbita de suas respectivas competências. 
"A Anatel poderá, na órbita de suas competências de defesa dos interesses e direitos do consumidor, celebrar compromissos de ajustamento de conduta às exigências legais, mediante cominações, que terão eficácia de título executivo extrajudicial".

Na seção subsequente, serão apresentados os princípios norteadores da regulamentação do Termo de Ajustamento de Conduta, o tratamento dado ao objeto central da norma, qual seja, a definição dos compromissos no âmbito dos TACs. Por fim, serão apresentadas considerações sobre os principais pontos da norma, buscando-se avaliar como foram endereçados os problemas de informação e estabelecidos os incentivos e identificar oportunidades para a melhoria, objeto de contribuição do presente trabalho a ser tratado na seção 5. 


\subsection{A solução apresentada: uma descrição com análise crítica}

A proposta de regulamentação do Termo de Ajustamento de Conduta visou regulamentar o art. $5^{\circ}$ do regulamento de Aplicação de Sanções Administrativas (RASA) aprovado pela resolução $\mathrm{n}^{\text {o }} 589$ de 07/05/2012 que conforme esclarecido anteriormente, positivou a possibilidade de celebração de termos de ajustamento de conduta, substitutivos à aplicação de sanções, pela Anatel.

Após trâmites internos ao órgão regulador, incluindo toda a fase de instrução processual e aprovação das instâncias deliberativas, a minuta de Norma para submissão à consulta pública foi aprovada pelo conselho diretor.

A consulta pública 13/2013 foi realizada num período de 60 (sessenta) dias a partir do dia 11/03/2013, contando, inclusive com a realização de uma audiência pública, na sede da Anatel, em Brasília, realizada no dia 08/05/2013. Foram apresentadas 259 (duzentos e cinquenta e nove) contribuições de diversos atores da sociedade, conforme apresentado na figura 4.1.

Concluído o período de consulta, a Anatel procedeu à análise das contribuições, bem como a todos os trâmites necessários à aprovação do novo regulamento. Ressaltem-se aqui a emissão de parecer pela Procuradoria Federal Especializada e as alterações promovidas no sentido de ajustar pontos levantados pelo órgão de consultoria jurídica, anteriormente à apreciação do conselho diretor.

De posse dos autos o conselheiro relator apresentou sua análise acerca da proposta remetida pela área técnica, com ajustes recomendados pela procuradoria, promovendo alterações (inclusões e exclusões) no texto da norma.

Em seguida, a minuta de norma foi apreciada pelos demais membros do conselho e deliberada na reunião $n^{\circ} 724$ de 05/12/2013 e aprovada por meio da Resolução 629 de $16 / 12 / 2013$.

A seguir, nas subseções à presente seção, serão apresentados os principais pontos contidos no regulamento de celebração e acompanhamento de termo de compromisso de ajustamento de conduta como, por exemplo, o endereçamento dos problemas de informação, os incentivos e os mecanismos para transformação do passivo de multas em investimentos no setor de telecomunicações. 


\subsubsection{O regulamento de Termos de Ajustamento de Conduta: princípios gerais}

Primeiramente, vale destacar, conforme disposto na Análise 454/2013-GCRZ, de 22/11/2013, que a Anatel buscou tratar o regulamento do TAC com base em "premissas principiológicas", especialmente no que tange:

a) À transparência e clareza no processo de negociação de acordos; e

b) À previsibilidade e segurança na estipulação dos compromissos.

Relativamente ao item (a) a referida análise discorre de forma a caracterizar a importância de se garantir transparência e clareza aos processos regulatórios. Para tanto, faz referência às Recomendações da $\mathrm{OCDE}^{26}$ que destacam a importância de se proporcionar maior confiança às decisões regulatórias, bem como a importância de mecanismos que melhorem a transparência e construam credibilidade para a dinâmica de investimentos. Ademais, é também destacada a importância atribuída à transparência para o fortalecimento da Regulação no Brasil, conforme documentos do PROREG ${ }^{27}$.

Adicionalmente, a análise supracitada destaca a existência de acordos substitutivos em outros órgãos da administração pública e apresenta a experiência do CADE como referência por possuir uma atuação mais diversificada na celebração de acordos com empresas que estão submetidas ao seu espectro de competência, podendo-se destacar os seguintes instrumentos: Termos de Compromisso de Desempenho (TCOs), Acordos de Reversibilidade de Operação (Apros), Acordos de Leniência e Termos de Cessação de Conduta (TCC).

Ainda segundo a análise, o CADE passou por diversas fases de implementação de acordos com empresas sujeitas a sua regulamentação, sendo que atualmente o órgão conta com uma normatização bastante detalhada a respeito - Resolução CADE 5/2013.

A experiência do CADE na celebração de acordos caminhou no sentido de aperfeiçoar os mecanismos visando enfrentar os potenciais problemas de informação inerentes à atividade regulatória.

Considerando a experiência do CADE e as recomendações da OCDE quanto a acordos substitutivos tem-se que a Anatel poderá ao longo da implementação dos dispositivos

262012 Recommendation of the Council on Regulatory Policy and Governance e Policy Framework for Investment (PFI) Toolkit.

27 Programa de Fortalecimento da Capacidade Institucional para a Gestão em Regulação. Decreto $\mathrm{n}^{\circ} 6062$ de $16 / 03 / 2007$. 
regulamentares e de eventual revisão da matéria se apropriar de sua experiência acumulada bem como advindas de outros órgãos, contextualizando-a a sua realidade.

Do exposto, resta clara a importância atribuída à transparência, à clareza e à objetividade para o êxito na aplicação do regulamento do TAC, uma vez que tanto o poder público como as empresas reguladas e a sociedade civil como um todo poderão ter mais segurança quanto aos resultados esperados dos acordos firmados, diferentemente de um cenário dominado pela discricionariedade e por negociações bilaterais caso a caso.

Relativamente ao item (b) cabe ressaltar que um dos objetivos da norma aprovada foi afastar as incertezas e imprevisibilidade dos termos e condições de um acordo a ser pactuado, evitando, assim, um cenário atualmente comum à Administração Pública quando da realização de negociações e estipulação de compromissos e obrigações exigíveis, no âmbito de processos administrativos que apesar de visarem ao bem público podem conduzir a resultados subótimos em função da assimetria de informação presente nas relações com particulares.

\subsubsection{O regulamento de Termos de Ajustamento de Conduta: objeto central dos Termos de Ajustamento de Conduta}

No que tange ao objeto central da regulamentação, qual seja a definição dos compromissos contemplados na celebração dos Termos de Ajustamento de Conduta, a norma assim os dividiu:

- Compromissos de ajustamento de conduta irregular que estão relacionados à regularização da conduta em conformidade com a regulamentação, à reparação dos usuários prejudicados e à prevenção de novas condutas infratoras;

- Compromissos adicionais: os quais não estão necessariamente atrelados ao objeto da infração, os quais foram, assim, subdivididos:

- Concessão de benefícios temporários diretamente aos consumidores; e

- Execução de projetos, escolhidos de um rol (menu de contratos) previamente definido pela Anatel com seus respectivos valores presentes líquidos (VPLs) ou propostos pelas interessadas em conformidade com as diretrizes finalísticas emanadas do próprio regulamento. 
O objetivo de fixação do rol de projetos, segundo o órgão regulador, foi exatamente o de superar incertezas e outras dificuldades decorrentes dos problemas de informação inerentes ao processo regulatório.

No cenário alternativo, onde a prestadora apresenta projetos à avaliação e aprovação da Anatel, só são admitidos aqueles projetos com VPLs negativos e que estejam vinculados a algum dos seguintes temas: atendimento à área de baixo desenvolvimento econômico e social, redução das diferenças regionais, modernização das redes de telecomunicações, elevação dos padrões de qualidade, conforme apresentado no art. $22^{\circ}$ da Resolução 629 de 16/12/2013:

Art. 22. Os projetos do art. 19 deverão observar as seguintes diretrizes:

I - atendimento a áreas de baixo desenvolvimento econômico e social, por meio de ampliação da capacidade, capilaridade ou cobertura das redes de telecomunicações;

II - redução das diferenças regionais;

III - modernização das redes de telecomunicações;

$I V$ - elevação dos padrões de qualidade propiciados aos usuários; $e$,

$V$ - massificação do acesso às redes e aos serviços de telecomunicações que suportam acesso à internet em banda larga.

A Agência sustentou que essa modelagem seria viável e resolveria os potenciais problemas de informação, alegando ter reconhecida expertise na elaboração de planos de negócios para fins de edital de licitação de frequência.

Segundo a lógica defendida pelo órgão regulador, quanto menor a viabilidade econômica dos projetos maior seria o montante de multas a ser abatido.

Destaca-se que visando incentivar o desenvolvimento de projetos que venham a reduzir as desigualdades sociais e regionais a Agência atribuirá a projetos dessa natureza maior fator de desconto das multas.

Outro comportamento que se buscou incentivar foi o de propositura de negociação nas fases iniciais da tramitação processual por meio da concessão de maiores descontos nos valores de multa.

Acerca do exposto, pode-se destacar que apesar dos esforços envidados pelo órgão regulador, o mecanismo proposto padece da necessidade de robustez, sobretudo no que tange ao grande potencial de "erro de medida" quando do cálculo ou validação dos valores de VPL dos 
projetos, tanto daqueles pertencentes ao rol a ser disponibilizado pela Agência como daqueles a serem submetidos pelas prestadoras.

A despeito da capacidade do corpo técnico da Anatel, sabe-se que a relação reguladoregulador, conforme amplamente apontado na literatura, é permeada de assimetria de informação, o que torna difícil para o regulador ser assertivo/preciso quanto ao cálculo dos VPLs dos planos de negócios para cada projeto.

Os erros de medida ou avaliação no caso das licitações de radiofrequências podem ser tolerados, pois o procedimento licitatório tem a capacidade de corrigi-los, isto é, a licitação recupera o mecanismo de mercado, produzindo uma correta precificação e a maximização do lucro para o vendedor ou a eficiência de Pareto, no sentido de que o objeto é destinado ao agente que atribui maior valor. (Varian, 2000, Krishna, 2002, Krishna 2009)

Neste sentido, o presente trabalho buscará contribuir com o processo de regulamentação do TAC proposto pela Anatel, podendo servir de referência para os demais órgãos da Administração Pública que venham a ter interesse na utilização de mecanismos de solução negociada, através da proposição de um mecanismo que seja apto a lidar com potenciais problemas de informação e gere incentivos compatíveis com os objetivos do poder público que em última análise é responsável por incorporar as demandas da sociedade.

\subsubsection{O regulamento de Termos de Ajustamento de Conduta: principais dispositivos, os problemas de informação e os mecanismos de incentivo}

Nesta subseção serão destacados, de forma sintética, os principais dispositivos do regulamento aprovado e como se relacionaram com os problemas de informação e a dinâmica de incentivos.

O regulamento foi construído segundo ditames da técnica legislativa e encontra-se estruturado em capítulos, seções, artigos, incisos e parágrafos. A presente exposição seguirá a agregação no nível de capítulos, fazendo, eventualmente referência a algum dispositivo quando necessário para a melhor compreensão.

O primeiro capítulo trata dos objetivos da Norma, os aspectos gerais para celebração dos termos de ajustamento de conduta tais como: a fundamentação legal que resguarda a 
competência da Anatel para atuar nesta matéria e a eficácia do TAC como título executivo extrajudicial.

O segundo capítulo do regulamento aborda todos os delineamentos a serem observados quando da propositura de compromissos de ajustamento de conduta, também conhecido como requisitos para a admissibilidade do pleito negocial, além de detalhar o trâmite processual interno, tanto no âmbito das superintendências como no âmbito deliberativo do conselho diretor.

Neste capítulo são estabelecidas algumas regras que buscam gerar incentivo à rápida resolução do problema identificado, ainda antes da decisão de primeira instância e estabelecer também incentivos no sentido de que os termos dos TACs sejam efetivamente cumpridos, sob pena de impossibilidade de se acessar tal mecanismo.

No capítulo terceiro encontram-se consignados os requisitos de mérito para a celebração do TAC, tais como: as cláusulas necessárias, a delimitação das espécies de compromissos que devem ser contemplados no ajuste, bem como sua composição e a vinculação deste com o montante de multas aplicadas ou estimadas envolvidas na contrapartida aos elementos contidos no TAC.

Trata-se, portanto, da parte central da norma, sobretudo quando avaliamos pela ótica econômica, na medida em que aborda as cláusulas, valor, condições e compromissos.

Na seção I são apresentados os dispositivos relacionados às cláusulas que devem constar do instrumento a ser celebrado, ao valor e às condições para a execução do objeto do TAC, bem como à punição em caso de descumprimento, uma espécie de incentivo "negativo" (reforço negativo).

Cabe ressaltar que o valor de referência ${ }^{28}$ a ser utilizado para fins do TAC não poderá ser inferior a $0,25 \%$ (zero vírgula vinte e cinco por cento) da receita operacional anual da compromissária ponderada pela área de abrangência do TAC e que deverá ser avaliado se o acordo está alinhado ao interesse público.

Trata-se de uma restrição atrelada à significância do volume sancionado que tem por objetivo evitar que valores muito pequenos sejam objeto tratamento, cujo benefício para a

28 Para fins de definição do valor de referência dos TACs serão considerados os valores de multa corrigidos, conforme a regulamentação, até a data da decisão do Conselho Diretor que aprova sua celebração. 
sociedade poderia ser inferior ao custo incorrido pela administração pública, o que feriria o princípio da economicidade.

Na seção II, a norma trata especificamente dos compromissos que deverão constar das cláusulas do TAC e as dividiu em dois grupos:

a) Compromissos de ajustamento de conduta irregular;

b) Compromissos adicionais:

i. Execução de projetos;

ii. Concessão temporária de benefícios diretos a usuários.

Em seguida, nos artigos $19^{\circ}$ e $20^{\circ}$ são detalhados os percentuais mínimos do valor de referência do TAC para a execução de projetos e concessão temporária de benefícios diretos aos usuários, respectivamente, considerando um incentivo para que os acordos sejam firmados antes da decisão de primeira instância, reduzindo assim o custo de carregamento processual e acelerando a solução dos problemas identificados.

Há que se ressaltar que os projetos deverão apresentar VPLs negativos e que a depender do impacto do projeto na redução de desigualdades sociais e regionais e seu enquadramento como projeto estratégico poder-se-á utilizar um multiplicador do VPL negativo, entre 1 (um) e 2 (dois), para fins de abatimento das multas.

O capítulo 4 trata basicamente do acompanhamento da execução do TAC, da verificação de seu cumprimento e das sanções.

A seção 1 do referido capítulo explicita o órgão responsável por acompanhar a execução dos compromissos do TAC, bem como a sistemática para seu acompanhamento.

$\mathrm{Na}$ seção 2, são apresentados, de forma detalhada, os procedimentos a serem implementados quando da constatação de indícios do descumprimento de itens do cronograma de metas e condições dos compromissos, incluindo a incidência de multa diária, o que visa mitigar os possíveis problemas na execução do acordado.

A seção 3, por sua vez, destaca o conceito de descumprimento e as medidas a serem adotadas quando verificado o descumprimento, bem como as sanções a serem impostas ao regulado. 
A seção 4 trata do cumprimento do TAC e da consequente emissão do certificado de cumprimento pelo órgão máximo de deliberação do regulador.

O capítulo 5 traz as disposições finais e transitórias, incluindo prazos e tratamento de situações de intersecção do regulamento do TAC com outros dispositivos regulamentares. 


\subsection{Uma breve revisão da literatura de leilões sequenciais de múltiplos objetos}

A realização de leilão, se considerado de forma ampla, remonta períodos antigos, mas o seu estudo de maneira científica é relativamente recente, tendo se iniciado, por assim dizer, com o trabalho seminal de Vickrey (1961) e desenvolvido progressivamente até os nossos dias para contemplar características distintas pertinentes ao ambiente de leilões.

Ao estudar a possibilidade de aplicação de mecanismos de leilão a problemas cotidianos, onde pessoas não sabem ao certo o valor a ser acordado sobre a venda de determinado bem, Ashenfelter (1989) destacou que a presença de um sistema de leilões permite a um vendedor desinformado acerca do preço do bem uma forma de obter um valor muito próximo ao valor de mercado pelo bem que possui.

Relativamente ao conceito do que vem a ser leilão, apesar das inúmeras definições de leilão, é possível registrar aquela contida em Menezes e Monteiro (2005) que define o referido a partir de sua propriedade central de ser um mecanismo de equilíbrio de mercado que iguala oferta e demanda, convergindo, portanto, com a ideia aventada por Ashenfelter.

Posto isso, passam-se a apresentar segmentos da literatura de leilões que serviram de base para a proposta de mecanismo apresentada a seguir.

\section{- Geral}

Riley e Samuelson (1981) considerando a evolução rápida, porém desigual, da literatura de leilões após o trabalho seminal de Vickrey (1961) e, tendo em vista que a implicação das diferentes regras dos leilões continuava ainda pouco conhecida, desenvolveu o presente trabalho visando prover um exame sistemático das diferentes formas de leilão. Para tanto, os autores utilizaram o modelo originalmente proposto por Vickrey e apresentaram uma caracterização geral das implicações dos diferentes desenhos de leilões sobre a alocação de recursos. Em particular os autores se ocuparam de duas questões naturais: Como se dá a competição entre poucos compradores nos leilões mais comuns? Como os preços selados são determinados? Como o vendedor pode melhor explorar sua posição de monopólio? A modelagem utilizada considerou o bem a ser leiloado indivisível, jogadores neutros ao risco, valores independentes e simetria entre os jogadores. Os principais resultados do trabalho são: demonstração de que as receitas esperadas dos diferentes tipos de leilões podem ser facilmente comparadas, o que implicou na apresentação da equivalência do leilão inglês (lances ascendentes) e o leilão Holandês (lance 
alto). Também foi mostrado que para uma ampla família de regras de leilão, a receita do leiloeiro é maximizada em qualquer um dos leilões comuns se o leiloeiro anunciar que não aceitará lances abaixo de um determinado preço de reserva. Segundo os autores, esse preço de reserva é independente do número de jogadores e sempre deverá ser estritamente maior que o valor atribuído pelo vendedor ao objeto. Importante ressaltar que os autores ainda fazem algumas modelagens alternativas flexibilizando alguns supostos.

Harris e Raviv (1981) estudaram duas questões principais. A primeira relativa à razão de se usarem leilões para alocação de recursos em certos ambientes e a segunda relacionada ao tipo de leilão mais eficiente. Após caracterizar o mecanismo ótimo, os autores fazem uma comparação entre os leilões competitivos e os leilões discriminatórios. Os autores concluíram que, relativamente à primeira questão, para ambientes simples qualquer mecanismo é equivalente para alguma forma de leilão selado. Relativamente à segunda questão, também em um contexto de ambientes simples, os autores caracterizaram um leilão "quasi-competitivo" que seria melhor para os leiloeiros. Por fim, destacaram que o trabalho realizado deveria ser visto como uma primeira tentativa de abordar as duas questões levantadas.

Myerson (1981) considerou em seu trabalho o problema de um vendedor que deseja vender um objeto para um ou mais compradores quando os vendedores têm informação imperfeita acerca de quanto os compradores estão dispostos a pagar pelo objeto. Desta forma, o problema do vendedor é desenhar um leilão que possua um equilíbrio que gere a maior utilidade esperada. Neste contexto, o autor apresenta leilões ótimos para uma classe ampla de problemas.

Benoit e Krishna (2001) avançam na discussão de importantes extensões para o caso de leilões de múltiplos objetos considerando a restrição orçamentária dos jogadores. Os autores consideram as hipóteses de que o vendedor com dois objetos encontra jogadores que estão sujeitos à restrição orçamentária. Os objetos são de valor comum para todos os jogadores, mas não necessariamente idênticos e podem ser tanto complementares como substitutos. Ademais, considerando um cenário de informação completa, os autores mostraram que: (1) é sempre ótimo vender o objeto mais valioso quando os objetos são vendidos por meio de leilões sequenciais de preços ascendentes; (2) para o caso de grande discrepância entre os valores dos bens ou se existir grande complementariedade o leilão sequencial gera mais receita para o leiloeiro do que o leilão simultâneo ascendente; (3) um leilão híbrido na forma "simultâneo-sequencial" apresenta receita superior ao leilão sequencial; e (4) a restrição orçamentária surge endogenamente. Por fim, os autores ressaltam que a presença de restrição orçamentária agrega muitas considerações aos 
leilões multi-objetos, na medida em que altera as estratégias dos jogadores e o interesse do vendedor para que o jogador mais rico vença o primeiro objeto. Ademais, considerar restrições orçamentárias em leilões multi-objeto, ainda que de maneira particular, pode ser considerado como permitir efeito renda, ou seja, a análise deles pode ser tida como um primeiro passo para uma consideração mais geral de leilões com efeito renda.

\section{- Preço de reserva em leilões}

Levin e Smith (1996) partindo de resultados apresentados por Riley e Samuelson (1981) e Myerson (1981) que mostravam um resultado curioso acerca do uso de preço de reserva no contexto modelos de leilões de valores independentes privados com risco neutro, qual seja, de que independentemente do número de jogadores, o vendedor deveria estabelecer um valor de reserva fixo acima de verdadeiro valor, o que indica que o vendedor extrairia ganho através do uso de procedimento ineficiente. Diante desse resultado os autores produziram o trabalho relaxando o suposto de valores independentes privados e derivando o valor de reserva ótimo para uma ampla classe de leilões, conseguindo demonstrar que quando a informação está correlacionada o preço ótimo de reserva para o vendedor converge para seu verdadeiro valor na medida em que o número de jogadores vai para infinito, geralmente de forma monótona e rápida. Por fim, os autores ressaltam que a competição pode servir como uma forma alternativa para reforçar a eficiência do leilão, ou seja, com informação correlacionada, o incentivo do vendedor de distorcer o mecanismo eficiente desaparece com o nível suficiente de competição e obtém-se, por consequência, a convergência do preço de reserva para o verdadeiro valor do vendedor e a redução a zero da eventual ineficiência.

Haile (2000), considerando o primeiro trabalho que modelou leilão com revenda (Milgron (1987)) e trabalhos subsequentes que mostraram que a oportunidade de revenda pode ter efeito importante sobre o leilão, incluindo as estratégias dos jogadores, o comportamento do vendedor e a interpretação dos dados de lances (Bikhchandani and Huang,1989; Gupta and Lebrun, 1997; Haile,1996,1999,2000), desenvolveu o presente trabalho com base nos anteriores, mas estendendo a análise para o caso em que os jogadores atribuem probabilidade positiva à aquisição do bem em um mercado secundário e identificando seus efeitos sobre o equilíbrio.

Blume e Heidhues (2004) caracterizaram um conjunto de equilíbrios de Nash para leilão de segundo preço com valores privados independentes e três ou mais jogadores. Ademais, os autores destacaram que um preço de reserva efetivo implica unicidade. O trabalho dos autores 
tratou de uma extensão de trabalhos anteriores, em particular ao tratar leilões de segundo preço com valores privados e mais de dois jogadores sem impor qualquer condição de regularidade às estratégias de equilíbrio, além da mensurabilidade.

Klemperer (2002) considerando as experiências de fracasso de muitas experiências de leilões realizados pelos países, em especial relacionadas às radiofrequências para a prestação de serviço móvel, identificou um problema de desenho do mecanismo de leilão e desenvolveu o presente trabalho com o objetivo de mostrar pontos relevantes para o sucesso dos leilões. Segundo o autor, o que de fato importa no desenho de leilões são as mesmas questões que qualquer regulador reconheceria como centrais: desencorajamento de conluio, dissuasão à entrada e comportamento predatório, ou seja, pontos elementares para a ciência econômica. $\mathrm{O}$ trabalho é desenvolvido por meio da apresentação de exemplos de possíveis armadilhas à modelagem e como contornar esses possíveis problemas.

Hu (2011) mostrou, conforme prova da Proposição 1, que para um cenário padrão de valores privados independentes e simétricos o preço de reserva ideal do vendedor apresenta-se como uma função decrescente do número de jogadores nos leilões de primeiro preço, num contexto de aversão ao risco, isto é, vendedor e/ou compradores avessos ao risco.

Özcan (2004) modelou um leilão sequencial de duas licenças para participar de um mercado oligopolista onde não havia incumbente. O modelo de leilão para a primeira licença foi o de primeiro preço com preço de reserva definido exogenamente. Já o segundo leilão considerou como preço de reserva o preço do primeiro item vendido (endógeno). O modelo segue o leilão do GSM realizado em 2000, na Turquia, para o setor de telecomunicações. Oportuno ressaltar que Klemperer ${ }^{29}$ (2002) identificou problemas em algumas modelagens de leilão como no caso da Turquia, indicando que as regras criadas favoreceram a criação de monopólio. Considerando os problemas identificados no leilão Özcan (2004) buscou analisar o seu setup. Inicialmente o autor trabalhou com dois agentes para simplificar a análise e em seguida estendeu para $n$ agentes. Os resultados obtidos apontam para o fato de que para determinados valores de parâmetros a receita gerada para o leiloeiro é igual ou inferior ao resultado de um leilão de segundo preço do direito de monopólio e para outros valores (possivelmente casos de forte externalidade de rede) a receita do leiloeiro é maior.

\footnotetext{
${ }^{29}$ Klemperer, Paul (2002). "What Really Matters in Auction Design,” Journal of Economic Perspectives-Volume 16, Number 1-Winter 2002-Pages 169-189
} 
Krishna (2009) destaca que em um leilão selado de segundo preço a introdução do preço de reserva não afeta a estratégia ótima dos jogadores, pois continua sendo uma estratégia fracamente dominante bidar o seu valor. Todavia, para o caso do leilão de primeiro preço é perceptível a necessidade de ajuste na análise em particular no caso de $\beta^{\mathrm{I}}(\mathrm{r})=\mathrm{r}$.

De acordo com material da universidade de Stanford a inclusão do preço de reserva (PR) atua como um potencializador da competição, tendendo a tornar os participantes mais fortes mais agressivos em seus lances e os mais fracos mais competitivos. O material destaca a existência de um trade-off na definição do preço de reserva, qual seja, da possibilidade de não se efetivar a negociação do bem, quando os valores forem menores do que o PR, fazendo com que a busca pela maximização da receita esperada do vendedor possa conduzir à ineficiência, o que tornaria o mecanismo que busque maximizar a receita esperada não ser VCG-M.

Relativamente ao efeito do sigilo do preço de reserva Milgrom e Weber (1982), em artigo seminal apresentaram entendimento de que sob a ótica da receita esperada a divulgação do preço de reserva seria melhor que o seu sigilo.

No mesmo sentido Silva (2011) conclui em seu trabalho que os resultados de seus estudos não conseguem contrapor o trabalho de Milgrom e Weber (1982), mas acrescenta à literatura achados acerca da receita esperada ínterim. Especificamente para o caso de leilões de primeiro preço o autor destaca que os achados são ambíguos relativamente ao efeito da divulgação ou não do preço de reserva sobre a receita esperada. Foi identificada uma relação entre o nível do preço de reserva, o fato deste ser público ou sigiloso e a receita esperada do leiloeiro.

\section{- Leilão sequencial}

A Teoria de Leilões reserva um amplo espaço para discutir os leilões sequenciais, em especial para os leilões sequenciais ótimos, considerando desde um modelo básico de leilões de objetos independentes até trabalhos mais recentes que buscam definir relações de sinergia (bens substitutos e complementares) e os possíveis impactos sobre as estratégias dos jogadores e, por consequência, sobre o equilíbrio.

McAfee e Vicent (1997) examinaram o equilíbrio sequencial dos leilões onde os vendedores podem estabelecer preços de reserva. Os autores focaram a análise para os casos de 
jogadores com valores privados independentes no qual o suporte para os tipos de jogadores se restringem àqueles situados acima do valor do vendedor. O trabalho destaca que existe um único equilíbrio Bayesiano para os leilões de segundo preço em cada período, bem como demonstra, via teorema de equivalência de receita, que existe um equilíbrio perfeito bayesiano de leilões de primeiro preço repetidos. Como o período de tempo que o vendedor pode comprometer-se a manter o objeto fora do mercado vai para zero, a receita esperada do vendedor converge para aquela derivada de um leilão estático sem preço de reserva. Outro ponto destacado pelos autores refere-se ao fato de que com o aumento do número de jogadores, a receita esperada do vendedor se aproxima da receita derivada de um leilão estático ótimo.

Levin (1996) considerou o problema de mecanismos de venda ótimos para bens complementares. $\mathrm{O}$ autor destacou que quando os compradores são perfeitamente simétricos, o procedimento ideal é agrupar os itens e executar um leilão padrão. Todavia, em geral, o agrupamento dos itens pode não ser desejável e, neste caso, os leilões padrão não maximizam a receita. Ademais, ressalta o autor, que quando existem assimetrias o leilão ótimo que maximiza a receita pode não ser socialmente eficiente, resultado de um agrupamento muito grande ou muito pequeno ou de uma discriminação de jogadores particulares. Por fim, o autor destaca a diferença entre o mecanismo proposto e o caso padrão, indicando a necessidade de se buscar procedimentos que tratem explicitamente à questão de existência de complementaridade entre os itens e destaca que o mecanismo proposto provê um benchmark para que eventuais regras de leilões múltiplos objetos possam ser comparados.

Fátima et. al.(2005) analisaram leilões sequenciais para objetos que apresentam tanto valores privados como comuns. Os autores destacam que outros estudos foram realizados considerando os objetos exclusivamente de valores privados ou comuns. Todavia, os autores ressaltam que, em muitos casos, os objetos podem apresentar as duas características e, considerando esse cenário os autores se propõem a estudar leilões sequenciais para objetos heterogêneos que apresentam ambos os valores privados e comuns. Para tanto, os autores trataram a informação de cada jogador acerca do valor comum como incerteza. Assim, derivaram o equilíbrio para cada leilão em uma sequência e, em seguida, considerando o fato de que a receita total dos leilões em sequência depende da ordem em que os objetos são leiloados (agenda) os autores determinaram uma agenda ótima, isto é, aquela que maximiza a receita esperada dos leilões em sequência. Por fim, os autores mostraram que para uma dada agenda o total de receitas é o mesmo para os leilões de primeiro e segundo preços e para o leilão inglês. 
Zeithammer (2007) analisou a estratégia ótima de venda de um monopolista em um contexto de jogadores pacientes num mercado de leilão sequencial. $\mathrm{O}$ vendedor neste contexto se depara com a possibilidade de escolher entre dois regimes de venda: o adaptativo, o qual envolve um processo de aprendizagem para os leilões subsequentes a partir do conhecimento dos preços praticados nas primeiras rodadas, e o de compromisso segundo o qual todas as decisões de compra são realizadas no início do jogo. $\mathrm{O}$ autor propõe um modelo que caracteriza um regime ótimo para escolha entre o vendedor e comprador. Como resultado indica que a lucratividade dos dois regimes depende da expectativa de ganho do negócio, isto é, quando o ganho esperado é baixo o regime de compromisso domina o regime de adaptação e vice-versa.

Katsenos (2007) apresentou em sua dissertação três ensaios sobre leilões sequenciais que examinaram as razões que levam o vendedor a optar pela realização de leilões múltiplas unidades sequencialmente mais do que simultaneamente. $\mathrm{O}$ trabalho também analisou como a informação gerada durante o leilão sequencial pode afetar o comportamento dos lances em benefício do vendedor e demonstrou a exigência de compromisso intertemporal para as regras do leilão.

Quando o vendedor não pode garantir que o preço de reserva não será alterado ao longo do tempo, os jogadores ficam relutantes em revelar sua valoração. Por isso, com demanda unitária, um equilíbrio simétrico monótono existe apenas em um leilão sequencial holandês.

O autor conclui que, sob comprometimento imperfeito, o leilão sequencial ótimo resulta em uma receita esperada menor do que um leilão simultâneo, uma vez que os jogadores tendem a não revelar ser verdadeiro valor e que o vendedor pode alterar a regra do leilão seguinte. Por outro lado, o leilão sequencial, na presença de externalidades alocativas e informacionais (em particular para a venda de duas licenças de oligopólio) consegue eliminar algumas incertezas de retorno através da alocação das licenças de maneira ordenada de acordo com a força de cada jogador. Desta forma, um jogador mais fraco consegue adquirir sua licença por um valor menor do que teria que pagar em um leilão simultâneo, evitando um sobrepagamento, o que segundo premissas de independência dos custos de produção gera a mesma receita esperada. Ainda segundo o autor, o leilão sequencial sem afetar a receita do vendedor e os objetivos de eficiência, resulta em uma distribuição mais igualitária da riqueza gerada pelo oligopólio, no exemplo citado. Por fim, o autor destaca que o leilão sequencial tende a resultar em maior receita esperada do que as vendas simultâneas, sobretudo quando o número de jogadores é grande, o custo de participação pequeno ou a distribuição dos valores convexa. 
Robu e Poutré (2010), considerando que os trabalhos apresentados até então não consideravam o efeito do risco sobre os licitantes, estudaram o efeito do perfil de risco, modelado através da medida padrão de risco de Arrow-Pratt, sobre a estratégia dos jogadores em leilões sequenciais. O trabalho modelou o processo de decisão sequencial, presente na formação dos lances, como um processo de decisão de Markov e, em seguida, analisou separadamente para os casos de leilões sequenciais de primeiro e segundo preços o efeito da aversão ao risco dos jogadores sobre a política teórica de lances para uma categoria de expectativas sobre a distribuição de preços futura. Por fim, os autores concluem com um estudo experimental acerca do efeito da aversão ao risco sobre o lucro dos jogadores e a receita do leiloeiro para diferentes cenários de mercado de complexidade crescente.

Leme, Syrgkanis e Tardos (2012) motivados pelo fato de que oportunidades futuras, externalidades, afetam a avaliação estratégica dos jogadores em um leilão estudaram um cenário de mercado de vendedores e compradores, onde cada vendedor possui um item, os jogadores têm valorações combinatórias e os vendedores conduzem leilões sequenciais. Os autores obtiveram resultados qualitativamente diferentes dos leilões simultâneos e provaram que se os vendedores conduzem leilões sequenciais de primeiro preço, então para jogadores com demanda unitária (mercado de matching) cada equilíbrio perfeito em subjogos atinge pelo menos metade do bem estar social ótimo enquanto que, para o caso de leilões de segundo preço, o bem estar social pode ser arbitrariamente pior que o ótimo. Por fim, os autores destacam que uma importante ferramenta da análise deles foi ter estudado leilões de primeiro e segundo preços com externalidade e mostraram que sempre existe equilíbrio de Nash puro em leilões de primeiro preço com externalidade.

Puranam e Katehakis (2012) estudaram o problema de uma firma que, em cada ciclo de um horizonte de planejamento, constrói inventário de itens idênticos que adquire através da participação em leilões, a fim de satisfazer a sua própria demanda do mercado. O objetivo da firma é ter uma estratégia para licitação que maximize o valor presente de seu lucro esperado para um horizonte infinito de planejamento de ciclos idênticos. Os autores formularam o problema como um processo de decisão de Markov e estabeleceram propriedades da função valor e da regra de lance ótima.

Jofre-Bonet e Persendorfer (2014) estudaram licitações sequenciais e examinaram quais regras de licitação minimizariam o custo. Para esclarecer esse ponto os autores destacam que a resposta a essa questão política está atrelada à relação de substituição e complementariedade 
entre os itens licitados. Os autores concluem afirmando que para o caso de bens substitutos uma licitação de primeiro preço é preferida, ao passo que para bens complementares a licitação de segundo preço é preferida.

Considerando o amplo debate presente na literatura acerca dos leilões sequenciais, incluindo o relaxamento de alguns supostos dos modelos básicos, passar-se-á, na seção seguinte, a apresentar o equilíbrio derivado da modelagem de licitação para os TACs considerando, inicialmente, um contexto de objetos independentes e ausência de preço de reserva e em seguida estabelecendo uma relação dinâmica para definição do preço de reserva endógeno. Diante dos resultados proceder-se-á à análise e descrição dos principais propriedades resultantes da modelagem.

Um aspecto importante a ser destacado é a assimetria de informação entre a Anatel e as prestadoras de serviços de telecomunicações no que tange à distribuição de seus tipos, o que restringirá as seções subsequentes à análise do preço de reserva endógeno.

Mesmo reconhecendo os avanços realizados recentemente pela Agência Nacional de Telecomunicações no que tange à modelagem de custos top-down e bottom-up das empresas do setor não é razoável ignorar o efeito persistente da assimetria de informação entre regulado e regulador.

Relativamente ao conhecimento dos tipos entre os operadores assumir-se-á que as companhias por estarem efetivamente operando e em constante interação comercial-competitiva apresentam conhecimento comum no que tange à distribuição dos tipos. 


\subsection{Proposta de licitação e análise de licitações sequenciais para TAC na Anatel}

A Anatel deriva sua utilidade de um maior nível de investimentos no setor de Telecomunicações. Poder-se-ia considerar a variável qualidade do serviço de telecomunicações, mas seria uma variável menos objetiva. Assim, a definição pela proxy investimento se deve ao fato de ser uma variável mais objetiva e pelo fato de sintetizar de maneira apropriada o comando legal que especifica as atribuições/objetivos da Agência Nacional de Telecomunicações.

Nesse contexto, é possível separar os investimentos realizados pelas operadoras dos serviços de telecomunicações em dois tipos:

1. Investimentos ordinários: referem-se aos investimentos realizados pelas operadoras regularmente dentro de seu planejamento empresarial, considerando a dinâmica de mercado, incluindo a atratividade econômica dos projetos implantados pelas companhias;

2. Investimentos adicionais: referem-se a investimentos que estão atrelados à contrapartida aceita pelas prestadoras em troca de abatimento de seus passivos de multas e, portanto, estarão relacionados a projetos com baixa ou nenhuma atratividade econômica, isto é, cujos VPLs se apresentem negativos, necessitando, assim, da cobertura de parcela de custos não recuperáveis que conforme proposto no presente trabalho serão abatidos do montante de multas das operadoras.

Importante ressaltar que o presente trabalho se concentrará na segunda categoria de investimentos de modo a contribuir para o aperfeiçoamento da política pública implantado pelo Regulamento do TAC.

A Anatel dispõe de um estoque de multas a arrecadar de cada empresa regulada de $M_{i}$, perfazendo um montante de multas globais $M=\sum_{i}^{n} M_{i}$. Esse montante de multas pode ser arrecadado e destinado à conta única do Tesouro Nacional, tendo uma destinação, com alta probabilidade, muito distinta de investimentos no setor de telecomunicações via definições do orçamento federal ou podem servir para ampliar os investimentos no setor de telecomunicações via celebração de TACs entre a Anatel e os regulados, $I_{a}$ (investimentos adicionais).

A utilidade da Anatel no presente trabalho diferirá daquela atinente ao Governo Federal de forma ampla, tendo em vista os dispositivos legais que tratam das competências da Agência e a visão de que ao atuar de forma a incrementar os investimentos setoriais a agência está 
contribuindo de forma relevante para o atingimento dos deveres ou objetivos estratégicos do Poder Público.

Art. $1^{\circ}$ Compete à União, por intermédio do órgão regulador e nos termos das políticas estabelecidas pelos Poderes Executivo e Legislativo, organizar a exploração dos serviços de telecomunicações.

Parágrafo único. A organização inclui, entre outros aspectos, o disciplinamento e a fiscalização da execução, comercialização e uso dos serviços e da implantação e funcionamento de redes de telecomunicações, bem como da utilização dos recursos de órbita e espectro de radiofrequências.

Art. $2^{\circ} \mathrm{O}$ Poder Público tem o dever de:

I - garantir, a toda a população, o acesso às telecomunicações, a tarifas e preços razoáveis, em condições adequadas;

II - estimular a expansão do uso de redes e serviços de telecomunicações pelos serviços de interesse público em benefício da população brasileira;

III - adotar medidas que promovam a competição e a diversidade dos serviços, incrementem sua oferta e propiciem padrões de qualidade compatíveis com a exigência dos usuários;

IV - fortalecer o papel regulador do Estado;

$V$ - criar oportunidades de investimento e estimular o desenvolvimento tecnológico e industrial, em ambiente competitivo;

$\mathrm{VI}$ - criar condições para que o desenvolvimento do setor seja harmônico com as metas de desenvolvimento social do País.

\section{(...)}

Art. 19. À Agência compete adotar as medidas necessárias para o atendimento do interesse público e para o desenvolvimento das telecomunicações brasileiras, atuando com independência, imparcialidade, legalidade, impessoalidade e publicidade, e especialmente:

Diante dos dispositivos legais, é possível inferir que a geração de multas com consequência meramente arrecadatória não contribui para o cumprimento do papel Anatel enquanto representante da União Federal e do Poder Público Regulador.

Conforme apresentado nos capítulos anteriores, a realidade enfrentada pela Anatel no passado, na prática, conduziu a uma experiência perversa de que as atividades de fiscalização e sancionamento estavam mais relacionadas com uma função arrecadatória/punitiva do que com a missão estabelecida no arcabouço legal que vai na linha de maior bem estar para a sociedade. 
A publicação do novo regulamento sobre TACs, bem como as discussões que o antecederam foram na direção de restaurar a verdadeira essência da atuação do órgão regulador no que tange ao desenvolvimento das telecomunicações, à promoção do desenvolvimento econômico e social e ao aumento da oferta dos serviços à sociedade, redundando assim no aumento de bem estar.

Assim, adotar-se-á o entendimento de que o a variável investimento setorial indicará, lato sensu, o sucesso da atuação do regulador no sentido de cumprir os objetivos legais definidos, tais como: o desenvolvimento setorial, o desenvolvimento econômico e social, o aumento da oferta, o fomento à competição e a oferta de serviços de qualidade.

Neste diapasão, temos que a utilidade da Anatel será estritamente crescente nos investimentos globais (ordinários e adicionais) no setor de telecomunicações e decrescente na arrecadação dos valores de multas aplicadas e nos custos processuais e será côncava ou linear.

\section{O mecanismo de leilão}

A literatura sobre desenho de mecanismo e em particular de leilões é bastante ampla e ao longo dos anos vem se sofisticando no que tange à consideração de aspectos que podem atuar diretamente no resultado dos leilões notadamente no que se refere à maximização dos resultados esperados dos participantes.

Desde os trabalhos de Myerson (1981) e Riley e Samuelsom (1981) que abordaram o desenho de leilões ótimos, o princípio de equivalência de receitas, bem como a ideia da importância da definição de um preço de reserva adequado que excedesse o próprio valor do leiloeiro para a maximização da receita esperada sob o suposto de valores privados independentes, a literatura tem avançado de forma bastante importante, sobretudo no que tange à definição de preços de reserva, leilões sequenciais, licitações de compras públicas, conforme evidenciado na seção de revisão da literatura.

Nesse sentido, a modelagem apresentada a seguir, partindo dos avanços identificados na literatura buscará explorar os efeitos da vinculação endógena de preço paga em uma licitação e preço de reserva de uma licitação seguinte, no âmbito dos leilões sequenciais para o contexto da celebração de TACs no âmbito da Administração Pública Federal. 
Inicialmente é apresentado o modelo básico para a licitação de TACs, bem como algumas extensões nas seções subsequentes. Em seguida, é apresentada a modelagem para o caso de licitação sequencial, as proposições derivadas e suas respectivas provas.

\subsubsection{Elementos básicos do modelo}

Jogadores:

Duas operadoras, $i=1,2$ e o governo, representado aqui pela Anatel.

\subsubsection{Valor atual esperado das operadoras antes da implementação do TAC}

Seja $l_{i}, i=1,2$, o valor (presente) da operadora $i$ não incluindo-se nesse cálculo a multa devida. Suponha ainda que a operadora $i$ estime que a probabilidade de vir a pagar sua multa é $p_{i}$. Então o valor esperado do custo da multa é $p_{i} m_{i}$, onde $m$ é o valor da multa.

Portanto, o valor final da operadora, incluindo o custo esperado do pagamento da multa é:

$$
v_{i}=l_{i}-p_{i} m_{i}, \quad i=1,2
$$

Note que se $m_{i}$ for muito elevado, como parece ser o caso atual para algumas operadoras $^{30}$, então é possível que $l_{i}-m_{i}<0$. Portanto, se $p_{i}$ estiver suficientemente próximo de 1 , o valor esperado da operadora é negativo.

\footnotetext{
${ }^{30}$ Conforme evidenciado por meio das figuras 4.3-4.5, apresentadas anteriormente.
} 
Tabela 4.1. Evolução anual do Valor de mercado das principais empresas (R\$ Milhões)

\begin{tabular}{|c|c|c|c|c|c|c|c|}
\hline Empresa & $\mathbf{2 0 0 7}$ & $\mathbf{2 0 0 8}$ & $\mathbf{2 0 0 9}$ & $\mathbf{2 0 1 0}$ & $\mathbf{2 0 1 1}$ & $\mathbf{2 0 1 2}$ & $\mathbf{2 0 1 3}$ \\
\hline Telefônica Brasil & 23.101 & 21.670 & 21.100 & 20.816 & 56.850 & 53.133 & 48.618 \\
\hline Vivo & 15.744 & 10.415 & 21.765 & 29.004 & - & - & - \\
\hline TIM Part. & 16.035 & 8.479 & 13.648 & 14.738 & 22.339 & 19.825 & 29.809 \\
\hline Oi & - & - & - & - & - & 14.455 & 6.464 \\
\hline Telemar (TNL) & 20.676 & 13.492 & 15.874 & 10.564 & 9.100 & - & - \\
\hline Telemar Norte Leste (Tmar) & 20.676 & 13.492 & 15.874 & 12.391 & 16.918 & - & - \\
\hline Brasil Telecom & 13.445 & 18.099 & 12.289 & 7.916 & 6.726 & - & - \\
\hline Embratel Part. & 6.763 & 8.413 & 15.783 & 10.670 & 9.847 & 13.311 & 9.425 \\
\hline NET & 8.199 & 5.544 & 7.773 & 7.538 & 5.820 & 9.444 & 8.458 \\
\hline Total & $\mathbf{1 2 4 . 6 3 9}$ & $\mathbf{9 9 . 6 0 4}$ & $\mathbf{1 2 4 . 1 0 6}$ & $\mathbf{1 1 3 . 6 3 7}$ & $\mathbf{1 2 7 . 6 0 0}$ & $\mathbf{1 1 5 . 6 9 9}$ & $\mathbf{1 0 2 . 7 7 4}$ \\
\hline
\end{tabular}

Fonte: Teleco $^{31}$

Com base na tabela acima é possível verificar que a Oi estava com um valor de mercado em 2013 de R \$ 6.464 milhões uma queda de mais de 50\% em relação ao ano anterior. Tendo em vista o montante de multas aplicado às empresas do setor tem-se que sua representatividade é bastante expressiva quando comparada com os valores de mercado apresentados, exceto para o caso do grupo Telefônica.

Ressalte-se também que o expressivo aumento do valor de mercado da Telefônica em 2011 vis-à-vis a 2010 se deve à fusão com a operadora móvel Vivo.

Relativamente à probabilidade de efetiva arrecadação das multas pode-se destacar que Miranda (2011) identificou correlação positiva entre o fato de ser aplicada uma sanção de multa e a probabilidade da decisão, em primeira instância, ser favorável ao órgão regulador, o que indica que a chance de perda das firmas reguladas tende a ser elevada.

31 http://www.teleco.com.br/vmercado.asp, acessado em 01/09/2014. 


\subsubsection{A possibilidade de TAC e o tipo de cada operadora}

A Anatel decide sobre um investimento prioritário e estima, na melhor de sua capacidade, o custo desse investimento, $c$. Esse custo é bem inferior às multas das duas operadoras consideradas neste modelo: $m_{1}, m_{2} \gg c$. O governo fará um leilão para o projeto de investimento prioritário. $\mathrm{O}$ formato do leilão poderá ser de primeiro ou de segundo preço.

No leilão, o lance da operadora $i$ será $d_{i}, i=1,2$. Esse lance corresponde a quantos reais a operadora exige por real de investimento $c$. Espera-se que a Anatel inclua no leilão o limite superior para $d_{i}, d_{i} \leq 1$, mas isso não é obrigatório. Naturalmente, nenhuma operadora aceitará um valor negativo para esse desconto, (que seria, nesse caso, um imposto sobre o investimento). Portanto, $0 \leq d_{i}$.

Digamos que a operadora $i$ vença o leilão com o valor de desconto de equilíbrio $d$. Então essa operadora terá:

(i) Um custo adicional de investimento c.

(ii) Uma redução na sua dívida de $d c$.

(iii) Um retorno adicional pelo ganho com o investimento de $g_{i}(c)$.

Portanto, o novo valor da firma será $v_{i}^{\prime}=l_{i}+g_{i}(c)-c-p_{i}\left(m_{i}-d c\right)$, ou ainda,

$$
v_{i}^{\prime}=l_{i}-p_{i} m_{i}+g_{i}(c)-c+p_{i} d c=v_{i}+g_{i}(c)-c+p_{i} d c
$$

Note que, se o investimento tiver valor presente líquido não negativo, ou seja, $g_{i}(c)-$ $c \geq 0$, então será do interesse da operadora participar do TAC qualquer que seja o valor do desconto d.

Oportuno ressaltar que os cálculos dos VPL pela Anatel poderá seguir a mesma metodologia atualmente utilizada para a definição do lance mínimo nos leilões de frequência.

Suponha agora que o projeto tenha VPL negativo: $g_{i}(c)-c<0 \Leftrightarrow g_{i}(c)<c$. 
Então, um desconto d somente será vantajoso para a operadora somente se:

$$
v_{i}^{\prime} \geq v_{i} \Leftrightarrow p_{i} d c \geq c-g_{i}(c) \Leftrightarrow d \geq \frac{c-g_{i}(c)}{p_{i} c}=\frac{1}{p_{i}}\left[1-\frac{g_{i}(c)}{c}\right]
$$

Então, o tipo da operadora i será dado por:

$$
d_{i}=\frac{1}{p_{i}}\left[1-\frac{g_{i}(c)}{c}\right]
$$

\subsubsection{Derivação do Equilíbrio}

O modelo ora proposto se assemelha a uma licitação, onde a estratégia de equilíbrio para os licitantes é $d\left(G_{1}\right)=\frac{G_{1}+1}{2 p c}$. Assim, derivando a solução do modelo proposto no presente trabalho temos que uma prestadora do tipo $G_{i}$ ofereceria um lance $d\left(G_{i}\right)=\frac{G_{i}+1}{2 p c}$.

O modelo foi desenvolvido de modo a viabilizar uma avaliação analítica da situação enfrentada pela Anatel em relação à celebração dos Termos de Ajustamento de Conduta de modo a contribuir como uma proposta de mecanismo passível de implementação pelo órgão regulador das telecomunicações, bem como para demais órgãos da administração pública que se defrontem com situações análogas e que desejem obter uma resolução eficiente do problema.

No presente modelo, consideraremos que existem duas empresas $i=1,2$ concorrendo pelo projeto ofertado pela Anatel que servirá de base para abatimento do valor de multas. A empresa $i$ consegue implantar o projeto com o resultado de VPL dado por $G_{i}=c-g_{i}(c)$ (custo líquido do projeto). O custo $c$ é de conhecimento de todos. A empresa $i$ conhece sua eficiência representada por sua tecnologia $g_{i}$, mas sua competidora e o governo sabem apenas que $G_{i}$ está uniformemente distribuída entre $[0,1]$.

De forma mais objetiva, o jogo pode ser modelado da seguinte forma:

- $n=2$

- $\Gamma_{1}=[0,1] ; \Gamma_{2}=[0,1]$ : refere-se ao valor que cada jogador atribui ao objeto. Este é desconhecido do outro jogador e está definido entre 0 e 1 , onde o limite superior pode ser entendido como uma unidade monetária que se enquadre no contexto do problema a ser 
equacionado (valor máximo do jogo). No presente caso será utilizada a variável $G_{i}$ para indicar um tipo específico do jogador $i$, ou seja, o valor que o jogador atribui ao objeto.

- $F_{1}(G)=\operatorname{prob}\left(G_{1} \leq G\right)=G ; F_{2}(G)=\operatorname{prob}\left(G_{2} \leq G\right)=G$, função de distribuição dos tipos, onde os valores de $G_{1}$ e $G_{2}$ são duas variáveis aleatórias independentes e uniformemente distribuídas entre 0 e 1 . Desta forma, temos que $f_{i}(G)=F_{i}^{\prime}(G)=1, i=1,2$ de modo que a função de densidade ex-ante é dada por:

$$
p\left(G_{1}, G_{2}\right)=p_{1}\left(G_{1}\right) \times p_{2}\left(G_{2}\right)=1,
$$

- $A_{1}=[0,1]=\lambda_{1}=d_{1}\left(G_{1}\right) ; A_{2}=[0,1]=\lambda_{2}=d_{2}\left(G_{2}\right)$ : referem-se às ações dos jogadores que na prática são seus lances. Para o caso deste trabalho denotar-se-á por $\Lambda_{i}$ um conjunto de possíveis lances do jogador $i$ e um lance específico denotado $\lambda_{i} \in \Lambda_{i}$.

Fazendo $\lambda_{i}: G_{i} \rightarrow \Lambda_{i}$ uma estratégia do jogador $\mathrm{i}=1,2$ teremos, conforme descrito a seguir, consequências do jogo correspondentes.

Pode-se apresentar a utilidade ex-post do jogador 1 quando o seu valor é $G_{1}$, o valor do jogador 2 é $G_{2}$ e os jogadores seguem um perfil de estratégias $\left(d_{1}(),. d_{2}().\right)$

$$
u_{1}\left(\left(d_{1}\left(G_{1}\right), d_{2}\left(G_{2}\right)\right),\left(G_{1}, G_{2}\right)\right)= \begin{cases}v_{1}^{\prime}, & \text { se } d_{1}\left(G_{1}\right)<d_{2}\left(G_{2}\right) \\ \frac{v_{1}^{\prime}}{2}, & \text { sed } d_{1}\left(G_{1}\right)=d_{2}\left(G_{2}\right) \\ v_{i} & , \quad \text { se } d_{1}\left(G_{1}\right)>d_{2}\left(G_{2}\right)\end{cases}
$$

Onde $d_{1}\left(G_{1}\right)=\lambda_{1}$ e $d_{2}\left(G_{2}\right)=\lambda_{2}$.

Conforme exposto acima, as definições permitem modelar o leilão como um jogo estático com informação incompleta. Nesse jogo cada participante i conhece o valor que atribui ao projeto leiloado $\left(G_{i}\right)$, mas desconhece o valor que o outro participante atribui ao mesmo objeto, o que nos remete a um leilão de valores privados (cada jogador tem uma valoração individual do objeto) e independentes (não existe relação estatística entre os valores que os participantes atribuem ao objeto). 


\subsubsection{O Equilíbrio de Nash Bayesiano}

Um equilíbrio da Nash bayesiano desse jogo é um par de estratégias $\left(\lambda_{1}, \lambda_{2}\right)$, em que $\lambda_{i}: G_{i} \rightarrow \Lambda_{i}$, satisfaz:

(i) Para cada realização do tipo do agente $1, G_{1} \in \Gamma_{1}, d_{1}\left(G_{1}\right)=\lambda_{1}$ é a solução do seguinte problema de maximização:

$$
\operatorname{Max}_{\lambda_{1}} v_{1}^{\prime} \times \operatorname{prob}\left[\lambda_{1}<d_{2}\left(G_{2}\right)\right]+\frac{1}{2} v_{1}^{\prime} \times \operatorname{prob}\left[\lambda_{1}=d_{2}\left(G_{2}\right)\right]+v_{1} \times \operatorname{prob}\left[\lambda_{1}>d_{2}\left(G_{2}\right)\right]
$$

(ii) Para cada realização do tipo do agente $2, G_{2} \in \Gamma_{2}, d_{2}\left(G_{2}\right)=\lambda_{2}$ é a solução do seguinte problema de maximização:

$$
\operatorname{Max}_{\lambda_{2}} v_{2}^{\prime} \times \operatorname{prob}\left[\lambda_{2}<d_{1}\left(G_{1}\right)\right]+\frac{1}{2} v_{2}^{\prime} \times \operatorname{prob}\left[\lambda_{2}=d_{1}\left(G_{1}\right)\right]+v_{2} \times \operatorname{prob}\left[\lambda_{2}>d_{1}\left(G_{1}\right)\right]
$$

Importante destacar que no momento de tomada de decisão o jogador 1 desconhece o valor/tipo do jogador $2 G_{2}, \operatorname{logo} G_{2}$ é visto como uma variável aleatória em (i). Da mesma forma, 2 considera $G_{1}$ uma variável aleatória (de distribuição conhecida) em (ii). As funções-objetivo dos problemas de maximização acima são as utilidades ínterim de cada um dos respectivos jogadores.

Para resolver o problema serão feitas algumas simplificações adicionais.

Simplificações e resolução.

(a) Dada a simetria do jogo com relação aos jogadores, buscaremos um equilíbrio simétrico, ou seja, um equilíbrio no qual os dois jogadores escolhem a mesma função estratégia: $d_{1}=d_{2}=d$. 
(b) Suporemos que quanto maior for o saldo líquido negativo do projeto para a firma $i$, isto é, $G_{i}$, maior será o desconto de equilíbrio a ser exigido pelas firmas, ou seja, a função $d$ é estritamente crescente. Além disso, supomos que $d$ é diferenciável.

(c) Como o lance $d$ é estritamente crescente, dado o valor $\lambda_{i}, i=1,2$, têm-se $\operatorname{prob}\left(d_{2}\left(G_{2}\right)=\lambda_{1}\right)=\operatorname{prob}\left(d_{1}\left(G_{1}\right)=\lambda_{2}\right)=0$, qualquer que seja a realização de $G_{i}$. Isso acontece porque essa igualdade ocorre em, no máximo, um ponto, um conjunto de medida (de probabilidade) zero.

Assim, como $d$ é estritamente crescente, o problema de maximização, de (30) e (31), torna-se equivalente a:

$$
\begin{aligned}
& \operatorname{Max}_{\lambda_{1}} v_{1}^{\prime} \times \operatorname{prob}\left[\lambda_{1}<d_{2}\left(G_{2}\right)\right]+v_{i} \times \operatorname{prob}\left[\lambda_{1}>d_{2}\left(G_{2}\right)\right] \\
& \operatorname{Max}_{\lambda_{2}} v_{2}^{\prime} \times \operatorname{prob}\left[\lambda_{2}<d_{1}\left(G_{1}\right)\right]+v_{2} \times \operatorname{prob}\left[\lambda_{2}>d_{1}\left(G_{1}\right)\right]
\end{aligned}
$$

Substituindo $v_{i}^{\prime}=v_{i}+g_{i}(c)-c+p_{i} d c$ na expressão acima, obtém-se:

$$
\operatorname{Max}_{\lambda_{1}}\left(v_{i}+g_{i}(c)-c+p_{i} d c\right) \times \operatorname{prob}\left[\lambda_{1}<d_{2}\left(G_{2}\right)\right]+v_{i} \times \operatorname{prob}\left[\lambda_{1}>d_{2}\left(G_{2}\right)\right]
$$

Colocando em evidência $v_{i}$, obtêm-se:

$\operatorname{Max}_{\lambda_{1}} v_{i} \times\left\{\operatorname{prob}\left[\lambda_{1}<d_{2}\left(G_{2}\right)\right]+\operatorname{prob}\left[\lambda_{1}>d_{2}\left(G_{2}\right)\right]\right\}+\left(g_{i}(c)-c+p_{i} d c\right) \times \operatorname{prob}\left[\lambda_{1}<\right.$ $\left.d_{2}\left(G_{2}\right)\right]$

Seja $p_{1}=p_{2}=p$ a probabilidade de que as operadoras tenham que pagar as multas. Ademais, sabe-se que a probabilidade de uma variável aleatória ser menor que um valor somada à probabilidade de ser maior que um valor é $1 \Rightarrow\left\{\operatorname{prob}\left[\lambda_{1}<d_{2}\left(G_{2}\right)\right]+\operatorname{prob}\left[\lambda_{1}>\right.\right.$ $\left.\left.d_{2}\left(G_{2}\right)\right]\right\}=1$. Assim, lembrando que o lance da firma é dado por $d_{1}=\lambda_{1}$ tem-se:

$$
\operatorname{Max}_{\lambda_{1}} v_{1}+\left(g_{1}(c)-c+p \lambda_{1} c\right) \times \operatorname{prob}\left[\lambda_{1}<d_{2}\left(G_{2}\right)\right]
$$




$$
\operatorname{Max}_{\lambda_{2}} v_{2}+\left(g_{2}(c)-c+p \lambda_{2} c\right) \times \operatorname{prob}\left[\lambda_{2}<d_{1}\left(G_{1}\right)\right]
$$

(d) Consideremos os problemas (35) e (36). Dada a função d: $[0,1] \rightarrow[0,1]$ e o valor (fixo) $\lambda_{i}$, temos $\lambda_{1}<d\left(G_{2}\right) \Leftrightarrow G_{2}>d^{-1}\left(\lambda_{1}\right)$, então prob $\left[\lambda_{1}<d\left(G_{2}\right)\right]=\operatorname{prob}\left[G_{2}>\right.$ $\left.d^{-1}\left(\lambda_{1}\right)\right]=1-\operatorname{prob}\left[G_{2}<d^{-1}\left(\lambda_{1}\right)\right]$ e $G_{1}=c-g_{1}(c)$, isto é, $G_{1}$ representa, por hipótese, o custo líquido do projeto a ser implantado para a firma 1, donde obtemos:

$$
\begin{aligned}
& \operatorname{Max}_{\lambda_{1}} v_{1}+\left(-G_{1}+p \lambda_{1} c\right) \times\left[1-d^{-1}\left(\lambda_{1}\right)\right] \\
& \operatorname{Max}_{\lambda_{2}} v_{2}+\left(-G_{2}+p \lambda_{2} c\right) \times\left[1-d^{-1}\left(\lambda_{2}\right)\right]
\end{aligned}
$$

(e) Como os problemas (37) e (38) são essencialmente idênticos, basta resolver um deles para obter a resolução para os dois problemas. A condição de primeira ordem de (37) em relação a $\lambda_{1}$ (supondo que a função-objetivo seja de fato côncava) é:

$$
\begin{gathered}
p c \times\left[1-d^{-1}\left(\lambda_{1}\right)\right]+\left(-G_{1}+p \lambda_{1} c\right) \times\left(-\left(d^{-1}\right)^{\prime}\left(\lambda_{1}\right)\right)=0 \\
p c-p c d^{-1}\left(\lambda_{1}\right)+G_{1} \times\left(\left(d^{-1}\right)^{\prime}\left(\lambda_{1}\right)\right)-p \lambda_{1} c \times\left(\left(d^{-1}\right)^{\prime}\left(\lambda_{1}\right)\right)=0
\end{gathered}
$$

(f) Em um equilíbrio de Nash bayesiano $\lambda_{1}$ é escolhido de forma que $\lambda_{1}=d\left(G_{1}\right)$. Assim, a equação (40) pode ser reescrita como:

$$
p c-p c G_{1}+G_{1} \times\left(\left(d^{-1}\right)^{\prime}\left(d_{1}\left(G_{1}\right)\right)-p c\left(d_{1}\left(G_{1}\right)\right) \times\left(\left(d^{-1}\right)^{\prime}\left(d_{1}\left(G_{1}\right)\right)=0\right.\right.
$$

(g) Como $d^{-1}$ é a inversa de $d$, resultando na igualdade $\left(\left(d^{-1}\right)^{\prime}\left(\lambda_{1}\right)\right)=\left(d^{\prime}\left(G_{1}\right)\right)^{-1}$, temos que a equação (41) se transforma em:

$$
\frac{G_{1}}{d^{\prime}\left(G_{1}\right)}+p c-p c G_{1}-\frac{p c d\left(G_{1}\right)}{d^{\prime}\left(G_{1}\right)}=0
$$




$$
\begin{gathered}
G_{1}+d^{\prime}\left(G_{1}\right) p c-d^{\prime}\left(G_{1}\right) p c G_{1}-p c d\left(G_{1}\right)=0, \\
p c\left[d^{\prime}\left(G_{1}\right)-d^{\prime}\left(G_{1}\right) G_{1}-d\left(G_{1}\right)\right]=-G_{1},
\end{gathered}
$$

Após alguma álgebra:

$$
\left[d^{\prime}\left(G_{1}\right)\left(1-G_{1}\right)-d\left(G_{1}\right)\right]=-\frac{G_{1}}{p c}
$$

(h) Considerando que $\frac{\partial\left[\left(1-G_{1}\right) d\left(G_{1}\right)\right]}{\partial G_{1}}=\left[d^{\prime}\left(G_{1}\right)\left(1-G_{1}\right)-d\left(G_{1}\right)\right]$ é possível resolver a equação diferencial (45). Assim, ao integrar a equação (45) se obtêm:

$$
\left[\left(1-G_{1}\right) d\left(G_{1}\right)\right]=-\frac{G_{1}^{2}}{2 p c}+k
$$

Fazendo $G_{1}=1$, obtém-se $k$ :

$$
k=\frac{1}{2 p c}
$$

Substituindo $k$ na equação (47), obtém-se após algumas operações algébricas ${ }^{32}$ :

$$
\begin{gathered}
{\left[d\left(G_{1}\right)\right]=\left[-\frac{G_{1}{ }^{2}}{2 p c}+\frac{1}{2 p c}\right] \times \frac{1}{\left(1-G_{1}\right)}=\frac{\left(1+G_{1}\right)\left(1-G_{1}\right)}{2 p c} \times \frac{1}{\left(1-G_{1}\right)}} \\
d\left(G_{1}\right)=\frac{G_{1}+1}{2 p c},
\end{gathered}
$$

Considerando a simetria, o lance do jogador 2 em equilíbrio é:

32 Para o caso de $G_{1}=g_{1}(c)-c$, isto é, como por hipótese temos que as firmas enfrentarão um custo líquido (negativo) isso implicaria $G_{1}<0$ e, portanto, teríamos que o lance de equilíbrio seria $d\left(G_{1}\right)=\frac{G_{1}+1}{2 p c}=d\left(G_{2}\right)$. 


$$
d\left(G_{2}\right)=\frac{G_{2}+1}{2 p c}
$$

Resta verificar que $d_{1}(G)=d_{2}(G)=\frac{G+1}{2 p c}$ corresponde, de fato, a um Equilíbrio de Nash Bayesiano (ENB) do jogo. Essa verificação, no entanto, é imediata. Fixando $d_{2}\left(G_{2}\right)=\frac{G_{2}+1}{2 p c}$, o problema de maximização do jogador 1 será:

$$
\operatorname{Max}_{\lambda_{1}}=v_{1}+\left(G_{1}+p \lambda_{1} c\right) \times\left[1-d_{2}^{-1}\left(\lambda_{1}\right)\right]
$$

A função inversa de $d_{2}\left(G_{2}\right)=\frac{G_{2}+1}{2 p c}$ é $d^{-1}\left(G_{2}\right)=2 p c G_{2}-1$ que quando aplicado a $\lambda_{1}$ resulta em $d_{2}^{-1}\left(\lambda_{1}\right)=2 p c \lambda_{1}-1$.

De outra forma,

$$
\begin{gathered}
\lambda_{1}<\frac{\left(G_{2}+1\right)}{2 p c} \Leftrightarrow 2 \lambda_{1} p c<\left(G_{2}+1\right) \Leftrightarrow\left(G_{2}+1\right)<2 \lambda_{1} p c \Leftrightarrow \\
\Leftrightarrow G_{2}<2 \lambda_{1} p c-1
\end{gathered}
$$

Assim ao substituir a expressão na função a ser maximizada obtemos:

$$
\begin{gathered}
\operatorname{Max}_{\lambda_{1}} v_{1}+\left(G_{1}+p \lambda_{1} c\right) \times\left[1-\left(2 p c \lambda_{1}-1\right)\right] \\
\operatorname{Max}_{\lambda_{1}} v_{1}+\left(G_{1}+p \lambda_{1} c\right) \times\left[2-2 p c \lambda_{1}\right] \\
\operatorname{Max} U=\operatorname{Max}_{\lambda_{1}} v_{1}+\left(2 G_{1}-2 G_{1} p c \lambda_{1}+2 p \lambda_{1} c-2\left(p \lambda_{1} c\right)^{2}\right) \\
\frac{\partial U}{\partial \lambda_{1}}=-2 G_{1} p c+2 p c-4 \lambda_{1}(p c)^{2}
\end{gathered}
$$




$$
\frac{\partial^{2} U}{\partial \lambda_{1}{ }^{2}}=-4(p c)^{2}<0
$$

Logo, trata-se de uma função côncava, em termos de $\lambda_{1}$ que apresenta máximo.

\subsubsection{Análise de estática comparativa}

1) Quanto maior o custo do projeto, menor tende a ser o lance de equilíbrio, isto é, o desconto do montante de multas exigido pelas empresas para participarem do leilão. Isto se deve ao fato de que um custo elevado tende a contribuir com a redução de significativa parcela do montante de multas;

2) Quanto maior o custo líquido percebido pela empresa maior tende a ser o lance de equilíbrio, isto é, maior tende a ser o desconto do montante de multas exigido pelas empresas para participarem do leilão. Isto se deve ao fato de que um custo líquido elevado tende a sinalizar um cenário ruim para a manutenção e expansão dos negócios da companhia, uma vez que contaminará a rentabilidade global da empresa;

3) Quanto maior a probabilidade de ter que pagar uma multa, menor tende a ser o lance de equilíbrio, isto é, o desconto do montante de multas exigido pelas empresas para participarem do leilão. Isto se deve ao fato de que se a empresa tem a expectativa de que, com uma probabilidade alta, a justiça determinará que sejam pagos os valores de multa e a companhia tenderá a aceitar participar do leilão exigindo um desconto menor, pois essa atitude tenderá a ser melhor do que simplesmente desembolsar o valor das multas, recolhendo aos cofres públicos, sem auferir qualquer benefício para o seu negócio.

\subsubsection{Extensões do Equilíbrio}

Nesta seção passar-se-á a realizar algumas generalizações do modelo proposto. Para tanto, será estudado o comportamento do equilíbrio de Nash em situações em que $G_{i}$ encontra-se distribuído em distintos intervalos.

Será considerado o modelo básico descrito anteriormente, apresentando como alteração apenas o intervalo onde $G_{i}$ se encontra distribuído. 


\subsubsection{Caso 1: $G_{i}$ uniformemente distribuído no intervalo $[0, M]$, onde $M$ seria valor presente máximo do custo (líquido) do projeto.}

Neste caso, a função de densidade é $f=\frac{1}{M}$ e a função de distribuição é $F=\frac{x-a}{b-a} \Rightarrow F=$ $\frac{X}{M}$. Considerando estas informações é possível resolver o problema de maximização, conforme apresentado a seguir.

$$
\begin{aligned}
& \operatorname{Max}_{\lambda_{1}} v_{1}+\left(-G_{1}+p \lambda_{1} c\right) \times\left[1-\frac{d^{-1}\left(\lambda_{1}\right)}{M}\right] \\
& \operatorname{Max}_{\lambda_{2}} v_{2}+\left(-G_{2}+p \lambda_{2} c\right) \times\left[1-\frac{d^{-1}\left(\lambda_{2}\right)}{M}\right]
\end{aligned}
$$

(e) Como os problemas (57) e (58) são essencialmente idênticos, basta resolver um deles para obter a resolução para os dois problemas. A condição de primeira ordem de (57) em relação a $\lambda_{1}$ (supondo que a função-objetivo seja de fato côncava) é:

$$
p c \times\left[1-\frac{d^{-1}\left(\lambda_{1}\right)}{M}\right]+\left(-G_{1}+p \lambda_{1} c\right) \times\left(-\frac{\left(d^{-1}\right) \prime\left(\lambda_{1}\right)}{M}\right)=0
$$

(f) Em um equilíbrio de Nash bayesiano $\lambda_{1}$ é escolhido de forma que $\lambda_{1}=d\left(G_{1}\right)$. Assim, a equação (59) pode ser reescrita como:

$$
p c \times\left[1-\frac{G_{1}}{M}\right]+\left(-G_{1}+p d\left(G_{1}\right) c\right) \times\left(-\frac{\left(d^{-1}\right) \prime\left(d\left(G_{1}\right)\right)}{M}\right)=0,
$$

(g) Como $d^{-1}$ é a inversa de $d$, resultando na igualdade $\left(\left(d^{-1}\right)^{\prime}\left(\lambda_{1}\right)\right)=\left(d^{\prime}\left(\lambda_{1}\right)\right)^{-1}$, temos que a equação (60) se transforma em: 


$$
\begin{gathered}
\left.p c-p c \frac{G_{1}}{M}+G_{1} \frac{\left(d^{-1}\right) \prime\left(d\left(G_{1}\right)\right)}{M}-p c d\left(G_{1}\right) \frac{\left(d^{-1}\right) \prime\left(d\left(G_{1}\right)\right)}{M}\right)=0, \\
\left.p c+p c \frac{G_{1}}{M}+\frac{G_{1}}{M\left(d^{\prime}\left(G_{1}\right)\right)}-\frac{p c d\left(G_{1}\right)}{M\left(d \prime\left(G_{1}\right)\right)}\right)=0, \\
M\left(d^{\prime}\left(G_{1}\right)\right) p c-\left(d^{\prime}\left(G_{1}\right)\right) p c G_{1}+G_{1}-p c d\left(G_{1}\right)=0, \\
{\left[M d^{\prime}\left(G_{1}\right)-d^{\prime}\left(G_{1}\right) G_{1}-d\left(G_{1}\right)\right]=-\frac{G_{1}}{p c},}
\end{gathered}
$$

Após alguma álgebra:

$$
\left[d^{\prime}\left(G_{1}\right)\left[M-G_{1}\right]-d\left(G_{1}\right)\right]=-\frac{G_{1}}{p c}
$$

(h) Considerando que $\frac{\partial\left[\left(M-G_{1}\right) d\left(G_{1}\right)\right]}{\partial G_{1}}=\left[d^{\prime}\left(G_{1}\right)\left[M-G_{1}\right]-d\left(G_{1}\right)\right]$ é possível resolver a equação diferencial (65). Assim, ao integrar a equação (65) se obtêm:

$$
\left[\left(M-G_{1}\right) d\left(G_{1}\right)\right]=-\frac{G_{1}^{2}}{2 p c}+k
$$

Fazendo $G_{1}=M$, obtém-se $k$ :

$$
k=\frac{M^{2}}{2 p c}
$$


Substituindo $k$ na equação (66), obtém-se após algumas operações algébricas ${ }^{33}$ :

$$
\begin{gathered}
{\left[d\left(G_{1}\right)\right]=\left[-\frac{G_{1}{ }^{2}}{2 p c}+\frac{M^{2}}{2 p c}\right] \times \frac{1}{\left(M-G_{1}\right)}=\frac{\left(M+G_{1}\right)\left(M-G_{1}\right)}{2 p c} \times \frac{1}{\left(M-G_{1}\right)}} \\
d\left(G_{1}\right)=\frac{G_{1}+M}{2 p c},
\end{gathered}
$$

Considerando a simetria, o lance do jogador 2 em equilíbrio é:

$$
d\left(G_{2}\right)=\frac{G_{2}+M}{2 p c}
$$

Assim, o modelo ora proposto se assemelha a uma licitação, onde a estratégia de equilíbrio para os licitantes $d\left(G_{1}\right)=\frac{G_{1}+M}{2 p c}$. Assim, derivando a solução do modelo proposto no presente trabalho temos que uma prestadora do tipo $G_{i}$ ofereceria um lance $d_{i}\left(G_{i}\right)=\frac{G_{i}+M}{2 p c}$.

O caso 1 trata de ampliar a avaliação do comportamento do equilíbrio quando alteramos o tamanho do intervalo para $M$. O aumento do tamanho do intervalo da distribuição, isto é, quando $M \rightarrow \infty$, está relacionado ao nível de incerteza da Anatel acerca das características dos licitantes, isto é, quanto maior o valor de $M$, entende-se que a Anatel possui grande incerteza acerca dos licitantes, o que poderia conduzir a erros de estimação. Nesse sentido, dada a relação positiva entre o desconto de equilíbrio e o tamanho do intervalo, conclui-se que o aumento da incerteza sobre o tipo do licitante tende a aumentar o desconto de equilíbrio.

33 Para o caso de $G_{1}=g_{1}(c)-c$, isto é, $G_{1}<0$ teríamos que o lance de equilíbrio seria $d\left(G_{1}\right)=\frac{G_{1}+1}{2 p c}=d\left(G_{2}\right)$. 
4.5.4.2 Caso 2: $G_{i}$ uniformemente distribuído no intervalo $[-1 / 2+m, m+1 / 2]$ : $m$ significa o valor esperado do custo do projeto que a Anatel estimará antes do processo licitatório. Caso $m>0$ (VPL negativo) caso $m<0$ (VPL positivo), caso excluído.

Neste caso, a função de densidade é $f=1$ e a função de distribuição é $F=\frac{x-a}{b-a} \Rightarrow F=$ $x-m+\frac{1}{2}$. Considerando estas informações, é possível resolver o problema de maximização, conforme apresentado a seguir.

$$
\begin{aligned}
& \operatorname{Max}_{\lambda_{1}} v_{1}+\left(-G_{1}+p \lambda_{1} c\right) \times\left[1-\left[d^{-1}\left(\lambda_{1}\right)+\frac{1}{2}-m\right]\right] \\
& \operatorname{Max}_{\lambda_{2}} v_{1}+\left(-G_{2}+p \lambda_{2} c\right) \times\left[1-\left[d^{-1}\left(\lambda_{2}\right)+\frac{1}{2}-m\right]\right]
\end{aligned}
$$

(e) Como os problemas (70) e (71) são essencialmente idênticos, basta resolver um deles para obter a resolução para os dois problemas. A condição de primeira ordem de (70) em relação a $\lambda_{1}$ (supondo que a função-objetivo seja de fato côncava) é:

$$
p c \times\left[1-d^{-1}\left(\lambda_{1}\right)+m-\frac{1}{2}\right]+\left(-G_{1}+p \lambda_{1} c\right) \times\left(-\left(d^{-1}\right)^{\prime}\left(\lambda_{1}\right)\right)=0
$$

(f) Em um equilíbrio de Nash bayesiano $\lambda_{1}$ é escolhido de forma que $\lambda_{1}=d\left(G_{1}\right)$. Assim, a equação (72) pode ser reescrita como:

$$
p c \times\left[1-G_{1}+m-\frac{1}{2}\right]+G_{1}\left(d^{-1}\right)^{\prime}\left(d\left(G_{1}\right)\right)-p c d\left(G_{1}\right)\left(d^{-1}\right)^{\prime}\left(d\left(G_{1}\right)\right)=0,
$$

(g) Como $d^{-1}$ é a inversa de $d$, resultando na igualdade $\left(\left(d^{-1}\right)^{\prime}\left(\lambda_{1}\right)\right)=\left(d^{\prime}\left(\lambda_{1}\right)\right)^{-1}$, temos que a equação (73) se transforma em: 


$$
\begin{gathered}
p c \times\left[1-G_{1}+m-\frac{1}{2}\right]+\frac{G_{1}}{d \prime\left(G_{1}\right)}-\frac{p c d\left(G_{1}\right)}{d r\left(G_{1}\right)}=0, \\
d^{\prime}\left(G_{1}\right) p c \times\left[1-G_{1}+m-\frac{1}{2}\right]+G_{1}-p c d\left(G_{1}\right)=0, \\
p c \times\left\{d^{\prime}\left(G_{1}\right)\left[1-G_{1}+m-\frac{1}{2}\right]-d\left(G_{1}\right)\right\}=-G_{1},
\end{gathered}
$$

Após alguma álgebra:

$$
\left\{d\left(G_{1}\right)\left[1-G_{1}+m-\frac{1}{2}\right]\right\}^{\prime}=-\frac{G_{1}}{p c}
$$

(h) Considerando que $\frac{\partial\left\{d\left(G_{1}\right)\left[1-G_{1}+m-\frac{1}{2}\right]\right\}}{\partial G_{1}}=\left\{d^{\prime}\left(G_{1}\right)\left[1-G_{1}+m-\frac{1}{2}\right]-d\left(G_{1}\right)\right\}$, é possível resolver a equação diferencial (77). Assim, ao integrá-la se obtêm:

$$
\left\{d\left(G_{1}\right)\left[1-G_{1}+m-\frac{1}{2}\right]\right\}=-\frac{G_{1}^{2}}{2 p c}+k
$$

Fazendo $G_{1}=\frac{1}{2}+m$, obtém-se $k$ :

$$
k=\frac{\left(\frac{1}{2}+m\right)^{2}}{2 p c}
$$

Substituindo $k$ na equação (78), obtém-se após algumas operações algébricas ${ }^{34}$ :

$$
\left[d\left(G_{1}\right)\right]=\left[-\frac{G_{1}{ }^{2}}{2 p c}+\frac{\left(\frac{1}{2}+m\right)^{2}}{2 p c}\right] \times \frac{1}{\left(\left(\frac{1}{2}+m\right)-G_{1}\right)}=
$$

34 Para o caso de $G_{1}=g_{1}(c)-c$, isto é, $G_{1}<0$ teríamos que o lance de equilíbrio seria $d\left(G_{1}\right)=\frac{G_{1}+1}{2 p c}=d\left(G_{2}\right)$. 


$$
\begin{gathered}
=\frac{\left[\left(\frac{1}{2}+m\right)+G_{1}\right] \times\left[\left(\frac{1}{2}+m\right)-G_{1}\right]}{2 p c} \times \frac{1}{\left(\left(\frac{1}{2}+m\right)-G_{1}\right)} \\
d\left(G_{1}\right)=\frac{G_{1}+\left(\frac{1}{2}+m\right)}{2 p c}
\end{gathered}
$$

Considerando a simetria, o lance do jogador 2 em equilíbrio é:

$$
d\left(G_{2}\right)=\frac{G_{2}+\left(\frac{1}{2}+m\right)}{2 p c}
$$

Assim, o modelo ora proposto se assemelha a uma licitação, onde a estratégia de equilíbrio para os licitantes

$d\left(G_{1}\right)=\frac{G_{1}+\left(\frac{1}{2}+m\right)}{2 p c}$. Derivando a solução do modelo proposto no presente trabalho temos que uma prestadora do tipo $G_{i}$ ofereceria um lance $d_{i}\left(G_{i}\right)=\frac{G_{i}+\left(\frac{1}{2}+m\right)}{2 p c}$.

No caso 2, temos a extensão dos cálculos do equilíbrio para o intervalo $[-1 / 2+m, m+$ $1 / 2$ ], onde $m$ significa o valor esperado do custo do projeto que a Anatel estimará antes do processo licitatório. $\mathrm{O}$ caso de $m>0$ indica que a empresa de fato incorrerá em custo líquido para implantar o projeto. Todavia, o caso de $m<0$ indica que a empresa obteria um resultado líquido positivo, o que indicaria a desnecessidade de qualquer mecanismo de incentivo para que a empresa efetivamente realizasse os investimentos. Este último caso, conforme mencionado anteriormente, não é considerado no presente trabalho, inclusive por sua pouca plausibilidade.

Caso $m \rightarrow 0$ temos um projeto de valor mais baixo e, portanto, de execução factível de forma menos dispendiosa. Para o caso de $m \rightarrow \infty$ temos um projeto muito custoso o que pode resultar na não celebração dos TACs. 
Nesse sentido, dada a relação positiva entre o desconto de equilíbrio e o valor de $m$, conclui-se que o aumento do custo esperado para o licitante tende a aumentar o desconto de equilíbrio.

4.5.4.3 Caso 3: $G_{i}$ uniformemente distribuído no intervalo $\left[m-\frac{M}{2}, m+\frac{M}{2}\right]$ o caso mais geral.

Neste caso, a função de densidade é $f=\frac{1}{M}$ e a função de distribuição é $F=\frac{x-a}{b-a} \Rightarrow F=$ $\frac{x+\left(\frac{M}{2}-m\right)}{M}$. Considerando estas informações é possível resolver o problema de maximização, conforme apresentado a seguir.

$$
\begin{aligned}
& \operatorname{Max}_{\lambda_{1}} v_{1}+\left(-G_{1}+p c \lambda_{1}\right) \times\left[1-\left[\frac{d^{-1}\left(\lambda_{1}\right)+\left(\frac{M}{2}-m\right)}{M}\right]\right] \\
& \operatorname{Max}_{\lambda_{2}} v_{2}+\left(-G_{2}+p c \lambda_{2}\right) \times\left[1-\left[\frac{d^{-1}\left(\lambda_{2}\right)+\left(\frac{M}{2}-m\right)}{M}\right]\right.
\end{aligned}
$$

(e) Como os problemas (84) e (85) são essencialmente idênticos, basta resolver um deles para obter a resolução para os dois problemas. A condição de primeira ordem de (84) em relação a $\lambda_{1}$ (supondo que a função-objetivo seja de fato côncava) é:

$$
p c \times\left[1-\left[\frac{d^{-1}\left(\lambda_{1}\right)+\left(\frac{M}{2}-m\right)}{M}\right]\right]+\left(-G_{1}+p c \lambda_{1}\right) \times\left(-\frac{\left(d^{-1}\right)^{\prime}\left(\lambda_{1}\right)}{M}\right)=0
$$

(f) Em um equilíbrio de Nash bayesiano $\lambda_{1}$ é escolhido de forma que $\lambda_{1}=d\left(G_{1}\right)$. Assim, a equação (86) pode ser reescrita como: 


$$
p c \times\left[\left[\frac{M-G_{1}-\left(\frac{M}{2}-m\right)}{M}\right]\right]+\frac{G_{1}\left(d^{-1}\right)^{\prime}\left(d\left(G_{1}\right)\right)}{M}-\frac{p c\left(d\left(G_{1}\right) G_{1}\left(d^{-1}\right)^{\prime}\left(d\left(G_{1}\right)\right)\right.}{M}=0,
$$

(g) Como $d^{-1}$ é a inversa de $d$, resultando na igualdade $\left(\left(d^{-1}\right)^{\prime}\left(\lambda_{1}\right)\right)=\left(d^{\prime}\left(\lambda_{1}\right)\right)^{-1}$, temos que a equação (87) se transforma em:

$$
\begin{aligned}
& p c \times\left[\frac{M}{2}-G_{1}+m\right]+\frac{G_{1}}{d \prime\left(G_{1}\right)}-\frac{p c\left(d\left(G_{1}\right)\right)}{d^{\prime}\left(G_{1}\right)}=0, \\
& d^{\prime}\left(G_{1}\right) p c \times\left[\frac{M}{2}-G_{1}+m\right]+G_{1}-p c\left(d\left(G_{1}\right)\right)=0, \\
& p c\left\{d^{\prime}\left(G_{1}\right) \times\left[\frac{M}{2}-G_{1}+m\right]-\left(d\left(G_{1}\right)\right)\right\}=-G_{1},
\end{aligned}
$$

Após alguma álgebra:

$$
\left\{d^{\prime}\left(G_{1}\right) \times\left[\frac{M}{2}-G_{1}+m\right]-\left(d\left(G_{1}\right)\right)\right\}=-\frac{G_{1}}{p c}
$$

(h) Considerando que $\frac{\partial\left\{d\left(G_{1}\right) \times\left[\frac{M}{2}-G_{1}+m\right]\right\}}{\partial G_{1}}=\left\{d^{\prime}\left(G_{1}\right) \times\left[\frac{M}{2}-G_{1}+m\right]-\left(d\left(G_{1}\right)\right)\right\}$ é possível resolver a equação diferencial (91). Assim, ao integrar a equação (91) se obtêm:

$$
\left\{d\left(G_{1}\right) \times\left[\frac{M}{2}-G_{1}+m\right]\right\}=-\frac{G_{1}{ }^{2}}{2 p c}+k
$$

Fazendo $G_{1}=\frac{M}{2}+m$, obtém-se $k$ :

$$
k=\frac{\left(\frac{M}{2}+m\right)^{2}}{2 p c}
$$


Substituindo $k$ na equação (92), obtém-se após algumas operações algébricas ${ }^{35}$ :

$$
\begin{gathered}
{\left[d\left(G_{1}\right)\right]=\left[-\frac{G_{1}{ }^{2}}{2 p c}+\frac{\left(\frac{M}{2}+m\right)^{2}}{2 p c}\right] \times \frac{1}{\left[\left(\frac{M}{2}+m\right)-G_{1}\right]},} \\
=\frac{\left[\left(\frac{M}{2}+m\right)-G_{1}\right] \times\left[\left(\frac{M}{2}+m\right)+G_{1}\right]}{2 p c} \times \frac{1}{\left(\left(\frac{M}{2}+m\right)-G_{1}\right)}, \\
d\left(G_{1}\right)=\frac{G_{1}+\left(\frac{M}{2}+m\right)}{2 p c}
\end{gathered}
$$

Considerando a simetria, o lance do jogador 2 em equilíbrio é:

$$
d\left(G_{2}\right)=\frac{G_{2}+\left(\frac{M}{2}+m\right)}{2 p c}
$$

Assim, o modelo ora proposto se assemelha a uma licitação, onde a estratégia de equilíbrio para os licitantes $d\left(G_{1}\right)=\frac{G_{1}+\left(\frac{M}{2}+m\right)}{2 p c}$. Assim, derivando a solução do modelo proposto no presente trabalho temos que uma prestadora do tipo $G_{i}$ ofereceria um lance $d\left(G_{i}\right)=\frac{G_{i}+\left(\frac{M}{2}+m\right)}{2 p c}$

No caso 3 temos a extensão dos cálculos do equilíbrio para o intervalo $\left[\boldsymbol{m}-\frac{\boldsymbol{M}}{\boldsymbol{2}}, \boldsymbol{m}+\frac{\boldsymbol{M}}{\mathbf{2}}\right]$. Conforme destacado anteriormente, $m$ significa o valor esperado do custo do projeto que a Anatel estimará antes do processo licitatório. Caso $m>0$ indica que a empresa de fato incorrerá em custo líquido para implantar o projeto. Todavia, o caso de $m<0$ indica que a empresa 35 Para o caso de $G_{1}=g_{1}(c)-c$, isto é, $G_{1}<0$ teríamos que o lance de equilíbrio seria $d\left(G_{1}\right)=\frac{G_{1}+1}{2 p c}=d\left(G_{2}\right)$. 
obteria um resultado líquido positivo, o que indicaria a desnecessidade de qualquer mecanismo de incentivo para que a empresa efetivamente realizasse os investimentos. Este último caso, conforme mencionado anteriormente, não é considerado no presente trabalho, inclusive por sua pouca plausibilidade.

No mesmo diapasão, caso $m \rightarrow 0$ temos um projeto de valor mais baixo e, portanto, de execução factível de forma menos dispendiosa. Para o caso de $m \rightarrow \infty$ temos um projeto muito custoso o que pode resultar na não celebração dos TACs.

Por outro lado, o tamanho deste novo intervalo é novamente $M$. Assim, o aumento do tamanho do intervalo da distribuição, isto é, quando $M \rightarrow \infty$, está relacionado ao nível de incerteza da Anatel acerca das características dos licitantes, isto é, quanto maior o valor de $M$ entende-se que a Anatel possui grande incerteza acerca dos licitantes, o que poderia conduzir a erros de estimação.

Nesse sentido, dada a relação positiva entre o desconto de equilíbrio e o tamanho do intervalo $M$ e o valor esperado do custo do projeto que a Anatel estimará antes do processo licitatório $m$, conclui-se que o aumento do custo esperado e da incerteza sobre o tipo do licitante tende a aumentar o desconto de equilíbrio.

\subsubsection{Generalização para o intervalo $(A, B)$}

$$
G_{1} \sim \text { unif }[A, B] \Rightarrow f=\frac{1}{B-A} ; F=\frac{x-a}{b-a}=\frac{x-A}{B-A}
$$

Logo, o problema de maximização se torna:

$$
\operatorname{Max} v_{1}+\left(-G_{1}+p c \lambda_{1}\right) \times\left(1-\frac{d^{-1}\left(\lambda_{1}\right)-A}{B-A}\right)
$$

A condição de primeira ordem do problema de maximização acima em relação a $\lambda_{1}$ (supondo que a função-objetivo seja de fato côncava) é: 


$$
\begin{aligned}
& \frac{\partial y}{\partial \lambda_{1}}=0 \Rightarrow p c\left(1-\frac{d^{-1}\left(\lambda_{1}\right)-A}{B-A}\right)+\left(-G_{1}+p c \lambda_{1}\right) \times\left(-\frac{d^{-1}\left(\lambda_{1}\right) \prime}{B-A}\right)=0, \\
& p c\left(\frac{(B-A)-d^{-1}\left(\lambda_{1}\right)-A}{B-A}\right)+G_{1}\left(\frac{d^{-1}\left(\lambda_{1}\right) \prime}{B-A}\right)-p c \lambda_{1}\left(\frac{d^{-1}\left(\lambda_{1}\right) \prime}{B-A}\right)=0,
\end{aligned}
$$

(f) Em um equilíbrio de Nash bayesiano $\lambda_{1}$ é escolhido de forma que $\lambda_{1}=d\left(G_{1}\right)$. Assim, a equação (100) pode ser reescrita como:

$$
p c\left(\frac{(B-A)-d^{-1}\left(d\left(G_{1}\right)\right)+A}{B-A}\right)+G_{1}\left(\frac{d^{-1}\left(d\left(G_{1}\right)\right) \prime}{B-A}\right)-p c \lambda_{1}\left(\frac{d^{-1}\left(d\left(G_{1}\right)\right) \prime}{B-A}\right)=0
$$

(g) Como $d^{-1}$ é a inversa de $d$, resultando na igualdade $\left(\left(d^{-1}\right)^{\prime}\left(\lambda_{1}\right)\right)=\left(d^{\prime}\left(G_{1}\right)\right)^{-1}$, temos que a equação (101) se transforma em:

$$
\begin{aligned}
& p c\left(B-G_{1}\right)+\left(\frac{G_{1}}{d \prime\left(G_{1}\right)}\right)-\left(\frac{p c d\left(G_{1}\right)}{d^{\prime}\left(G_{1}\right)}\right)=0, \\
& d^{\prime}\left(G_{1}\right) p c\left(B-G_{1}\right)+G_{1}-p c d\left(G_{1}\right)=0, \\
& p c\left[d^{\prime}\left(G_{1}\right)\left(B-G_{1}\right)-d\left(G_{1}\right)\right]=-G_{1},
\end{aligned}
$$

Após alguma álgebra:

$$
\left[d^{\prime}\left(G_{1}\right)\left(B-G_{1}\right)-d\left(G_{1}\right)\right]=-\frac{G_{1}}{p c^{\prime}}
$$

(h) Considerando que $\frac{\partial\left[\left(B-G_{1}\right) d\left(G_{1}\right)\right]}{\partial G_{1}}=\left[d^{\prime}\left(G_{1}\right)\left(B-G_{1}\right)-d\left(G_{1}\right)\right]$ é possível resolver a equação diferencial (105). Assim, ao integrar a equação (105) se obtêm:

$$
\left[\left(B-G_{1}\right) d\left(G_{1}\right)\right]=-\frac{G_{1}{ }^{2}}{2 p c}+k,
$$


Fazendo $G_{1}=B$, obtém-se $k$ :

$$
k=\frac{B^{2}}{2 p c}
$$

Substituindo $k$ na equação (106), obtém-se após algumas operações algébricas ${ }^{36}$ :

$$
\begin{gathered}
{\left[d\left(G_{1}\right)\right]=\left[-\frac{G^{2}}{2 p c}+\frac{B^{2}}{2 p c}\right] \times \frac{1}{\left(B-G_{1}\right)}=\frac{\left(B+G_{1}\right)\left(B-G_{1}\right)}{2 p c} \times \frac{1}{\left(B-G_{1}\right)},} \\
d\left(G_{1}\right)=\frac{G_{1}+B}{2 p c},
\end{gathered}
$$

Considerando a simetria, o lance do jogador 2 em equilíbrio é:

$$
d\left(G_{2}\right)=\frac{G_{2}+B}{2 p c}
$$

Proposição: Para o caso do modelo em tela, a alteração nos limites do intervalo da distribuição implica que a razão $\frac{G_{i}}{2 p c}$ será acrescida do limite superior do intervalo sobre o mesmo denominador $\frac{L S}{2 p c}$.

\subsubsection{Generalização do modelo para mais de dois jogadores sem preço de reserva}

A partir desta seção adotar-se-á a notação padrão utilizada pela teoria de leilões, de modo a facilitar o desenvolvimento dos cálculos, uma vez que a implicação é direta para o modelo básico proposto para a realização e/ou celebração dos TACs.

Suponha que o indivíduo 1 ganha se seu lance for $b$, tal que $b<\min _{i \neq 1} \beta\left(X_{i}\right)$. Como $\beta$ é crescente, por hipótese, $\min _{i \neq 1} \beta\left(X_{i}\right)=\beta\left[\min _{i \neq 1}\left(X_{i}\right)\right]=\beta\left(Z_{1}\right)$. O jogador ganha se $\beta\left(Z_{1}\right)>$

36 Para o caso de $G_{1}=g_{1}(c)-c$, isto é, como por hipótese temos que as firmas enfrentarão um custo líquido (negativo) isso implicaria $G_{1}<0$ e, portanto, teríamos que o lance de equilíbrio seria $d\left(G_{1}\right)=\frac{G_{1}+1}{2 p c}=d\left(G_{2}\right)$. 
$b \Leftrightarrow Z_{1}>\beta^{-1}(b)$, onde $Z_{1}=\min _{i \neq 1} \beta\left(X_{i}\right)<b$. Logo, temos que resolver o seguinte problema:

$$
\left[1-G\left(\beta^{-1}(b)\right)\right] \times(b-c)
$$

Maximizando em $b$ :

$$
-\frac{g\left(\beta^{-1}(b)\right)}{\beta^{\prime}\left(\beta^{-1}(b)\right)} \times(b-c)+\left(1-G\left(\beta^{-1}(b)\right)\right)=0
$$

onde $z=Z^{\prime}$ é a densidade de probabilidade de $Z_{1}$.

Em um equilíbrio simétrico, $b=\beta(c)$, e, portanto, a equação (112) se transforma na equação diferencial:

$$
-\frac{z(c)}{\beta^{\prime}(c)} \times(b-c)+(1-Z(c))=0
$$

Após algumas manipulações algébricas, obtemos a equação diferencial:

$$
[\beta(c)(1-Z(c))]^{\prime}=-z(c) c
$$

Integrando o lado esquerdo da equação para os limites $(c, 1)$ :

$$
[\beta(c)(1-Z(c))]_{c}^{1}=-\int_{c}^{1} y z(y) d y
$$

Integrando por partes o lado direito da equação e considerando $\beta(1)=1$, 


$$
[\beta(1)(1-Z(1))-\beta(c)(1-Z(c))]=-\left\{Z(1)-c Z(c)-\int_{c}^{1} Z(y) d y\right\}
$$

Como estamos considerando uma distribuição uniforme $[0,1]$

$$
[1(1-1)-\beta(c)(1-c)]=-\left\{1-c^{2}-\frac{1-c^{2}}{2}\right\}
$$

Logo,

$$
\beta(c)=\left[\frac{(c+1)}{2}\right]
$$

Para convergência à modelagem inicialmente proposta, basta considerar o $c \operatorname{como} d\left(G_{1}\right)$.

\subsubsection{Cálculo do abatimento esperado da dívida com dois jogadores para uma distribuição uniforme $[0,1]$}

Inicialmente vamos calcular o abatimento esperado dado que o jogador 1 vence. Para tanto, integraremos $d G_{2}$ para o intervalo em que o jogador 1 ganha e depois integraremos $d\left(G_{1}\right) d G_{1}$ para todo o intervalo $[0,1]$.

$$
\begin{aligned}
\int_{0}^{1} \int_{G_{1}}^{1} d\left(G_{1}\right) d G_{2} d G_{1} & =\int_{0}^{1} d\left(G_{1}\right)\left(1-G_{1}\right) d G_{1}=\int_{0}^{1} \frac{\left(G_{1}+1\right)}{2 p c}\left(1-G_{1}\right) d G_{1}= \\
& =\frac{1}{2 p c}\left(1-\frac{1}{3}\right)=\frac{1}{2 p c}\left(\frac{2}{3}\right)=\left(\frac{1}{3 p c}\right),
\end{aligned}
$$


Por simetria, esse também seria o abatimento/pagamento esperado do leiloeiro quando o jogador 2 vence. Assim, o abatimento/pagamento esperado total do governo é $\left(\frac{2}{3 p c}\right)$.

\subsubsection{O preço ótimo de reserva/pagamento ótimo de reserva}

Inicialmente, vale destacar que o ganho obtido com o preço de reserva decresce à medida que o número de jogadores cresce.

No contexto de um leilão tradicional, a definição do preço de reserva segue a lógica de definição do lance mínimo aceitável, isto é, limite que indica que valores menores não serão aceitos. Para os casos de licitação, onde em geral se busca o pagamento de menores valores por um bem ou serviço prestado pelos licitantes o preço de reserva segue a lógica do preço máximo aceitável a ser pago.

No caso do presente trabalho temos uma licitação e o preço de reserva está relacionado como o valor máximo de desconto das dívidas com multas aceito pelo Estado para a realização dos projetos de investimento que serão licitados.

Considerando que o preço ótimo de reserva é o mesmo em um leilão de primeiro ou segundo preço (Bichler e Kalagnanam, 2006 e Garratt (2011)), a seguir é apresentada a derivação do preço/desconto ótimo para o caso em tela para o caso de um leilão de segundo preço.

- $\quad$ Sejam 2 jogadores e $G_{i} \sim$ unif $[0,1]$.

- É possível definir três situações no que tange à realização do negócio:

1. Caso os dois licitantes demandem descontos sobre montante de multas acima do valor de reserva (máximo desconto aceitável pelo Governo), $R$, não será realizado o negócio. O referido ocorre com uma probabilidade $(1-R)^{2}$ e o desembolso é 0 (zero);

2. Caso um dos licitantes demande um desconto sobre o montante de multas abaixo do valor de reserva e o outro acima o negócio se concretizará. A probabilidade de ocorrência do negócio é $2(1-R) R$ e o desembolso será de $R$;

3. Na hipótese dos dois licitantes demandem um desconto sobre o montante de multas abaixo do valor de reserva o negócio se realizará no nível do segundo 
menor lance. Neste caso, o negócio ocorrerá com uma probabilidade de $R^{2}$ e o desembolso será $E\left[\max G_{i} \mid \max G_{i} \leq R\right]=\frac{2 R}{3}$, conforme demonstrado a seguir:

Temos que $G_{1}$ e $G_{2} \sim$ unif $[0,1]$ e independentes. Seja $w=\max \left\{G_{1}, G_{1}\right\}$. Temos que a densidade de $w$ é dada por $d_{w}(w)=\frac{d P(W<w)}{d w}$, onde $P(W<w)=P\left\{G_{1} \leq w, G_{2} \leq w\right\}$ que pelo fato de estarmos em uma distribuição uniforme entre 0 e 1 implica ser igual a $P\left(G_{1} \leq w\right)^{2}=$ $w^{2}, 0 \leq w \leq 1$.

Logo, temos a função de distribuição assim definida:

$$
P(W \leq w)=\left\{\begin{array}{cc}
0, & w \leq 0 \\
w^{2}, & 0 \leq w \leq 1 \\
1, & w>1
\end{array}\right.
$$

E a função de densidade assim definida:

$$
f_{w}(w)=\left\{\begin{array}{cc}
2 w, & 0 \leq w \leq 1 \\
0 & , \quad \text { c.c }
\end{array}\right.
$$

Assim,

$$
\begin{gathered}
E[w \mid w<R]=\frac{1}{P(w<R)} \int_{0}^{R} w f_{w}(w) d w=\frac{1}{R^{2}} \int_{0}^{R} w \cdot 2 w d w=\frac{2}{R^{2}} \int_{0}^{R} w^{2} d w= \\
E[w \mid w<R]=\frac{2}{R^{2}}\left(\frac{w^{3}}{3}\right)_{0}^{R}=\frac{2}{R^{2}} \frac{R^{3}}{3}=\frac{2 R}{3},
\end{gathered}
$$

Considerando o resultado acima obtido é possível calcular o desembolso esperado:

$$
D E=2(1-R) R \times R+R^{2} \times \frac{2 R}{3}=
$$




$$
=2 R^{2}-2 R^{3}+\frac{2 R^{3}}{3} \frac{6 R^{2}-6 R^{3}+2 R^{3}}{3}=\frac{6 R^{2}-4 R^{3}}{3},
$$

Derivando em R para obtermos os valores críticos:

$$
\begin{gathered}
\frac{d D E}{d R}=0 \Rightarrow \frac{1}{3}\left(12 R-12 R^{2}\right)=0 \Rightarrow 4 R-4 R^{2}=0 \Rightarrow R(4-4 R)=0 \\
R=0 \text { ou } 4-4 R=0 \Rightarrow R=1
\end{gathered}
$$

Dados os valores de R é possível concluir que se $R=0 \Rightarrow D E=0$ e se $R=1 \Rightarrow D E=$ $\frac{2}{3}$

\subsubsection{Equilíbrio da Licitação padrão $c \sim \mathrm{U}[0,1]$ com teto de preço $r$ :}

Suponha que o indivíduo 1 ganha se seu lance for $b$ tal que $b<\min _{i \neq 1} \beta\left(X_{i}\right)$. Como $\beta$ é crescente, por hipótese, $\min _{i \neq 1} \beta\left(X_{i}\right)=\beta\left[\min _{i \neq 1}\left(X_{i}\right)\right]=\beta\left(Z_{1}\right)$. O jogador ganha se $\beta\left(Z_{1}\right)>$ $b \Leftrightarrow Z_{1}>\beta^{-1}(b)$, onde $Z_{1}=\min _{i \neq 1} \beta\left(X_{i}\right)<b$. Logo, temos que resolver o seguinte problema:

$$
\left[1-G\left(\beta^{-1}(b)\right)\right] \times(b-c)
$$

Maximizando em $b$ :

$$
-\frac{g\left(\beta^{-1}(b)\right)}{\beta^{\prime}\left(\beta^{-1}(b)\right)} \times(b-c)+\left(1-G\left(\beta^{-1}(b)\right)\right)=0,
$$


Onde $g=G^{\prime}$ é a densidade de $Z_{1}$.

Em um equilíbrio simétrico, $b=\beta(c)$, e, portanto, a equação (123) se transforma na equação diferencial:

$$
-\frac{g(c)}{\beta^{\prime}(c)} \times(b-c)+(1-G(c))=0
$$

de onde:

$$
[\beta(c)(1-G(c))]^{\prime}=-g(c) c
$$

Integrando o lado esquerdo da equação para os limites $(c, r)$,

$$
[\beta(c)(1-G(c))]_{c}^{r}=-\int_{c}^{r} y g(y) d y
$$

Integrando por partes o lado direito da equação e considerando $\beta(r)=r$,

$$
[r(1-G(r))-\beta(c)(1-G(c))]=-\left\{r G(r)-c G(c)-\int_{c}^{r} G(y) d y\right\}
$$

Como estamos considerando uma distribuição uniforme $[0,1]$ :

$$
[r(1-r)-\beta(c)(1-c)]=-\left\{r^{2}-c^{2}-\frac{r^{2}-c^{2}}{2}\right\}
$$


Logo,

$$
\begin{gathered}
{[r(1-r)-\beta(c)(1-c)]=-r^{2}+c^{2}+\frac{r^{2}-c^{2}}{2},} \\
\beta(c)=\left[r(2-r)-c^{2}\right] \frac{1}{2(1-c)},
\end{gathered}
$$

Observe que se $r=1 \Rightarrow \beta(c)=\frac{1+c}{2}$.

\subsubsection{Desconto de equilíbrio na licitação, considerando uma distribuição uniforme $[0,1]$ com desconto de reserva}

Considerando todos os passos apresentados por ocasião do desenvolvimento do equilíbrio para o licitação de projetos de investimento, a seguir apresentar-se-á o resultado do equilíbrio considerando a presença de um valor de desconto de reserva:

$$
\left[\left(1-G_{1}\right) d\left(G_{1}\right)\right]_{G_{1}}^{r}=-\int_{G_{1}}^{r} \frac{G_{1}}{p c} d G_{1},
$$

Sabe-se que $d(r)=r$,

$$
d\left(G_{1}\right)=\frac{1}{\left(1-G_{1}\right)}\left[(1-r) r+\frac{r^{2}-G_{1}{ }^{2}}{2 p c}\right]
$$

Considerando a simetria, o lance do jogador 2 em equilíbrio é:

$$
d\left(G_{2}\right)=\frac{1}{\left(1-G_{2}\right)}\left[(1-r) r+\frac{r^{2}-G_{2}{ }^{2}}{2 p c}\right]
$$

Importante destacar que o desconto de equilíbrio é agora função do valor de reserva a ser estabelecido pelo leiloeiro. Assim, quando $r=1$ temos a situação expressa pelo modelo geral. 


\subsubsection{Cálculo do retorno esperado do leiloeiro no modelo de licitação, considerando uma distribuição uniforme $[0,1]$ e a ausência de valor de reserva.}

Inicialmente vamos calcular o ganho esperado dado que o jogador 1 vence. Para tanto integraremos $d G_{2}$ para o intervalo em que o jogador 1 ganha $\left[G_{1}, 1\right]$ e depois integraremos $d\left(G_{1}\right) d G_{1}$ para todo o intervalo $[0,1]$.

$$
\int_{0}^{1} \int_{G_{1}}^{1}\left(v-d\left(G_{1}\right)\right) d G_{2} d G_{1}=\int_{0}^{1}\left(v-d\left(G_{1}\right)\right)\left(1-G_{1}\right) d G_{1}=\frac{3 v p c-2}{6 p c}
$$

Retorno esperado para os dois jogadores:

$$
=\frac{3 v p c-2}{3 p c}
$$

Portanto, essa expressão indica o retorno esperado do leiloeiro em uma licitação sem preço de reserva e considerando uma distribuição uniforme $[0,1]$ e indica que quanto menor a probabilidade de o agente ter que pagar a multa e o custo estimado do projeto e maior o valor para o licitante, maior será seu valor esperado.

\subsubsection{Duas Licitações com preço de reserva endógeno}

A presente seção analisará uma proposta de desenho de licitação com preço de reserva endógeno tanto para o primeiro como para o segundo, comparando o resultado obtido com o modelo padrão não sequencial.

\subsubsection{Setup}

Considere, inicialmente, que fixemos um jogador: $J_{1}$. Permita que a variável aleatória $Y_{1} \equiv Y_{1}^{(N-1)}$ denote o maior valor entre os N-1 jogadores restantes. De outra maneira, $Y_{1}$ é a 
menor ordem estatística de $X_{2}, X_{3}, \ldots, X_{N}$. Seja $G$ a função de distribuição de $Y_{1}$. Assim, $\forall y,(1-$ $G(y))=(1-F(y))^{N-1}$ e considerando o valor de reserva positivo, isto é, $r>0$.

Mostraremos de forma preliminar que a recebimento esperado pelo jogador (licitante) do tipo $c$ tende a ser, em média, a mesma nas duas licitações.

\subsubsection{Licitação de segundo preço}

Para o caso da licitação de segundo preço não existe diferença no comportamento dos participantes, ou seja, $\beta^{I I}(c)=c$. Donde temos que:

Temos que o recebimento esperado do fornecedor é dado pela esperança

$$
\begin{gathered}
R E=\operatorname{prob}[\text { vencer }] \times E\left[2^{\circ} \text { menor lance } \mid x \text { é } o \text { menor lance }\right] \\
R E=\operatorname{prob}[\text { vencer }] \times E\left[2^{\circ} \text { menor valor } \mid x \text { é } o \text { menor valor }\right] \\
E\left[Y_{1} \mid Y_{1}>X\right] \times[1-G(x)]
\end{gathered}
$$

Assim,

- $\operatorname{Se} c<r \Rightarrow R E^{I I}(c, r)=r(1-G(r))+\int_{c}^{r} y g(y) d y$

- $\operatorname{Se} c=r \Rightarrow R E^{I I}(c, r)=r(1-G(r))$

- $\operatorname{Se} c>r \Rightarrow R E^{I I}(c, r)=0$

Logo, $R E^{I I}(c, r)=r(1-G(r))+\int_{c}^{r} y g(y) d y$

\subsubsection{Licitação de primeiro preço}

Considerando o fato de que o lance de equilíbrio na licitação de primeiro preço, no contexto apresentado, deve considerar a presença de preço de reserva, pode-se escrevê-lo como se segue:

$$
\begin{aligned}
& \text { Se } c<r \Rightarrow \beta^{I}(c)=E\left[\min \left[Y_{1}, r\right] \mid Y_{1}>c\right] \\
& \beta^{I}(c)=\frac{1}{1-G(c)}\left[\int_{c}^{r} y g(y) d y+\int_{r}^{1} r g(y) d y\right],
\end{aligned}
$$




$$
\begin{gathered}
\beta^{I}(c)=\frac{1}{1-G(c)}\left[\int_{c}^{r} y g(y) d y+r[G(1)-G(r)]\right], \\
\beta^{I}(c)=\frac{1}{1-G(c)} \int_{c}^{r} y g(y) d y+r \frac{1-G(r)}{1-G(c)}
\end{gathered}
$$

\subsubsection{Recebimento esperado pelo fornecedor}

Na mesma direção, o recebimento esperado pelo fornecedor é obtido pelo lance oferecido multiplicado pela probabilidade de vencer o certame, conforme apresentado a seguir:

$$
\begin{gathered}
R E^{I}(c, r)=\beta^{I}(c) \times(1-G(c)), \\
R E^{I}(c, r)=\left(\frac{1}{1-G(c)} \int_{c}^{r} y g(y) d y+r \frac{1-G(r)}{1-G(c)}\right) \times(1-G(c)), \\
R E^{I}(c, r)=\int_{c}^{r} y g(y) d y+r(1-G(r)),
\end{gathered}
$$

Note que $R E^{I}(c, r)=R E^{I I}(c, r)$, isto é, o jogador do tipo $c$ espera receber a mesma receita (em média) nas duas licitações.

Na seção subsequente mostraremos qual é o pagamento esperado pelo Estado (Anatel) que, para o caso em análise, será efetivado por meio de abatimento do montante de multas e qual é o valor de reserva ótimo a ser estabelecido pelo regulador para o certame.

\subsubsection{Pagamento esperado pelo Estado (Anatel)}

Considerando os cálculos anteriores, o pagamento esperado em qualquer uma das licitações $(A=I, I I)$ para o Estado é:

$$
P E(c, r)=E\left[R E^{A}(c, r)\right]=\int_{\underline{w}}^{r} R E^{A}(c, r) f(c) d c
$$


Trocando a ordem da integração:

$$
\int_{\underline{w}}^{r} \int_{c}^{r} y g(y) d y f(c) d c=\int_{\underline{w}}^{r} \int_{\underline{w}}^{y} f(c) d c y g(y) d y=\int_{\underline{w}}^{r}[F(y)-F(\underline{w})] y g(y) d y(*),(14
$$

Portanto, como $F(\underline{w})=0$, o pagamento esperado do Estado é

$$
P E(c, r)=r(1-G(r)) F(r)+\int_{\underline{w}}^{r} F(y) y g(y) d y,
$$

Supondo que o objeto tem valor $c_{0}$ para o comprador e que existam $N$ fornecedores, o pagamento esperado total para o comprador é:

$$
\gamma\left(c_{0}, r\right)=N \times P E(c, r)+1-(1-F(r))^{N} c_{0}
$$

Onde,

$P E$ é o pagamento esperado para um jogador; e $1-(1-F(r))^{N} c_{0}=$ pagamento esperado, considerando que os jogadores cobrem o valor atribuído pelo leiloeiro.

\subsubsection{Calculando o preço ótimo de reserva}

A presente subseção apresenta o desenvolvimento dos cálculos para a obtenção do preço ótimo de reserva que permite contribuir para a otimização do valor de pagamento esperado pelo comprador:

$$
\begin{gathered}
\frac{d \gamma\left(c_{0}, r\right)}{d r}=N \frac{d P E(c, r)}{d r}-N(1-F(r))^{N-1} f(r) c_{0}, \\
\frac{d \gamma\left(c_{0}, r\right)}{d r}=N\{F(r)+r f(r)\}\left(1-G(r)-N(1-F(r))^{N-1} f(r) c_{0}=0,\right.
\end{gathered}
$$

$\operatorname{Como}(1-F(r))^{N-1}=(1-G(r))$

$$
\frac{d \gamma\left(c_{0}, r\right)}{d r}=N\left\{F(r)+r f(r)-f(r) c_{0}\right\}(1-G(r)=0,
$$




$$
\begin{aligned}
& \text { Para } 0<c_{0}<1,\left.\frac{d \gamma\left(c_{0}, r\right)}{d r}\right|_{r=c_{0}}=N F\left(c_{0}\right)\left(1-G\left(c_{0}\right)>0 .\right. \text { Logo, } \\
& 1+\frac{f(r)}{F(r)}\left[r-c_{0}\right]=0 \Leftrightarrow 1=\frac{f(r)}{F(r)}\left[c_{0}-r\right] \Leftrightarrow \frac{F(r)}{f(r)}=\left[c_{0}-r\right] \Leftrightarrow r=c_{0}-\frac{F(r)}{f(r)}
\end{aligned}
$$

Fazendo $F \sim U[0,1] \Rightarrow F(r)=r ; f(r)=1 ; c_{0}=1$

$$
r=\frac{1}{2}
$$

Conforme evidenciado nos cálculos acima o valor ótimo de reserva deve corresponder à metade do valor (custo) atribuído pelo leiloeiro. A seção subsequente destaca o cálculo do lucro esperado pelo fornecedor ao decidir participar do certame.

\subsubsection{Payoff esperado pelo fornecedor}

O payoff esperado pelo fornecedor é sua receita esperada menos o seu custo esperado:

$$
\Pi(r)=r(1-G(r)) F(r)+\int_{\underline{w}}^{r} F(y) y g(y) d y-\int_{\underline{w}}^{r} c_{0} G\left(c_{0}\right) f\left(c_{0}\right) d c_{0},
$$

Para o caso de $N=2, G\left(c_{0}\right)=F\left(c_{0}\right)$ e $f(y)=g(y)$, portanto, o payoff esperado é:

$$
\Pi(r)=r(1-F(r)) F(r)+\int_{\underline{w}}^{r} F(y) y f(y) d y-\int_{\underline{w}}^{r} c_{0} F\left(c_{0}\right) f\left(c_{0}\right) d c_{0},
$$

Integrando por partes:

$$
\Pi(r)=r(1-F(r)) F(r)+\frac{1}{2} \int_{\underline{w}}^{r} 2 F(y) y f(y) d y-\frac{1}{2} \int_{\underline{w}}^{r} 2 c_{0} F\left(c_{0}\right) f\left(c_{0}\right) d c_{0},
$$

Fazendo para a primeira integral $u=y \Rightarrow d u=d y ; d v=2 F(y) f(y) d y \Rightarrow v=F(y)^{2}$ e para a segunda integral $u=c_{0} \Rightarrow d u=d c_{0} ; d v=c_{0} F\left(c_{0}\right) f\left(c_{0}\right) d c_{0} \Rightarrow v=F\left(c_{0}\right)^{2}$, temos: 


$$
\begin{gathered}
\Pi(r)=r(1-F(r)) F(r)+\frac{1}{2}\left[r F(r)^{2}-\int_{\underline{w}}^{r} F(y)^{2} d y+r F(r)^{2}+\int_{\underline{w}}^{r} F\left(c_{0}\right)^{2} d c_{0}\right], \\
\Pi(r)=r F(r)-\frac{1}{2} \int_{\underline{w}}^{r} F(y)^{2} \mathrm{dy}-\frac{1}{2} \int_{\underline{w}}^{r} F\left(c_{0}\right)^{2} d c_{0},
\end{gathered}
$$

Para o caso uniforme,

$$
\Pi(r)=r^{2}-\left.\frac{1}{2} \frac{y^{3}}{3}\right|_{0} ^{r}-\left.\frac{1}{2} \frac{c_{0}^{3}}{3}\right|_{0} ^{r}=r^{2}-\frac{r^{3}}{3}
$$

A seguir, com base no desenvolvimento realizado até este ponto, buscar-se-á obter a solução para o problema de licitação sequencial com a vinculação do valor de reserva. A solução é apresentada utilizando a indução retroativa.

\subsubsection{Primeiro período para Licitação de primeiro preço}

Seja $\beta($.$) uma função lance monotônica para cada jogador. \mathrm{O} \pi_{i}(z, c)$ é o lucro esperado agregado (tanto do primeiro como do segundo período) do jogador $i$ se o jogador $j$ segue a estratégia $\beta($.$) e o jogador i$ dá um lance $\beta(z)$, quando seu verdadeiro custo é $c$.

Vamos assumir que o tipo do indivíduo $i$ é $c$ e todos os outros jogadores jogam de acordo com sua função lance $\beta($.$) , supondo que \beta$ é estritamente crescente e contínua. Desta forma, $\beta(\underline{w})$ é o menor lance e deve valer $\beta(r)=r$ para que seja um equilíbrio (no limite, pela continuidade).

Adicionalmente, nenhum lance $b<\beta(\underline{w})$ poderia ser uma melhor resposta para $i$, pelo fato de ter certeza de ganhar mesmo com um lance maior no intervalo $(b, \beta(\underline{w}))$ e receber mais.

Portanto, $i$ escolherá um lance no intervalo $(\beta(\underline{w}), \beta(r)=r)$. Seja $\beta(z)$ o lance e $y$ um tipo genérico do outro jogador. Assim, o payoff esperado do jogador $i$ do tipo $c$ é: 
$\Pi(z, c)=[\beta(z)-c+\pi(\beta(z))] \times \operatorname{prob}[\beta(z) \leq \beta(y)]+E[\pi(\beta(y)) \mid[\beta(z) \geq \beta(y)] \times$ $\operatorname{prob}[\beta(z) \geq \beta(y)]$,

$$
\Pi(z, c)=[\beta(z)-c+\pi(\beta(z))] \times(1-F(z))+\int_{\underline{w}}^{z} \pi(\beta(y)) f(y) d y,
$$

Note que, Pelo Teorema Fundamental do Cálculo $\frac{d \int_{\underline{w}}^{z} \Pi(\beta(y)) f(y) d y}{d z}=\Pi(\beta(z)) f(z)$. Assim, tomando a derivada de (156), obtemos a condição de primeira ordem:

$\frac{d \Pi}{d z}(z, c)=\left[\beta^{\prime}(z)+\pi^{\prime}(\beta(z)) \beta^{\prime}(z)\right](1-F(z))+[\beta(z)-c+\pi(\beta(z))](-f(z))+$ $\pi(\beta(z)) f(z)=0$,

$$
\beta^{\prime}(z)=\frac{[\beta(z)-c](f(z))}{[1+\pi \prime(\beta(z))](1-F(z))},
$$

É equilíbrio de Nash se for ótimo para $i$ escolher $z=c$, isto é, $z=c$ resolve a equação (158).

$$
\beta^{\prime}(c)=\frac{[\beta(c)-c]}{\left[1+\Pi^{\prime}(\beta(c))\right]} \frac{f(c)}{(1-F(c))}
$$

Para efeito de comparação, a estratégia de lances $\gamma$ no FPPA é:

$$
\gamma^{\prime}(c)=\frac{[\gamma(c)-c] f(c)}{(1-F(c))}
$$

Para o caso de distribuição uniforme: $f(c)=1 ; F(c)=c ; \Pi^{\prime}(r)=2 r-r^{2}$ :

$$
\beta^{\prime}(c)=\frac{[\beta(c)-c]}{\left[1+2 \beta(c)-\beta(c)^{2}\right]} \frac{1}{(1-c)} \Leftrightarrow
$$




$$
\beta^{\prime}(c)\left[1+2 \beta(c)-\beta(c)^{2}\right](1-c)+[c-\beta(c)]=0
$$

Fazendo $y=\beta(c)$ e $x=c$ podemos reescrever:

$$
y^{\prime}(1-x)\left(1+2 y-y^{2}\right)+x-y=0,
$$

Para obtermos a solução do lance de equilíbrio, considerando as condições apresentadas, faz-se necessária a resolução da equação diferencial (159), o que não é possível ser feito analiticamente Por isso, a equação foi resolvida considerando-a como um problema de valor de contorno (PVC) no qual as condições $\beta(1)=1$ e $\beta(0)=\alpha$ foram aplicadas. $\mathrm{O}$ valor de $\alpha$ é determinado durante a solução do problema, de forma a que o problema satisfaça a segunda condição do PVC. As equações foram integradas usando a rotina BVP do software Maple que utiliza um método iterativo para determinar $\alpha$.

\section{Figura 4.6. Licitação Sequencial - Primeiro Preço}

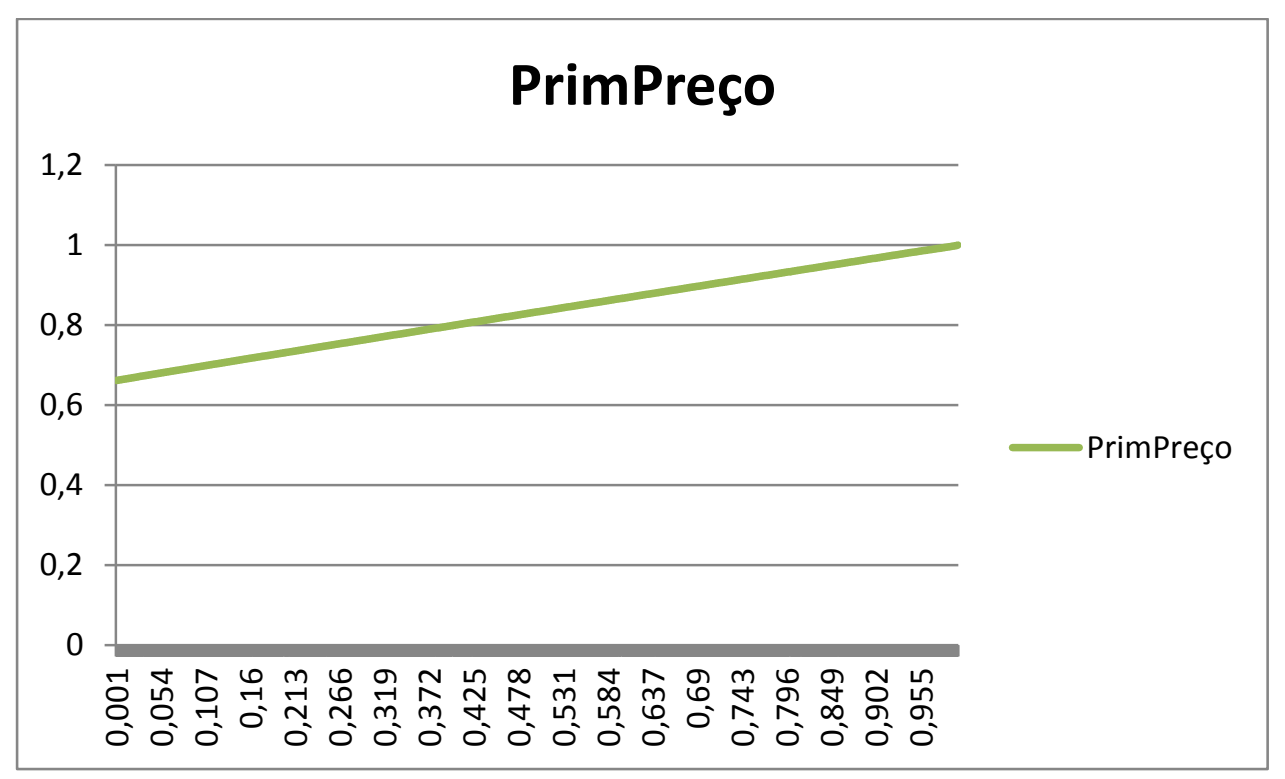

O gráfico revela que os lances partem de, aproximadamente, $\frac{2}{3}$ o que é coerente com o desembolso esperado por parte do licitante, conforme apresentado anteriormente.

A partir dos pontos obtidos no processo de solução numérica e com a utilização do método de ajuste de mínimos quadrados foi possível chegar a uma forma funcional aproximada 
$f(x)=0,338087 x+0,662855$ com um $R^{2}=0,9999$, o que nos fornece uma margem de erro inferior a $1 \%$ no ajuste dos mínimos quadrados.

Figura 4.7. Licitação Sequencial - Primeiro Preço - Ajustamento

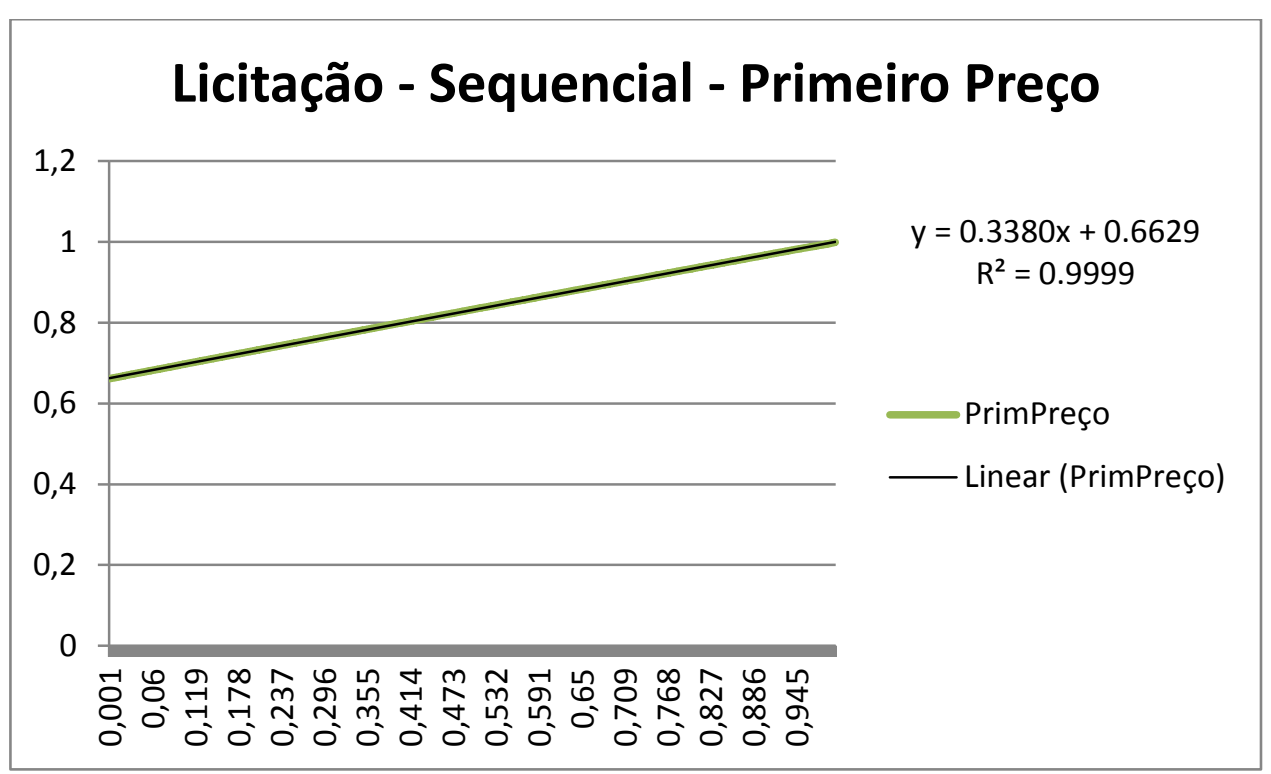

\subsection{Propriedades da estratégia do primeiro período da licitação de primeiro preço}

\section{Proposições e Conjecturas}

No trabalho Sequencial auction with endogenous reserve price (Sergei Izmalkov comunicação privada) o autor apresenta propriedades sobre o lance de equilíbrio do leilão sequencial vis-à-vis ao leilão padrão de primeiro preço. Entretanto, segundo nossa visão as demonstrações não se encontram completas.

Neste sentido, o desenvolvimento feito no presente trabalho para licitação também se depara com o questionamento sobre a forma como poderíamos provar para todo $c$ a conjectura 1 que, pela análise gráfica indica que pelo menos no domínio $(0,1), \gamma(\boldsymbol{c})<\boldsymbol{\beta}(\boldsymbol{c})$. Importante destacar que para fins de tomada de decisão quanto ao modelo mais vantajoso para o poder público a solução gráfica é reveladora. A demonstração formal da conjectura 1 é deixada para trabalho futuro. 


\section{Proposição 1: $\beta$ é função crescente;}

Prova: Sabemos que $\beta^{\prime}(c)=\frac{[\beta(c)-c]}{[1+\pi \prime(\beta(c))]} \frac{f(c)}{(1-F(c))}$. Note que para todo $c$ tal que $\beta(c) \leq c$ implica que $\beta^{\prime}(c) \leq 0$. Combinando esta sentença com o fato de $\beta(1)=1$ resulta em $\beta(c) \geq c$. Assim, para todo $c$ tal que $\beta(c) \geq c$ implica que $\beta^{\prime}(c) \geq 0$. Suponha que $(a, b)$ é um intervalo no qual $\beta(c)=t$ para alguma constante $t$. Então, deve ser o caso que $\beta^{\prime}(c)=0, \forall c \in(a, b)$. Essa última expressão implica que $\beta(c)=c$ o que contradiz a hipótese de $\beta$ ser constante em $(a, b)$. Portanto, $\beta$ é uma função crescente.

3. Conjectura 1: $\gamma(c)<\beta(c), c \in(0,1)$.

Prova: Sabemos que $\beta^{\prime}(c)=\frac{[\beta(c)-c]}{\left[1+\pi^{\prime}(\beta(c))\right]} \frac{f(c)}{(1-F(c))}$ refere-se à equação que fornece a estratégia de equilíbrio do modelo sequencial e $\gamma^{\prime}(\mathrm{c})=[\gamma(\mathrm{c})-\mathrm{c}] \frac{\mathrm{f}(\mathrm{c})}{(1-\mathrm{F}(\mathrm{c}))}$ é a equação que fornece a estratégia de equilíbrio do modelo padrão. Suponha, por contradição, que $\gamma(c)>\beta(c), \forall c>0$. Neste caso a relação entre as derivadas é $\gamma^{\prime}(\mathrm{c})>\beta^{\prime}(\mathrm{c})$. Por outro lado, ao considerarmos $\gamma(\mathrm{c})<\beta(\mathrm{c})$, obtém-se o resultado que dependerá do valor de $\pi^{\prime}(\beta(c))$. Portanto, chega-se a uma situação, inicialmente, inconclusiva.

Todavia, considerando uma solução gráfica para o problema, no domínio $(0,1)$ é possível verificar que $\gamma(\boldsymbol{c})<\boldsymbol{\beta}(\boldsymbol{c})$, conforme apresentado na figura 4.8, a seguir:

\section{Figura 4.8. Licitação padrão e sequencial - Primeiro Preço}

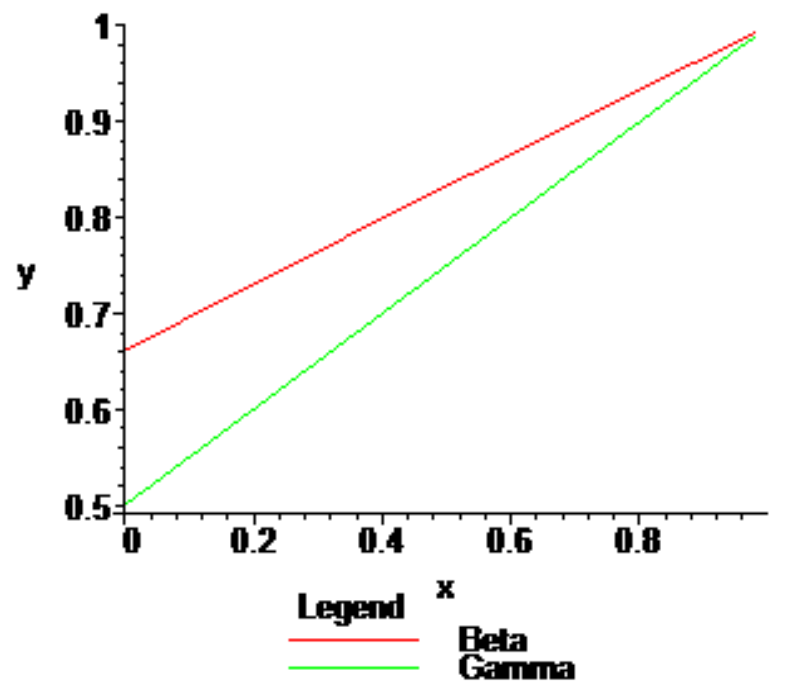




\subsubsection{Primeiro período para licitação de segundo preço}

Seja $\beta\left(\right.$. ) Uma função lance monotônica para cada jogador. $\pi_{i}(z, c)$ é o lucro esperado agregado (tanto do primeiro como do segundo período) do jogador $i$ se o jogador $j$ segue a estratégia $\beta($.$) e o jogador i$ dá um lance $\beta(z)$ quando seu verdadeiro custo é $c$.

Assumindo que o tipo do indivíduo $i$ é $c$.

Todos os outros jogadores jogam de acordo com sua função lance $\beta($.$) , supondo que \beta$ é estritamente crescente e contínua. Desta forma, $\beta(\underline{w})$ é o menor lance e deve valer $\beta(r)=r$ para que seja um equilíbrio (no limite, pela continuidade).

Adicionalmente, nenhum lance $\mathrm{b}<\beta(\underline{\mathrm{w}})$ poderia ser uma melhor resposta para $\mathrm{i}$, pelo fato de ter certeza de ganhar mesmo com um lance maior no intervalo $(b, \beta(\underline{w}))$ e receber mais.

Portanto, i escolherá um lance no intervalo $(\beta(\underline{w}), \beta(r)=r)$. Seja $\beta(z)$ o lance e y um tipo genérico do outro jogador. Assim, o payoff esperado do jogador i do tipo c é:

$$
\begin{aligned}
& \Pi(z, c)=E[\beta(y)-c+\pi(\beta(y)) \mid \beta(z) \leq \beta(y)] \times \operatorname{prob}[\beta(z) \leq \beta(y)]+\pi(\beta(z)) \times \\
& \operatorname{prob}[\beta(z)>\beta(y)],
\end{aligned}
$$

$$
\Pi(z, c)=\int_{z}^{\bar{w}}[\beta(y)-c+\pi(\beta(y))] f(y) d y+\pi(\beta(z)) \times F(z)
$$

Note que, Pelo Teorema Fundamental do Cálculo $\frac{d \int_{z}^{\bar{w}}[\beta(y)-c+\Pi(\beta(y))] f(y) d y}{d z}=$ $-[\beta(z)-c+\Pi(\beta(z))] f(z)$. Assim, tomando a derivada de $(* * * *)$, obtemos a condição de primeira ordem:

$$
\begin{gathered}
\frac{d \Pi}{d z}(z, c)=-[\beta(z)-c+\pi(\beta(z))] f(z)+\left[\pi^{\prime}(\beta(z)) \beta^{\prime}(z)\right] F(z)+\pi(\beta(z)) f(z)=0, \\
\beta^{\prime}(z)=\frac{[\beta(z)-c] f(z)}{\pi \prime(\beta(z)) F(z)},
\end{gathered}
$$


É equilíbrio de Nash se for ótimo para $i$ escolher $z=c$, isto é, $z=c$ resolve a equação (163).

$$
\beta^{\prime}(c)=\frac{[\beta(c)-c] f(c)}{\pi \prime(\beta(c)) F(c)}
$$

Para o caso de distribuição $f(c)=1 ; F(c)=c ; \pi^{\prime}(r)=2 r-r^{2}$ :

$$
\begin{gathered}
\beta^{\prime}(c)=\frac{[\beta(c)-c]}{\left[2 \beta(c)-\beta(c)^{2}\right] c} \\
c \beta^{\prime}(c)\left[2 \beta(c)-\beta(c)^{2}\right]-\beta(c)+c=0
\end{gathered}
$$

Fazendo $y=\beta(c)$ e $x=c$ podemos reescrever:

$$
x y^{\prime}\left(2 y-y^{2}\right)-y+x=0
$$

Da mesma maneira, essa equação diferencial não possui solução exata. Por isso a equação foi resolvida considerando-a como um problema de valor de contorno (PVC) no qual as condições $\beta(1)=1$ e $\beta(0)=\alpha$ foram aplicadas. $\mathrm{O}$ valor de $\alpha$ é determinado durante a solução do problema, de forma a que o problema satisfaça a segunda condição do PVC. As equações foram integradas usando a rotina BVP do software Maple que utiliza um método iterativo para determinar $\alpha$. A figura 4.9, apresentada a seguir mostra o comportamento da solução: 
Figura 4.9. Licitação Sequencial - Segundo Preço

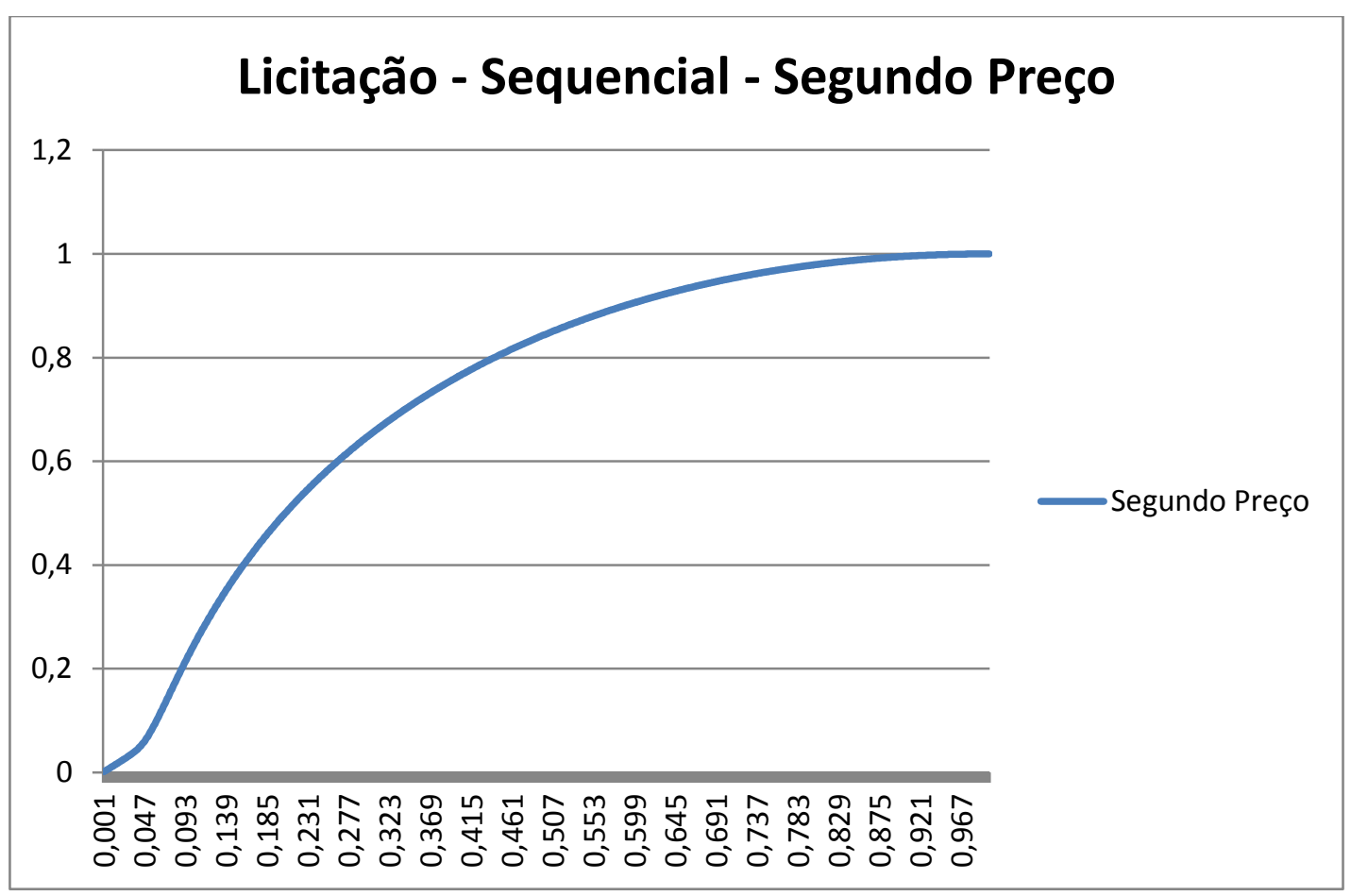

A partir dos pontos obtidos no processo de solução numérica e com a utilização do método de ajuste de mínimos quadrados ordinários foi possível chegar a uma forma funcional aproximada por uma função logarítmica $g(x) y=0.2828 \ln (x)-0.9405$ com um $R^{2}=$ 0,9279 , conforme figura apresentada a seguir: 
Figura 4.10. Licitação Sequencial - Segundo Preço - Ajustamento

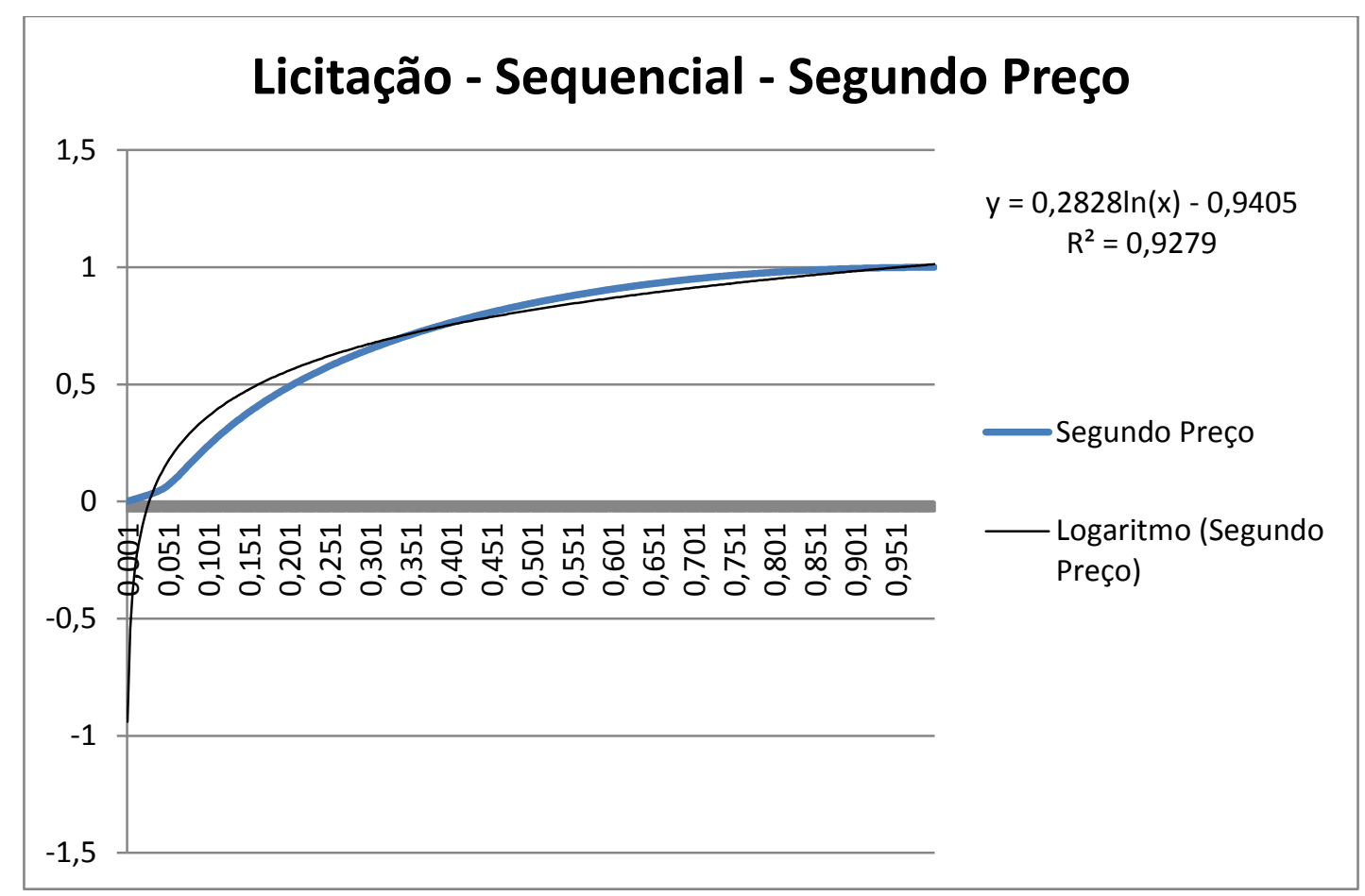

4.5.8.9.1 Propriedades da estratégia do primeiro período da licitação de segundo preço

\section{Proposição: $\beta$ é função crescente;}

Prova: Sabemos que $\beta^{\prime}(c)=\frac{[\beta(c)-c] f(c)}{\pi \prime(\beta(c)) F(c)}$. Note que para todo $c$ tal que $\beta(c) \leq c$ implica que $\beta^{\prime}(c) \leq 0$. Combinando esta sentença com o fato de $\beta(1)=1$ resulta em $\beta(c) \geq c$. Assim, para todo $c$ tal que $\beta(c) \geq c$ implica que $\beta^{\prime}(c) \geq 0$. Suponha que $(a, b)$ é um intervalo no qual $\beta(c)=t$ para alguma constante $t$. Então, deve ser o caso que $\beta^{\prime}(c)=0, \forall c \in(a, b)$. Essa última expressão implica que $\beta(c)=c$ o que contradiz a hipótese de $\beta$ ser constante em $(a, b)$. Portanto, $\beta$ é uma função crescente.

2. $\beta(c)>c$ para todo $x \in(0,1)$ e $\beta(0)=0$;

Prova: Como $\beta^{\prime}(c)>0$ de acordo com a proposição $1 \beta(c)>c$ para todo $x \in(0,1) . \beta(0)=0$ segue diretamente da equação. 


\subsection{Considerações finais e sugestão de estudos futuros}

O presente capítulo buscou contribuir com o processo de regulamentação do TAC proposto pela Anatel, bem como com processos semelhantes levados a cabo pelos demais órgãos da Administração Pública que venham a ter interesse na utilização de mecanismos de solução negociada, através da modelagem de leilão.

Para construção da proposta de mecanismo foi desenvolvido, primeiramente, um modelo básico para licitação, seguido de um modelo de licitação sequencial com definição do preço de reserva endogenamente.

Ambos os modelos de leilão tiveram como premissa a busca pela maximização da eficiência no processo de definição da taxa de troca a ser aplicada quando da celebração de termos de ajustamento de conduta, entre os investimentos realizados no setor e o correspondente abatimento de parcela do estoque de multas das prestadoras contratantes.

Conforme demonstrado no corpo do capítulo, foi possível mostrar que o modelo de leilão sequencial se apresentou menos vantajoso para o Estado (Anatel) na medida em que tende a majorar os lances na licitação, o que redundaria em taxa de desconto maior a incidir sobre o montante de multas, implicando menor eficiência na aplicação dos recursos que por assim dizer pertencem em termos probabilísticos ao Estado via possível arrecadação das multas.

Uma modelagem alternativa pode ser feita na direção de se restringir a oferta para uma mesma firma, oferta unitária de projetos de investimento, por exemplo, para um determinado bloco licitado. Com esta nova modelagem os resultados podem se apresentar distintos, o que é deixado para a verificação em trabalho futuro.

Oportuno ressaltar que a literatura de leilões é bastante rica e interessante, sobretudo para aqueles que compreendem a importância de favorecer o mecanismo de mercado vis-à-vis a outra forma menos eficiente de definição de valores de troca.

Ao longo do presente trabalho foi possível estudar outros temas altamente relevantes, inclusive para tornar mais robusta a presente proposta, mas que em função da limitação de tempo e espaço são deixados aqui como oportunidade de extensões futuras. 
A literatura de biding rings conforme apresentada por McAfee e McMillan (1992), Porter e Zona (1992), Thomas (2001), Thomas (2005), Che e Kim (2008), busca tratar os problemas de colusão, incluindo a possibilidade de se utilizar preço de reserva como forma de combater esse tipo de situação indesejada. Para o caso em discussão no presente capítulo pode-se afirmar que a utilização de mecanismos anticolusão pode ser considerada bastante apropriada, uma vez que o volume de firmas tende a não ser muito grande.

A literatura de Barganing games apresenta um extenso volume de trabalhos relevantes, incluindo os trabalhos de Nash (1950), Roth (1977), Chatterjee e Samuelson (1983), Ausubel et. al. (2002), Kalandrakis (2004), dentre outros, que também pode ser usada em trabalhos futuros de modo a construir com o aumento da eficiência no processo licitatório.

Por fim, é possível destacar, ainda, outros temas abordados pela literatura consultada e que podem ser objeto de trabalhos futuros. Estes estão relacionados ao debate sobre a eficiência dos leilões sequenciais versus leilões simultâneos, a questão da qualidade dos produtos ou serviços prestados como produto de um processo licitatório, bem como ao mecanismo de pregão eletrônico. 


\section{CAPÍTULO 5 - Conclusões}

A evolução do setor de telecomunicações no Brasil nos últimos 15 anos foi notável, fazendo com que o país atingisse o estado da arte tecnológico. Em especial, os cidadãos mais humildes passaram a ter acesso a serviços e aplicações que aumentaram sua inserção no mercado de trabalho e permitiram maior acesso às fontes de informação.

Conforme apresentado no presente trabalho, os benefícios do maior fluxo de investimentos nas telecomunicações contribuíram para o crescimento econômico do país que, por sua vez, também contribuiu para a elevação do bem estar da população brasileira.

Nesta direção o trabalho destacou a existência de relação de causalidade unidirecional de curto e longo prazos indo das variáveis estoque de capital $(\mathrm{K})$ e terminais por população ocupada (T) para PIB real, o que significa que o crescimento dessas variáveis causam crescimento do produto. Importante destacar que o impacto das telecomunicações sobre o produto pode se dar tanto pela via direta, via aumento dos investimentos em infraestrutura quanto pela via indireta, isto é, contribuindo para o aumento de produtividade de múltiplos setores da economia.

O trabalho também destacou que o sentido da causalidade é de telecomunicações para produto, isto é, telecomunicações implicam PIB e não o contrário. Desta forma, ao se pensar em políticas públicas faz-se oportuno considerar essa relação, bem como o efeito multiplicador de telecomunicações nas demais indústrias.

Entretanto, é de conhecimento comum que a prestação dos serviços de telecomunicações carece ainda de melhoria em sua qualidade e no que tange ao nível de atendimento, motivos do grande volume de reclamações e instauração de procedimentos administrativos de apuração de descumprimento.

Esse grande volume de infrações ao longo dos anos foi resultado, dentre outras questões, de um desalinhamento da conduta dos prestadores em relação aos contratos celebrados com o poder público. Associado a isto, pode-se destacar que a Anatel teve sua instrumentalização para atuar na regulação do mercado postergada em alguns anos, o que contribuiu para o tratamento tímido dos problemas de ações ocultas nos primeiros anos do novo modelo de prestação dos serviços.

O acúmulo temporal da aplicação de sanções agravou a situação de descumprimentos de obrigações uma vez que parte do esforço das operadoras foi direcionado para litigar em âmbito 
administrativo e judicial com o regulador para cancelar ou reduzir os valores sancionados, o que, na prática, não contribuiu para a correção de condutas indevidas. A atuação do regulador, diante de grandes desafios, foi lenta no que se refere à busca de melhores mecanismos para lidar com os problemas de informação.

Neste sentido, o presente trabalho também buscou endereçar a questão do desenho de contratos como central para a adequação das práticas dos regulados, através de mecanismos de incentivo definidos a partir de um conhecimento mais profundo do tipo das firmas ou, eventualmente, a redução de obrigações consideradas não essenciais para a satisfação dos usuários, mitigando, assim, os incentivos para que as firmas desviem do comportamento esperado. Assim, a atuação ex-ante ou preventiva do órgão regulador no que diz respeito à busca de maiores informações sobre o tipo das firmas que atuem ou venham atuar no setor, considerando como pressuposto a existência de um ambiente contratual flexível, poderia contribuir para uma formatação mais adequada e eficiente dos contratos.

Ademais, este trabalho, ao mesmo tempo em que destaca a importância do setor de telecomunicações para o crescimento econômico e discute a importância de se lidar adequadamente com os problemas de perigo moral para construir um futuro mais promissor para as telecomunicações, buscou oferecer uma proposta concreta para contribuir com a solução do problema do elevado estoque de multas, via mecanismo de licitação. Conforme apresentado nos resultados, segundo uma análise gráfica, a abordagem tradicional de licitação mostrou-se mais vantajosa do que a versão sequencial, o que indica que a modelagem sequencial com definição endógena do preço de reserva deve ser preterida, uma vez que tende a majorar os lances, isto é a cobrança ou desconto exigido pelos jogadores para implementar os projetos. A ideia motriz do desenvolvimento e proposição deste mecanismo de leilão é a busca por mecanismo que contribua para maximizar a eficiência do processo de celebração dos termos de ajustamento de conduta e, por consequência, a maximização da eficiência dos investimentos no setor, favorecendo, assim, a modernização da indústria de telecomunicações no Brasil, em conformidade com o dispositivo legal.

Considerando a amplitude dos temas aqui tratados, foram apresentadas ideias e possibilidades de extensões do trabalho desenvolvido para incluir aspectos que a literatura discute em outros contextos, como, por exemplo, o desenho de mecanismo robusto à tentativa de conluio. 
Diante de todo exposto, pode-se afirmar que o presente trabalho buscou contribuir com o debate recente no setor de telecomunicações do Brasil. Buscou-se evidenciar a importância do setor de telecomunicações sobre o crescimento econômico, bem como as dificuldades enfrentadas pelo setor no que se refere ao volume de reclamações encaminhadas à Anatel e de sanções aplicadas. A despeito dos problemas sinalizados, esse ambiente pode se tornar uma oportunidade para favorecer a realização eficiente de investimentos, economicamente menos atrativos, que de outra maneira não seriam feitos no curto prazo, via mecanismo de licitação apresentado. Assim, o presente trabalho espera ter contribuído com o processo de discussão e tomada de decisão acerca das medidas a serem implementadas no setor de telecomunicações com vistas a sua ampliação e geração de valor para a sociedade. 


\section{Referências Bibliográficas}

AHKING, Francis W. The power of the'objective'Bayesian unit-root test. The Open Economics Journal, v. 2, p. 71-79, 2009.

AKAIKE, Hirotugu. A new look at the statistical model identification. Automatic Control, IEEE Transactions on, v. 19, n. 6, p. 716-723, 1974.

ASCHAUER, David Alan. Is public expenditure productive?. Journal of monetary economics, v. 23, n. 2, p. 177-200, 1989.

ASHENFELTER, Orley. How auctions work for wine and art. The Journal of Economic Perspectives, p. 23-36, 1989.

AUSUBEL, Lawrence M.; CRAMTON, Peter; DENECKERE, Raymond J. Bargaining with incomplete information. Handbook of game theory with economic applications, v. 3, p. 18971945, 2002.

AZEVEDO ARAUJO, Ricardo. Assessing the efficiency of the anti-money laundering regulation: an incentive-based approach. Journal of Money Laundering Control, v. 11, n. 1, p. 67-75, 2008.

BAI, Jushan; PERRON, Pierre. Computation and analysis of multiple structural change models. Journal of applied econometrics, v. 18, n. 1, p. 1-22, 2003.

BAI, Jushan; PERRON, Pierre. Estimating and testing linear models with multiple structural changes. Econometrica, p. 47-78, 1998.

BARRO, Robert J. Government spending in a simple model of endogenous growth. 1988.

BENOIT, Jean-Pierre; KRISHNA, Vijay. Multiple-object auctions with budget constrained bidders. The Review of Economic Studies, v. 68, n. 1, p. 155-179, 2001.

BERNHARDT, Dan; SCOONES, David. A note on sequential auctions. The American Economic Review, p. 653-657, 1994. 
BICHLER, Martin; KALAGNANAM, Jayant R. A non-parametric estimator for setting reservation prices in procurement auctions. Information Technology and Management, v. 7, n. 3, p. 157-169, 2006.

BIERMAN, Scott. e FERNANDEZ, Luis. Teoria dos Jogos, segunda edição, São Paulo: Pearson Education do Brasil, 2010.

BLUME, Andreas; HEIDHUES, Paul. All equilibria of the Vickrey auction. Journal of Economic Theory, v. 114, n. 1, p. 170-177, 2004.

BOLTON, Patrick; DEWATRIPONT, Mathias. Contract theory. MIT press, 2005

BRASIL. Constituição (1988). Constituição da República Federativa do Brasil: promulgada em 5 de $\quad$ outubro de $1988 . \quad$ Disponível em < http://www.planalto.gov.br/ccivil_03/constituicao/constituicao.htm. $>$ Acesso em 03/04/2014.

BRASIL. Lei 7347/1985 - Lei de Ação Civil Pública. Disciplina a ação civil pública de responsabilidade por danos causados ao meio-ambiente, ao consumidor, a bens e direitos de valor artístico, estético, histórico, turístico e paisagístico (VETADO) e dá outras providências. Sítio <www.planalto.gov.br/ccivil_03/leis/17347orig.htm>. Acesso em 01/09/2013.

Agência Nacional de Telecomunicações. Análise 454/2013-GCRZ, de 22 de novembro de 2013. Proposta de Resolução que aprova o Regulamento que estabelece critérios e procedimentos para celebração e acompanhamento de Termo de Compromisso de Ajustamento de Conduta - TAC entre a Anatel e as prestadoras de serviços de telecomunicações, e dá outras providências, visando adequar a conduta da Compromissária às disposições legais, regulamentares ou contratuais, mediante o estabelecimento de compromissos, com eficácia de título executivo extrajudicial, tendo em vista o disposto no art. $5^{\circ}, \S 6^{\circ}$, da Lei n..$^{\circ} 7.347$, de 24 de julho de 1985, no art. 68 da Lei n. ${ }^{\circ} 9.784$, de 29 de janeiro de 1999, e no art. $5^{\circ}$ do Regulamento de Aplicação de Sanções Administrativas, aprovado pela Resolução n. ${ }^{\circ}$ 589, de 7 de maio de 2012. Disponível em <http://www.anatel.gov.br> . Acesso em 15/01/2014. 
Agência Nacional de Telecomunicações. Consulta Pública 13/2013: Proposta de Regulamento de Celebração e Acompanhamento de Termo de Ajustamento de Conduta - TAC. Disponível em http://sistemas.anatel.gov.br/SACP. Acesso em 01/02/2014.

Agência Nacional de Telecomunicações. Consulta Pública 847/2007: Proposta de Alteração no Regulamento de Aplicação de Sanções Administrativas. Disponível em http://sistemas.anatel.gov.br/SACP . Acesso em 01/02/2014.

Agência Nacional de Telecomunicações. Contratos de concessão Local, Longa Distância Nacional, Longa Distância Internacional. Disponível em http://www.anatel.gov.br/Portal/exibirPortalInternet.do . Acesso em 01/09/2013.

. Agência Nacional de Telecomunicações. Informe nº 12/2013-COQL/PRRE/SCO/SPR de 08/08/2013. Disponível no Processo Administrativo 53500.016839/2012.

Agência Nacional de Telecomunicações. Relatório Anual 2012.

Agência Nacional de Telecomunicações. Resolução 344 de 18 de julho de 2003. Aprova o Regulamento de Aplicação de Sanções Administrativas. Diário Oficial da União, Brasília, p. 36, 21 jul. 2003. Disponível www.anatel.gov.br. Acesso em 15 jan. 2014.

Agência Nacional de Telecomunicações. Resolução 629 de 16 de dezembro de 2013. Aprova o Regulamento de celebração e acompanhamento de Termo de Compromisso de Ajustamento de Conduta (TAC). Diário Oficial da União, Brasília, p. 59, 18 dez. 2013. Disponível www.anatel.gov.br . Acesso em 15 jan. 2014.

Agência Nacional de Telecomunicações. Resolução n. ${ }^{\circ}$ 589, de 7 de maio de 2012. Aprova o Regulamento de Aplicação de Sanções Administrativas. http://legislacao.anatel.gov.br/resolucoes/2012/191-resolucao-589 em 01/09/2013.

. Decreto 2.181/1997. Dispõe sobre a organização do Sistema Nacional de Defesa do Consumidor - SNDC, estabelece as normas gerais de aplicação das sanções administrativas previstas na Lei $\mathrm{n}^{\circ} 8.078$, de 11 de setembro de 1990, revoga o Decreto $\mathrm{N}^{\mathrm{o}} 861$, de 9 julho de 
1993,

e

dá

outras

providências.

Disponível

em

<http://www.planalto.gov.br/ccivil_03/decreto/D2181.htm>. Acesso em 01/09/2013.

\section{Decreto}

2.338/1997.

Aprova o Regulamento da Agência Nacional de Telecomunicações e dá outras providências. Diário Oficial da União, Brasília, p. 22591, 08 out. 1997. Disponível em <http://www.planalto.gov.br/ccivil_03/decreto/D2338.htm>. Acesso em 01/09/2013.

- Decreto 2.592/1998. Aprova o Plano Geral de Metas para a Universalização do Serviço Telefônico Fixo Comutado Prestado no Regime Público. Diário Oficial da União, Brasília, p. 5644, 21 mar. 1997. Disponível em <http://www.planalto.gov.br/ccivil_03/decreto/D2592.htm>. Acesso em 01/09/2013.

- Lei 8078/1990 - Código de Defesa do Consumidor. Dispõe sobre a proteção do consumidor e dá outras providências. Diário Oficial da União, suplemento ao $\mathrm{N}^{\mathrm{o}} 176$, Brasília, 12 set. 1990. Sítio <www.planalto.gov.br/ccivil_03/leis/17347orig.htm>. Acesso em 01/09/2013.

. Lei 9472/1997 - Lei Geral de Telecomunicações. Dispõe sobre a organização dos serviços de telecomunicações, a criação e funcionamento de um órgão regulador e outros aspectos institucionais, nos termos da Emenda Constitucional $\mathrm{n}^{\circ}$ 8, de 1995. Sítio <www.planalto.gov.br/ccivil_03/leis/19472.htm> . Acesso em 01/09/2013.

. Lei $\mathrm{n}^{\circ} 9.784$ de 29 de janeiro de 1999. Regula o processo administrativo no âmbito da Administração Pública Federal. Diário Oficial União. Brasília, DF, 29 jan. 1999a. Disponível em: <http://www.planalto.gov.br/ccivil_03/leis/L9784.htm>. Acesso em: 01/09/2013.

. Exposição de motivos da Lei Geral de Telecomunicações (1996). Disponível em <http://www.anatel.gov.br/Portal/verificaDocumentos/documento.asp?numeroPublicacao=331\& assuntoPublicacao=Exposi\%E7\%E3o\%20de\%20Motivos\%20n.\%BA\%20231\%20/MC,\%20de\% 2010/12/96,\%20que\%20encaminha\%20a\%20\%20Lei\%20Geral\%20das\%20Telecomunica\%E7 \%F5es.\&caminhoRel=null\&filtro=1\&documentoPath=biblioteca/leis/exposicao_motivos_lgt.pdf $>$. Acesso em 03/04/2014. 
BRESSER-PEREIRA, Luiz Carlos. O conceito histórico de desenvolvimento econômico. Rio de Janeiro: Fundação Getulio Vargas, 2006.

BUGARIN; Maurício S.; MENEGUIN, Fernando. A Emenda Constitucional dos Precatórios: Histórico, Incentivos e Leilões de Deságio. Est. Econ., São Paulo, vol. 42, n.4, p.671-699, out.dez. 2012.

BUGARIN; Mauricio. S.; SOTOMAYOR, Marilda. A. O. Lições de teoria dos jogos. Livro no prelo.

CALDERON, Cesar; MORAL-BENITO, Enrique; SERVÉN, Luis. Is infrastructure capital productive? A dynamic heterogeneous approach. 2011.

CALDERÓN, César; SERVÉN, Luis. The effects of infrastructure development on growth and income distribution. World Bank Publications, 2004.

CANNING, David; PEDRONI, Peter. Infrastructure, long- run economic growth and causality tests for cointegrated panels. The Manchester School, v. 76, n. 5, p. 504-527, 2008.

CHATTERJEE, Kalyan; SAMUELSON, William. Bargaining under incomplete information. Operations Research, v. 31, n. 5, p. 835-851, 1983.

CHE, Yeon-Koo; KIM, Jinwoo. Optimal collusion-proof auctions. Journal of Economic Theory, v. 144, n. 2, p. 565-603, 2009.

CHOW, Gregory C. Tests of equality between sets of coefficients in two linear regressions. Econometrica: Journal of the Econometric Society, p. 591-605, 1960.

COHEN, Jeffrey P. Economic benefits of investments in transport infrastructure. 2007.

DA SILVEIRA BUENO, Rodrigo De Losso. Econometria de séries temporais. Cengage Learning, 2011.

DA SILVEIRA BUENO, Rodrigo De Losso. Econometria de séries temporais. Cengage Learning, 2011. 
DAVIDSON, Russell; MACKINNON, James G. (2004). Econometric Theory and Methods. New York: Oxford University Press. p. 623. ISBN $\underline{\text { 0-19-512372-7. }}$

DAVIDSON, Russell; MACKINNON, James G. Estimation and inference in econometrics. OUP Catalogue, 1993.

DEJONG, David N.; WHITEMAN, Charles H. The case for trend- stationarity is stronger than we thought. Journal of Applied Econometrics, v. 6, n. 4, p. 413-421, 1991.

DIAS, Karina. M. A Celebração de Termo de Compromisso de Ajustamento de Conduta no Âmbito da Agência Nacional de Telecomunicações e suas Principais Implicações. Monografia. Cadernos centro de políticas, direito, economia e tecnologias das comunicações - CCOM VOLUME X, 2008.

DICKEY, David A.; FULLER, Wayne A. Distribution of the estimators for autoregressive time series with a unit root. Journal of the American statistical association, v. 74, n. 366a, p. 427-431, 1979.

DURBIN, James; WATSON, Geoffrey S. Testing for serial correlation in least squares regression: I. Biometrika, p. 409-428, 1950.

DURBIN, James; WATSON, Geoffrey S. Testing for serial correlation in least squares regression. II. Biometrika, p. 159-177, 1951.

ENGLE, Robert F.; GRANGER, Clive WJ. Co-integration and error correction: representation, estimation, and testing. Econometrica: journal of the Econometric Society, p. 251-276, 1987.

FATIMA, S. S.; WOOLDRIDGE, Michael; JENNINGS, Nicholas R. Optimal agendas for sequential auctions for common and private value objects. In: Proc. International Workshop on Game Theory and Decision Theory, Edinburgh, Scotland. 2005. p. 159-171.

FIANI, Ronaldo. Teoria da Regulação Econômica: Estado Atual e Perspectivas Futuras. Textos Para Discussão, Instituto de Economia/UFRJ, n. 423 33p, 1998. 
GIBBONS, R. Game theory for applied economists. Princeton: Princeton Univ. Press, 1992.

GRANGER, Clive WJ. Investigating causal relations by econometric models and cross-spectral methods. Econometrica: Journal of the Econometric Society, p. 424-438, 1969.

GUTIERREZ, Carlos Enrique Carrasco; DE MOURA ALMEIDA, Fernanda Matos. Modelagem e Previsão do Preço do Café Brasileiro. Revista de Economia, v. 39, n. 2.

HAILE, Philip A. Partial pooling at the reserve price in auctions with resale opportunities. Games and Economic Behavior, v. 33, n. 2, p. 231-248, 2000.

HARRIS, Milton; RAVIV, Artur. Allocation mechanisms and the design of auctions. Econometrica: Journal of the Econometric Society, p. 1477-1499, 1981.

HU, Audrey. How bidder's number affects optimal reserve price in first-price auctions under risk aversion. Economics Letters, v. 113, n. 1, p. 29-31, 2011.

ITU, International Telecommunication Union (2001). Effective regulation - Case study: Brazil, Place des Nations CH-1211 Geneva, Switzerland.

JEHLE, G. A.; RENY, P.J. Advanced Microeconomic Theory, 3rd edition, Editora Prentice Hall, 2011.

JOFRE-BONET, Mireia; PESENDORFER, Martin. Optimal sequential auctions. International Journal of Industrial Organization, v. 33, p. 61-71, 2014.

JOHANSEN, Søren; JUSELIUS, Katarina. Maximum likelihood estimation and inference on cointegration - with applications to the demand for money.Oxford Bulletin of Economics and statistics, v. 52, n. 2, p. 169-210, 1990

JÚNIOR, Antônio Fialho Galvão; GOMES, Fábio Augusto Reis; SALVATO, Márcio Antônio. Mudança cíclica versus mudança estrutural: uma análise da produtividade da mão-de-obra na indústria brasileira. Pesquisa e Planejamento Econômico, v. 35, n. 1, 2005. 
JÚNIOR, Antônio Fialho Galvão; GOMES, Fábio Augusto Reis; SALVATO, Márcio Antônio. Mudança cíclica versus mudança estrutural: uma análise da produtividade da mão-de-obra na indústria brasileira. Pesquisa e Planejamento Econômico, v. 35, n. 1, 2005.

KALANDRAKIS, Tasos. Equilibria in sequential bargaining games as solutions to systems of equations. Economics Letters, v. 84, n. 3, p. 407-411, 2004.

KATSENOS, Georgios. Three Essays on Sequential Auctions. 2007. Tese de Doutorado. University of Pittsburgh.

KAUR, Kawaljeet; MALHOTRA, Neena. (2014) TELECOMMUNICATIONS AND ECONOMIC GROWTH IN INDIA: CAUSALITY ANALYSIS.

KENDALL, Maurice G.; STUART, Alan. The advanced theory of statistics: Inference and relationship. Charles Griffin, 1961.

KENDALL, Maurice George et al. The advanced theory of statistics. The advanced theory of statistics., n. 2nd Ed, 1946.

KLEMPERER, Paul. What really matters in auction design. The Journal of Economic Perspectives, v. 16, n. 1, p. 169-189, 2002.

KOOP, Gary. 'Objective'bayesian unit root tests. Journal of Applied Econometrics, v. 7, n. 1, p. $65-82,1992$.

KRISHNA, V. Auction Theory. 2002, Elsevier, USA.

KRISHNA, Vijay. Auction theory. Academic press, 2009.

KWIATKOWSKI, Denis et al. Testing the null hypothesis of stationarity against the alternative of a unit root: How sure are we that economic time series have a unit root?. Journal of econometrics, v. 54, n. 1, p. 159-178, 1992.

LAFFONT, J. J.; MARTIMORT, D. The Theory of Incentives: The Principal-Agent Model. New Jersey: Princeton University Press, 2002. 
LAFFONT, J. J.; MARTIMORT, D.; SALANIÉ, B. Principal-Agent Models. 2003.

LAFFONT, J.J. The new economics of regulation ten years after. Econometrica, v.62, p.507$537,1994$.

LAFFONT, Jean-Jacques; MARTIMORT, David. The theory of incentives: the principalagent model. Princeton university press, 2002.

LEE, Junsoo; STRAZICICH, Mark C. Minimum Lagrange multiplier unit root test with two structural breaks. Review of Economics and Statistics, v. 85, n. 4, p. 1082-1089, 2003.

LEME, Renato Paes; SYRGKANIS, Vasilis; TARDOS, Éva. Sequential auctions and externalities. In: Proceedings of the twenty-third annual ACM-SIAM symposium on Discrete Algorithms. SIAM, 2012. p. 869-886.

LEME, Renato Paes; SYRGKANIS, Vasilis; TARDOS, Éva. Sequential auctions and externalities. In: Proceedings of the twenty-third annual ACM-SIAM symposium on Discrete Algorithms. SIAM, 2012. p. 869-886.

LEVIN, Dan; SMITH, James L. Optimal reservation prices in auctions. The Economic Journal, p. 1271-1283, 1996.

LINDER, D. R. L. Acordo substitutivo na ação regulatória: o Termo de Ajuste de Conduta TAC no âmbito da Agência Nacional de Transportes Terrestres - ANTT. Monografia. Instituto Brasiliense de Direito Público - IDP Curso de Pós-Graduação Lato Sensu em Direito Administrativo, 2012.

LINDERT, Peter H. Growing public: Volume 1, the story: Social spending and economic growth since the eighteenth century. Cambridge University Press, 2004.

LÜTKEPOHL, Helmut; KRÄTZIG, Markus (Ed.). Applied time series econometrics. Cambridge University Press, 2004.

MACHO-STADLER, I. ; PEREZ-CASTRILLO, J.D.: An introduction to the economics of information: incentives and contracts, 2nd edition, Oxford University Press, 2001. 
MANDALA, G.S. Introduction to Econometrics. [S.1.]: Prentice Hall, 1992.

MAS-COLELl, A.; WHISTON, M.; GREEN, J. R. Microeconomic Theory. Oxford: Oxford University Press, 1995.

MASOOD, Saqib. The Telecommunications (ICT) Investment and Economic growth (GDP): A causality analysis-case study of Sweden. 2012.

MCAFEE, R. Preston; MCMILLAN, John. Bidding rings. The American Economic Review, p. 579-599, 1992.

MCAFEE, R. Preston; VINCENT, Daniel. Sequentially optimal auctions. Games and Economic Behavior, v. 18, n. 2, p. 246-276, 1997.

MCAFEE, R. Preston; VINCENT, Daniel. The Afternoon Effect. Center for Mathematical Studies in Economics and Management Science, Northwestern University, 1991.

MENEZES, Flavio M.; MONTEIRO, Paulo K. An introduction to auction theory. Oxford University Press, 2005.

MILGROM, Paul R.; WEBER, Robert J. A theory of auctions and competitive bidding. Econometrica: Journal of the Econometric Society, p. 1089-1122, 1982.

Mills, T.C. (1993) The Econometric Modelling of Financial Time Series. Cambridge, UK: Cambridge University Press.

MIRANDA, Rachel de Castro. O sistema judiciário brasileiro: evidências empíricas dos incentivos ao litígio.

MYERSON, Roger B. Optimal auction design. Mathematics of operations research, v. 6, n. 1, p. 58-73, 1981.

NASH JR, John F. The bargaining problem. Econometrica: Journal of the Econometric Society, p. $155-162,1950$. 
NEEMAN, Z. A Course on Mechanism Design. Central European University. January 24 to February 11, 2011.

OZCAN, Rasim. Sequential Auctions with Endogenously Determined Reserve Prices. Boston College Department of Economics, 2004.

PHILlIPS, P. C. B.; PERRON, P. (1988). "Testing for a Unit Root in Time Series Regression". Biometrika 75 (2): 335-346. doi:10.1093/biomet/75.2.335. edit

PHILLIPS, Peter CB; OULIARIS, Sam. Asymptotic properties of residual based tests for cointegration. Econometrica: Journal of the Econometric Society, p. 165-193, 1990.

PORTER, Robert H.; ZONA, J. Douglas. Detection of bid rigging in procurement auctions. National Bureau of Economic Research, 1992.

PURANAM, Kartikeya S.; KATEHAKIS, Michael N. On optimal bidding and inventory control in sequential procurement auctions: the multi period case.Annals of Operations Research, v. 217, n. 1, p. 447-462, 2014.

QUANDT, Richard E. Tests of the hypothesis that a linear regression system obeys two separate regimes. Journal of the American statistical Association, v. 55, n. 290, p. 324-330, 1960

RILEY, John G.; SAMUELSON, William F. Optimal auctions. The American Economic Review, p. 381-392, 1981.

ROBU, Valentin; LA POUTRÉ, Han. Designing bidding strategies in sequential auctions for risk averse agents. Multiagent and Grid Systems, v. 6, n. 5, p. 437-457, 2010.

RÖLLER, Lars-Hendrik; WAVERMAN, Leonard. Telecommunications infrastructure and economic development: A simultaneous approach.American economic review, p. 909-923, 2001.

ROTH, Alvin E. Individual rationality and Nash's solution to the bargaining problem. Mathematics of Operations Research, v. 2, n. 1, p. 64-65, 1977. 
SCHWARZ, Gideon et al. Estimating the dimension of a model. The annals of statistics, v. 6, n. 2, p. 461-464, 1978.

SILVA, Â. Henrique Lopes da. Preço de reserva sigiloso em licitações publicas. Prêmio Tesouro Nacional, n. 16, Brasília, 2011. P. 36. Disponível em: http://www3.tesouro.fazenda.gov.br/Premio_TN/XVIPremio/politica/3pfceXVIPTN/Tema_3 _3.pdf. Acesso em: 01.08.2014.

SIMS, Christopher A. Bayesian skepticism on unit root econometrics.Journal of Economic dynamics and Control, v. 12, n. 2, p. 463-474, 1988.

SIMS, Christopher A. Macroeconomics and reality. Econometrica: Journal of the Econometric Society, p. 1-48, 1980.

SIMS, Christopher A. Money, income, and causality. The American economic review, p. 540552, 1972.

SIMS, Christopher A. Money, income, and causality. The American economic review, p. 540$552,1972$.

SIMS, Christopher A.; UHLIG, Harald. Understanding unit rooters: A helicopter tour. Econometrica: Journal of the Econometric Society, p. 1591-1599, 1991.

TAASIM, Shairil Izwan; YUSOFF, Remali (2014). Telecommunications Infrastructure Consequence to Economic Growth in Malaysia: Time Series Analysis.

THOMAS, Charles J. USING RESERVE PRICES TO DETER COLLUSION IN PROCUREMENT COMPETITION*. The Journal of Industrial Economics, v. 53, n. 3, p. 301326, 2005.

THOMAS, Charles Jonathan. Collusion and optimal reserve prices in repeated procurement auctions. Bureau of Economics, Federal Trade Commission, 2001.

TIROLE, Jean. The theory of industrial organization. MIT press, 1988. 
VAN DEN BERG, Gerard J.; VAN OURS, Jan C.; PRADHAN, Menno P. The declining price anomaly in Dutch Dutch rose auctions. American Economic Review, p. 1055-1062, 2001.

VARIAN, Hal.: Microeconomic analysis, 3rd edition, W. W. Norton \& Company, New York, 1992.

VICKREY, William. Counterspeculation, auctions, and competitive sealed tenders. The Journal of finance, v. 16, n. 1, p. 8-37, 1961.

VON DER FEHR, Nils-Henrik Morch. Predatory bidding in sequential auctions. Oxford Economic Papers, p. 345-356, 1994.

ZAGHA, Roberto; NANKANI, Gobind T. (Ed.). Economic Growth in the 1990s: Learning from a Decade of Reform. World Bank Publications, 2005.

ZEITHAMMER, Robert. Research Note-Optimal Selling in Dynamic Auctions: Adaptation Versus Commitment. Marketing Science, v. 26, n. 6, p. 859-867, 2007.

ZIVOT, Eric; ANDREWS, D. W. Further Evidence on the Great Crash, the Oil-Price Shock, and the Unit-Root. Journal of Business \& Economic Statistics, v. 10, n. 0, p. 3, 1992. 